\title{
0.9\% SALINE VERSUS PLASMA-LYTE 148 FOR INTRAVENOUS FLUID THERAPY
}

\author{
BY \\ DR SUMEET KUMAR REDDY, MBCHB. \\ A thesis submitted to the Victoria University of Wellington \\ in fulfilment of the requirements for the degree of Doctor of Philosophy
}

Victoria University of Wellington

2016 
This thesis is dedicated to my parents (DrC. K. Reddy and Dr Reeta Lochan Reddy) and my late grandparents (Mr D. L. Reddy, Mrs Rukhmani Reddy, Mr Ram Lochan and Mrs Padma Lochan) for their love and support. 


\section{Contents}

3 List of abbreviations

4 Preface

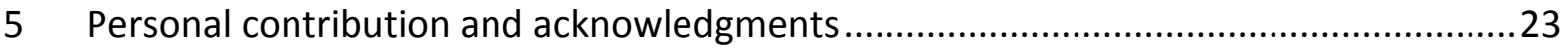

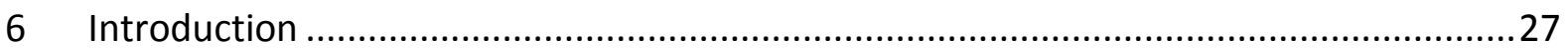

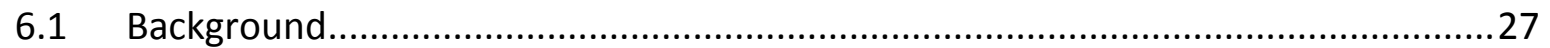

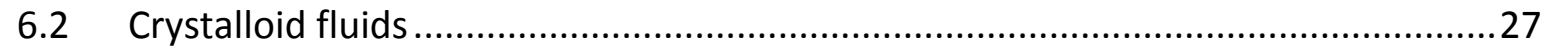

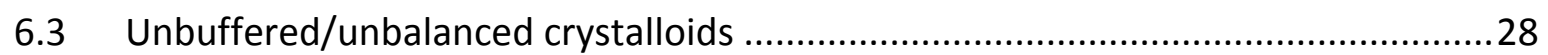

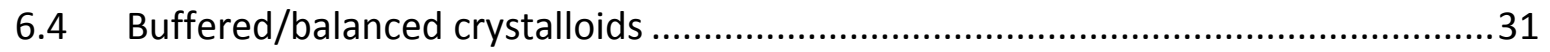

6.5 Current literature that has compared $0.9 \%$ saline to buffered crystalloids in adult patients. 34

6.6 Evidence comparing the effects of renal function between unbuffered and buffered crystalloid fluid...... .35

6.7 Evidence comparing the influence on haemostasis and blood transfusion requirements between unbuffered and buffered crystalloid fluid ..... 45

6.8 Evidence comparing gastrointestinal effects of unbuffered and buffered crystalloid fluid .53

6.9 Current recommendations for the prescribing of intravenous fluids in hospitals ...57

6.10 Summary of background information ...................................................... 57

7 Hypotheses .59 
8 Study one: A multi-centre, cluster randomised, double cross over, feasibility trial investigating the effect of using $0.9 \%$ saline or Plasma-Lyte ${ }^{\circledR} 148$ as fluid therapy in intensive care patients on the risk of developing acute kidney injury.

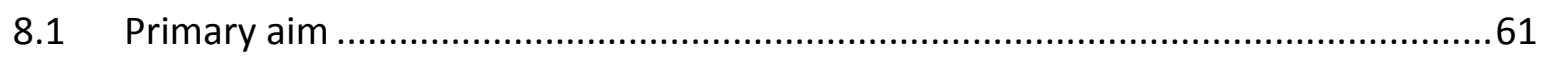

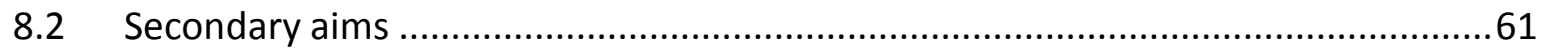

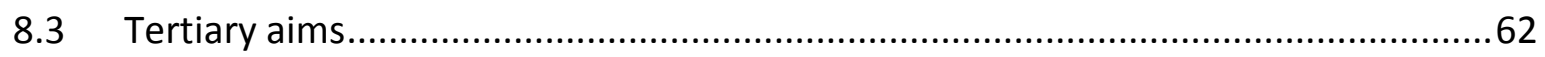

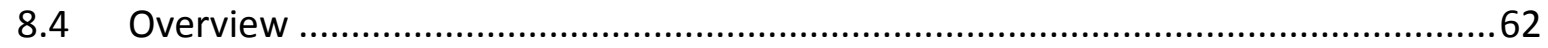

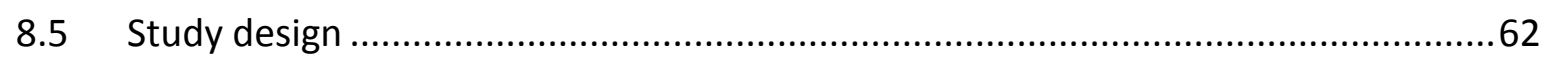

8.6 Primary outcome

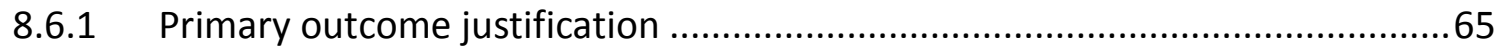

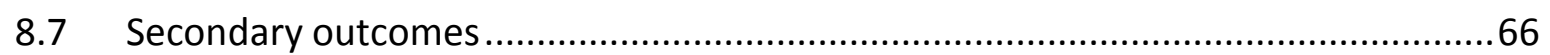

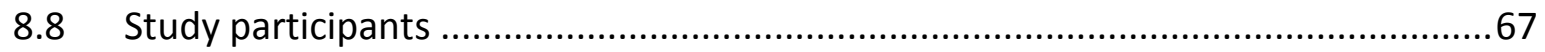

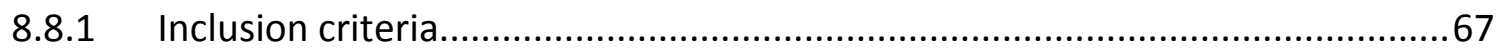

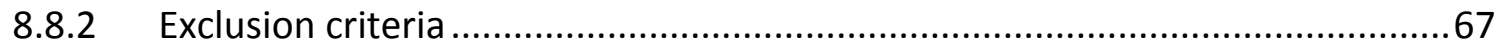

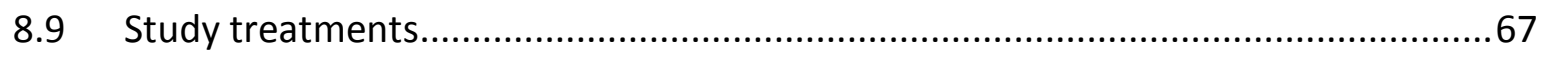

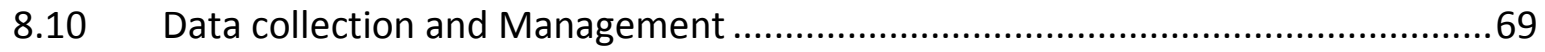

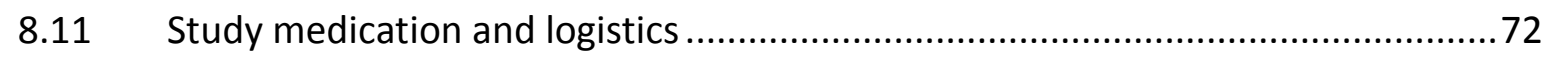

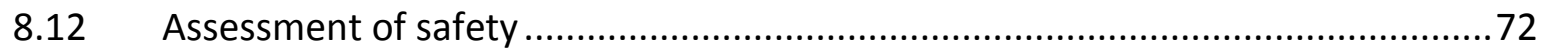

8.13 Data safety monitoring board and monitoring …............................................ 72

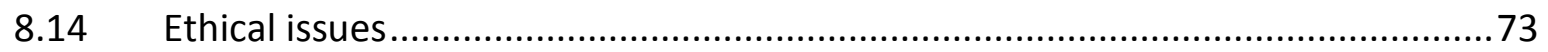

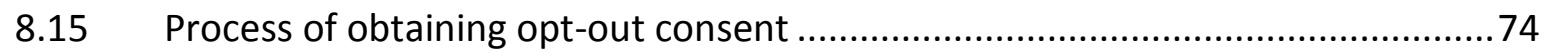

8.16 Data handling and confidentiality .......................................................... 75

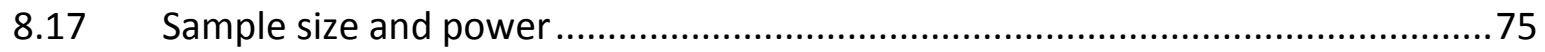




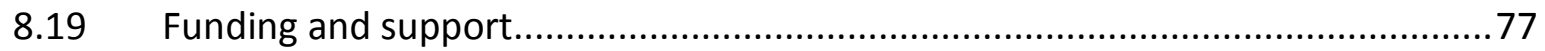

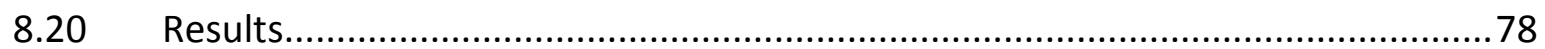

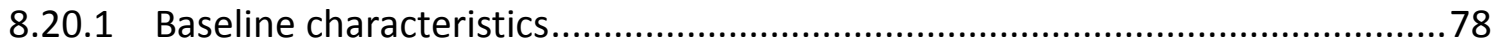

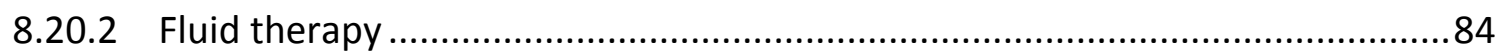

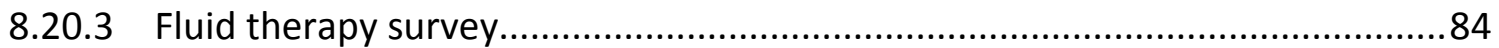

8.20.4 Primary outcome variable: the proportion of patients with either AKI or renal

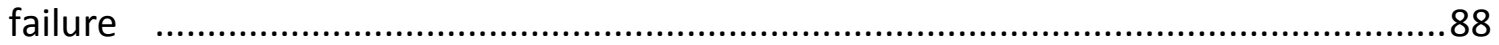

8.20.5 Primary outcome variable: missing data sensitivity analysis .........................8

8.20.6 Secondary outcome variables: Renal outcomes............................................90

8.20.7 Secondary outcome variables: Service utilisation .......................................99

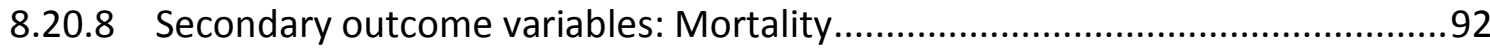

8.20.9 Primary and secondary outcomes variables: Adjusted analyses.....................94

8.20.10 Subgroup analyses: Renal outcomes ......................................................94

8.20.11 Subgroup analyses: In-hospital mortality ...............................................95

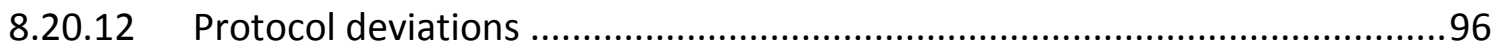

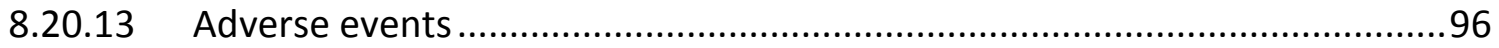

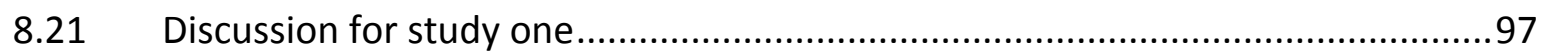

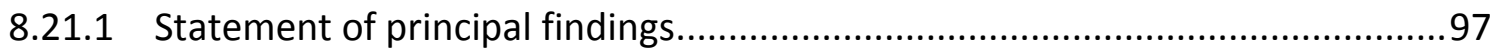

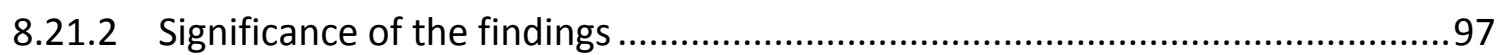

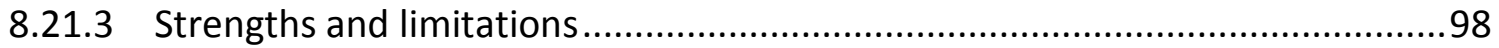

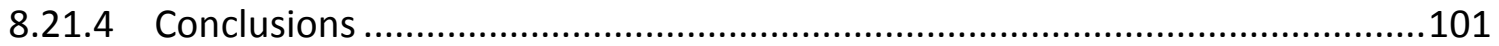


9 Study two: A post-hoc exploratory subgroup analysis and single centre pilot study nested cohort within study one to evaluate the effects of $0.9 \%$ saline and Plasma-Lyte-148 on blood product use and post-operative bleeding .103

9.1 Rationale 103

9.2 Primary aim .104

9.3 Secondary aims 105

9.4 Overview .105

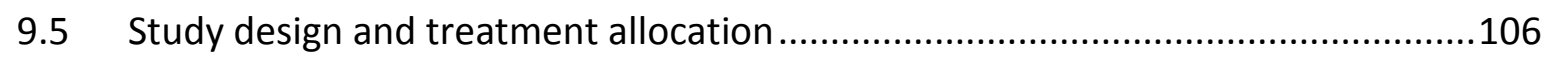

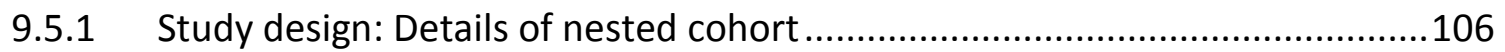

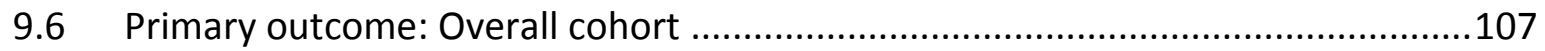

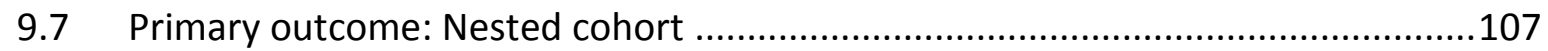

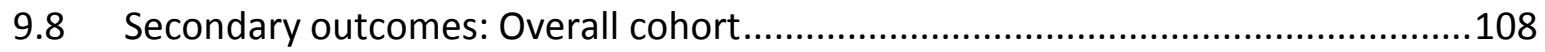

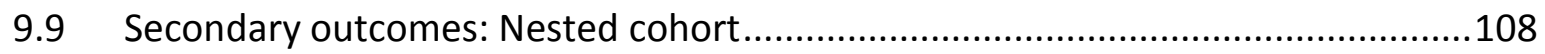

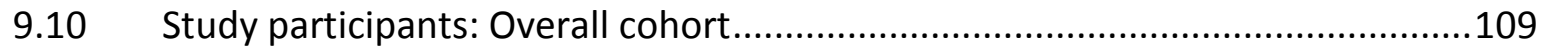

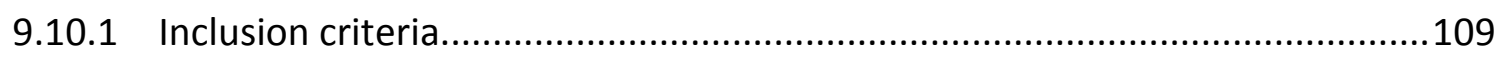

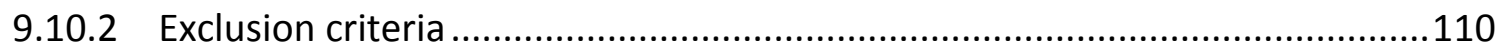

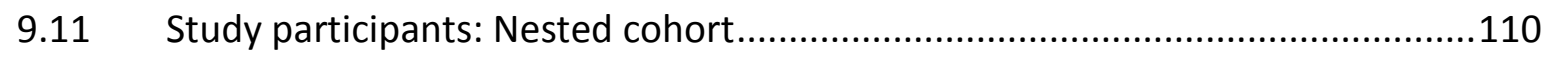

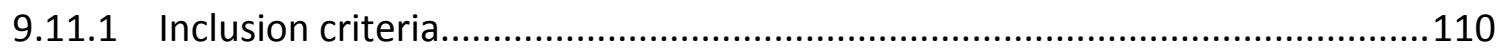

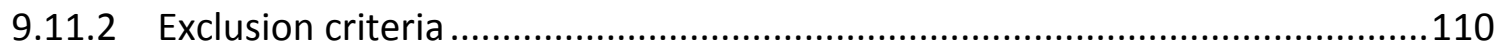

9.11.3 Approach to blood transfusions in cardiac surgical patients in the nested cohort study.

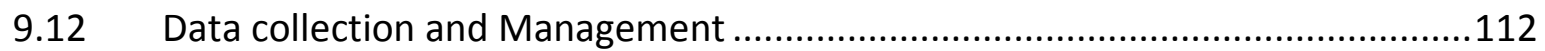

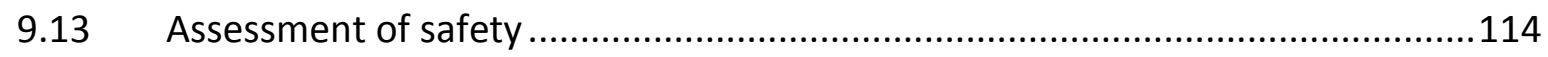

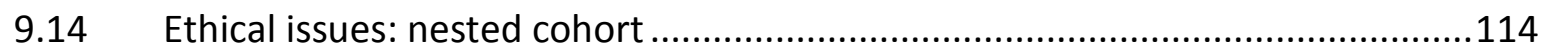


9.15 Process of obtaining opt-out consent: nested cohort

9.16 Data handling and confidentiality: nested cohort.......................................115

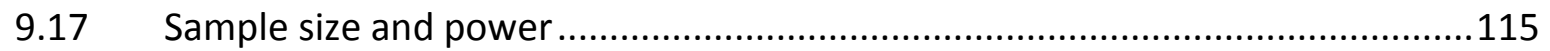

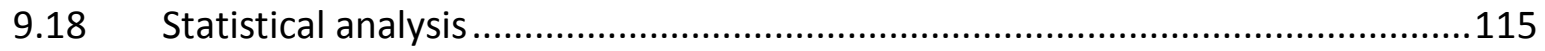

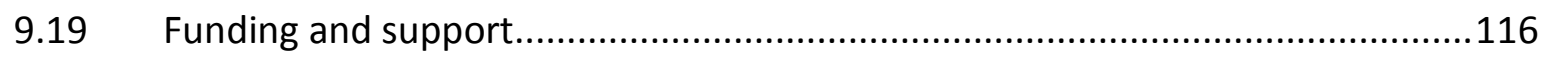

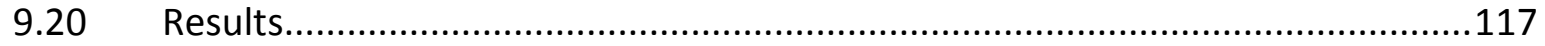

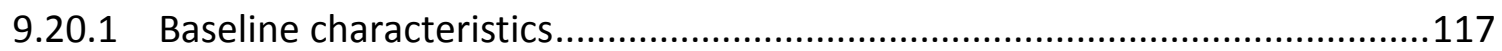

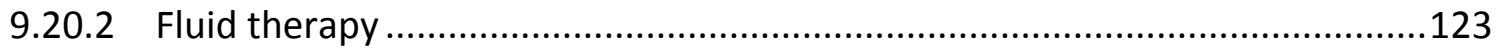

9.20.3 Primary outcome variable-overall cohort: the proportion of patients receiving

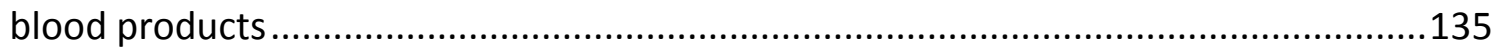

9.20.4 Secondary outcome variables: overall cohort .............................................136

9.20.5 Primary outcome variable-nested cohort: the chest drain losses at 12 hours 137

9.20.6 Secondary outcome variables: nested cohort ..........................................138

9.20.7 Subgroup analyses nested cohort: chest drain losses at 12 hours.................142

9.20.8 Subgroup analyses nested cohort: risk of requiring blood products following surgery

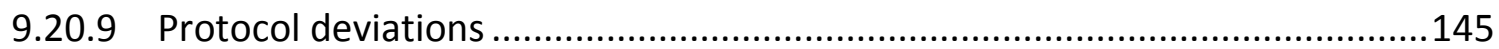

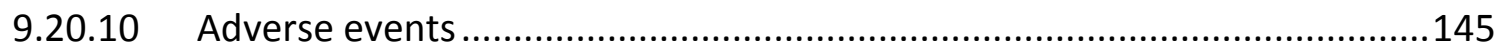

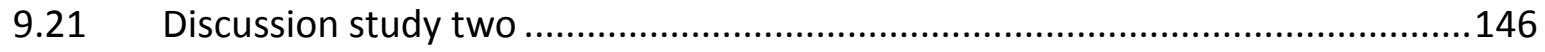

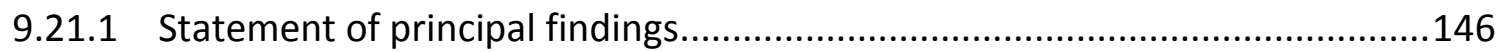

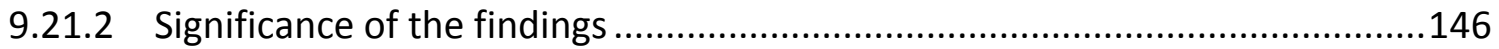

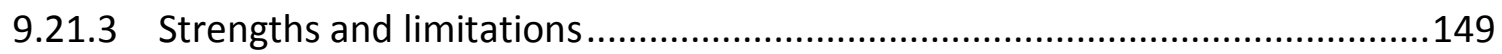

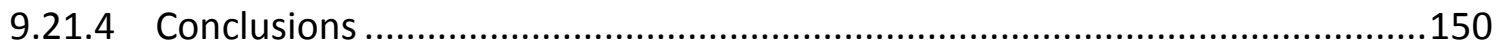


10 Study three: A single centre pilot study nested within study one to evaluate the effect of using $0.9 \%$ saline or Plasma-Lyte $148{ }^{\circledR}$ as crystalloid fluid therapy on gastrointestinal feeding intolerance in mechanically ventilated patients receiving nasogastric enteral nutrition.

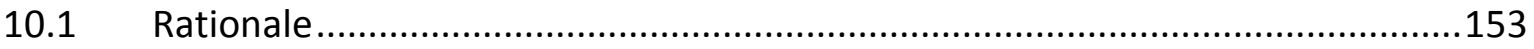

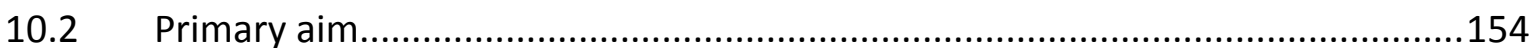

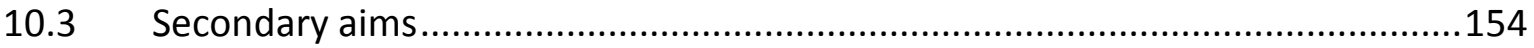

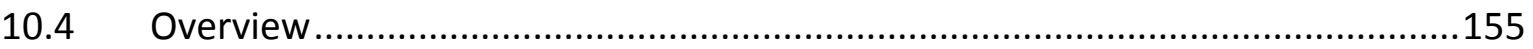

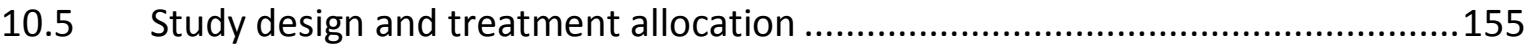

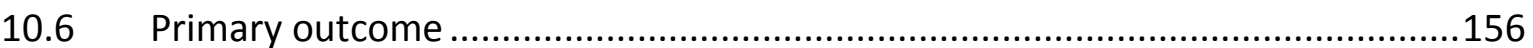

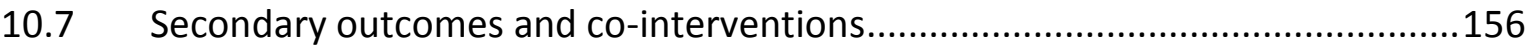

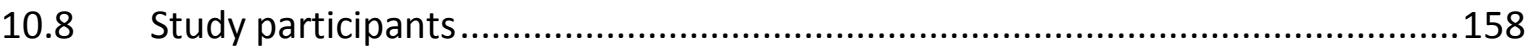

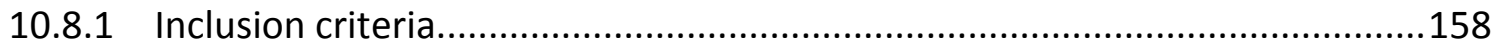

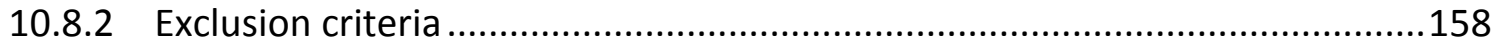

10.8.3 Approach to enteral feeding in mechanically ventilated patients. ................158

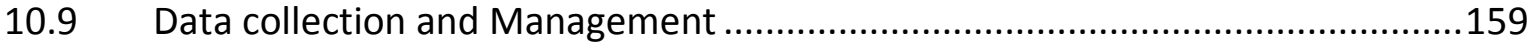

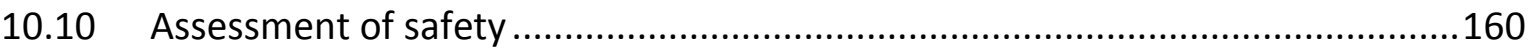

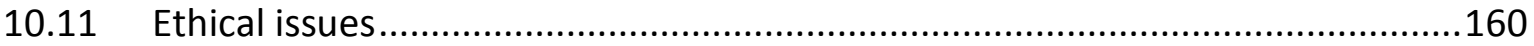

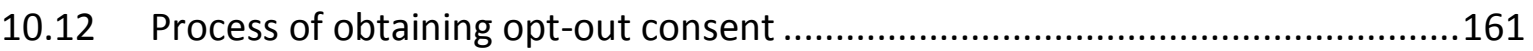

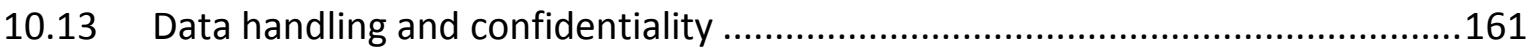

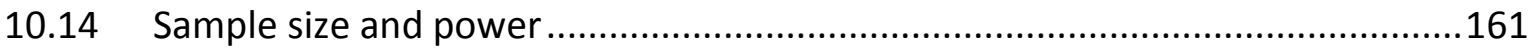

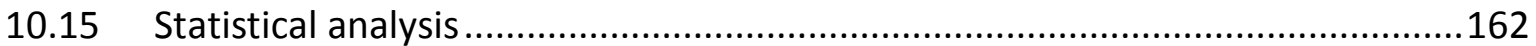

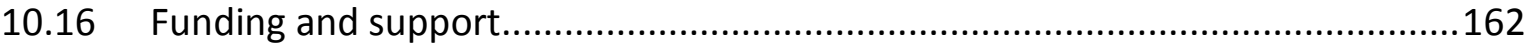

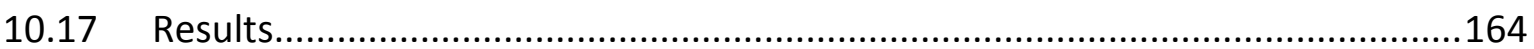


10.17.1 Baseline characteristics

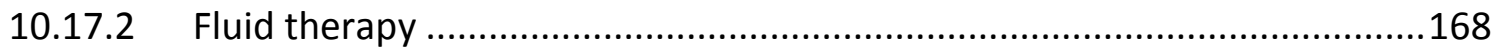

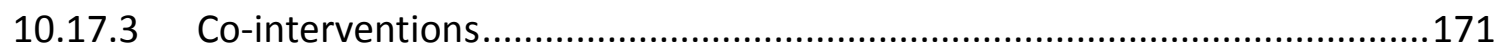

10.17.4 Primary outcome variable: the proportion of patients with gastrointestinal feeding intolerance

10.17.5 Secondary outcome variables: gastrointestinal outcomes.......................171

10.17.6 Multivariable sensitivity analyses of primary and key secondary gastrointestinal outcome variables.

10.17.7 Secondary outcome variables: Service utilisation .174

10.17.8 Secondary outcome variables: Biochemical data .175

10.17.9 Subgroup analyses: total proportion of patients with gastrointestinal feeding intolerance

10.17.10 Protocol deviations 177

10.17.11 Adverse events .177

10.18 Discussion for study three 178

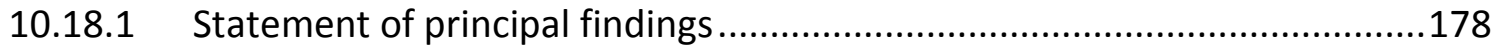

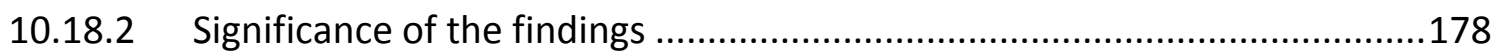

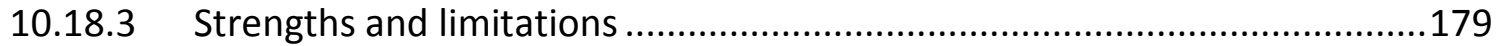

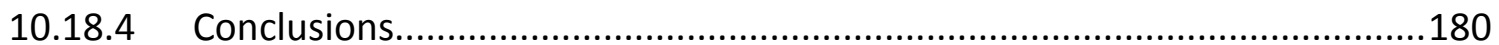

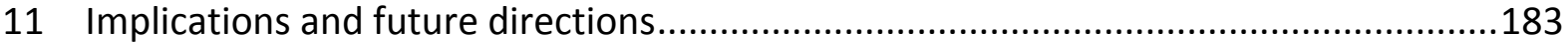

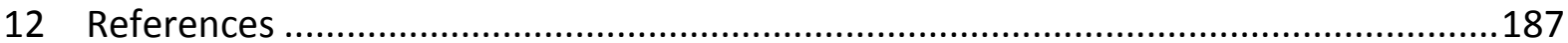

13 Appendix 1: Data monitoring committee charter ..................................................203

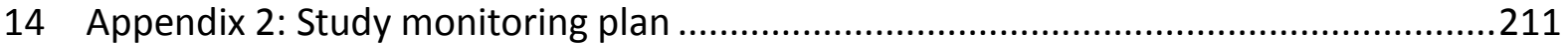

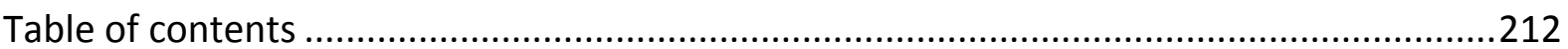




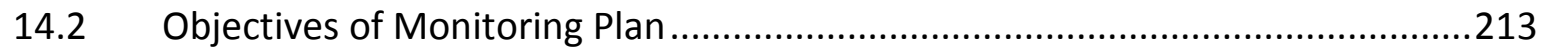

14.3 Coordinating Centres Study Team and Roles ..................................................22

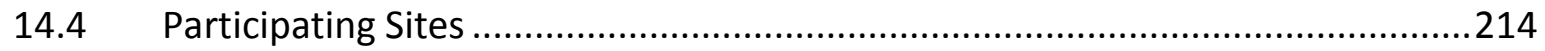

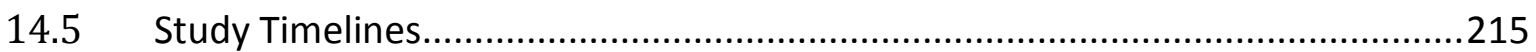

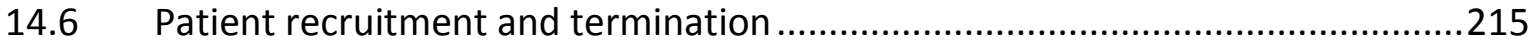

14.7 Monitoring Activities: Set up, ongoing and closure ........................................216

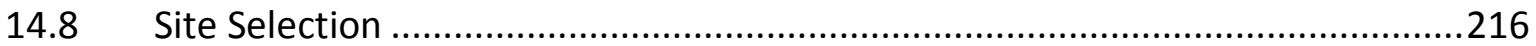

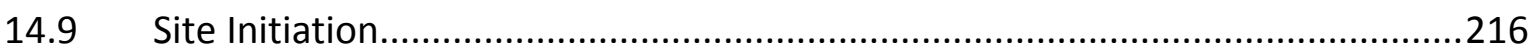

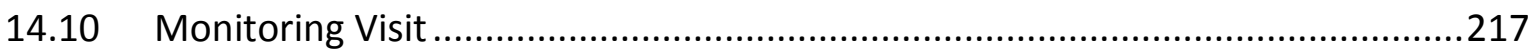

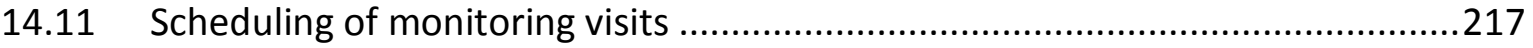

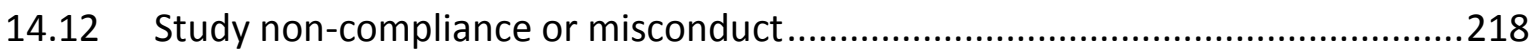

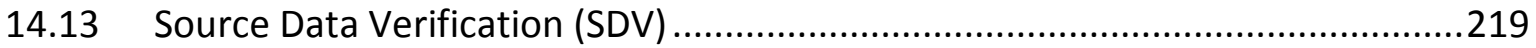

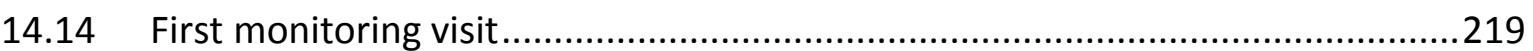

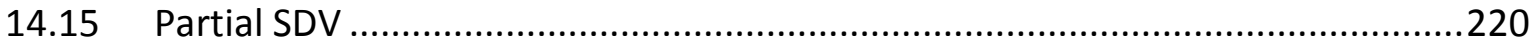

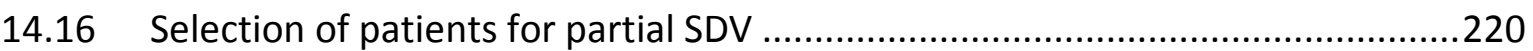

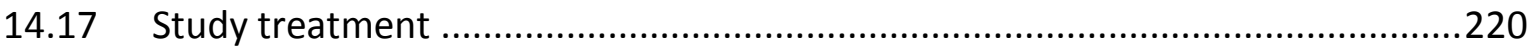

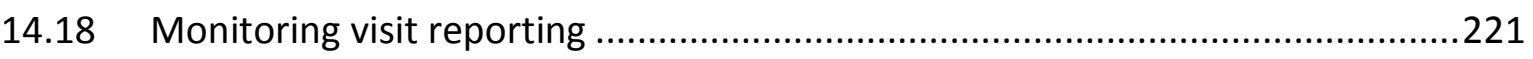

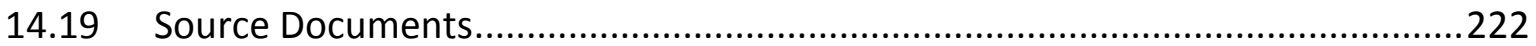

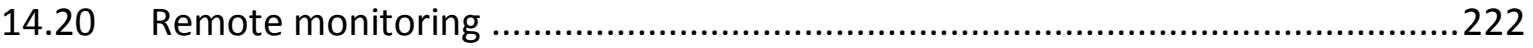

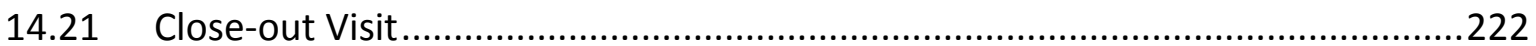

14.22 Interim analyses and Data Monitoring Committee..........................................222

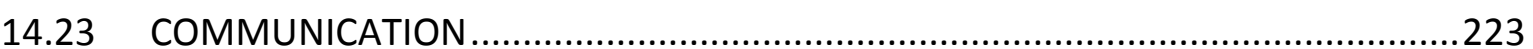




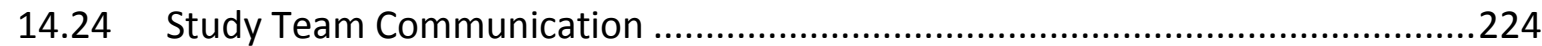

14.25 monitoring visit report template / EXAMPLE ...................................................225

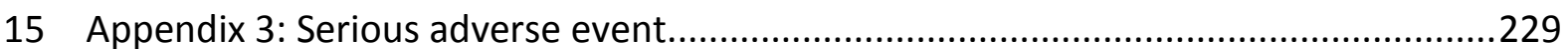




\section{Abstract}

\section{BACKGROUND}

Intravenous fluid therapy is one of the most common interventions used in acute medicine. Worldwide, there are variations in the prescription of intravenous fluids and no consensus on the best intravenous fluid to use. Currently, $0.9 \%$ saline is the most frequently prescribed intravenous fluid; however, there is emerging evidence to suggest that $0.9 \%$ saline may be associated with an increased risk of acute kidney injury (AKI), increased blood transfusion requirements and gastrointestinal dysfunction when compared to a buffered crystalloid fluid, such as Plasma-Lyte 148.

\section{METHODS}

Study one

A prospective, multicentre, randomised, double-blind, cluster, double crossover study conducted over 28 weeks in four New Zealand intensive care units (ICU) comparing 0.9\% saline to Plasma-Lyte 148 . The primary outcome was the proportion of patients with either AKI or renal failure according to the RIFLE criteria definitions based on serum creatinine levels.

\section{Study two}

An exploratory subgroup analysis of cardiac surgical patients enrolled in study one to compare the effects of $0.9 \%$ saline vs. Plasma-Lyte 148 on the need for blood transfusions. The primary outcome was the proportion of patients receiving blood or blood products in the ICU. Additionally, an in-depth single-centre nested cohort study comparing the effect of $0.9 \%$ saline vs. Plasma-Lyte 148 on blood loss and blood products was also conducted.

\section{Study three}

A single-centre nested study within study one comparing the effect of $0.9 \%$ saline vs. Plasma-Lyte 148 on gastrointestinal dysfunction in patients expected to be mechanically ventilated for $>48$ hours and receiving enteral nutrition via the nasogastric route. The 
primary outcome was the proportion of patients with gastrointestinal intolerance (high gastric residual volumes (GRV), vomiting, and diarrhoea).

\section{RESULTS}

\section{Study one}

2262 patients were enrolled and analysed, 1152 patients were allocated to receive PlasmaLyte 148 and 1110 participants were allocated to receive 0.9\% saline. In the Plasma-Lyte 148 group, 102 of 1067 patients (9.6\%) developed AKI, compared with 94 of 1025 patient (9.2\%) in the $0.9 \%$ saline group ( $R R$ 1.05; $95 \% \mathrm{Cl}, 0.78$ to $1.41 ; p=0.76$ ). Overall, 87 of 1152 patients (7.6\%) in the Plasma-Lyte 148 group and 95 of 1110 patients (8.6\%) in the $0.9 \%$ saline group died in hospital (RR, $0.88 ; 95 \% \mathrm{Cl} 0.67$ to $1.17 ; \mathrm{p}=0.40)$.

\section{Study two}

954 cardiac surgical patients were included, 475 patients were allocated to receive PlasmaLyte 148 and 479 were allocated to receive $0.9 \%$ saline. 128 of 475 patients (26.9\%) in the Plasma-Lyte 148 group received blood or a blood product compared with 94 of 479 (19.6\%) patients in the $0.9 \%$ saline group (OR [95\% Cl], 1.51 [1.11-2.05]; $p=0.008$ ). Within the nested cohort ( $n=251,131$ assigned to Plasma-Lyte 148 and 120 assigned to $0.9 \%$ saline), there were no differences between groups in chest drain losses at 12 hours.

\section{Study three}

69 patients were enrolled and analysed, with 35 allocated to receive Plasma-Lyte 148 and 34 allocated to receive $0.9 \%$ saline. In the Plasma-Lyte 148 group, 21 of 35 patients (60.0\%) developed gastrointestinal feeding intolerance, compared with 22 of 34 patients $(64.7 \%)$ in the $0.9 \%$ saline group (OR, $0.82 ; 95 \% \mathrm{Cl}, 0.31-2.17 ; \mathrm{p}=0.69$ ). A high $\mathrm{GRV}$ was seen in 4 of 35 patients (11.4\%) in the Plasma-Lyte 148 group, and in 11 of 34 patients (32.4\%) in the $0.9 \%$ saline group (OR, $0.27 ; 95 \% \mathrm{Cl}, 0.08-0.96 ; \mathrm{p}=0.04)$.

\section{CONCLUSION}

This research programme provides data from the first interventional study conducted in critically unwell patients on the comparative effectiveness of $0.9 \%$ saline compared to a buffered crystalloid solution for intravenous fluid therapy. 
Among patients receiving crystalloid fluid in the ICU, allocation to Plasma-Lyte 148 compared to $0.9 \%$ saline did not influence the risk of AKI. Within a subgroup of patients undergoing cardiac surgery allocation to Plasma-Lyte 148 was associated with an increased requirement for blood or blood products. Among mechanically ventilated patients receiving nasogastric feeding, the use of Plasma-Lyte 148 compared to $0.9 \%$ saline did not reduce the proportion of patients developing gastrointestinal feeding intolerance but was associated with a decreased incidence of high GRV.

These findings suggest that Plasma-Lyte 148 as compared with $0.9 \%$ saline may have differing effects within the biological/organ systems and sub-groups of patients admitted to the ICU. Further large randomised clinical trials (RCT) are needed to assess the efficacy in higher-risk populations and to measure ongoing areas of uncertainty in clinically important outcomes such as mortality. 


\section{List of abbreviations}

\begin{tabular}{|c|c|}
\hline ADQI & Acute dialysis quality initiative \\
\hline $\mathrm{AE}$ & Adverse event \\
\hline AIDS & Acquired immune deficiency syndrome \\
\hline ANZ & Australia and New Zealand \\
\hline ANZICS-APD & $\begin{array}{l}\text { Australian and New Zealand intensive care society adult patient } \\
\text { database }\end{array}$ \\
\hline ANZICS-CTG & $\begin{array}{l}\text { Australian and New Zealand intensive care society- clinical trials } \\
\text { group }\end{array}$ \\
\hline AKIN & Acute kidney injury network \\
\hline APACHE & Acute physiology and chronic health evaluation \\
\hline ARF & Acute renal failure \\
\hline APTT & Activated partial thromboplastin time \\
\hline CABG & Coronary artery bypass graft \\
\hline cc & Cubic centimetre \\
\hline $\mathrm{Cl}$ & Confidence interval \\
\hline CPB & Cardiopulmonary bypass \\
\hline $\mathrm{CO}_{2}$ & Carbon Dioxide \\
\hline CRF & Case report form \\
\hline CRP & $\mathrm{C}$ reactive protein \\
\hline DSMB & Data safety monitoring board \\
\hline eCRF & Electronic case report form \\
\hline eSID & Effective strong ion difference \\
\hline ED & Emergency department \\
\hline
\end{tabular}




\begin{tabular}{|c|c|}
\hline euroSCORE & European system for cardiac operative risk evaluation \\
\hline FFP & Fresh frozen plasma \\
\hline GFR & Glomerular filtration rate \\
\hline GRV & Gastric residual volume \\
\hline HRC & Health research council of New Zealand \\
\hline ICD-9-CM & $\begin{array}{l}\text { International classification of disease, ninth edition clinical } \\
\text { modification }\end{array}$ \\
\hline ICU & Intensive care unit \\
\hline IL & Interleukin \\
\hline INR & International normalised ratio \\
\hline IQR & Interquartile range \\
\hline IV & Intravenous \\
\hline KDIGO & Kidney disease improving global outcomes \\
\hline $\mathrm{kg}$ & Kilogram \\
\hline $\mathrm{kPa}$ & Kilopascal \\
\hline MAP & Mean arterial pressure \\
\hline MDRD & Modification of diet in renal disease \\
\hline $\mathrm{mL}$ & Millilitre \\
\hline MRI & Magnetic resonance imaging \\
\hline MRINZ & Medical research institute of New Zealand \\
\hline NEAC & New Zealand national ethics committee \\
\hline NGAL & Neutrophil gelatinase-associated lipocalin \\
\hline $\mathrm{NHI}$ & National Health Index \\
\hline NICE & National Institute for Health and Care Excellence \\
\hline
\end{tabular}




\begin{tabular}{|ll|}
\hline OR & Odds ratio \\
PRBC & Packed red blood cells \\
PI & Principal investigator \\
PT & Prothrombin time \\
SAE & Serious adverse event \\
SAS & Statistical analysis system \\
SD & Standard deviation \\
SDV & Source data Verification \\
SID & Strong ion difference \\
SIRS & Systemic inflammatory response syndrome \\
SPLIT & $0.9 \%$ saline versus Plasma-Lyte 148 for intensive care fluid \\
RCT & therapy \\
RIFLE & Randomised control trial \\
RRT & Risk, injury, failure, loss, end-stage \\
& Renal replacement therapy \\
\hline
\end{tabular}




\section{Preface}

"she filled his ancient veins with rich elixir. As he received it ... his wasted form renewed, appeared in all the vigor of bright youth, no longer lean and sallow, for new blood coursed in his well-filled veins."

- Publius Ovidius Naso, Metamorphoses Book VII - The Story of Medea and Jason, 8 AD.

Our desire to find solutions that rejuvenate and resuscitate is captured in the story of Medea revitalizing Jason's elderly father by filling his veins with a specially prepared elixir. Although no such elixir exists, intravenous fluids are an integral component of the multimodal resuscitation strategy used in acute medicine (Myburgh \& Mythen, 2013). Intravenous fluids were first administered over 180 years ago and despite their widespread use there remains ongoing uncertainty about their comparative safety and efficacy.

$0.9 \%$ saline is the most commonly used intravenous fluid in the world and there is emerging concern that $0.9 \%$ saline may be associated with adverse clinical outcomes when compared to a buffered/balanced crystalloid fluid (Plasma-Lyte 148). This thesis outlines a research programme and provides the best available evidence on the comparative effectiveness of 0.9\% saline versus Plasma-Lyte 148 for intravenous fluid therapy. 


\section{Personal contribution and acknowledgments}

To date, I am the first author of six of the seven publications (one book chapter and six manuscripts) that have arisen from or are linked to the research work presented in this thesis.

I was a member of the study management committee for study one. I am the first author for the study protocol for study one that was published and was involved in the acquisition, analysis, interpretation, monitoring, drafting and revision of the final manuscript. The statistical analysis for study one was undertaken by the study statistician (Michael Bailey).

Study 2 and study 3 were designed and conceived by me. I was the first author in a joint overview of the study protocols and statistical analysis plan for these studies. All additional data required for the study were collected by me and I undertook the statistical analysis for both studies under the guidance from Michael Bailey. I am the first author for the manuscript for study 3 which has been accepted for publication and I am also leading the drafting of the manuscript for study 2 .

\section{PUBLICATIONS}

BOOK CHAPTER

Reddy, S., Weinberg, L., \& Young, P. (2016). Crystalloid fluid therapy. In V. L. Vincent (Ed.), Annual Update in Intensive Care and Emergency Medicine (2016 ed., pp. 133-148). Springer International Publishing.

\section{ARTICLES}

Reddy, S., Weinberg, L., \& Young, P. (2016). Crystalloid fluid therapy. Critical Care. 20 (59), 59. doi: 10.1186/s13054-016-1217-5.

Reddy,S., McGuinness, S., Parke, R., \& Young, P. (2015). Choice of fluid therapy and bleeding risk after cardiac surgery. Journal of Cardiothoracic and Vascular Anesthesia. Retrieved from doi: 10.1053/j.jvca.2015.12.025. [Epub ahead of print]

Young, P., Bailey, M., Beasley, R., Henderson, S., Mackle, D., McArthur, C., McGuinness, S., Mehrtens, J., Myburgh, J., Psirides, A., Reddy, S., \& Bellomo, R. (2015) Effect of a 
buffered crystalloid solution vs saline on acute kidney injury among patients in the intensive care unit: the SPLIT randomized clinical trial. The Journal of the American Medical Association. 314(16), 1701-10.

Reddy, S., Bailey, M., Beasley, R., Bellomo RA, Mackle D, Psirides A, \& Young, P. A single centre nested pilot study investigating the effect of using $0.9 \%$ saline or Plasma-Lyte $148{ }^{\circledR}$ as crystalloid fluid therapy on gastrointestinal feeding intolerance in mechanically ventilated patients receiving nasogastric enteral nutrition. Critical Care and Resuscitation. Article in press.

Reddy, S., Young, P., Beasley, R., Mackle, D., McGuinness, S., McArthur, C., Henderson, S., Weinberg, L., French, C., Orford, N., Bailey, M., Bellomo, R., \& the ANZICS CTG investigators. (2015) An overview of the study protocols and statistical analysis plan for the Saline vs. Plasma-Lyte $148^{\circledR}$ for Intravenous Fluid Therapy (SPLIT) research programme. Critical Care and Resuscitation.17,29-36.

Reddy, S., Bailey, M., Beasley, R., Bellomo, R., Henderson, S., Mackle, D., McArthur, C., Mehrtens, J., Myburgh, J., McGuinness, S., Psirides, A., \& Young, P. (2014) A protocol for the $0.9 \%$ saline versus Plasma-Lyte 148 for intensive care fluid therapy (SPLIT) study. Critical Care and Resuscitation. 16,274-9. 


\section{ACKNOWLEDGMENTS}

I would like to acknowledge all co-authors on manuscripts published during my PhD thesis: Paul Young, Diane Mackle, Alex Psirides, Rinaldo Bellomo, Michael Bailey, Laurence Weinberg, Shay McGuinness, Rachael Parke, John Myburgh, Seton Henderson, Jan Mehrtens, Colin McArthur, Craig French, Neil Orford and Richard Beasley.

I would also like to acknowledge the members of the data safety monitoring board for study one: Anders Perner, Andrew Forbes and John Morgan.

In addition I would like to specifically acknowledge the investigators from each of the hospitals that contributed to study one: Seton Henderson, Louise Hitchings, David Closey (Christchurch Hospital Intensive Care Unit); Colin McArthur (Department of Critical Care Medicine, Auckland Hospital); Shay McGuinness (Cardiac and Vascular Intensive Care Unit, Auckland Hospital). Research Co-ordinators: Kim Parker, Emmeline Minto, Anna Morris, Jan Mehrtens, Research nurses; (Christchurch Hospital Intensive Care Unit, Christchurch, New Zealand). Rachael McConnochie, Yan Chen, Lynette Newby, (Department of Critical Care Medicine, Auckland, New Zealand); Rachael Parke, Lianne McCarthy, Eileen Gilder, (Cardiac and Vascular ICU, Auckland, New Zealand) Anna Hunt, Sally Hurford, Leanlove Navarra, Adelaide Jason-Smith, Lynn Andrews. (Wellington Hospital Intensive Care Unit, Wellington, New Zealand).

I wish to also thank the entire team at the Medical Research Institute of New Zealand (MRINZ) for their direct and indirect contribution to my research. It has been a privilege working with you all.

To the doctors, nurses and administrative staff at the Intensive Care Unit (ICU) in Wellington Regional Hospital thank you for your support and patience when I recruited patients and collected data. I would also like to thank the Health Research Council of New Zealand (HRC) for awarding me a clinical research training fellowship and the Australian and New Zealand Intensive Care Society- Clinical Trials Group (ANZICS-CTG) for their endorsement of study one.

I would like to give special thanks to Dr Paul Young for his guidance and mentorship, to my primary supervisor Professor Richard Beasley for being a constant source of inspiration and 
to Professor John Miller for his support as my second supervisor. Finally, I would like to extend my sincerest thanks and appreciation to those patients and their families who participated in the studies included in this thesis.

Thank you. 


\section{Introduction}

\subsection{Background}

Worldwide, there is variation in the prescribing of resuscitative intravenous fluids and the preferred choice of the type of intravenous fluid to use appears to be based on local customs, marketing, fluid cost and availability (Finfer et al., 2010; Myburgh \& Mythen, 2013). The majority of intravenous fluid types were introduced into clinical practice during an era where they did not undergo the same scrutiny as other drugs (Raghunathan, Shaw, \& Bagshaw, 2013). Hence, there is a paucity of research in this area of medicine and only recently has there been an increase in academic interest in the comparative effectiveness of different intravenous fluids. This has been sparked by large studies conducted by the Australian and New Zealand Intensive Care Society Clinical Trials Group (ANZICS CTG) that have reported no benefit and potential harm with the use of certain types of intravenous colloid fluid when compared to $0.9 \%$ saline in critically ill patients (Finfer et al., 2004; Myburgh et al., 2012).

This chapters reviews the composition of different crystalloid fluids and reviews the existing literature on the potential pathophysiological responses of different crystalloid fluids on renal function, haemostasis/coagulation, and gastrointestinal function.

\subsection{Crystalloid fluids}

Crystalloid fluids are a heterogeneous group of aqueous solutions containing different concentrations of inorganic ions and small organic molecules (Lira \& Pinsky, 2014). A point prevalence study by Finfer et al. (2010), including 391 ICUs from 25 countries, reported that fluid resuscitation with crystalloid fluid was proportionally the highest in New Zealand (approaching 60\%) compared with all other participating countries.

Crystalloid fluids have evolved since first being used during the cholera epidemic in the 1830 s and they are now commonly classified according to their main solute (e.g. sodium chloride, glucose, etc.) or tonicity compared to human plasma (isotonic, hypotonic, hypertonic) (Awad, Allison, \& Lobo, 2008). The differing electrolyte composition of each crystalloid fluid contributes to the ability of infused fluid to remain within the intravascular 
space and results in different biological properties. There has recently been a push to further distinguish fluids into physiologically buffered/balanced or physiologically unbuffered/unbalanced fluids (Burdett et al., 2012).

\subsection{Unbuffered/unbalanced crystalloids}

Unbuffered crystalloid fluid mainly refers to $0.9 \%$ saline, however, by definition, it can also include dextrose and mannitol based solutes (Morgan \& Venkatesh, 2003). Worldwide, 0.9\% saline is the most commonly prescribed, cheapest and most well-researched intravenous fluid available (Lobo \& Awad, 2014; Myburgh \& Mythen, 2013). The composition of 0.9\% saline was first mentioned by Jakob Hamburger in the 1890s (Awad et al., 2008). It is unknown how $0.9 \%$ saline became known as "normal saline"; however, use of the term "normal" may have contributed to the widespread acceptance of $0.9 \%$ saline in clinical practice (Awad et al., 2008).

Composition of $0.9 \%$ saline

Despite being referred to as "normal", 0.9\% saline is not physiologically "normal" (Wakim, 1970). First, $0.9 \%$ saline has a higher chloride concentration than plasma (Table 6.1). Second, $0.9 \%$ has a different strong ion difference (SID) to plasma. According to the Stewart physiochemical approach to describing acid-base balance, fluid $\mathrm{pH}$ is in part determined by the SID, which is the sum of the strong cation concentrations in the solution (e.g. sodium, potassium, magnesium), minus the sum of the strong anion concentrations in the solution (e.g. chloride and lactate) (Morgan, 2013; Morgan \& Venkatesh, 2003). The SID of the extracellular fluid is approximately $40 \mathrm{mEq} / \mathrm{L}$ whereas the SID of $0.9 \%$ saline is zero. Following an infusion of $0.9 \%$ saline there is a net decrease in the plasma SID and as a result, $0.9 \%$ saline administration in appreciable volumes may lead to hyperchloraemic metabolic acidosis (Scheingraber, Rehm, Sehmisch, \& Finsterer, 1999).

$0.9 \%$ saline is often thought of as a relatively hypertonic solution because the sum of its osmotically active components gives a theoretical in vitro osmolality of $308 \mathrm{mosmol} / \mathrm{kg} \mathrm{H}_{2} \mathrm{O}$ (154 $\mathrm{mmol} / \mathrm{L}$ sodium plus $154 \mathrm{mmol} / \mathrm{L}$ chloride). However, $0.9 \%$ saline is more accurately referred to as an isotonic solution as its constituents sodium and chloride, are only partially 
active with an osmotic coefficient of 0.926 . The calculated in vivo osmolality (tonicity) of saline is 285 mosmol/ $\mathrm{kg} \mathrm{H}_{2} \mathrm{O}$, which is the same as plasma osmolality (tonicity). 
Table 6.1. Characteristics of common crystalloid solutions compared to human plasma.

\begin{tabular}{|c|c|c|c|c|c|c|c|c|}
\hline & Plasma & $\begin{array}{l}0.9 \% \\
\text { saline }\end{array}$ & $\begin{array}{l}0.9 \text { saline } \\
\text { (New } \\
\text { Zealand) }\end{array}$ & $\begin{array}{l}\text { Compound } \\
\text { Sodium } \\
\text { Lactate } \\
\text { (lactate } \\
\text { buffered } \\
\text { solution) }\end{array}$ & $\begin{array}{l}\text { Ringer's } \\
\text { Lactate } \\
\text { (lactate } \\
\text { buffered } \\
\text { solution) }\end{array}$ & $\begin{array}{l}\text { Ionosteril }^{\circledR} \\
\text { (acetate } \\
\text { buffered } \\
\text { solution) }\end{array}$ & $\begin{array}{l}\text { Sterofundi } \\
\text { n ISO }{ }^{\circledR} \\
\text { (acetate \& } \\
\text { malate } \\
\text { buffered } \\
\text { solution) }\end{array}$ & $\begin{array}{c}\text { Plasma- } \\
\text { Lyte } 148^{\circledR} \\
\text { (acetate \& } \\
\text { gluconate } \\
\text { buffered } \\
\text { solution) }\end{array}$ \\
\hline $\begin{array}{l}\text { Sodium } \\
\text { (mmol/L) }\end{array}$ & $136-145$ & 154 & 150 & 129 & 130 & 137 & 145 & 140 \\
\hline $\begin{array}{l}\text { Potassium } \\
\text { (mmol/L) }\end{array}$ & $3.5-5.0$ & & & 5 & 4 & 4 & 4 & 5 \\
\hline $\begin{array}{l}\text { Magnesium } \\
\text { (mmol/L) }\end{array}$ & $0.8-1.0$ & & & & & 1.25 & 1 & 1.5 \\
\hline $\begin{array}{l}\text { Calcium } \\
\text { (mmol/L) }\end{array}$ & $2.2-2.6$ & & & 2.5 & 3 & 1.65 & 2.5 & \\
\hline $\begin{array}{l}\text { Chloride } \\
\text { (mmol/L) }\end{array}$ & $98-106$ & 154 & 150 & 109 & 109 & 110 & 127 & 98 \\
\hline $\begin{array}{l}\text { Acetate } \\
(\mathrm{mmol} / \mathrm{L})\end{array}$ & & & & & & 36.8 & 24 & 27 \\
\hline $\begin{array}{l}\text { Gluconate } \\
\text { (mmol/L) }\end{array}$ & & & & & & & & 23 \\
\hline $\begin{array}{l}\text { Lactate } \\
\text { (mmol/L) }\end{array}$ & & & & 29 & 28 & & & \\
\hline $\begin{array}{l}\text { Malate } \\
(\mathrm{mmol} / \mathrm{L})\end{array}$ & & & & & & & 5 & \\
\hline $\mathrm{eSID}(\mathrm{mEq} / \mathrm{L})$ & 42 & 0 & 0 & 27 & 28 & 36.8 & 25.5 & 50 \\
\hline $\begin{array}{l}\text { Theoretical } \\
\text { osmolarity } \\
\text { (mosmol/L) }\end{array}$ & 291 & 308 & 300 & 278 & 273 & 291 & 309 & 295 \\
\hline $\begin{array}{l}\text { Actual or } \\
\text { measured } \\
\text { *osmolality } \\
\text { (mosmol/kg } \\
\mathrm{H}_{2} \mathrm{O} \text { ) }\end{array}$ & 287 & 286 & 279 & 256 & 256 & 270 & Not stated & 271 \\
\hline $\mathrm{pH}$ & $7.35-7.45$ & $4.5-7$ & $4.5-7.5$ & $5-7$ & $5.0-7$ & $6.9-7.9$ & $5.1-5.9$ & $4-8$ \\
\hline
\end{tabular}

* Freezing point depression

Both versions of $0.9 \%$ saline manufactured by Baxter Healthcare, Toongabie, NSW, Australia

Plasma-Lyte 148 manufactured by Baxter Healthcare, Toongabie, NSW, Australia

Ringer's Lactate manufactured by Baxter Healthcare, Deerfield, IL, USA

Hartmann's solution manufactured by Baxter Healthcare, Toongabie, NSW, Australia

Ionosteril manufactured by Fresenius Medical Care, Schweinfurt, Germany

Sterofundin ISO manufactured by B. Braun Melsungen AG, Melsungen, Germany 


\subsection{Buffered/balanced crystalloids}

In the 1880s, Sydney Ringer, while investigating the influence of blood constituents on heart contractions, serendipitously discovered that inorganic contaminants (namely calcium) introduced to a $0.75 \%$ saline solution through the use of pipe water, prolonged cardiac contractility in frog ventricles compared to a saline solution prepared from distilled water (Srinivasa, Singh, Kahokehr, Taylor, \& Hill, 2012; Zimmer, 2005). Alexis Hartmann further modified Ringer's solution in the 1930s through the addition of sodium lactate to combat acidosis in dehydrated paediatric patients and in the 1950s, Charles Fox Jr. reported clinical use of a solution containing an acetate buffer (Aoki et al., 2010). These conceptual advances in the development of crystalloid fluids laid the foundation for the emergence of this new class of intravenous fluid (Srinivasa \& Hill, 2012).

\section{Composition of buffered crystalloids}

Unlike $0.9 \%$ saline, the available buffered crystalloid solutions contain physiological or near physiological volumes of chloride. One of the key differences between $0.9 \%$ saline and buffered crystalloids is the presence of additional anions such as lactate, acetate, malate and gluconate that act as physiological buffers to generate bicarbonate. These bicarbonate substitutes are largely metabolised in the liver and will have a net positive strong ion difference that results in an alkalinising effect when infused (Morgan \& Venkatesh, 2003). Buffered fluids such as Hartmann's solution and Ringer's lactate also have a near physiological effective in-vivo strong ion difference of 27 and $29 \mathrm{mEq} / \mathrm{L}$ respectively (Morgan \& Venkatesh, 2003). In contrast, Plasma-Lyte $148^{\circledR}$ has an effective SID in vivo of $50 \mathrm{mEq} / \mathrm{L}$. In addition to differences in buffering agents, buffered solutions also vary in the presence and concentration of ancillary cations (sodium, potassium, calcium, magnesium), which means they are not biologically equivalent.

Despite the fact that buffered crystalloid fluids are designed to better mimic the composition of human plasma no perfectly balanced or physiological "normal" crystalloid fluid is currently available (see Table 1). Hartmann's solution or Ringer's lactate are clearly hypotonic solutions with a calculated in vivo osmolality (tonicity) of approximately 254 $\mathrm{mOsmol} / \mathrm{kg} \mathrm{H}_{2} \mathrm{O}$. Administration of hypotonic fluids can represent a significant free water load that may not be easily cleared in the presence of the high anti-diuretic hormone 
concentrations commonly associated with physiological stress (McLoughlin \& Bell, 2010). Failure to excrete this water load may result in positive fluid balance, weight gain and resulting oedema. Hypotonic fluids are also contraindicated in patients with or at risk of cerebral oedema.

\section{Considerations when prescribing buffered crystalloids}

Each type of buffered crystalloid fluid has unique properties that prescribers should be aware of. Hartmann's solution contains $2 \mathrm{mmol} / \mathrm{L}$ of calcium and is contraindicated with blood or blood related products due to concerns about precipitation and the possibility of coagulation and clot formation (Shaw et al., 2012). A recent warning has been issued about mixing calcium-containing solutions, including Hartmann's solution or Ringer's lactate, with ceftriaxone causing the formation of the insoluble ceftriaxone calcium salt (Murney, 2008). Solutions that contain lactate (Hartmann's and Ringer's lactate) can also cause an iatrogenic hyperlactatemia which could create diagnostic confusion as hyperlactatemia is commonly used as a surrogate marker of hypoperfusion (Kogan et al., 2012; Shin et al., 2011).

\section{Potential impact of different physiological buffers}

Bicarbonate is the physiological buffer and major non-chloride anion in human plasma (Table 1) (Waikar \& Winkelmayer, 2012). However, bicarbonate in solution is problematic for manufacturers as high a $\mathrm{PCO}_{2}$ must be maintained in the solution to prevent dissociation and precipitation (Morgan, 2013). Currently, there are a variety of stable organic anions that are used as bicarbonate surrogates, in differing compositions and concentrations (Morgan \& Venkatesh, 2003). Historically, sodium acetate was used during haemodialysis as an alternative to bicarbonate because of the incompatibility of bicarbonate with solutions containing calcium and magnesium salts. Early evidence suggested that a sodium acetate solution was effective in restoring blood $\mathrm{pH}$ and plasma bicarbonate in patients suffering from metabolic acidosis (Eliahou, Feng, Weinberg, laina, \& Reisin, 1970). However, a more recent study suggested that acetate was associated with haemodynamic instability, vasodilatation and negative inotropic effects in patients undergoing high volume renal replacement therapy (Schrander-vd Meer, ter Wee, Kan, Donker, \& van Dorp, 1999). Concern about the potential for myocardial depression with acetate is supported by studies suggesting that acetate decreases myocardial contractility and blood pressure in dogs and 
impairs contractile function in an isolated perfused rat heart model (Jacob, Elkins, Reiss, Chan, \& Shapiro, 1997; R. L. Kirkendol, Pearson, Bower, \& Holbert, 1978). A small quantity of acetate present in various dialysis fluids (usually $35 \mathrm{mmol} / \mathrm{L}$ ) can result in a plasma acetate concentration of 10 to 40 times the physiological level (50 to $100 \mu \mathrm{mol} / \mathrm{L}$ ) (Coll et al., 2007). The use of acetate containing solutions as a circuit prime for cardiac patients undergoing cardiopulmonary bypass (CPB) resulted in a short-lived supra-physiological concentration of acetate (Davies et al., 2011), however, it is unknown if these concentrations have detrimental clinical effects.

The use of acetated solutions may, however, confer several advantages over the lactatecontaining crystalloids. Acetate is metabolised widely throughout the body and not reliant entirely on hepatic metabolism. A canine study showed that acetate metabolism was well preserved in profound shock while lactate metabolism is significantly impaired (Kveim \& Nesbakken, 1979). Acetate is metabolised more rapidly than lactate, with an increase in bicarbonate levels that is evident 15 minutes after the start of an acetate infusion (Hamada et al., 1997; Mudge, Manning, \& Gilman, 1949). Ekblad, Kero, and Takala (1985) reported that the continuous infusion of sodium acetate $(3 \mathrm{mmol} / \mathrm{kg} / 24$ hours $)$ was suitable for the slow correction of metabolic acidosis in premature infants. More recently, in a larger clinical trial of 78 critically ill trauma patients resuscitation with sodium acetate as an alternative to $0.9 \%$ saline or Ringer's lactate patients receiving acetate had stable haemodynamic profiles without evidence of haemodynamic instability at any point (McCague, Dermendjieva, Hutchinson, Wong, \& Dao, 2011). Normalisation of hyperchloraemic and metabolic acidosis occurred faster in the patients who received acetate than in patients who received Ringer's lactate. Acetate turnover shows no age-related differences and acetate may protect against malnutrition by replacing fat as an oxidative fuel without affecting glucose oxidation, or causing hyperglycaemia differences (Akanji \& Hockaday, 1990; Skutches, Holroyde, Myers, Paul, \& Reichard, 1979). Finally, acetate metabolism does not result in changes in glucose or insulin concentrations, whereas exogenously administered lactate can be converted to glucose via gluconeogenesis resulting in significant hyperglycaemia (Akanji, Bruce, \& Frayn, 1989; Akanji \& Hockaday, 1990). In diabetic patients, intraoperative glucose levels have been shown to double following administration of exogenous lactate solutions (Thomas \& Alberti, 1978). 
Little is known about the clinical effects of gluconate. Gluconate is largely excreted unchanged in the urine $(80 \%)$ and compared with bicarbonate, lactate or acetate, the alkalizing effect of gluconate is almost zero (P. L. Kirkendol, Starrs, \& Gonzalez, 1980; Naylor \& Forsyth, 1986). Therefore its clinical effects in vivo as a metabolisable anion also appear to be limited. Studies of gluconate have demonstrated protection against post-ischaemic myocardial dysfunction and oxidative injury (Murthi, Wise, Weglicki, Komarov, \& Kramer, 2003). In a recent Phase II evaluation of an acetated solution vs. a bicarbonate buffered CPB prime fluid, CPB commencing with acetated solution was associated with an immediate surge in unmeasured anions of $>10 \mathrm{mEq} / \mathrm{L}$, with residual elevations still present just prior to CPB cessation (Morgan, Power, Venkatesh, \& Jones, 2008). Liskaser et al. (2000) reported a similar phenomenon. In both studies, the unmeasured anions were considered to be acetate and gluconate, however, neither study measured individual concentrations of either anion at any time point. Davies et al. (2011) showed that the use of acetate and gluconate solutions as a CPB pump-prime fluid led to supra-physiologic plasma levels of acetate and gluconate when compared to a bicarbonate buffered pump prime. There were no clear differences in systemic inflammation (as reflected by Interleukin-6 levels) between the acetate and gluconate containing solution when compared to a bicarbonate buffered pump prime. However, the clinical significance of elevated gluconate and acetate levels remains unclear and remains an area that requires further investigation.

\subsection{Current literature that has compared $0.9 \%$ saline to buffered crystalloids in adult patients.}

The type of crystalloid fluid used for fluid resuscitation is an easily modifiable component of patient care. There has recently been increasing interest in the effect of crystalloid fluids in different organ systems and in different patient populations. The three main areas of research and clinical interest have been in renal function, haemostasis/blood transfusion requirements and gastrointestinal function. The relevant research will be discussed in these three categories and broken into three sections; experimental and animal studies, observational studies and interventional studies. 


\subsection{Evidence comparing the effects of renal function between unbuffered and buffered crystalloid fluid.}

\section{Experimental and animal studies}

The biological plausibility that $0.9 \%$ saline may affect renal function is supported by experimental and animal studies that have reported that $0.9 \%$ saline and/or hyperchloremia may alter renal blood flow, impair cortical perfusion or lead to inflammatory mediated renal injury.

Chowdhury, Cox, Francis, and Lobo (2012) conducted a double-blind, crossover study of 12 young (mean age=22.7 years) male volunteers and reported that in participants who received two litres of $0.9 \%$ saline, over one hour, compared to those patients that had received Plasma-Lyte $148^{\circledR}$ had a significantly a higher peak serum chloride level (109 $\mathrm{mmol} / \mathrm{L}$ in $0.9 \%$ saline group vs. $<105 \mathrm{mmol} / \mathrm{L}$ in the Plasma-Lyte 148 group, $\mathrm{p}<0.0001$ ), a significantly lower apparent SID (exact values not reported, $p=0.025$ ), reduced MRI estimated renal artery blood flow velocity ( $9 \%$ reduction in the velocity in the $0.9 \%$ saline group from baseline, $p=0.045)$ and a reduced magnetic resonance imaging (MRI) estimated renal cortical tissue $(11.7 \%$ reduction in the cortical perfusion in the $0.9 \%$ saline group from baseline, $p=0.008$ ). By the end of the study period (240 minutes after the start of the infusion) participants in the Plasma-Lyte $148^{\circledR}$ group had a significantly shorter time to first micturition (mean time of $142 \mathrm{~min}$ in the $0.9 \%$ saline group vs. $90 \mathrm{~min}$ in the Plasma-Lyte $148^{\circledR}$ group, $\mathrm{p}=0.006$ ), larger post infusion urinary volume (mean value, $836 \mathrm{~mL}$ in the Plasma-Lyte $148^{\circledR}$ group vs. $533 \mathrm{~mL}$ in the $0.9 \%$ saline group, $p=0.002$ ) and less change in weight from baseline (mean weight gain $0.84 \mathrm{~kg}$ in Plasma-Lyte $148^{\circledR}$ vs. $1.2 \mathrm{~kg}$ in the saline group, $p=0.02$ ). The extracellular fluid compartment expansion, which was calculated from a change in body weight, was also reported to be significantly greater in the $0.9 \%$ saline group compared to the Plasma-Lyte $148^{\circledR}$ group (mean expansion, $1484 \mathrm{~mL}$ in $0.9 \%$ saline group vs. $1155 \mathrm{~mL}$ in the Plasma-Lyte $148^{\circledR}$ group, $p=0.03$ ). There was no difference found in urinary neutrophil gelatinase-associated lipocalin (NGAL) - a urinary biomarker of renal tubular damage. These study findings suggest that even a modest volume of $0.9 \%$ saline in healthy individuals is associated with a transient hyperchloremia, altered acid/base balance, reduced renal perfusion, reduced urinary output, but no evidence of renal tubular injury. However, 
this study was only conducted in a young, male population, that had only short term followup (four hours) and also used surrogate measures for renal blood flow/perfusion and extracellular fluid expansion.

Several animal studies have demonstrated that $0.9 \%$ saline is associated with acute kidney injury, altered renal perfusion, and have identified several potentially responsible pathophysiological mechanisms. Recently, Zhou et al. (2014) conducted an unblinded randomised study comparing fluid resuscitation with Plasma-Lyte ${ }^{\circledR}$ to $0.9 \%$ saline in an animal model of sepsis. 60 rats were randomised to receive fluid resuscitation with $0.9 \%$ saline or Plasma-Lyte ${ }^{\circledast}$ for four hours $(10 \mathrm{~mL} / \mathrm{kg}$ for the first hour and $5 \mathrm{~mL} / \mathrm{kg}$ over the next three hours) duration after 18 hours of cecal ligation and puncture. After fluid resuscitation rats that received $0.9 \%$ saline were reported to have significantly higher level of serum chloride $(p<0.05)$ and significant decreased serum $\mathrm{pH}(\mathrm{p}<0.05)$ compared to baseline measurements whereas there was no change found in those rats receiving Plasma-Lyte ${ }^{\circledR}$. Rats receiving $0.9 \%$ saline had higher mortality rates 24 hours after resuscitation $(76.6 \%$ vs. $53.3 \%, p=0.01)$, higher rates of AKI $(100 \%$ vs. $76 \%, p<0.05)$ and significantly worse AKI severity based on the renal risk, injury, failure, loss, end-stage (RIFLE) criteria creatinine definitions (RIFLE-I or RIFLE-F: $83 \%$ vs. $28 \%, p<0.001$ ). Cystatin C and NGAL, urinary biomarkers of $\mathrm{AKI}$, were significantly worse in rats that received $0.9 \%$ saline compared to rats that received Plasma-Lyte ${ }^{\circledR}(3,013$ vs $1,660 \mathrm{IU} / \mathrm{mL}$ and 2,408 vs $1,912 \mathrm{IU} / \mathrm{mL}$, respectively, $p<0.05$ ). Plasma interleukin (IL)-6, an inflammatory biomarker, levels were significantly greater after infusion with $0.9 \%$ saline compared with Plasma-Lyte ${ }^{\circledR}$ resuscitation ( 2.87 vs $2.50 \log \mathrm{pg} / \mathrm{mL}, \mathrm{p}=0.04$ ). On kidney histology, evidence of acute kidney injury, loss of brush border, vacuolisation and dilation of the tubular lumen, were more prominent in rats that received $0.9 \%$ saline. Within the same paper, in a population of rats $(n=12)$ that did not have cecal ligation and puncture but underwent the same resuscitation fluid protocol, there was no between-group difference in change from baseline in plasma chloride, arterial pH, plasma creatinine, plasma IL-6, urine NGAL and urine cystatin C. This study suggests that in an animal model of sepsis the use of $0.9 \%$ saline when compared to Plasma-Lyte ${ }^{\circledR}$ is associated with significantly greater biochemical and histopathological signs of AKI and inflammation. 
Although the exact underlying causative mechanism leading to AKI with the use of $0.9 \%$ saline and hyperchloremia are not fully understood, there are several animal studies that have explored this issue. In a canine animal model Wilcox (1983) reported that chloride containing solutions were associated with an altered renal blood flow, renal specific vasoconstriction and reduced glomerular filtration rate. In the experiment 48 male greyhounds were anaesthetised and had their kidneys denervated (auto-transplanted to the vessels in their necks). They then received a 30 minute intra-renal artery infusion of a variety of crystalloid fluids that included $0.9 \%$ saline, sodium acetate and dextrose. Those dogs $(n=17)$ that were allocated to $0.9 \%$ saline developed a metabolic acidosis and when compared to baseline measurements there was a significantly decreased renal blood flow, renal plasma flow and glomerular filtration rate during the infusion of $0.9 \%$ saline. Whereas, those dogs allocated to sodium acetate $(n=5)$ are reported to have developed a metabolic alkalosis, an increase in renal blood flow and renal plasma flow during the infusion compared to baseline measurements. Wilcox (1983) also reported that the changes in renal blood flow and glomerular filtration rate were significantly correlated with the fractional reabsorption of sodium at the proximal renal tubule and suggested that tubular chloride reabsorption may be a major contributing factor in renal vasoconstriction.

Renal auto-regulation to prevent mismatching of renal filtration with absorption is thought to be a protective homeostatic mechanism which is regulated by tubuloglomerular feedback (Blantz, Deng, Miracle, \& Thomson, 2007; Schnermann \& Briggs, 1999). A rat model exploring the influence of a variety of different salt solutions on tubuloglomerular feedback demonstrated that chloride containing solutions significantly reduced the early proximal flow rate within the renal tubules (Schnermann, Ploth, \& Hermle, 1976). These findings suggest that nephron filtration rate may be independently influenced by the concentration of chloride exposed to the macula densa cells (specialised cells within the renal tubules that are thought to sense changes in sodium and chloride concentration). A high concentration of luminal chloride may trigger the macula densa cells to reduce glomerular filtration rate through afferent arteriolar vasoconstriction (Schnermann \& Briggs, 1999).

Additionally, studies that have explored the impact of hyperchloremia on renal vasoconstriction in canine and rats models have also reported that there were significantly lower renal blood flows and lower glomerular filtration rates in animals that were 
administered non-steroidal anti-inflammatory drugs (indomethacin) suggesting a possible role of prostaglandins, namely thromboxane, in renal vasoconstriction secondary to hyperchloremia (Bullivant, Wilcox, \& Welch, 1989; Wilcox, 1988). Some authors have also suggested that hyperchloremia and/or metabolic acidosis from $0.9 \%$ saline infusion may increase direct kidney injury through the expression of pro-inflammatory cytokines such as IL-6 (Zhou et al., 2014).

\section{Observational studies}

The largest studies that have explored the potential adverse effects with the use of $0.9 \%$ saline compared to buffered crystalloids have been from recent observational studies in both critically unwell patients and also surgical patients.

In a single centre, open-label, sequential six month period study of 1533 critically ill patients, the change from standard chloride-liberal fluids (0.9\% saline, $4 \%$ succinylate gelatin or $4 \%$ albumin) to chloride-restrictive fluids (Hartmann's solution, Plasma-Lyte $148^{\circledR}$ and $20 \%$ albumin) was associated with a significantly lower increase in creatinine during the ICU stay from baseline (14.8 umol/L in the chloride-restrictive fluids group vs. $22.6 \mathrm{umol} / \mathrm{L}$ in the chloride-liberal fluids group, $p=0.03$ ), a decreased risk in the development of RIFLE-defined AKI (8.4\% in the chloride-restrictive fluids group vs. $14 \%$ in the chloride-liberal fluids group, odds ratio, $0.52 ; 95 \% \mathrm{Cl}, 0.37$ to $0.75 ; \mathrm{p}<0.01$ ) and lower requirement for renal replacement therapy (RRT) while in the ICU $(6.3 \%$ in the chloride-restrictive fluids group vs. $10 \%$ in the standard chloride-liberal fluids group, odds ratio, $0.52 ; 95 \% \mathrm{Cl}, 0.33$ to $0.81 ; p=0.004$ ) (Yunos et al., 2012). In an exploratory subgroup analysis the risk of AKI was significantly lower in the chloride-restrictive fluids group for patients with sepsis (odds ratio, $0.25,95 \% \mathrm{Cl}, 0.08$ to 0.74), $p=0.012$ ), APACHE II risk of death $>5 \%$ (odds ratio, $0.53,95 \% \mathrm{Cl}, 0.36$ to $0.79, \mathrm{p}=0.002$ ) and ICU stay length of stay $>43$ hours (odds ratio, $0.51,95 \% \mathrm{Cl}, 0.35$ to 0.74 ), $p=0.0004$ ). Whereas, there was no between-group difference in risk of AKI in patients undergoing cardiac surgery, with an APACHE II risk of death $<5 \%$ or ICU length of stay $<43$ hours. There were no differences between groups in hospital mortality and hospital or ICU length of stay. Because multiple changes in intravenous fluids occurred simultaneously in this study it is not possible to determine what component of the fluid change strategy (if any) was responsible for the observed changes. There is also observational evidence to suggest that reducing the 
prescribing of gelatin in critically unwell patients is associated with a lower incidence of AKI and therefore the findings of this study may be explained by the reduced prescribing of gelatin (Bayer et al., 2011). A further limitation of this study was that the specific volume of fluid administered to individual patients was not collected and a detailed analysis of the fluid administered was only conducted on a nested cohort of 199 patients (99 patients from the chloride-liberal fluids group and 100 patients from the chloride-restrictive fluids group). The primary outcome for this study (AKI based on RIFLE criteria) required a baseline creatinine which was missing for over $10 \%$ of patients $(13.7 \%$ in the chloride-restrictive fluids group vs. $14.2 \%$ in the chloride-liberal fluids group) and had to be estimated using the modification of diet in renal disease (MDRD) equation that assumed a lower limit of normal baseline glomerular filtration rate (GFR) of $75 \mathrm{~mL} / \mathrm{min}$. Other limitations of this study were that it was an unblinded study and there is a risk that the observed change was due to other factors not controlled for in the study such as a Hawthorne effect from the period of staff education which occurred in between the change from the standard chloride-liberal fluids period to chloride-restrictive period (Waikar \& Winkelmayer, 2012).

The two largest studies that have assessed the effects of buffered versus unbuffered crystalloid fluid were retrospective observational studies with patient data collected from centralised health-economic databases (Raghunathan et al., 2014; Shaw et al., 2012). The most recent study was conducted in non-surgical, adult patients with the International Classification of Disease, Ninth Edition Clinical Modification (ICD-9-CM) codes for sepsis that were receiving vasopressor in ICU by day two, having three consecutive days of antibiotics and having had a blood culture (Raghunathan et al., 2014). In total 53,448 patients were found from 360 hospitals over five years. Of this cohort, only 3,365 patients (6.4\%) had received some "balanced fluids" during their first two hospital days. This sample was compared with a propensity-matched group of 3,365 that had "not received balanced fluids" (received either $0.9 \%$ saline or $5 \%$ dextrose). Patients that had received balanced fluids had a significantly lower in-hospital mortality (19.6\% vs. $22.8 \%$; relative risk, $0.86 ; 95 \% \mathrm{Cl}, 0.78$ to $0.94, p=0.001$ ) compared to the group that had not received balanced fluids. However, no difference was found between groups in acute renal failure (defined by ICD-9-CM codes), need for dialysis and hospital or ICU length of stay. The vast majority of patients in the balanced group had received a mixture of intravenous fluids and it was reported that less 
than $1 \%$ of patients in the balanced fluids group had exclusively received balanced fluids. On further analysis, patients were stratified on the proportion of balanced to unbalanced fluid they received and the relative risk of in-hospital mortality was progressively lower among patients who received a greater proportion of balanced fluid.

A similar retrospective study was conducted in adult patients who had undergone nontraumatic, open, general surgical abdominal operations who had exclusively received either $0.9 \%$ saline or a balanced fluid (defined as a calcium-free buffered fluid: Plasma-Lyte $148^{\circledR}$ or Plasma-Lyte $A^{\circledR}$ ) on the day of surgery (Shaw et al., 2012). In total 271,189 patients from approximately 600 hospitals had received fluids on the day of surgery. Of these patients, 30,994 received $0.9 \%$ saline and 926 received balanced fluid. Propensity matching was used to mitigate for baseline group imbalances that included a significantly higher proportion of minorities, less commercial insurance, greater proportion of patients from non-teaching hospitals, greater proportion of admission via emergency department and significantly higher rates of co-morbidities (based on ICD-9-CM codes) like renal failure, diabetes and congestive heart failure in patients that had exclusively received $0.9 \%$ saline. On matched analysis, patients that exclusively received balanced fluid had a decreased risk of major complications (odds ratio, $0.79 ; 95 \% \mathrm{Cl}, 0.66$ to $0.97 ; \mathrm{p}<0.05)$ and need for dialysis $(1.0 \%$ vs. $4.8 \% ; \mathrm{p}<0.001)$. However, those in the balanced group had a longer hospital length of stay (6.4 vs. 5.9 days; $p<0.001)$.

Overall, since 2012 there have been three large observational studies that have tried to assess the association between high chloride containing solutions and adverse clinical outcomes (Raghunathan et al., 2014; Shaw et al., 2012; Yunos et al., 2012). These studies have been performed in heterogeneous populations and have reported conflicting results. Two studies have reported increased RRT requirements in patients that received high chloride fluids (Shaw et al., 2012; Yunos et al., 2012). Whereas, the study by Raghunathan et al. reported no difference in renal failure or need for RRT (Raghunathan et al., 2014). Although statistical measures were taken to reduce the chance of bias in these studies, due to the risk of unmeasured factors confounding the results, the risk of bias cannot be fully removed and therefore the findings need to be interpreted with caution (Austin, 2011). 


\section{Interventional studies}

There have been few interventional studies that have compared $0.9 \%$ saline to buffered crystalloid fluids. Table 6.2 shows a summary of the design, setting, participants and key findings of the interventional studies that have been performed up until April, 2014. The studies were arranged in order from newest to oldest with regard to publication and placed into two categories: studies performed in acutely unwell populations and studies performed in surgical populations. Most notably all interventional studies comparing $0.9 \%$ saline to buffered crystalloids had a small sample size $(n<100)$ and focused primarily on short-term physiological or biochemical outcomes.

Table 6.2. Summary of the key interventional clinical studies that have compare $0.9 \%$ saline to buffered crystalloid fluid in adult patients. AKI: acute kidney injury; ED: emergency department; RCT: randomised control trial; RRT: renal replacement therapy; SIRS: systemic inflammatory response syndrome.

\begin{tabular}{|c|c|c|}
\hline Study & Design, setting and participants & Key Findings \\
\hline \multicolumn{3}{|c|}{ Acutely unwell population } \\
\hline $\begin{array}{l}\text { (J. B. Young et } \\
\text { al., 2014) }\end{array}$ & $\begin{array}{l}\text { Single centre, double-blind } R C T \\
\text { comparing } 0.9 \% \text { saline with Plasma-Lyte } \\
A^{\oplus} \text { in patients presenting to ED with } \\
\text { severe acute trauma; } n=46\end{array}$ & $\begin{array}{l}\text { - Patients receiving } 0.9 \% \text { saline had an } \\
\text { increase in serum chloride concentration } \\
\text { and decrease in serum pH } \\
\text { - No significant differences in mortality } \\
\text { hospital length of stay, blood transfusion } \\
\text { requirements or utilisation of resources }\end{array}$ \\
\hline $\begin{array}{l}\text { (Cieza, } \\
\text { Hinostroza, } \\
\text { Huapaya, \& } \\
\text { Leon, 2013) }\end{array}$ & $\begin{array}{l}\text { Single centre, open label } \mathrm{RCT} \\
\text { comparing } 0.9 \% \text { saline with Ringer's } \\
\text { lactate in patients with severe } \\
\text { dehydration secondary to choleriform } \\
\text { diarrhoea; } \mathrm{n}=40\end{array}$ & $\begin{array}{l}\text { - Patients receiving } 0.9 \% \text { saline had lower } \\
\text { serum } \mathrm{pH} \text { at } 2 \text { and } 4 \text { hours } \\
\text { - No differences in serum creatinine, lactate } \\
\text { or potassium concentration }\end{array}$ \\
\hline $\begin{array}{l}\text { (Hasman et al., } \\
\text { 2012) }\end{array}$ & $\begin{array}{l}\text { Single centre, double-blind RCT } \\
\text { comparing either } 0.9 \% \text { saline, Ringer's } \\
\text { lactate or Plasma-Lyte }{ }^{\circledR} \text { in patients } \\
\text { presenting to ED with dehydration; } n= \\
90\end{array}$ & $\begin{array}{l}\text { - Patients receiving } 0.9 \% \text { saline had a } \\
\text { significantly lower serum pH and lower } \\
\text { serum bicarbonate concentration } \\
\text { - No differences between groups in chloride, } \\
\text { potassium, or sodium concentrations }\end{array}$ \\
\hline $\begin{array}{l}\text { (Van Zyl, } \\
\text { Rheeder, \& } \\
\text { Delport, 2012) }\end{array}$ & $\begin{array}{l}\text { Multicentre, double-blind RCT of } \\
\text { Ringer's lactate versus } 0.9 \% \text { saline in } \\
\text { patients presenting to ED with diabetic } \\
\text { ketoacidosis; } n=54\end{array}$ & $\begin{array}{l}\text { - There was no significant difference } \\
\text { between groups in time interval for } \\
\text { correction of acidosis } \\
\text { - Patients receiving } 0.9 \% \text { saline a } \\
\text { significantly shorter time to lower blood } \\
\text { glucose } \\
\text { - No difference between groups in hospital } \\
\text { length of stay }\end{array}$ \\
\hline
\end{tabular}




\begin{tabular}{|c|c|c|}
\hline $\begin{array}{l}\text { (Mahler, } \\
\text { Conrad, Wang, } \\
\text { \& Arnold, } \\
\text { 2011) } \\
\end{array}$ & $\begin{array}{l}\text { Single centre, double-blind } \quad \text { RCT } \\
\text { comparing either } 0.9 \% \text { saline with } \\
\text { Plasma-Lyte } A^{\otimes} \text { in patients presenting } \\
\text { to ED with diabetic ketoacidosis; } n=45\end{array}$ & $\begin{array}{l}\text { - Patients receiving } 0.9 \% \text { saline had } \\
\text { significantly higher serum chloride and } \\
\text { lower bicarbonate concentration }\end{array}$ \\
\hline $\begin{array}{l}\text { (Wu et al., } \\
2011 \text { ) }\end{array}$ & $\begin{array}{l}\text { Multicentre, open label RCT comparing } \\
0.9 \% \text { saline with Ringer's lactate in } \\
\text { patients diagnosed with acute } \\
\text { pancreatitis; } n=40\end{array}$ & $\begin{array}{l}\text { - Patients receiving Ringer's lactate had } \\
\text { lower rates of SIRS and lower CRP } \\
\text { concentration at } 24 \text { hours } \\
\text { No difference between groups in } \\
\text { development of complications or hospital } \\
\text { length of stay }\end{array}$ \\
\hline $\begin{array}{l}\text { (Cho, Lim, \& } \\
\text { Kim, 2007) }\end{array}$ & $\begin{array}{l}\text { Multicentre, single-blind RCT of Ringer's } \\
\text { lactate versus } 0.9 \% \text { saline in patients } \\
\text { presenting to ED with rhabdomyolysis; } \\
n=28\end{array}$ & $\begin{array}{l}\text { - Patients receiving } 0.9 \% \text { saline had a } \\
\text { significantly higher serum chloride and } \\
\text { sodium concentration and lower serum pH } \\
\text { - There was no significant difference } \\
\text { between groups in time interval for } \\
\text { normalisation of creatine kinase }\end{array}$ \\
\hline \multicolumn{3}{|c|}{ Operative population } \\
\hline $\begin{array}{l}\text { (Kim et al., } \\
2013 \text { ) }\end{array}$ & $\begin{array}{l}\text { Single centre, blinded RCT comparing } \\
\text { either } 0.9 \% \text { saline with Plasma-Lyte }{ }^{\circledR} \text { in } \\
\text { patients undergoing renal } \\
\text { transplantation; } n=60\end{array}$ & $\begin{array}{l}\text { - Patients receiving } 0.9 \% \text { saline had lower } \mathrm{pH} \\
\text { and base excess values } \\
\text { - No difference between groups in } \\
\text { postoperative urine output, creatinine or } \\
\text { need for RRT }\end{array}$ \\
\hline $\begin{array}{l}\text { (Modi, Vora, } \\
\text { Parikh, \& Shah, } \\
\text { 2012) }\end{array}$ & $\begin{array}{l}\text { Single centre, double-blind } \mathrm{RCT} \\
\text { comparing } 0.9 \% \text { saline with Ringer's } \\
\text { lactate in patients undergoing renal } \\
\text { transplantation; } n=74\end{array}$ & $\begin{array}{l}\text { - Patients receiving } 0.9 \% \text { saline had lower } \\
\text { serum pH and base excess values } \\
\text { - No difference between groups in } \\
\text { postoperative urine output or creatinine }\end{array}$ \\
\hline $\begin{array}{l}\text { (Heidari SM, } \\
\text { Saryazdi H, } \\
\text { Shafa A, \& } \\
\text { Arefpour R, } \\
\text { 2011) }\end{array}$ & 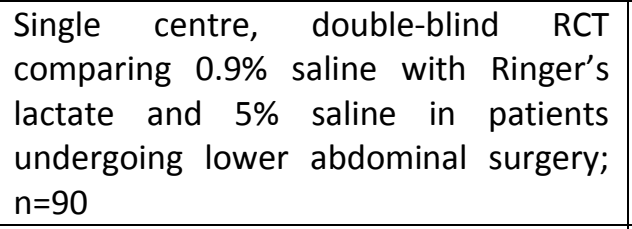 & $\begin{array}{l}\text { A higher proportion of patients that had } \\
\text { received } 0.9 \% \text { saline experienced vomiting } \\
6 \text { hours post-operatively }\end{array}$ \\
\hline $\begin{array}{l}\text { (Hadimioglu, } \\
\text { Saadawy, } \\
\text { Saglam, Ertug, } \\
\text { \& Dinckan, } \\
\text { 2008) }\end{array}$ & $\begin{array}{l}\text { Single centre, double-blind RCT } \\
\text { comparing either } 0.9 \% \text { saline, Ringer's } \\
\text { lactate or Plasma-Lyte }{ }^{\circledR} \text { in patients } \\
\text { undergoing renal transplantation; } n=90\end{array}$ & $\begin{array}{l}\text { - Patients receiving } 0.9 \% \text { saline had an } \\
\text { increase in serum chloride concentration } \\
\text { and decrease in serum pH } \\
\text { - Patients receiving Ringer' lactate had a } \\
\text { significantly increased serum lactate } \\
\text { concentration } \\
\text { - Patients in the } 0.9 \% \text { saline had significantly } \\
\text { greater urine output on post-operative day } \\
1,2 \text { and } 3 \text {. } \\
\text { - There was no significant difference } \\
\text { between in postoperative creatinine or } \\
\text { need for RRT }\end{array}$ \\
\hline
\end{tabular}




\begin{tabular}{|c|c|c|}
\hline $\begin{array}{l}\text { (Khajavi et al., } \\
\text { 2008) }\end{array}$ & $\begin{array}{l}\text { Single centre, double-blind } \mathrm{RCT} \\
\text { comparing } 0.9 \% \text { saline with Ringer's } \\
\text { lactate in patients undergoing renal } \\
\text { transplantation; } n=52\end{array}$ & $\begin{array}{l}\text { - Patients receiving } 0.9 \% \text { saline had a } \\
\text { significantly lower serum } \mathrm{pH} \text { and higher } \\
\text { serum potassium concentration at the end } \\
\text { of the operation }\end{array}$ \\
\hline $\begin{array}{l}\text { (Chin, } \\
\text { Macachor, } \\
\text { Ong, \& Ong, } \\
\text { 2006) }\end{array}$ & $\begin{array}{l}\text { Single centre, open label RCT } \\
\text { comparing } 0.9 \% \text { saline with Ringer's } \\
\text { lactate, } 0.9 \% \text { saline with dextrose } 5 \% \text { in } \\
\text { non-diabetic patients undergoing } \\
\text { elective surgery; } n=50\end{array}$ & $\begin{array}{l}\text { No difference between groups in serum } \\
\text { urea, sodium or potassium concentration } \\
\text { Dextrose } 5 \% \text { resulted in significant, albeit } \\
\text { transient hyperglycaemia, even in non- } \\
\text { diabetic patients }\end{array}$ \\
\hline $\begin{array}{l}\text { (Karaca B, } \\
2006)\end{array}$ & $\begin{array}{l}\text { Single centre, single-blinded RCT } \\
\text { comparing } 0.9 \% \text { saline with Ringer's } \\
\text { lactate and } 4 \% \text { gelatin polysuccinate in } \\
\text { patients undergoing transurethral } \\
\text { prostatectomy under spinal anaesthesia } \\
; n=60\end{array}$ & $\begin{array}{l}\text { - No difference between groups in nausea, } \\
\text { vomiting, dizziness and post spinal hearing } \\
\text { loss. }\end{array}$ \\
\hline $\begin{array}{l}\text { (Chanimov, } \\
\text { Gershfeld, } \\
\text { Cohen, } \\
\text { Sherman, \& } \\
\text { Bahar, 2006) }\end{array}$ & $\begin{array}{l}\text { Single centre, } \text { double-blinded RCT } \\
\text { comparing } 0.9 \% \text { saline with Ringer's } \\
\text { lactate in patients undergoing } \\
\text { caesarean section; } n=40\end{array}$ & $\begin{array}{l}\text { - No difference between groups in inotrope } \\
\text { requirements } \\
\text { - No significant differences in the Apgar } \\
\text { scores at } 1 \text { and } 5 \text { min or infant well-being }\end{array}$ \\
\hline $\begin{array}{l}\text { (O'Malley et } \\
\text { al., 2005) }\end{array}$ & $\begin{array}{l}\text { Single centre, double blind RCT } \\
\text { comparing } 0.9 \% \text { saline with Ringer's } \\
\text { lactate in patients undergoing renal } \\
\text { transplantation; } n=51\end{array}$ & $\begin{array}{l}\text { - Significantly more patients receiving } 0.9 \% \\
\text { saline required intra-operative treatment } \\
\text { for metabolic acidosis and hyperkalaemia } \\
\text { - No difference between groups in } \\
\text { postoperative urine output, creatinine or } \\
\text { need for RRT }\end{array}$ \\
\hline $\begin{array}{l}\text { (Takil, Eti, } \\
\text { Irmak, \& Yilmaz } \\
\text { Gogus, 2002) }\end{array}$ & $\begin{array}{l}\text { Single centre, open label } \text { RCT } \\
\text { comparing } 0.9 \% \text { saline with Ringer's } \\
\text { lactate in patients undergoing spinal } \\
\text { surgery; } n=30\end{array}$ & $\begin{array}{l}\text { Patients receiving } 0.9 \% \text { saline had an } \\
\text { increase in serum chloride, sodium } \\
\text { concentration and decrease in serum pH } \\
\text { - No difference between groups in } \\
\text { intraoperative haemodynamic variable or } \\
\text { hospital and ICU length of stay }\end{array}$ \\
\hline $\begin{array}{l}\text { (Waters et al., } \\
\text { 2001) }\end{array}$ & $\begin{array}{l}\text { Single centre, double-blind RCT } \\
\text { comparing } 0.9 \% \text { saline with Ringer's } \\
\text { lactate in patients undergoing } \\
\text { abdominal aortic aneurysm surgery; } \\
\mathrm{n}=66\end{array}$ & $\begin{array}{l}\text { Patients receiving } 0.9 \% \text { saline had an } \\
\text { increase in serum chloride, sodium } \\
\text { concentration and decrease in serum } \mathrm{pH} \\
\text { - Patients receiving } 0.9 \% \text { saline received a } \\
\text { greater volume of platelets } \\
\text { No difference between groups in estimated } \\
\text { blood loss, postoperative complications, } \\
\text { hospital and ICU length of stay }\end{array}$ \\
\hline $\begin{array}{l}\text { (Scheingraber } \\
\text { et al., 1999) }\end{array}$ & $\begin{array}{l}\text { Single centre, open label RCT } \\
\text { comparing } 0.9 \% \text { saline with Ringer's } \\
\text { lactate in patients undergoing } \\
\text { gynaecologic surgery; } n=24\end{array}$ & $\begin{array}{l}\text { - Patients receiving } 0.9 \% \text { saline had an } \\
\text { increase in serum chloride concentration } \\
\text { and decrease in serum } \mathrm{pH}\end{array}$ \\
\hline $\begin{array}{l}\text { (Ramanathan, } \\
\text { Masih, Ashok, } \\
\text { Arismendy, \& } \\
\text { Turndorf, 1984) }\end{array}$ & $\begin{array}{l}\text { Single centre, open label RCT } \\
\text { comparing } 0.9 \% \text { saline with Ringer's } \\
\text { lactate, Ringer's lactate with dextrose } \\
5 \% \text { and Plasma-Lyte } A^{\circledast} \text { in patients } \\
\text { undergoing caesarean section; } n=60\end{array}$ & $\begin{array}{l}\text { - Patients receiving } 0.9 \% \text { saline had a } \\
\text { decrease in serum } \mathrm{pH} \\
\text { - } \quad \begin{array}{l}\text { No difference between groups in blood } \\
\text { pressure or inotrope requirements }\end{array}\end{array}$ \\
\hline
\end{tabular}


A recently published systemic review conducted a meta-analysis of 11 studies (published up to May, 2012) that had reported renal function based on urine volume (195 patients in Ringer's lactate group vs. 196 patients in the 0.9\% saline group) and serum creatinine after the first 24 hours of fluid administration (205 patients in Ringer's lactate group vs. 206 patients in the $0.9 \%$ saline group) found there was no significant differences between fluid groups (Orbegozo Cortes, Rayo Bonor, \& Vincent, 2014). However, the authors limited the meta-analysis to studies that only compared Ringer's lactate to $0.9 \%$ saline. Additionally over $2 / 3$ of the patients included in the meta-analysis of renal outcomes were from studies performed exclusively in renal transplant recipient patients. However, on a subgroup analysis, there was also no significant difference found in urine output or creatinine in both renal transplant and non-renal transplant populations.

There has only been one study which has reported renal outcome measures that has directly compared Plasmalyte, Ringer's lactate and $0.9 \%$ saline. Hadimioglu et al. (2008) conducted a double-blind study of 90 renal transplant recipient patients randomised to receive intraoperative Plasmalyte, Ringer's lactate or $0.9 \%$ saline at a rate of $20-30 \mathrm{~mL} / \mathrm{kg} / \mathrm{hr}$ to maintain a central venous pressure at $12-15 \mathrm{mmHg}$. There was no difference in the volume of study fluid administered to each arm of the study with the mean volume of study fluid administered to each group ranging between $2700-2900 \mathrm{~mL}$. The authors reported patients in the $0.9 \%$ saline group required significantly $(p<0.05)$ less intraoperative furosemide, less intraoperative mannitol and had a higher 24 hour urine output on post-operative day 1, 2 and 3 compared to those that were randomised to Plasmalyte or Ringer's lactate. Patients in the $0.9 \%$ saline group were also reported to have significantly higher levels of serum chloride for the first three post-operative days compared to patients in the Plasmalyte or Ringer's lactate group. There was no between-group difference in serum creatinine, creatinine clearance or blood urea nitrogen on post-operative day 1, 2, 3 and 7. However, patients in this study did not exclusively receive study fluid, following the end of surgery all patients were commenced on dextrose $5 \% / 0.45 \%$ saline at a rate of $70 \mathrm{~mL} / \mathrm{h}$ and had an hourly " $\mathrm{mL}$ for $\mathrm{mL}^{\prime \prime}$ urine output replacement with $0.45 \%$ saline.

Between May, 2012 and April, 2014 there have been two RCTs that have been published that have compared Plasma-Lyte A (differs from Plasma-Lyte 148 in having a magnesium concentration of $3 \mathrm{mmol} / \mathrm{L}$ instead on $1.5 \mathrm{mmol} / \mathrm{L}$ ) to $0.9 \%$ saline that have reported renal 
outcomes (Kim et al., 2013; J. B. Young et al., 2014). Kim et al. (2013) conducted a doubleblind RCT of 60 renal transplant recipient patients randomised to receive intraoperative Plasma-Lyte A or $0.9 \%$ saline to maintain the central venous pressure at 12 to $15 \mathrm{~mm} \mathrm{Hg}$. All patients also received $750 \mathrm{~mL}$ of $5 \%$ albumin throughout surgery and received $0.45 \%$ saline following surgery. There was no between-group difference reported on post-operative day 1,2 and 7, 24 hour urine output or serum creatinine and in the need for dialysis postoperatively.

In a more recent study conducted by Young et al. (2014), severe acute trauma patients were randomised to receive blinded Plasma-Lyte A or $0.9 \%$ saline within 60 minutes of arrival to the emergency department (ED) for the first 24 hours of their admission. Of the 65 patients that were randomised, only 46 were analysed. The reasons for exclusion were consent withdrawal $(n=15)$ and protocol violations $(n=4)$. With regard to outcomes, there were no significant between-group differences in urine output, change in creatinine from baseline within the first five days of admission or in AKI defined by the Acute Kidney Injury Network (AKIN) criteria (R. L. Mehta et al., 2007).

The overall evidence linking the use of $0.9 \%$ saline to impaired renal function and AKI from interventional clinical trials is poor. The majority of research that has reported renal outcomes has been conducted in renal transplant populations. Findings from this population are difficult to generalise due to a number of variables specific to renal transplantation patients such as the recipient's pre-existing renal impairment, post-operative immunosuppression, time of renal ischaemia and the characteristics of the donor's kidney. In addition, as study populations overall have been heterogeneous, studies typically under powered and using different intravenous fluid regimens generalisable conclusions about clinically relevant renal outcome measures are difficult to draw from the existing literature.

\subsection{Evidence comparing the influence on haemostasis and blood transfusion requirements between unbuffered and buffered crystalloid fluid}

Impaired haemostasis is an important contributing factor leading to abnormal bleeding (Chee, Crawford, Watson, \& Greaves, 2008). There is evidence to suggest that crystalloid 
fluids may influence haemostasis through a variety of mechanisms. Due to the concern for bleeding and blood transfusion requirements being greatest in surgical patients the majority of studies that have explored $0.9 \%$ saline and buffered crystalloids have been conducted in surgical populations. Prior to reviewing the current literature available on this topic below is a brief overview of haemostasis.

\section{Overview of haemostasis}

There is a haemostatic balance between coagulation and fibrinolysis reducing the risk of both bleeding and thrombosis (Brummel-Ziedins, Whelihan, Ziedins, \& Mann, 2006). In-vitro, coagulation is arranged into "intrinsic" and "extrinsic" pathways which converge to form a common pathway that activates thrombin and converts fibrinogen to fibrin (O'Carroll-Kuehn \& Meeran, 2007). This classical enzymatic "waterfall" cascade model was useful in the early understanding of coagulation and still remains useful in the interpretation of laboratory tests: prothrombin time (PT) tests the extrinsic pathway and activated partial thromboplastin time (APTT) tests the intrinsic pathway. During the mid-1990s a cell-based model of haemostasis was proposed that emphasised the importance of the in-vivo cellular components for haemostasis and described three overlapping phases of coagulation: 1) initiation, the commencement of coagulation on the surface of tissue-factor bearing cells; 2) amplification, activation of platelets and other coagulation factors on the platelet's surface; and, 3) propagation, whereby large amounts of thrombin are generated on the surface of platelets leading to the formation of a fibrin clot (Hartmann et al., 2006; Hoffman \& Monroe, 2001). Coagulation is limited by natural anticoagulants (anti-thrombin III, tissue factor inhibitor, protein $\mathrm{C}$ and S) and plasma protease inhibitors. Fibrin clot degradation occurs through fibrinolysis (Brummel-Ziedins et al., 2006). This conceptual model provides a better in-vivo understanding of haemostasis and correlates with viscoelastic point of care testing such as thromboelastography (Johansson et al., 2014; Weber, Klages, \& Zacharowski, 2013).

\section{Experimental and animal studies}

Initially it was thought that the infusion of crystalloid fluid would lead to a progressive hypocoagulable state through the passive haemodilution of clotting factors; however, there is evidence to suggest that crystalloid fluids may have a more complex interaction with haemostasis. Early in vitro experiments by Tocantins, Carroll, and Holburn (1951) reported 
that dilution of human blood of up to $20 \%$ with $0.85 \%$ saline resulted in faster clotting times compared to an undiluted control. Similar in vitro experiments with $20 \%$ haemodilution using $0.9 \%$ saline, when compared to undiluted controls, was associated with a hypercoagulable profile in all thromboelastography parameters (Ruttmann, James, \& Viljoen, 1996). These findings suggest that a moderate haemodilution with $0.9 \%$ saline may be associated with a hypercoagulable state and that the faster/stronger clot formation may be due to increased platelet activity and/or increased fibrin activity.

More recently, Brummel-Ziedins et al. (2006) have investigated the influence of the dilution of whole blood with a variety of different fluids, including $0.9 \%$ saline and Ringer's lactate. At $10 \%$ and $75 \%$ dilution, platelet activation was significantly less with $0.9 \%$ saline when compared to Ringer's lactate $(p<0.05)$. Above $50 \%$ dilution thrombin generation decreased more rapidly with $0.9 \%$ saline compared to Ringer's lactate and at $60 \%$ there were longer clotting times with the $0.9 \%$ saline fluid. Both $0.9 \%$ saline and Ringer's lactate resulted in decreased fibrin clot mass with a dilution of $10 \%$ or greater. These in vitro studies suggest that crystalloid fluids influence haemostasis differently based on the percentage of dilution and type of fluid being used. The study by Brummel-Ziedins et al. (2006) provides evidence that $0.9 \%$ saline may impair haemostasis more than Ringer's lactate. However in-vitro studies of haemostasis need to be interpreted with caution as they have been typically performed on blood from a small number of healthy volunteers and tests of coagulation do not include factors that are important for haemostasis such as vascular endothelium (Roche, James, Bennett-Guerrero, \& Mythen, 2006). Due to the limitations of in vitro studies and the limitations of laboratory tests for haemostasis it is difficult to pinpoint what specific haematological pathways are most influenced by the use of different crystalloid fluids.

There have been few in vivo studies that have explored the influence of crystalloid fluids on haemostasis. Ng, Lam, and Chan (2002) conducted a study of 20 elective major hepatobiliary patients randomised immediately after induction of anaesthesia to have either $30 \%$ of their calculated blood volume removed and replaced with $0.9 \%$ saline or no blood withdrawal and no $0.9 \%$ saline replacement. At 30 minutes following the start of study patients in the $0.9 \%$ saline group had a significantly greater hypercoagulable profile in all thromboelastography parameters compared to the control group $(p<0.05)$. This study supports the findings of in vitro studies that suggest crystalloid fluids may lead to a hypercoagulable state at lower 
dilutions. However, this study was small, only assessed a single intravenous fluid with a single dilutional percentage and did not fully explore the potential mechanism that may be involved.

The only in-vivo studies which have explored haemostasis and directly compared volume replacement with $0.9 \%$ saline to Ringer's lactate have been animal studies. The largest animal study comparing $0.9 \%$ saline versus buffered fluid is a swine model of haemorrhagic shock that randomised 116 pigs into crystalloid fluid replacement at different percentages of volume of replacement of blood loss ( $0.9 \%$ saline at $14 \%$ replacement volume of blood loss; $0.9 \%$ saline at $100 \%$ replacement volume of blood loss; $0.9 \%$ saline at $300 \%$ replacement volume of blood loss; Ringer's lactate at $300 \%$ replacement of blood loss; Plasma-Lyte $A^{\circledR}$ at $300 \%$ replacement volume of blood loss; Plasma-Lyte $\mathrm{R}^{\circledR}$ at $300 \%$ replacement volume of blood loss) (Traverso, Lee, \& Langford, 1986). On comparing the different 300\% replacement volume of blood loss groups, a significant difference was found in survival at 24 hours in pigs that received Ringer's lactate (67\%) compared to Plasma-Lyte $A^{\circledR}(30 \%)$. No difference was found in survival rates in $0.9 \%$ saline $(50 \%)$ or Plasma-Lyte $\mathrm{R}^{\circledR}(40 \%)$ group.

In a smaller $(n=20)$ randomised swine model of uncontrolled severe haemorrhagic shock blinded Ringer's lactate or $0.9 \%$ saline was given to maintain a pre-injury mean arterial pressure (Kiraly et al., 2006). Resuscitation with $0.9 \%$ saline when compared with Ringer's lactate required a significantly greater volume of crystalloid fluid to maintain a pre-injury mean arterial pressure (mean volume, 10.9 litres vs. 5.2 litres, $p=0.009$ ), greater estimated blood loss after resuscitation (mean volume, $12 \mathrm{~mL} / \mathrm{kg}$ vs. $5 \mathrm{~mL} / \mathrm{kg}, \mathrm{p}=0.014$ ), longer PT two hours post injury (mean, 19.0 seconds vs. 15.5 seconds, $p=0.037$ ), longer APTT two hours post injury (mean, 25.2 seconds vs. 21.4 seconds, $p=0.004$ ) and a hypocoagulable profile on thromboelastography in all parameters two hours post injury $(<0.05)$. Similarly, in a swine model of uncontrolled severe haemorrhagic shock $(n=20)$ Todd et al. reported that significantly greater volumes of $0.9 \%$ saline were required to maintain a mean arterial pressure of $90 \mathrm{mmHg}$ compared to Ringer's lactate (mean volume, $256.3 \mathrm{~mL} / \mathrm{kg}$ vs. 125.7 $\mathrm{mL} / \mathrm{kg}, \mathrm{p}=0.04$ ). Allocation to $0.9 \%$ saline was associated with hyperchloraemic metabolic acidosis and significantly lower plasma fibrinogen levels (mean, $99 \mathrm{mg} / \mathrm{dL}$ versus $123 \mathrm{mg} / \mathrm{dL}$, $p=0.02$ ) compared to allocation to Ringer's lactate (Todd, Malinoski, Muller, \& Schreiber, 2007). Conversely, in an unblinded, randomised swine model $(n=20)$ of fixed volume $(60 \%$ 
estimated total blood volume) controlled haemorrhagic shock Martini, Cortez, and Dubick (2013) reported no between-group difference in platelet count, APTT, PT, plasma fibrinogen or any thromboelastography parameter during the first six hours after resuscitation, despite $50 \%$ more volume of $0.9 \%$ saline being administered to subjects compared to Ringer's lactate (mean, 6.1 litres vs. 4.1 litres, $p<0.05$ ).

To explore the relationship of the severity of haemorrhage and the volume of crystalloid fluid replacement ( $0.9 \%$ saline or Ringer's lactate combined with washed red blood cells) Healey, Davis, Liu, Loomis, and Hoyt (1998) used a rat model of moderate (crystalloid fluid replacement of $36 \%$ of estimated blood volume) and severe haemorrhage (crystalloid fluid replacement of $218 \%$ of estimated blood volume). There were significantly lower survival rates in the severe haemorrhage group that had been allocated to the $0.9 \%$ saline group compared to the Ringer's lactate group ( $50 \%$ vs. $100 \%, p<0.05$ ). There was no betweengroup difference in acid-base disturbance or survival in the moderate haemorrhage group. Based on animal studies, in the setting haemorrhagic shock, it appears that a differential effect between $0.9 \%$ saline and buffered crystalloids on haemostasis and mortality may only be apparent when there are extremely large volumes of fluid replacement.

Previous experimental and animal studies exploring the influence of $0.9 \%$ saline on haemostasis compared to buffered crystalloids shows a complex interaction. There appear to be differing effects on haemostasis based on the level of haemodilution. Evidence from in vitro and in vivo studies suggest the use of both $0.9 \%$ saline and Ringer's lactate at moderate levels $(<30 \%)$ of haemodilution may be associated with a hypercoagulable effect. Whereas, at higher levels of haemodilution there appears to be a progressive hypocoagulable effect. Notable differences between $0.9 \%$ saline and buffered crystalloids on haemostasis may not be apparent until there is large volume fluid replacement. The underlying mechanisms contributing to these reported findings are not fully understood but in addition to a dilutional coagulopathy there may be several contributing factors that may occur as a consequence of the metabolic acidosis from the large volume $0.9 \%$ saline resuscitation including: 1) impaired platelet activation; 2) impaired effectiveness of coagulation factor; and 3) decrease in thrombin generation rates (Brummel-Ziedins et al., 2006; Kiraly et al., 2006). 


\section{Observational studies}

Few observational studies have compared $0.9 \%$ saline to buffered crystalloid fluids and have reported on bleeding or blood transfusion requirements. There have been two relevant large observational studies, one in major abdominal surgery patients (Shaw et al., 2012) and the other in ICU patients (Raghunathan et al., 2014).

Shaw et al. (2012) reported that in a propensity-matched observational study of adult patients undergoing major open abdominal surgery, patients who only received $0.9 \%$ saline compared to those who only received Plasma-Lyte 148 or Plasma-Lyte were more likely to receive blood transfusions $(11.5 \%$ versus $1.8 \%, \mathrm{p}<0.001)$ and receive a significantly greater number of units of blood products if transfused (median, 2.92 vs. 2.69, $p=0.005$ ). The reported reduction in the proportion of patients requiring a blood transfusion is large (absolute risk reduction of almost 10\%). The authors do not have an explanation for this finding other than the observed volume difference of crystalloid fluid infused between groups of approximately $300 \mathrm{~mL}$ (mean, $1976 \mathrm{~mL}$ in $0.9 \%$ saline group vs. $1658 \mathrm{~mL}$ in buffered crystalloid group, $\mathrm{p}<0.0013$ ) is unlikely to lead to a difference in coagulation abnormalities. Additionally, the same lead investigators have conducted a similar observational study in adult ICU patients with sepsis (Raghunathan et al., 2014). In this study patients that received various proportions of buffered crystalloid were matched and compared to a group of patients that had not received any buffered solutions. Patients were categorised into quintiles based on the volume of crystalloid fluid received over the first two hospital days, the median crystalloid fluid volume in each quintile range from 2.5 litres to 10.5 litres. There were no differences in the proportion of patients requiring red blood cell or whole blood transfusion by ICU day two between the group that had no buffered fluid group and the group that had some buffered fluid.

Overall, there is a paucity of observational studies exploring the association between the type of crystalloid fluid used and the bleeding risk or blood transfusion requirements. Current observational studies report differing results. Amongst patients undergoing abdominal surgery, there is evidence to suggest that the exclusive use of buffered crystalloid fluid may be associated with a significantly reduced need for blood products postoperatively when compared to $0.9 \%$ saline. Conversely, there is no evidence to suggest that 
there is a difference in blood transfusion requirements amongst ICU patients with sepsis. To our knowledge, no observational studies have explored the risk of bleeding with the use of different types of balanced crystalloid fluids.

\section{Interventional studies}

In a meta-analysis of three non-cardiac surgery (vascular, liver transplantation and major spinal surgery) studies ( $n=156$ ) a lower volume of red blood cells was transfused in patients that had received Ringer's lactate compared to $0.9 \%$ saline (relative risk, $0.42 ; 95 \% \mathrm{Cl}, 0.11$ to 0.73 ) (Orbegozo Cortes et al., 2014). The total proportion of patients requiring blood products was not reported in these studies and only one study reported the volume of other blood products administered. In a RCT of 66 patients undergoing abdominal aortic aneurysm repair patients randomised to receive intraoperative $0.9 \%$ saline vs. Ringer's lactate Waters et al. (2001) reported that patients in the Ringer's lactate group required a significantly lower volume of platelets (mean volume, $223 \mathrm{~mL}$ vs $392 \mathrm{~mL}, \mathrm{p}<0.05$ ). There were no between-group differences in packed red blood cells (PRBC) or fresh frozen plasma (FFP) received. Cell salvage was also used in this study to reduce the need for blood transfusion. Notably, patients in both fluid groups had a large median estimated blood loss (>two litres) and large crystalloid fluid volume replacement (>6.5 litres).

Orbegozo Cortes et al. (2014) also conducted a meta-analysis of six studies, including 255 patients undergoing non-cardiac surgery (vascular, orthopaedic, renal transplant and colorectal surgery). There were no differences in post-operative blood loss in patients that had received Ringer's lactate compared $0.9 \%$ saline. However, in a subgroup analysis of three studies containing 120 "high risk" patients (defined by the investigators as studies with a reported blood loss of at least $800 \mathrm{~mL}$ ) there were lower blood loss volumes in patients that received Ringer's lactate fluid (relative risk, $0.42 ; 95 \% \mathrm{Cl}, 0.06$ to 0.78 ). However, as this subgroup was defined after fluid administration it is subject to bias. Although it is plausible that clinically significant differences in haemostasis between balanced and unbalanced fluid may only manifest following large volume crystalloid fluid infusion (mean volumes of over $5000 \mathrm{~mL}$ in the three studies included in this subgroup analysis) it may also be that patients who bled more received more intravenous fluids and therefore this post hoc analysis needs to be interpreted with caution. 
Amongst surgical studies only one has compared $0.9 \%$ saline to Plasma-Lyte and has reported bleeding and blood transfusion requirements. Kim et al. (2013) conducted a RCT in 60 renal transplant patients and reported no between-group differences intraoperative blood loss or intraoperative volume of PRBC. However, this study was conducted in an elective surgical population and patients received a moderate amount of study fluid (mean volume, $3249 \mathrm{~mL}$ in the $0.9 \%$ saline group vs. $3083 \mathrm{~mL}$ in the Plasmalyte A group, $\mathrm{p}=0.52$ ). In a more recent study by J. B. Young et al. (2014) in severe acute trauma patients $(n=24)$ there were no differences in the proportion of patients or the average number of units transfused of PRBC, FFP or platelets 24 hours following randomisation to receive Plasma-Lyte $\mathrm{A}$ or $0.9 \%$ saline. There was also no reported between-group differences in the INR or APPT. Patients in this study received a large volume of study fluid over the first 24 hours after study enrolment (mean volume, 9.0 litres in $0.9 \%$ saline group vs. 10.3 litres in the Plasma-Lyte A group, $\mathrm{p}>0.05$ ) and had a high requirement for blood products (with over $50 \%$ needing PRBC). Although small, this study is the only interventional study that has assessed the comparative effectiveness of two different types of crystalloid fluids and has also reported outcomes on markers of coagulation.

There has been one large RCT that has reported coagulation outcomes; however, this compared an acetate containing buffered fluid to a lactate containing fluid. Shin et al. (2011) conducted a single centre study of elective 104 living donor right hepatectomy patients randomised to receive intraoperative Ringer's lactate or Plasma-Lyte to maintain a systolic blood pressure $>90 \mathrm{mmHg}$. The INR peaked on post-operative day two and was significantly higher in the Ringer's lactate compared to the Plasma-Lyte group (mean value, 1.64 vs. 1.55, $p=0.009$ ). There were no patients in this study that required blood transfusions and the average amount of fluid administered was between $3300-3400 \mathrm{~mL}$ for both groups. The patients in the Plasma-Lyte group also had significantly lower serum lactate levels one hour following surgery and a lower bilirubin level on post-operative day one. These findings indicate that Plasma-Lyte may be associated with improved coagulation profile following surgery when compared to Ringer's lactate. However, this study was an unblinded single centre study in a population of patients that received only a moderate amount of fluid and were at low-risk of needing blood products. 


\section{Summary}

Interventional studies assessing the comparative effectiveness of unbuffered versus buffered crystalloids that have reported outcomes for bleeding, haemostasis and blood transfusion have largely been performed in a heterogeneous elective surgical population. There has been some evidence to suggest that in populations with high estimated blood loss that $0.9 \%$ saline, when compared to Ringer's lactate, may be associated with a higher observed blood loss and increased platelet transfusion volumes. However, most of the data from elective surgical populations have been in low-risk patients with modest-moderate requirements for intravenous fluids and blood products. In addition, the majority of intravenous fluid regimens have only been administered during the intraoperative period and therefore patients may have received a variety of different types of intravenous fluids before and after surgery that is not controlled for. Outcome measures for bleeding and blood transfusion requirements in clinical trials have all been secondary outcome measures and there is a paucity of data on the effect that different crystalloid fluid may have on markers of coagulation and haemostasis. There is also emerging evidence that acetate containing buffered fluid and lactate containing buffered fluid may have differing effects on coagulation in patients following surgery.

\subsection{Evidence comparing gastrointestinal effects of unbuffered and buffered crystalloid fluid}

The gastrointestinal system is one of the most under-investigated parts of the human body. There is also no universal consensus of what defines abnormal gastrointestinal function and how to assess/monitor its severity (Martindale et al., 2009; McClave et al., 2009). The maintenance and return of normal gastrointestinal function have been given the greatest importance in patients that have undergone abdominal surgery hence the majority of research on the potential adverse effects of crystalloid fluids on gastrointestinal function has been in conducted in this population. Additionally, the main focus of research to date on the effect of intravenous fluid on gastrointestinal function has been on the volume of fluid given rather than the type of fluid administered (Corcoran, Rhodes, Clarke, Myles, \& Ho, 2012). 


\section{Experimental and animal studies}

In a single-blinded, crossover study by Williams, Hildebrand, McCormick, and Bedel (1999) 20 healthy adult patients were given $50 \mathrm{~mL} / \mathrm{kg}$ of $0.9 \%$ saline or Ringer's lactate over one hour. There was significantly lower blood $\mathrm{pH}$ levels following an infusion with $0.9 \%$ saline compared to Ringer's lactate and there were numerically more patients who complained of abdominal discomfort following infusion of $0.9 \%$ saline than after Ringer's lactate. The only variable found to be significantly associated with abdominal discomfort was serum $\mathrm{pH}$ at the end of the crystalloid fluid infusion $(p<0.01)$. The authors reported that the finding of abdominal discomfort following crystalloid fluid infusion was an unexpected finding but one that warranted further investigation.

Tournadre, Allaouchiche, Malbert, and Chassard (2000) have conducted a small $(n=5)$ study in a swine model on the effect of acidosis on gastroduodenal motility. Metabolic acidosis was associated with a significantly decreased gastric pyloric contraction amplitude, increased fundic tone and dysrhythmic gastric antral contractions. There were no differences found in duodenal contractions amplitude or rate. The authors suggest that gastric dysrhythmias in combination with increased intragastric pressure may lead to gastroparesis and/or delayed gastric emptying. These findings may provide a mechanism to explain the development of upper gastrointestinal feeding intolerance symptoms such has nausea and vomiting; however, this study had a small sample size and did not explore gastrointestinal motility beyond 75 minutes after the induction of metabolic acidosis.

Several studies in rat models that involved large volume fluid resuscitation with $0.9 \%$ saline have reported an association with the development of acute hydrostatic gut oedema (Moon, Hollyfield-Gilbert, Myers, \& Kramer, 1994; Moore-Olufemi, Xue, Allen, et al., 2005; MooreOlufemi, Xue, Attuwaybi, et al., 2005). The resuscitation-induced organ oedema in one study was shown to be greatest in the small intestine compared to other organs (Moon et al., 1994) and in a separate study resuscitation-induced gut oedema was associated with delayed intestinal transit time (Moore-Olufemi, Xue, Attuwaybi, et al., 2005). Chowdhury et al. (2012) have previously reported that interstitial fluid oedema may be greater following administration of $0.9 \%$ saline compared to Plasma-Lyte 148 ; however, there have been no 
studies that have compared the development of intestinal oedema with the use of $0.9 \%$ saline to a buffered fluid.

\section{Observational studies}

There has only been one observational study that has compared $0.9 \%$ saline and has reported gastrointestinal outcomes. Shaw et al. (2012) conducted a propensity matched observational study of patients undergoing major abdominal surgery and reported that the odds of having a minor gastrointestinal complication (defined as ICD-9-CM codes for nausea, vomiting or ileus) were significantly higher in patients that had received exclusively PlasmaLyte -148 or Plasma-Lyte $A^{\circledR}$ compared to those that had exclusively received $0.9 \%$ saline $(\mathrm{OR}, 1.45,95 \% \mathrm{Cl}, 1.17$ to $1.79, \mathrm{P}<0.05)$. There were no reported differences in use of antinausea medication between groups. In this study, the composite gastrointestinal outcomes were categorised into minor or major gastrointestinal complication based on the ICD-9-CM codes for post-operative complications. No details were reported on the individual proportion of patients with each type of gastrointestinal complication. However, as return of normal gastrointestinal function is an important factor in the discharge of patients following major abdominal surgery (Berger, Ridolfi, \& Ludwig, 2015) the findings of higher minor gastrointestinal complications in patients receiving Plasma-Lyte -148 or Plasma-Lyte $A^{\circledR}$ in this study may have been of clinical importance as there was a significantly longer length of hospital stay in the balanced fluid group compared to those that had exclusively received $0.9 \%$ saline (6.4 vs. 5.9 days; $p<0.001)$ despite significantly higher rates of major complications reported in the $0.9 \%$ saline group $(33.7 \%$ of the $0.9 \%$ saline group and $23 \%$ of the balanced group, $p<0.001$ ).

\section{Interventional studies}

Heidari et al. (2011) conducted a three armed RCT involving 90 patients undergoing lower abdominal surgery randomised to receive preoperative (30 minutes before surgery) Ringer's lactate $(15 \mathrm{~mL} / \mathrm{kg}), 0.9 \%$ saline $(15 \mathrm{~mL} / \mathrm{kg})$ or hypertonic saline $5 \%(2 \mathrm{~mL} / \mathrm{kg})$. There was a significantly lower incidence of vomiting in the first six hours after surgery in patients that had received Ringer's lactate (10 of 30 patients [33.3\%] in the Ringer's lactate group vs. 18 of 30 patients [60\%] in the $0.9 \%$ saline group vs. 9 of 30 patients [30\%] in the hypertonic saline group, $p=0.04$ ) and similar rates of vomiting between groups at 24 hours 
postoperatively. This has been the only study that has directly compared $0.9 \%$ saline to a buffered crystalloid fluid that has reported gastrointestinal outcome measures. However, this study did not control for the intravenous fluid used intra operatively or provide details on the use of antiemetics in patients.

Other relevant interventional studies that have explored the comparative effectiveness of unbuffered/unbalanced fluids or buffered/balanced fluids have been in studies that have used colloids in either a $\mathbf{0 . 9 \%}$ saline or Ringer's lactate carrier solution. A recent Cochrane review identified two trials that reported outcomes on postoperative vomiting or nausea in adult surgical patients given either buffered (hetastarch in Ringer's lactate) versus unbuffered fluid (hetastarch in $0.9 \%$ saline)(Burdett et al., 2012). On meta-analysis, there were no between-group differences in the number of episodes of postoperative vomiting in a total of 108 patients. There has been one RCT published by Wilkes et al. (2001) in 47 elderly patients undergoing non-cardiac surgery receiving either hetastarch in Ringer's lactate or hetastarch in $0.9 \%$ saline. There was a small but statistically significant difference in the $\mathrm{CO}_{2}$ gradient on gastric tonometry $(1.7 \mathrm{kPa}$, with the hetastarch in Ringer's lactate group vs $0.9 \mathrm{kPa}$ with the hetastarch in $0.9 \%$ saline group, $\mathrm{p}=0.039$ ) which may suggest better gastric perfusion in the hetastarch in Ringer's lactate group compared to the hetastarch in $0.9 \%$ saline group. However, it is uncertain whether this difference in $\mathrm{CO}_{2}$ gradient is of clinical significance.

More recently Aoki et al. (2010) conducted a single centre, unblinded study of 20 consecutive patients with burns alternatively given Ringer's lactate or Ringer' acetate for fluid resuscitation. Both groups of patients in this study received approximately 10 litres over the first 48 hours after study enrolment. The $\mathrm{CO}_{2}$ gradient on gastric tonometry was significantly reduced in the first 72 hours in patients resuscitated with Ringer's acetate compared with Ringer's lactate $(p=0.047)$. This study provides evidence that different types of balanced crystalloid fluids may have different effects on gastric/splanchnic perfusion; however, this study was a small, unblinded and unrandomised.

Overall, there is a paucity of evidence investigating the potential gastrointestinal effects of $0.9 \%$ saline compared to balanced crystalloid fluid. There is some evidence from animal and early experimental studies to suggest potential mechanisms leading to impaired 
gastrointestinal function with the use of $0.9 \%$ saline including impaired gastrointestinal motility and increased submucosal gastrointestinal oedema. Data from clinical studies are conflicting, with some evidence from observational studies reporting a lower risk of minor gastrointestinal complications with the use of $0.9 \%$ saline and interventional studies reporting lower vomiting and potentially better gastric mucosal with the use of buffered fluids. However, most trials that have investigated gastrointestinal function have used surrogate measures of gastrointestinal function (gastric tonometry), were conducted in heterogeneous patient populations and have been underpowered.

\subsection{Current recommendations for the prescribing of intravenous fluids in hospitals}

Based on published evidence prior to 2014 the National Institute for Health and Care Excellence (NICE) guidelines on intravenous fluid therapy in adults in hospital currently recommend the use of crystalloids that contain sodium in the range 130-154 mmol/L for fluid resuscitation (Padhi, Bullock, Li, \& Stroud, 2013). However, the guidelines state that the available evidence at the time of writing was limited and of "poor" quality.

Research to date has been in heterogeneous populations and has been underpowered to allow for differences to be detected in clinically significant outcome measures. The NICE committee specifically identified that future research comparing buffered/balanced solutions to $0.9 \%$ saline for the fluid resuscitation was a high priority.

\subsection{Summary of background information}

Crystalloid fluids are the most commonly used intravenous fluids in the world. Currently, there are a large number of different types of crystalloid fluids available for prescribers; however, there is a paucity of data on their relative safety. There is an emerging interest to classify and to investigate the comparative effectiveness of crystalloid fluids based on buffered/balance and unbuffered/unbalanced fluid types. $0.9 \%$ saline is the predominant unbuffered crystalloid fluid and contains supraphysiological concentrations of chloride. When used in appreciable volumes $0.9 \%$ saline leads to a foreseeable hyperchloraemic metabolic acidosis. The clinical consequence of this metabolic change is uncertain and the 
three main areas of clinical interest have been the influence of crystalloid fluids on renal function, haemostasis/blood transfusion requirements and gastrointestinal function.

Animal and experimental data have reported that $0.9 \%$ saline may be associated with altered renal perfusion, reduced glomerular filtration and may affect the release of proinflammatory cytokines. Observational studies have reported that the use of high chloride containing fluid may be associated with AKI and an increased need for dialysis. However, there is no significant evidence from prospective interventional research linking the use of unbuffered crystalloid fluid and impaired renal function.

There is supporting evidence from in-vitro studies suggesting that crystalloid fluids have a differing effect on haemostasis dependent on the amount of volume replacement required. There have been few in-vivo studies on this topic; however, there is evidence from observational studies to suggest that there is less need for blood products in patients that only received buffered fluids compared to those that received $0.9 \%$ saline. Interventional studies have been largely conducted in surgical populations and there is evidence in high-risk subgroups of patients that the use of $0.9 \%$ saline may be associated with increased blood loss volume and increased requirement for platelets.

There has been less evidence exploring the effect of different crystalloid fluids on gastrointestinal function. Animal studies have reported that the use of crystalloid fluids may be associated with an acute hydrostatic gut oedema and slower intestinal transit time. Observational data suggests that $0.9 \%$ saline may be associated with a lower rate of minor gastrointestinal complications (such as nausea, vomiting and ileus) when compared to buffered crystalloid fluid. However, there is evidence from interventional studies reporting that buffered fluids may be associated with reduced post-operative vomiting and improved gastric mucosal perfusion.

Intravenous fluids are one of the most common interventions used in acute medicine. Although crystalloid fluids are the most common type of intravenous fluid used in New Zealand ICUs there have been no prospective interventional trials assessing the comparative effectiveness of buffered vs. unbuffered crystalloid fluids in critically unwell patients. The current lack of evidence in this patient population to guide prescribing is of major concern and an issue of global significance. 


\section{Hypotheses}

1. The use of Plasma-Lyte ${ }^{\circledR} 148$ instead of $0.9 \%$ saline for intravenous fluid therapy will decrease the risk of developing renal complications in the ICU.

2. The use of Plasma-Lyte ${ }^{\circledR} 148$ instead of $0.9 \%$ saline for intravenous fluid therapy will decrease the proportion of patients requiring blood products following cardiac surgery and admitted to the ICU.

3. Plasma-Lyte ${ }^{\circledast} 148$ instead of $0.9 \%$ saline will reduce gastrointestinal feeding intolerance in patients that are mechanically ventilated in the ICU and receiving nasogastric feeding. 
8 Study one: A multi-centre, cluster randomised, double cross over, feasibility trial investigating the effect of using $0.9 \%$ saline or Plasma-Lyte ${ }^{\circledR} 148$ as fluid therapy in intensive care patients on the risk of developing acute kidney injury.

\subsection{Primary aim}

To provide preliminary data on the comparative effectiveness of $0.9 \%$ saline compared Plasma-Lyte 148 on the risk of developing AKI in critically ill patients based on creatinine levels in accordance with the RIFLE criteria (Bellomo, Ronco, Kellum, Mehta, \& Palevsky, 2004).

\subsection{Secondary aims}

The secondary aims were to determine whether, in critically ill patients randomised to receive $0.9 \%$ saline or Plasma-Lyte 148 , there were differences between treatment groups in terms of the:

1. Delta creatinine (the difference between the pre-enrolment creatinine and the peak creatinine measured during the ICU stay).

2. Cumulative incidence of AKI by RIFLE criteria based on creatinine levels and classified into the following AKI groups: Risk, Injury, Failure, Loss, and Endstage renal failure.

3. Cumulative incidence of AKI by Kidney Disease: Improved Global Outcomes (KDIGO) AKI category based on creatinine levels and classified into the following AKI groups: stage 1, stage 2, stage 3 (Kellum, Lameire, \& KDIGO AKI Guideline Work Group, 2013).

4. Proportion of patients requiring RRT during ICU stay.

5. Proportion of patients requiring RRT after hospital discharge (among those patients who required RRT in the ICU).

6. Proportion of patients requiring mechanical ventilation. 
7. Duration of mechanical ventilation.

8. Length of ICU admission from the time of study enrolment.

9. Length of hospital admission from the time study of enrolment.

\subsection{Tertiary aims}

To establish whether a large-scale cluster crossover trial of $0.9 \%$ saline vs. Plasma-Lyte 148 as routine fluid therapy in ICU is feasible. This was achieved by:

1. Establishing that the intervention can be administered in accordance with the study protocol

\subsection{Overview}

The protocol for study one was published in a peer-reviewed journal before study recruitment had been completed (Reddy et al., 2014) and was also prospectively registered on the Australian and New Zealand Clinical Trial Registry (Registration number: 12613001370796). Study one was a prospective, multicentre, randomised, double-blind, cluster, double crossover feasibility study conducted over 28 weeks in four New Zealand ICUs comparing $0.9 \%$ saline to Plasma-Lyte 148 as the routine IV crystalloid fluid therapy. Study one has been published in the Journal of the American Medical Association (Young et al., 2015).

\subsection{Study design}

Study one recruited patients from four tertiary ICUs in New Zealand (Auckland Hospital's Cardiac and Vascular ICU, Auckland Hospital's Department of Critical Care Medicine, Christchurch ICU and Wellington ICU) over a 28 week period. A novel multicentre cluster double crossover design study design was used. The cluster, double crossover design, means that the participating ICUs, rather than individual patients, were randomly assigned to use the study IV fluids. Two ICUs initially used blinded $0.9 \%$ saline as the routine IV fluid while the other two used blinded Plasma-Lyte 148. Subsequently, after the seven week period, the ICUs changed to the opposite blinded IV fluid (Figure 8.1). Further crossovers occurred so that each ICU ultimately used each default fluid twice. Patients who remain in the ICU 
through one or more crossover periods continued to use the fluid to which they were originally assigned for 90 days. As a result, no washout periods between crossovers were required.

Figure 8.1 Overview of double crossover design for the study one.

\begin{tabular}{|c|c|c|c|c|}
\hline & 7 weeks & 7weeks & 7 weeks & 7 weeks \\
\hline ICU 1 & trial fluid $\mathrm{A}$ & trial fluid B & trial fluid $\mathrm{A}$ & trial fluid B \\
\hline ICU 2 & trial fluid $B$ & trial fluid $\mathrm{A}$ & trial fluid B & trial fluid $\mathrm{A}$ \\
\hline ICU 3 & trial fluid $A$ & trial fluid B & trial fluid $A$ & trial fluid $B$ \\
\hline ICU 4 & trial fluid $B$ & trial fluid $\mathrm{A}$ & trial fluid B & trial fluid $\mathrm{A}$ \\
\hline
\end{tabular}

\subsection{Primary outcome}

The primary outcome was the proportion of patients with either AKI or renal failure according to the RIFLE criteria definitions as based on serum creatinine levels (Table 8.1) (Bellomo et al., 2004). For the purposes of the RIFLE criteria, the baseline creatinine levels were recorded as the lowest creatinine in the hospital laboratory records for the six months prior to the current ICU admission. The peak creatinine was defined as the highest creatinine during the ICU admission. 
All outcome data were censored at day 90 (2160 hours) from the time of study enrolment. ICU data was only collected for the index ICU admission. If patients were transferred between study ICUs they continued to receive the study fluid they were originally assigned.

Table 8.1: RIFLE criteria categories (Risk of renal of dysfunction, Injury to the kidney, Failure of kidney function, Loss of kidney function, End stage renal failure) and KDIGO AKI criteria. AKI: acute kidney injury, KDIGO: Kidney Disease: Improving Global Outcomes.

\begin{tabular}{|c|c|}
\hline $\begin{array}{l}\text { Classification of kidney } \\
\text { injury }\end{array}$ & Criteria \\
\hline Risk & $\begin{array}{l}1.5 \text { - } 1.9 \text { times increase from baseline creatinine during ICU } \\
\text { admission. }\end{array}$ \\
\hline Injury & $\begin{array}{l}2.0 \text { - } 2.9 \text { times increase from baseline creatinine during ICU } \\
\text { admission }\end{array}$ \\
\hline Failure & $\begin{array}{l}\geq 3.0 \text { times increase from baseline creatinine, or increase in } \\
\text { serum creatinine to } \geq 400 \mu \mathrm{mol} / \mathrm{L} \text { with a rise of } \geq 50 \mu \mathrm{mol} / \mathrm{L} \\
\text { during ICU admission }\end{array}$ \\
\hline Loss & Persistent loss of kidney function $>4$ weeks \\
\hline End stage renal failure & Dialysis dependent $>3$ months \\
\hline KDIGO stage 1 & $\begin{array}{l}1.5-1.9 \text { times increase from baseline creatinine during ICU } \\
\text { admission or } \geq 26.5 \mu \mathrm{mol} / \mathrm{L} \text { increase in serum creatinine }\end{array}$ \\
\hline KDIGO stage 2 & $\begin{array}{l}2.0 \text { - } 2.9 \text { times increase from baseline creatinine during ICU } \\
\text { admission }\end{array}$ \\
\hline KDIGO stage 3 & $\begin{array}{l}\geq 3.0 \text { times increase from baseline creatinine, or increase in } \\
\text { serum creatinine to } \geq 353.6 \mu \mathrm{mol} / \mathrm{L} \text { OR commencement of RRT }\end{array}$ \\
\hline
\end{tabular}




\subsubsection{Primary outcome justification}

Over 200 definitions of ARF/AKI exist and there is an ongoing debate on the single best definition to use (Ricci et al., 2006). The RIFLE criteria was the first consensus definition in critically ill patients conducted by the Acute Dialysis Quality Initiative (ADQI) group that attempted to standardise the definition and the stratification of AKI severity (Bellomo et al., 2004). The RIFLE criteria was constructed around several key considerations, specifically that the ideal definition of AKI should: consider sensitivity and specificity; be easy to use; be clinically applicable; consider change from baseline and include classifications for acute on chronic renal disease.

The RIFLE criteria classify patients based on the serum creatinine values, changes in GFR and/or urine output volumes, considers three severity classes of AKI (risk, injury and failure) and two outcome classes (loss of kidney function and end-stage kidney disease). The RIFLE criteria has been largely validated in determining the incidence of AKI, its prognostic accuracy in terms of mortality and having a stepwise increase in mortality with increased AKI severity (Lopes \& Jorge, 2013). There are now alternative classifications systems that have been described, including the AKIN and the KDIGO classifications (Kellum et al., 2013; R. L. Mehta et al., 2007). A recent NICE systematic review reported that there was insufficient evidence to suggest the superiority of one definition over another and recommended that using the RIFLE, AKIN or KDIGO are all acceptable for diagnosing AKI in adults (National Clinical Guideline Centre, 2013).

For study one, only the serum creatinine criteria from the RIFLE criteria was used to define AKI. The primary reason for this is that the crystalloid versus hydroxyethyl starch trial demonstrated that increased urine output can occur concurrently with a rise in serum creatinine and an increased requirement for dialysis (Myburgh et al., 2012). Such a result can lead to the erroneous conclusion that a nephrotoxic fluid that causes diuresis reduces the incidence of AKI. Additionally, using only the serum creatinine values allowed for $100 \%$ source data verification of the primary outcome. This approach allowed alignment of study one's primary outcome with the study conducted by Yunos et al. (2012), that also used only the RIFLE creatinine criteria to define AKI. Serum creatinine measurement has the advantage 
of being already incorporated into routine clinical care, is inexpensive and easy to perform with rapidly available results.

There are important physiological and analytical limitations with using serum creatinine to define AKI. Following a sudden decrease in renal function, creatinine gradually accumulates and serum creatinine may take several days to reflect a new steady state (Waikar \& Bonventre, 2009). Using only creatinine definitions of AKI may also be less accurate in patients whose creatinine kinetics and volume of distribution are extreme and variable, leading to both under- and over-diagnosis of AKI depending on catabolic and nutritional status, muscle mass, sepsis-induced suppression of creatinine production, tissue oedema and/or fluid overload (National Clinical Guideline Centre, 2013). However, in situations where urine output has not been available, using only the serum creatinine criteria or GFR has been shown to still predict hospital mortality in large retrospective studies (Ostermann \& Chang, 2007; Uchino, Bellomo, Goldsmith, Bates, \& Ronco, 2006)

\subsection{Secondary outcomes}

Secondary outcomes within the 90-day follow-up period were the delta creatinine (increase between creatinine measured immediately prior to study enrolment and peak creatinine in ICU); the cumulative incidence of AKI by category based on the RIFLE classification; the cumulative incidence of AKI based on the creatinine thresholds of the KDIGO criteria (Kellum et al., 2013)(Table 8.1); the need for RRT during ICU and after hospital discharge among those patients who required RRT in the ICU; the proportion of patients that required mechanical ventilation and duration of mechanical ventilation; the proportion of patients who required ICU readmission within their index hospital admission; ICU and in-hospital allcause mortality and cause-specific mortality.

We also conducted a survey at the completion of the study for all clinicians at each study centre and asked them to guess whether fluid A was Plasma-Lyte 148 or $0.9 \%$ saline. 


\subsection{Study participants}

\subsubsection{Inclusion criteria}

All ICU patients requiring crystalloid fluid therapy were eligible to be included in this study.

\subsubsection{Exclusion criteria}

1. Patients who were currently receiving or expected to receive RRT therapy within six hours of ICU admission

2. Patients who were usually on dialysis for end stage renal failure

3. Patients who were admitted to the ICU solely for consideration of organ donation or for palliative care

4. Patients previously enrolled into the study

\subsection{Study treatments}

Eligible patients requiring intravenous fluid therapy received blinded study fluid with the rate, duration, and frequency of fluid administration determined by the treating clinician (see Figure 8.2). For the studies in this thesis $0.9 \%$ saline with $150 \mathrm{mmol} / \mathrm{L}$ of sodium and 150 $\mathrm{mmol} / \mathrm{L}$ of chloride was used as study fluid as this was the composition of $0.9 \%$ saline currently available in New Zealand (see table 6.1). As much as possible, crystalloid fluid therapy during investigations and procedures performed outside the ICU was the study fluid the patient was allocated to. Open-label study fluids were available for use in rare situations where the treating clinician believed that there was a specific indication for either $0.9 \%$ saline or Plasma-Lyte 148. This may occur, for example, in the setting of acute brain injury where the higher sodium content of $0.9 \%$ saline may make this fluid advantageous because it may decrease the risk of developing cerebral oedema (Ropper, 2012). Concomitant treatment with non-study specialised crystalloid solutions, colloids and blood products was at the discretion of the treating clinician. 
Figure 8.2 Flow diagram illustrating fluid administration during the study.

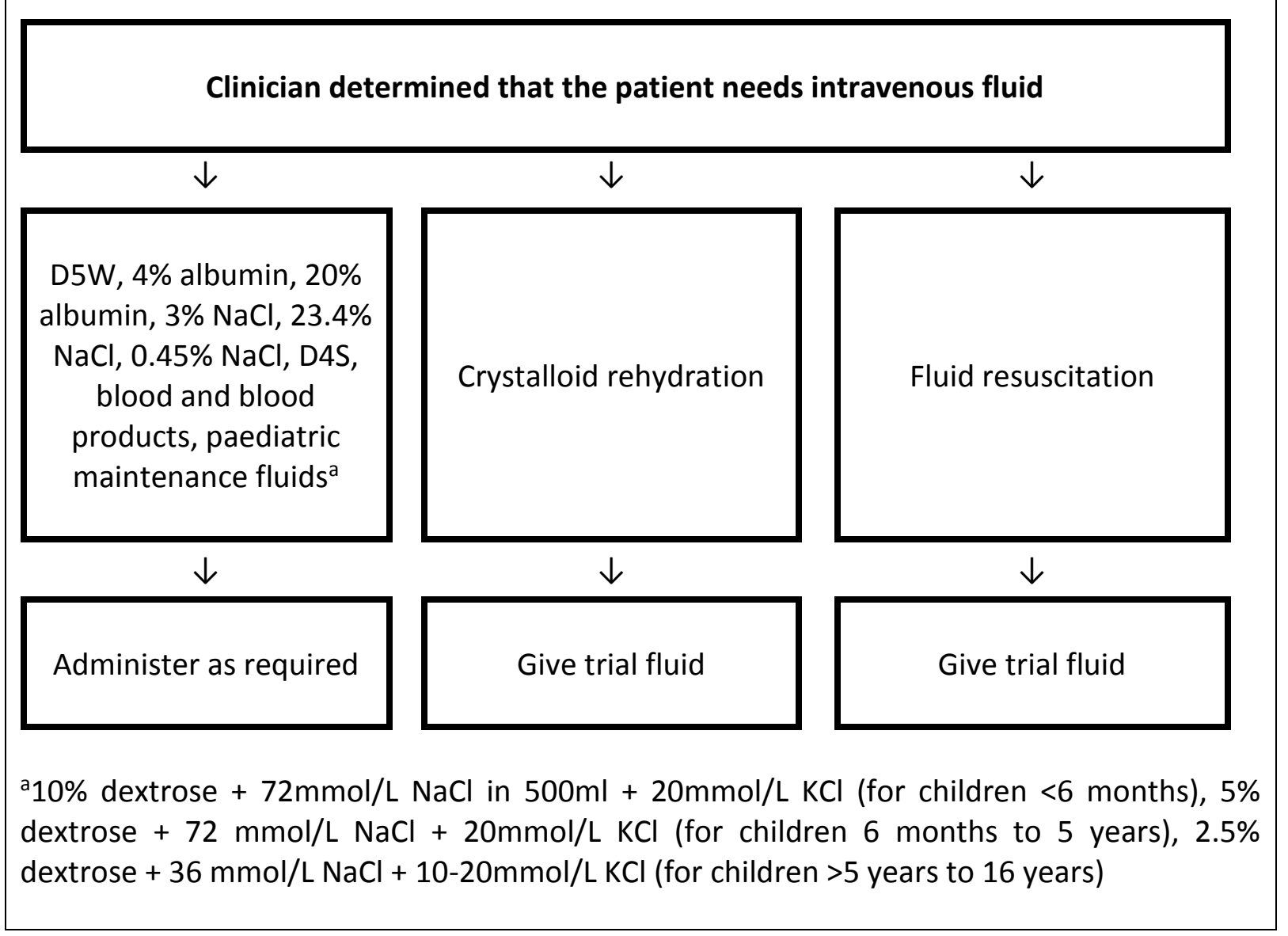

The allocation of study treatments in each cluster were determined ahead of time by the study statistician. Masked study fluids appropriate for each study block were manufactured in a blinded fashion labelled either 'fluid A' or 'fluid B' in indistinguishable $1000 \mathrm{~mL}$ bag (see Figure 8.3). The allocation was known only to the manufacturer of the fluid and two members of the administrative staff at the co-ordinating centre who were not otherwise involved in the study. 
Figure 8.3. Masked study fluids used for study.

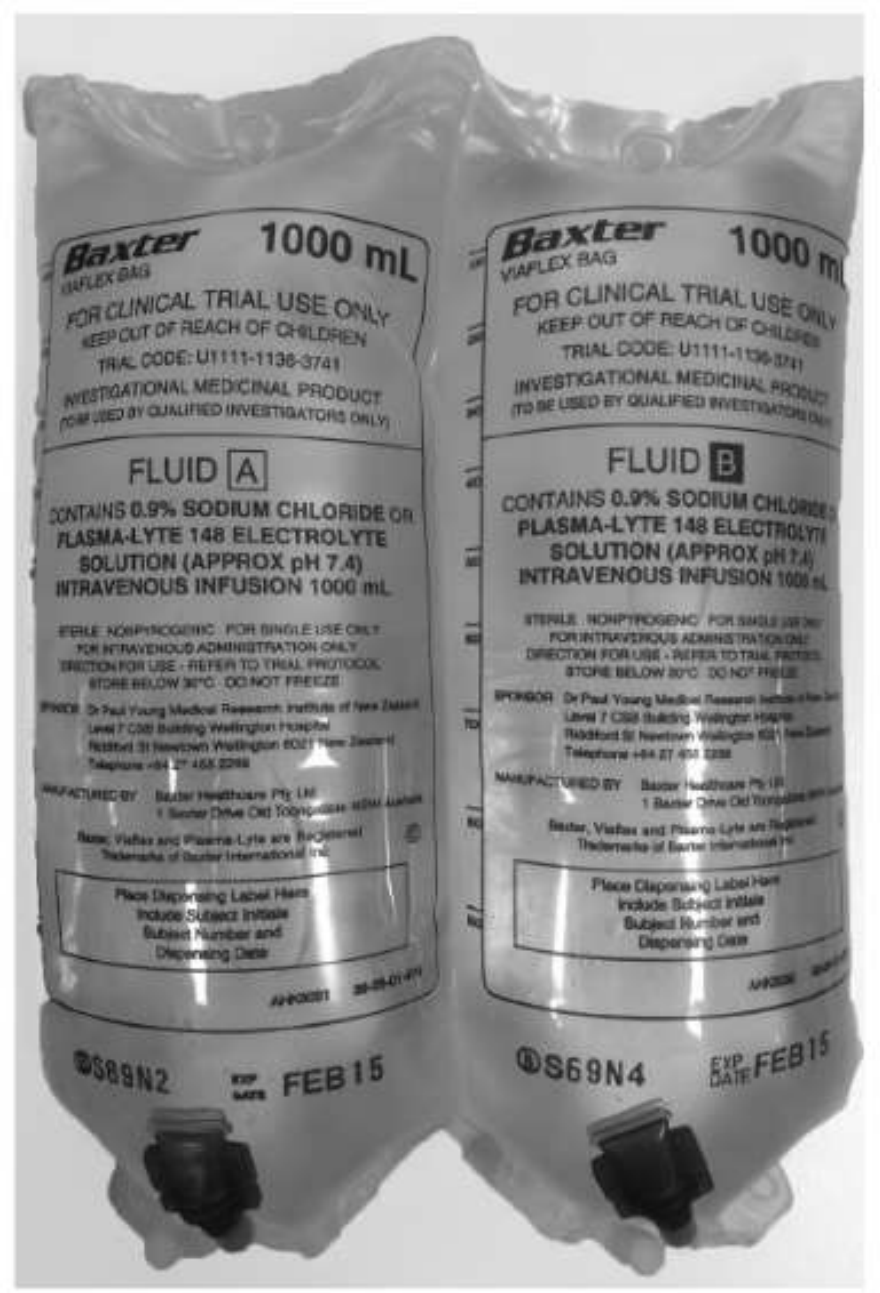

Because the study allowed for the per-protocol use of open label $0.9 \%$ saline or Plasma-Lyte 148 there were no situations in which unblinding of treatment interventions were thought to be required. As revealing treatment allocation of a single patient would unblind an entire cluster, all requests to unblind were made directly to the independent Data Safety Monitoring Board (DSMB). If the DSMB determined that, for patient safety reasons, unblinding of study fluid is required, systems were in place for this to occur.

\subsection{Data collection and Management}

Data were collected in each centre by trained research co-ordinators and entered into a web-based case report form (see Table 8.2 for details of the data to be collected). Baseline data included ICU admission source, Acute Physiology and Chronic Health Evaluation 
(APACHE) II score (ranging from 0 to 71, with higher scores indicating an increased risk of death) in the 24 hours prior to first fluid administration (Knaus, Draper, Wagner, \& Zimmerman, 1985), APACHE III diagnostic code(Pilcher, Hicks, Slater, Huckson, \& O'Sullivan, 2013), and underlying medical comorbidities. Requirements for mechanical ventilation at the time of enrolment and details of the intravenous fluid administrated in the 24 hours prior to enrolment were also collected. During the ICU stay, daily data included the volumes of specific intravenous fluids and blood products administered to patients from day 0 (day of study enrolment) to day 3 (inclusive). Where the creatinine is measured as part of routine clinical care, the highest daily measure was recorded from day 0 to day 7 . The need for RRT in ICU was assessed daily and, for patients who receive RRT in ICU, the indication(s) for commencing RRT as well as any requirement for RRT after hospital discharge were recorded. Pre-specified indications for RRT were as follows: (i) clinically significant oliguria, (ii) serum potassium $>6.5 \mathrm{mmol} / \mathrm{L}$, (iii) arterial or venous $\mathrm{pH}<7.2$, (iv) serum urea $>25 \mathrm{mmol} / \mathrm{L}$, (v) serum creatinine $>300 \mathrm{mmol} / \mathrm{L}$, (vi) organ oedema, (vii) other renal failure-related indication, (viii) other non-renal failure-related indication. All indications for RRT that were present prior to the commencement of RRT were recorded on the case report form. In addition to renal failure-related data points, duration of mechanical ventilation, the length of ICU and hospital stay from time of study enrolment, and in-hospital mortality data were recorded. 
Table 8.2 Data collected in study one.

\section{Baseline information}

Age, sex, ethnicity

ICU admission source

Baseline APACHE II score

APACHE III diagnostic code

Baseline creatinine (lowest pre-illness creatinine in the previous six months prior to

ICU admission)

Pre-enrolment creatinine

Comorbidities (chronic respiratory disease, chronic cardiovascular disease, leukaemia/ myeloma, immunosuppression by disease, immunosuppression by therapy, hepatic failure, cirrhosis, lymphoma, AIDS, metastatic cancer)

Mechanical ventilation at study enrolment

Type and amount of IV fluids ${ }^{\mathrm{a}}$ in the 24 prior to study enrolment

\section{Daily Data}

Total volume and type of IV fluids received on Day 0 to Day 3 inclusive

Highest creatinine recorded in ICU on Day 0 to Day 7

\section{Hospital discharge data and Day 90 follow-up}

Total amount of study fluid, open label Plasma-Lyte $148^{\circledR}$, open label $0.9 \%$ saline, received in ICU up until day 90 from SPLIT enrolment

Highest creatinine recorded in ICU (censored at day 90 from study enrolment)

Duration of mechanical ventilation

Need and indication for RRT

Need for RRT patients after hospital discharge among those patients who require RRT in the ICU

ICU length of stay from time of study enrolment

Hospital length of stay from time of study enrolment

Vital status (alive / dead) at ICU and hospital discharge

APACHE = Acute physiology and chronic health evaluation; AIDS = Acquired

Immunodeficiency Syndrome; IV = intravenous; ICU = Intensive Care Unit; RRT = renal

replacement therapy

a Specific IV fluids recorded will include; 1 ) Crystalloid fluids : Plasma-Lyte $148^{\circledR}, 0.9 \%$ saline, $5 \%$ dextrose, paediatric maintenance fluid, and 'other crystalloids', 2) Colloids : $4 \%$ albumin, $20 \%$ albumin, gelofusion, voluven/volulyte, and 'other colloids' 3) Blood products : packed red blood cells, fresh frozen plasma, platelets, and cryoprecipitate. 
A web-based screening log captured the details of patients who were eligible but not enrolled in the study as well as the number of patients excluded and the reason for exclusion. The study website included features for automatic checking for the internal consistency of data and requires manual verification of values which are outside specified expected ranges. A range of website reporting functions allowed for remote monitoring of study data by monitoring staff at the co-ordinating centre.

\subsection{Study medication and logistics}

All study fluids were manufactured and blinded by Baxter Pty Ltd, Old Toongabbie, New South Wales, Australia. The study fluids were stored at a central location in Auckland, New Zealand and distributed to study sites as required. During the crossover periods each ICU ensured patients continued to receive the study fluid ('fluid $A$ ' or 'fluid B') to which they were originally assigned.

\subsection{Assessment of safety}

It is recognised that critically ill patients have adverse experiences and a variety of aberrations in laboratory values, clinical signs and symptoms due to the nature of their underlying illness and the impact of standard therapies. These events and aberrations may not constitute adverse events ( $A E$ ) or serious adverse events (SAE). For the purposes of this study there was mandatory reporting of SAE that resulted in patient death. All data entry for patients, date and time of death, as well as the principal investigator confirming the "cause of death" and relationship (possibly, probably, or definitely) to study treatment were completed within 24 hours of the investigator becoming aware of the death. Other $A E$ and SAE that are, in the judgment of the principal investigator, thought to be potentially (possibly, probably, or definitely) related to study treatment (i.e. a Serious Adverse Reaction) were also reported. The investigators or site staff were responsible for detecting, documenting and reporting of $\mathrm{AE}$ and SAE.

\subsection{Data safety monitoring board and monitoring}

A committee of independent experts were appointed to the DSMB. The members of the DSMB were Prof Anders Perner (Chair), Prof Andrew Forbes (Statistician), and Dr John 
Morgan. The responsibilities of the DSMB were outlined in a charter which was prepared by the study management committee and was signed by all of the members of the DSMB. The DSMB were responsible for the general safety monitoring and to make recommendations to the management committee where they felt that the ethical conduct of the study or scientific integrity was potentially jeopardised. The DSMB also reviewed summaries of adverse events. However, given the existing knowledge and current widespread use of the IV fluids being tested, it was not anticipated that the DSMB would have made a recommendation to stop the trial early on the basis of reported adverse events known or suspected to be due to either intravenous fluid. As such and also due to the short duration of the study, there were no planned interim analyses for this study. The DSMB charter is provided in Appendix 1.

Independent monitoring of the data collected from the study sites was conducted by the Medical Research Institute of New Zealand in accordance with the pre-specified data monitoring plan (see Appendix 2). Verification of study data was done against source materials- laboratory data were collected directly from the hospital laboratory reporting system. There was $100 \%$ source data verification of all creatinine values including baseline, pre-study, ICU daily highest creatinine days 0-7 and the peak creatinine while in the ICU. The purpose of this source data verification was to ensure the integrity of the data that would be used for the primary outcome of the study.

\subsection{Ethical issues}

This study was performed in accordance with World Medical Association declaration of Helsinki: Ethical principles for medical research involving human subjects (World Medical Association, 2013) and the New Zealand National Ethics Advisory Committee (NEAC) Ethical guidelines for interventional studies and operational standards for ethic committees (National Ethics Advisory Committee, 2006, 2012). This study was granted ethical approval by the New Zealand Health and Disability Northern B Ethics Committee (reference: 12-NTB57) on the basis of the provision of information to patients and/or their next of kin and the opportunity for them to opt-out of the use of their data if they wish.

The NEAC operations standards and ethical guidelines for intervention studies state where an established therapeutic practice has not been scientifically validated organisations and 
health practitioners should foster and evaluate that therapeutic practice to assess safety, quality and ensure that it is in the best interest of their patients.

Although this study is clearly an interventional study on the basis of guidelines, it has many features that are more akin to an observational study than an interventional one. Specifically, this study involves no departure from standard care and does not involve the collection of any data that are not already being collected for clinical and/or quality assurance purposes. All patients in this study received standard treatment except that the default intravenous fluid therapy they received was randomly allocated according to the 7 week block in which they were admitted to in the study hospital. Attending ICU specialists had full discretion to use whichever study fluid they choose if a specific indication for one fluid or the other arose. As a result of these factors, this study involved negligible risk.

The major ethical issues in this study relate to the fact that participants involved in the study will be patients who were critically unwell and in need of immediately lifesaving therapy. The Guidelines make provision for the inclusion of participants in a study without informed consent in these circumstances; however, "the specific reasons for involving subjects with a condition that renders them unable to give informed consent must have been stated in the research protocol and the study must have been approved by a research ethics committee." (World Medical Association, 2013).

\subsection{Process of obtaining opt-out consent}

The NEAC guidelines on Research Involving Unconscious Participants states that research involving patients who are heavily dependent on medical care, such as the patients included in this study, is necessary to assess and improve the efficacy and safety of interventions used in their treatment (National Ethics Advisory Committee, 2012). Given the low-risk nature of the research and that randomisation occurred at the level of the ICU, an 'opt-out consent' was used which involves the provision of information to patients and their next of kin and the opportunity to opt-out from the use of their data if they wished.

As soon as is reasonably possible and appropriate patients, their families, and/or legal representatives were provided with opt-out form/information sheet by study staff. The optout form contained a brief outline of the research, contact details of the local research 
coordinator and a section allowing for opting out from the study. If patients or next of kin were not able to receive an opt-out form prior to hospital discharge or patient death a letter detailing the study along with a copy of the opt form were sent to the patient/next of kin.

\subsection{Data handling and confidentiality}

Prior to initiation of the study at each participating site training was provided to the study personnel. The training covered all aspects of the study protocol and included practical training in completing the electronic case report form (eCRF) and the study materials. A site file containing a data dictionary and paper versions of the data collections forms were given to each site. Study documents were stored in secure locked cabinets.

The investigators maintained the confidentiality of all study documentation. All patients given study fluid were allocated a unique study number. The site research co-ordinator compiled an enrolment log that included the National Health Index (NHI) number and the unique study number. The enrolment log and the study data were kept separately in a locked office. Data entered into the study database were identified by the unique study number only. Study data were entered into a specifically designed web application (Spinnaker Software, Wellington, New Zealand) that had restricted access (only to trained study staff) with authenticated login using a personal user name and password combination.

\subsection{Sample size and power}

A detailed statistical analysis plan was reported prior to any statistical analysis (Reddy et al., 2015; P. Young et al., 2014).

Due to the current lack of established statistical methodologies for calculating sample size for cluster randomised double crossover trials with binary outcome variables, sample size calculations for this study were not performed. The data obtained in this study may be used to model the sample size requirements for a larger scale study of $0.9 \%$ saline vs. Plasma-Lyte $148^{\circledR}$ for ICU fluid therapy using this study design. Based on expected admission rates, it was expected that approximately 2500 patients would be enrolled over the 28 weeks of the study. 


\subsection{Statistical analysis}

Analyses were conducted on an intention-to-treat basis. The Australian and New Zealand Research Centre, Melbourne, Australia performed the data analyses.

Analyses for the primary outcome variable were unadjusted and reported as raw outcomes. As missing data required for the primary outcome exceeded $5 \%$ a sensitivity analyses was undertaken to account for extreme scenarios for missing values. For patients with no creatinine data at all, extreme scenarios were considered that with either all patients with missing data having $\mathrm{AKI} /$ failure or no patients with missing data having $\mathrm{AKI} /$ failure. For patients with missing baseline creatinine data, extreme scenarios were considered with either the baseline creatinine value equalling the peak measured value in the ICU or that the baseline value is normal based on the Modification of Diet in Renal Disease formula, as recommended by the ADQI working group (assuming an average GFR of $75 \mathrm{~mL} / \mathrm{min} / 1.73 \mathrm{~m}^{2}$ ) (Levey et al., 1999). If the peak creatinine value was missing, the extreme scenarios were considered with either the peak measured creatinine being equal to the baseline measured creatinine or that all patients with a missing peak creatinine levels had AKI/failure.

All continuous variables were assessed for normality and log-transformed where appropriate. Baseline comparisons between groups were determined using chi-square tests for equal proportion (or Fishers exact tests for small numbers), Student t-tests for normally distributed variables and Wilcoxon rank sum tests otherwise. Binomial outcomes were assessed using generalised estimating equations with results reported as Odds Ratios $(95 \% \mathrm{Cl})$ while continuous outcomes were analysed using generalised linear modelling and reported as either differences $(95 \% \mathrm{Cl})$ or ratios $(95 \% \mathrm{Cl})$ as appropriate.

Key outcomes (primary outcome, RIFLE stages, KDIGO stages, RRT in ICU, Died in ICU and Died in hospital) were analysed at an individual patient level using hierarchical longitudinal analysis techniques accounting for attending hospital and fluid sequence with patients nested within sites and sites crossing over, not patients. Sensitivity analyses were performed adjusting for a priori defined list of covariates (APACHE-III admission diagnosis, age, ICU admission source, and APACHE-II score). Survival time and time free of RRT from 
randomisation to day 90 were analysed using the log-rank test. The distribution of causes of death among patients who died was compared using a Chi-square test. Heterogeneity across ICU sites for the primary outcome and in-hospital mortality were determined by fitting interactions between treatment and site.

Subgroup analyses were performed on the pre-specified subgroups of interest based on APACHE III-j admission diagnoses and the APACHE II illness severity score (Knaus et al., 1985; Pilcher et al., 2013). The subgroups were the presence or absence of each of the following: an admission diagnosis of sepsis, an admission diagnosis of trauma with or without a diagnosis of traumatic brain injury, a cardiac surgical admission diagnosis, and a preenrolment APACHE II score of 25 or higher.

All analyses were performed using Statistical Analysis System (SAS) version 9.3 (SAS Institute Inc., Cary, USA) and a two-sided p-value of 0.05 were considered to be statistically significant.

\subsection{Funding and support}

This study was an investigator-initiated study which was endorsed by the ANZICS-CTG. The study was primarily funded by a Research Partnership Grant from the HRC. In addition, Baxter Pty Ltd manufactured and provided the blinded study fluid and a grant to support the study. Baxter Pty Ltd had no role in the development of the study protocol and all study analyses were conducted independently of the funding organisations. 


\subsection{Results}

\subsubsection{Baseline characteristics}

From April 2014 through October 2014, 2278 participants were enrolled into this study from 4 adult medical-surgical ICUs in New Zealand, with 1162 allocated into the Plasma-Lyte 148 group and 1116 into the $0.9 \%$ saline group (Figure 8.4 ).

Overall, 16 of enrolled participants (0.7\%) opted out of the study leaving an intention to treat population of 2262 of which 1152 participants were in the Plasma-Lyte 148 group and 1110 participants were in the $0.9 \%$ saline group. The primary outcome was available for $92.5 \%$ of the intention to treat population. 
Figure 8.4. Flow of participants through the study.

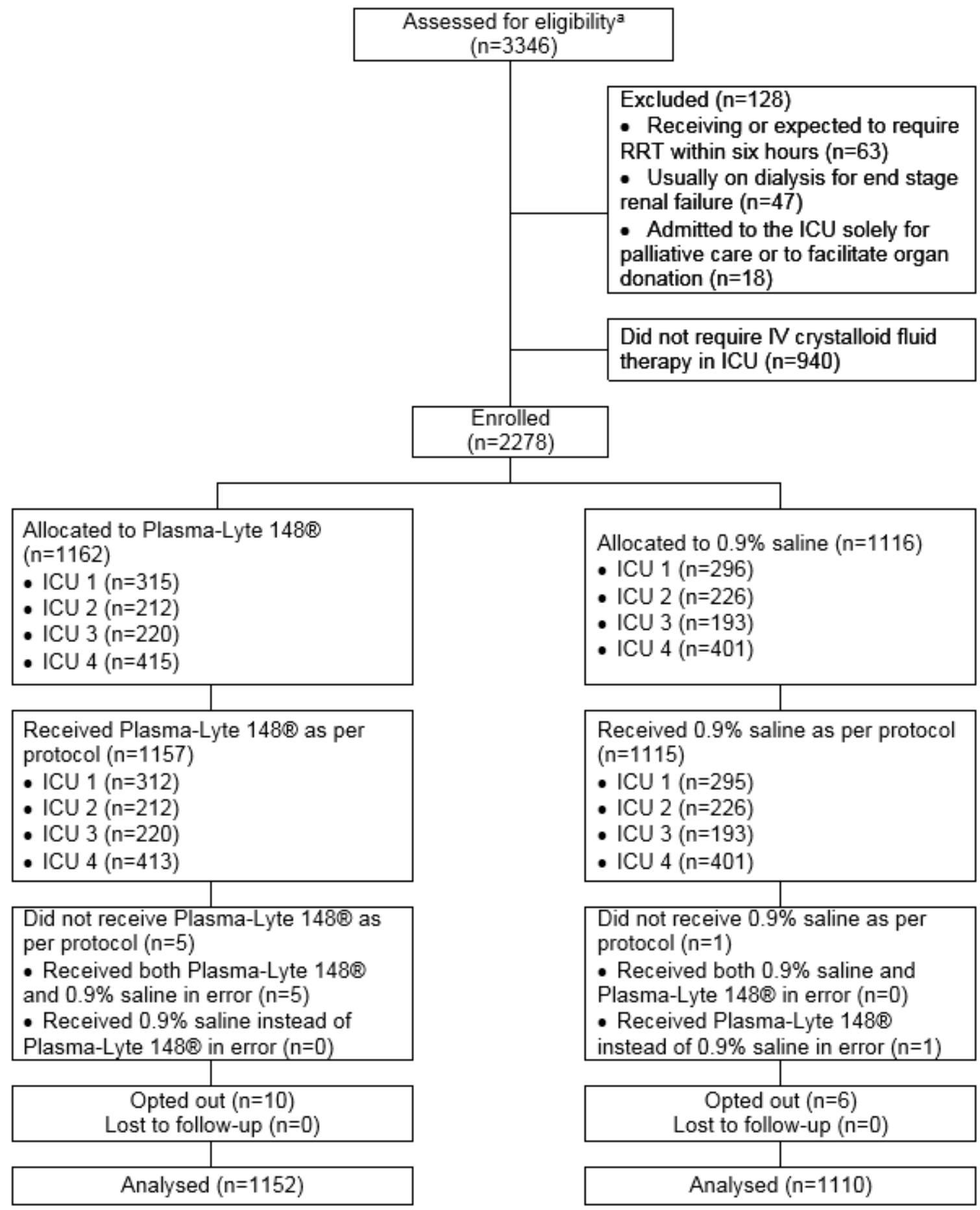

a. All patients admitted to one of the study ICUs during the 28 weeks of recruitment were screened for study enrolment except for two patients who decided not to participate in the study prior to ICU admission. 
Participants in the two groups had similar baseline characteristics. Operative admission diagnoses were more common than non-operative admission diagnosis, with nearly half the participants admitted after cardiovascular surgery (Table 8.3). Demographic and clinical characteristics at baseline are shown in Table 8.4. The majority of the study participants were men and 2/3 were New Zealand Europeans. There were few comorbidities amongst study participants, however there were significant between group differences in the proportion of patients with chronic cardiovascular disease (12 of 1152 patients (1.0\%) in the Plasma-Lyte 148 group vs. 23 of 1110 patients (2.1\%) in the $0.9 \%$ saline group, $p=0.047$ ) and lymphoma (14 of 1152 patients (1.2\%) in the Plasma-Lyte 148 group vs. 5 of 1110 patients $(0.5 \%)$ in the $0.9 \%$ saline group, $p=0.046)$. The mean APACHE II score was 14.1 in both groups. There were less than $10 \%$ of the participants that had an APACHE II score of greater or equal 25 and only $4 \%$ of the patients that had an admission diagnosis of sepsis (based on APACHE III j admission diagnostic codes). 
Table 8.3. ICU admission diagnoses. ${ }^{a}$

\begin{tabular}{|c|c|c|}
\hline Diagnosis & $\begin{array}{c}\text { Plasma-Lyte } 148 \\
(\mathrm{~N}=1152)\end{array}$ & $\begin{array}{c}0.9 \% \text { saline } \\
(\mathrm{N}=1110)\end{array}$ \\
\hline \multicolumn{3}{|c|}{ Operative admission diagnoses, No. (\%) } \\
\hline Cardiovascular & 560 (49) & $548(49)$ \\
\hline Gastrointestinal & $98(9)$ & $87(8)$ \\
\hline Gynaecological & $6(1)$ & $11(1)$ \\
\hline Neurological & $38(3)$ & $35(3)$ \\
\hline Musculoskeletal / skin & $18(2)$ & $13(1)$ \\
\hline Renal & $17(1)$ & $23(2)$ \\
\hline Respiratory & $48(4)$ & $59(5)$ \\
\hline Trauma & $17(1)$ & $7(1)$ \\
\hline Other postoperative & $20(2)$ & $15(1)$ \\
\hline \multicolumn{3}{|c|}{ Non-operative admission diagnoses, No (\%) } \\
\hline Cardiovascular & $54(5)$ & $52(5)$ \\
\hline Gastrointestinal & $18(2)$ & $12(1)$ \\
\hline Haematological & $0(0)$ & $1(0)$ \\
\hline Metabolic & $40(3)$ & $23(2)$ \\
\hline Musculoskeletal / skin & $1(0)$ & $3(0)$ \\
\hline Neurological & $47(4)$ & $50(5)$ \\
\hline Renal & $4(0)$ & $0(0)$ \\
\hline Respiratory & $70(6)$ & $59(5)$ \\
\hline Sepsis & $41(4)$ & $43(4)$ \\
\hline Trauma & $40(3)$ & $61(5)$ \\
\hline Other medical diseases & $15(1)$ & $8(1)$ \\
\hline
\end{tabular}

${ }^{a}$ Admission diagnoses are based on the Acute Physiology and Chronic Health Evaluation (APACHE) III j admission diagnostic codes. 
Table 8.4. Characteristics of the patients at baseline. ${ }^{\text {a }}$

\begin{tabular}{|c|c|c|}
\hline Characteristic & $\begin{array}{l}\text { Buffered crystalloid } \\
(\mathrm{N}=1152)\end{array}$ & $\begin{array}{c}0.9 \% \text { saline } \\
(\mathrm{N}=1110)\end{array}$ \\
\hline Age, mean (SD), y & $60.1(16.79)$ & $60.95(16.25)$ \\
\hline Male sex, No. (\%) & $739(64)$ & $746(67)$ \\
\hline Weight, mean (SD), kg & $80.4(20.1)$ & $80.7(20.0)$ \\
\hline \multicolumn{3}{|l|}{ Ethnicity, No. (\%) } \\
\hline New Zealand European & $749(65)$ & $723(65)$ \\
\hline Maori & $116(10)$ & $110(10)$ \\
\hline Pacific Island Peoples & $90(8)$ & $91(8)$ \\
\hline Other & $197(17)$ & $186(17)$ \\
\hline \multicolumn{3}{|l|}{ Comorbidities, No. (\%) } \\
\hline Chronic respiratory disease & $27(2)$ & $30(3)$ \\
\hline Chronic cardiovascular disease & $12(1)$ & $23(2)$ \\
\hline Leukemia / myeloma & $9(1)$ & $7(1)$ \\
\hline Immunosuppression by disease & $17(1)$ & $12(1)$ \\
\hline Immunosuppression by therapy & $46(4)$ & $50(5)$ \\
\hline Hepatic failure & $5(<1)$ & $7(1)$ \\
\hline Cirrhosis & $8(1)$ & $12(1)$ \\
\hline Lymphoma & $14(1)$ & $5(0)$ \\
\hline AIDS & $1(<1)$ & $1(<1)$ \\
\hline Metastatic cancer & $25(2)$ & $31(3)$ \\
\hline \multicolumn{3}{|l|}{ Source of admission to ICU, No. (\%) } \\
\hline Emergency department & $168(15)$ & $148(13)$ \\
\hline Hospital floor & $87(8)$ & $88(8)$ \\
\hline Another ICU & $32(3)$ & $29(3)$ \\
\hline Another hospital (excluding from another ICU) & $43(4)$ & $47(4)$ \\
\hline Operating room & $822(71)$ & $798(72)$ \\
\hline After emergency surgery & $172(15)$ & $156(14)$ \\
\hline After elective surgery & $650(56)$ & $642(58)$ \\
\hline Operative admission diagnoses ${ }^{\mathrm{b}}$, No. (\%) & $822(71)$ & $798(72)$ \\
\hline Cardiovascular & $560(49)$ & 548 (49) \\
\hline Gastrointestinal & $98(9)$ & $87(8)$ \\
\hline Gynaecological & $6(1)$ & $11(1)$ \\
\hline Neurological & $38(3)$ & $35(3)$ \\
\hline Musculoskeletal / skin & $18(2)$ & $13(1)$ \\
\hline Renal & $17(1)$ & $23(2)$ \\
\hline Respiratory & $48(4)$ & $59(5)$ \\
\hline Trauma & $17(1)$ & $7(1)$ \\
\hline Other postoperative & $20(2)$ & $15(1)$ \\
\hline Non-operative admission diagnoses ${ }^{\mathrm{b}}$, No (\%) & $330(29)$ & $312(28)$ \\
\hline Cardiovascular & $54(5)$ & $52(5)$ \\
\hline Gastrointestinal & $18(2)$ & $12(1)$ \\
\hline Hematological & $0(0)$ & $1(<1)$ \\
\hline Metabolic & $40(3)$ & $23(2)$ \\
\hline Musculoskeletal / skin & $1(<1)$ & $3(<1)$ \\
\hline Neurological & $47(4)$ & $50(5)$ \\
\hline Renal & $4(<1)$ & $0(0)$ \\
\hline Respiratory & $70(6)$ & $59(5)$ \\
\hline Sepsis & $41(4)$ & $43(4)$ \\
\hline Trauma & $40(3)$ & $61(5)$ \\
\hline Other medical diseases & $15(1)$ & $8(1)$ \\
\hline APACHE-IIc score, mean (SD) & $14.1(6.9)$ & $14.1(6.7)$ \\
\hline Mechanical ventilation, №. (\%) & $768(67)$ & $731(66)$ \\
\hline \multicolumn{3}{|l|}{ Serum creatinine, $\mathrm{mg} / \mathrm{dL}$} \\
\hline Baseline (pre-illness), mean (SD) & $0.98(0.76)(n=1133)$ & $0.99(0.68)(n=1092)$ \\
\hline Most recent , mean (SD) & $1.18(1.0)(n=847)$ & $1.15(1.15)(n=820)$ \\
\hline Time from ICU admission to first fluid, median (IQR), $\mathrm{hr}$ & $1.17[0.22-3.80]$ & $1.25[0.17-3.50]$ \\
\hline \multicolumn{3}{|l|}{ Subgroups ${ }^{c}$, No. (\%) } \\
\hline Sepsis & $41(4)$ & $43(4)$ \\
\hline Trauma & $40(3)$ & $61(5)$ \\
\hline Traumatic brain injury & $25(2)$ & $32(3)$ \\
\hline Cardiac surgery & $475(41)$ & $485(44)$ \\
\hline APACHE-II score $\geq 25$ & $95(8)$ & $87(8)$ \\
\hline
\end{tabular}

Abbreviations: AIDS: acquired immunodeficiency syndrome; ICU: Intensive Care Unit.

a plus-minus values are mean $\pm S D$. Values followed by ranges in square brackets are median [IQR].

b Scores on the Acute Physiology and Chronic Health Evaluation (APACHE) II range from 0 to 71, with higher scores indicating an increased risk of death.

${ }^{c}$ Subgroups are based on the APACHE III admission diagnostic codes. 
Approximately $2 / 3$ of participants had received Plasma-Lyte 148 and $1 / 3$ had received $0.9 \%$ saline in the 24 hours prior to study enrolment. There were no significant differences in the volumes of crystalloids, colloids or blood products received by participants in the 24 hours prior to study enrolment (Table 8.5).

Table 8.5. Intravenous fluid received in 24 hours before randomisation.

\begin{tabular}{|c|c|c|}
\hline Fluid & $\begin{array}{c}\text { Plasma-Lyte } 148 \\
(\mathrm{~N}=1152)\end{array}$ & $\begin{array}{c}0.9 \% \text { saline } \\
(\mathrm{N}=1110)\end{array}$ \\
\hline \multicolumn{3}{|c|}{ Crystalloids received in the $24 \mathrm{hr}$ before randomisation, median (IQR) $\mathrm{mL}$} \\
\hline - Plasma-Lyte $148{ }^{\circledR}$ & $\begin{array}{c}1200[0-3000] \\
n=726(63 \%)\end{array}$ & $\begin{array}{c}1000[0-3000] \\
n=675(61 \%)\end{array}$ \\
\hline - $0.9 \%$ saline & $\begin{array}{c}0[0-875] \\
n=343(30 \%)\end{array}$ & $\begin{array}{c}0[0-1000] \\
n=351(32 \%)\end{array}$ \\
\hline - $5 \%$ dextrose & $0[0-0]$ & $0[0-0]$ \\
\hline - Paediatric maintenance fluids ${ }^{a}$ & $0[0-0]$ & $0[0-0]$ \\
\hline - Other crystalloids & $0[0-0]$ & $0[0-0]$ \\
\hline \multicolumn{3}{|c|}{ Colloids received in the $24 \mathrm{hr}$ before randomisation, median (IQR), $\mathrm{mL}$} \\
\hline - $4 \%$ albumin & $0[0-0]$ & $0[0-0]$ \\
\hline - $20 \%$ albumin & $0[0-0]$ & $0[0-0]$ \\
\hline - Gelofusine & $0[0-0]$ & $0[0-0]$ \\
\hline - Voluven or Volulyte & $0[0-0]$ & $0[0-0]$ \\
\hline - Other colloids & $0[0-0]$ & $0[0-0]$ \\
\hline \multicolumn{3}{|c|}{ Blood products received in the $24 \mathrm{hr}$ before randomisation, median (IQR), $\mathrm{mL}$} \\
\hline - Packed red cells & $0[0-0]$ & $0[0-0]$ \\
\hline - Fresh frozen plasma & $0[0-0]$ & $0[0-0]$ \\
\hline - Platelets & $0[0-0]$ & $0[0-0]$ \\
\hline - Cryoprecipitate & $0[0-0]$ & $0[0-0]$ \\
\hline
\end{tabular}

a 'paediatric maintenance fluids' are $10 \%$ dextrose $+72 \mathrm{mmol} / \mathrm{L} \mathrm{NaCl}$ in $500 \mathrm{ml}+20 \mathrm{mmol} / \mathrm{L}$ $\mathrm{KCl}$ (for children $<6$ months), $5 \%$ dextrose $+72 \mathrm{mmol} / \mathrm{L} \mathrm{NaCl}+20 \mathrm{mmol} / \mathrm{L} \mathrm{KCl}$ (for children 6 months to 5 years), $2.5 \%$ dextrose $+36 \mathrm{mmol} / \mathrm{L} \mathrm{NaCl}+10-20 \mathrm{mmol} / \mathrm{L}$ (for children $>5$ years to 16 years). 


\subsubsection{Fluid therapy}

The median time from ICU admission to receiving study fluid was just over one hour in both groups (Table 8.4). Both groups received a similar volume of study fluid (median [IQR], $2000 \mathrm{~mL}$ [1000-3500mL] for the Plasma-Lyte 148 group vs. $2000 \mathrm{~mL}[1000-3250 \mathrm{~mL}$ ] in the $0.9 \%$ saline group, $p=0.63$ ). Most of the study fluid was administered on the first day of study enrolment (Figure 8.5). The proportion of patients remaining in ICU that required study fluid decreased from $100 \%$ on study day 0 to approximately $30 \%$ by study day 3 for both groups (Table 8.6).

Table 8.7 shows the volume and proportion of patients administered open-label Plasma-Lyte 148 or $0.9 \%$ saline, non-study fluid and blood products. Open-label $0.9 \%$ saline or PlasmaLyte 148 were rarely administered and there were no significant between-group differences in the volume of open-label Plasma-Lyte 148 or $0.9 \%$ saline, other crystalloids fluid or colloid fluid administered to patients (Table 8.7).

Participants allocated to Plasma-Lyte 148 required significantly higher volumes of PRBC on study day 0 (mean [SD], 54mL [220mL] for Plasma-Lyte 148 group vs. $30 \mathrm{~mL}$ [ $144 \mathrm{~mL}$ ] for $0.9 \%$ saline group, $p=0.037$ ), higher volumes of PBRC on study day 1 (mean [SD], $37 \mathrm{~mL}$ [143mL] for Plasma-Lyte 148 group vs. $27 \mathrm{~mL}$ [176mL] for $0.9 \%$ saline group, $p=0.027$ ) and higher volumes of FFP on study day 0 (mean [SD], 33mL [171mL] for Plasma-Lyte 148 group vs. $20 \mathrm{~mL}$ $[131 \mathrm{~mL}]$ for $0.9 \%$ saline group, $p=0.025)$.

\subsubsection{Fluid therapy survey}

The overall response rate to the fluid therapy survey to guess whether fluid A was PlasmaLyte 148 or $0.9 \%$ saline was $63 \%$ (55 of 87 clinicians). Of those that responded 36 clinicians (66\%, 95\%Cl, 52\% to $77 \%$ ) correctly guessed that fluid A was Plasma-Lyte 148. 
Figure 8.5. Mean daily study fluid administered by treatment group.

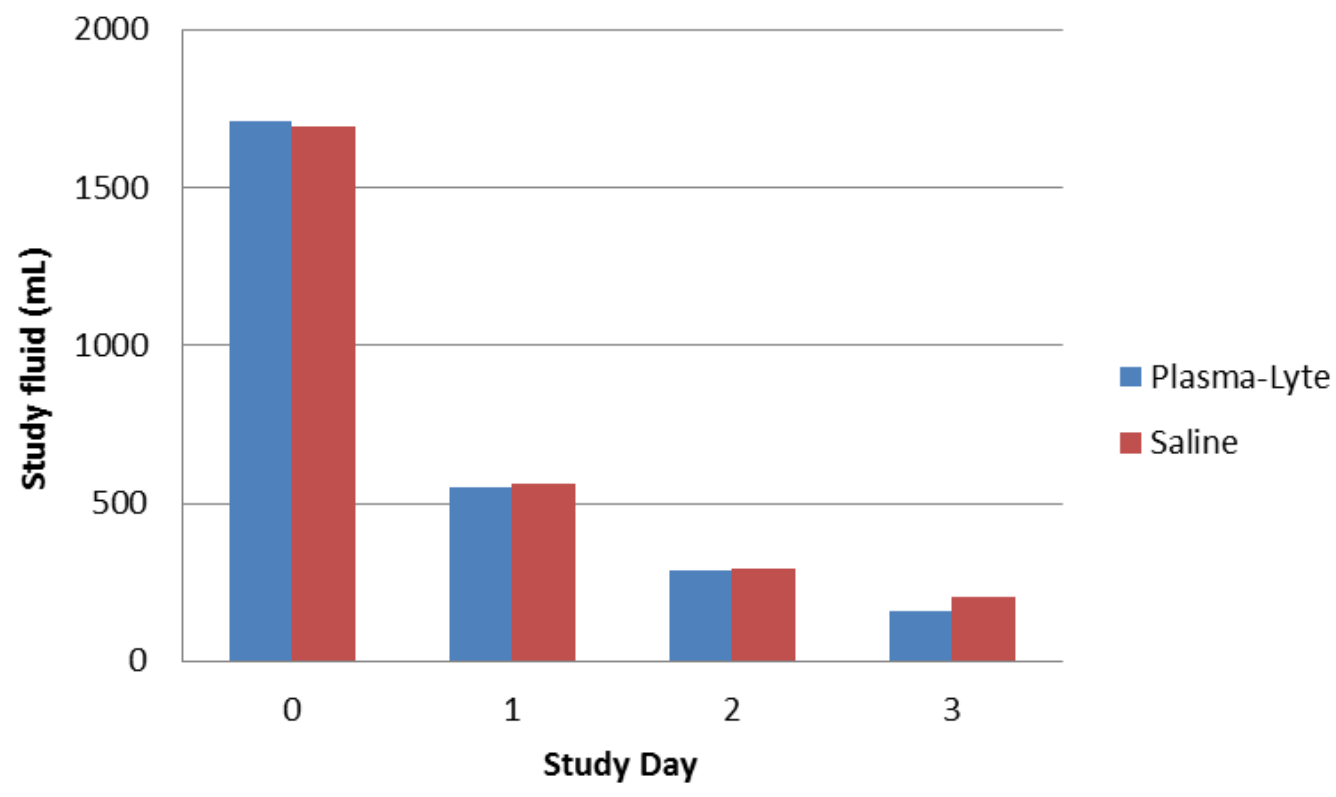

Table 8.6. Study fluids administered to patients in ICU.

\begin{tabular}{|c|c|c|}
\hline $\begin{array}{l}\text { Fluid }-\mathrm{mL} \\
\text { Proportion of patients receiving fluid }\end{array}$ & Plasma-Lyte 148 & $0.9 \%$ saline \\
\hline \multicolumn{3}{|l|}{ Plasma-Lyte 148 (study fluid) } \\
\hline Day 0 - mean ( $\pm S D)$ & $1711(1385)$ & $1(45)$ \\
\hline no. / total no. (\%) & $1152 / 1152(100)$ & $1 / 1110(0)$ \\
\hline Day 1 - mean ( $\pm S D)$ & $554(1088)$ & $0.5(15)$ \\
\hline no. / total no. (\%) & $562 / 1102(51)$ & $1 / 1056(1)$ \\
\hline Day 2 - mean ( \pm SD) & $285(606)$ & $0(0)$ \\
\hline no. / total no. (\%) & $199 / 530(38)$ & $0 / 494(0)$ \\
\hline Day 3 - mean ( $\pm S D)$ & $157(382)$ & $0(0)$ \\
\hline no. / total no. (\%) & $89 / 323(28)$ & $0 / 300(0)$ \\
\hline Day 4 to 90 - mean ( \pm SD) & $1285(4590)$ & $0(0)$ \\
\hline no. / total no. (\%) & $83 / 214$ (39) & $0 / 197(0)$ \\
\hline Total - mean $( \pm S D)$ & $2655(3052)$ & $1.8(60)$ \\
\hline \multicolumn{3}{|l|}{$0.9 \%$ saline (study fluid) } \\
\hline Day 0 - mean ( $\pm S D)$ & $0(0)$ & $1694(1292)$ \\
\hline no. / total no. (\%) & $0 / 1152(0)$ & $1105 / 1110(100)$ \\
\hline Day 1 - mean ( $\pm S D)$ & $0.1(1.5)$ & $564(890)$ \\
\hline no. / total no. (\%) & $1 / 1152(0)$ & $572 / 1056(54)$ \\
\hline Day 2 - mean ( $\pm S D)$ & $0(0)$ & 295 (609) \\
\hline no. / total no. (\%) & $0 / 530(0)$ & $176 / 494(36)$ \\
\hline Day 3 - mean $( \pm S D)$ & $0(0)$ & $202(542)$ \\
\hline no. / total no. (\%) & $0 / 323(0)$ & $82 / 300(27)$ \\
\hline Day 4 to 90 - mean ( $\pm S D$ ) & $2(34)$ & 777 (1615) \\
\hline no. / total no. (\%) & $1 / 214(0)$ & $85 / 197(43)$ \\
\hline Total - mean $( \pm S D)$ & $0.5(15)$ & $2554(2120)$ \\
\hline
\end{tabular}


Table 8.7. Non-study fluids and blood products in ICU.

\begin{tabular}{|c|c|c|}
\hline $\begin{array}{l}\text { Fluid }-\mathrm{mL} \\
\text { Proportion of patients receiving fluid }\end{array}$ & Plasma-Lyte 148 & $0.9 \%$ saline \\
\hline \multicolumn{3}{|l|}{ Plasma-Lyte 148 (open label) } \\
\hline Day 0 - mean $( \pm S D)$ & $27(205)$ & $24(216)$ \\
\hline no. / total no. (\%) & $24 / 1152(2)$ & $24 / 1110(2)$ \\
\hline Day 1 - mean $( \pm S D)$ & $17(160)$ & $25(269)$ \\
\hline no. / total no. (\%) & $19 / 1102(2)$ & $16 / 1056(2)$ \\
\hline Day 2 - mean $( \pm S D)$ & $7(104)$ & $12(170)$ \\
\hline no. / total no. (\%) & $4 / 530(1)$ & $4 / 494(1)$ \\
\hline Day 3 - mean $( \pm S D)$ & $14(175)$ & 25 (209) \\
\hline no. / total no. (\%) & $5 / 323(2)$ & $5 / 300(2)$ \\
\hline Day 4 to 90 - mean ( $\pm S D$ ) & $126(1761)$ & $83(523)$ \\
\hline no. / total no. (\%) & $2 / 214(1)$ & $9 / 197(5)$ \\
\hline \multicolumn{3}{|l|}{$0.9 \%$ saline (open label) } \\
\hline Day 0 - mean $( \pm S D)$ & $23(221)$ & $21(158)$ \\
\hline no. / total no. (\%) & $24 / 1152(2)$ & $34 / 1110(3)$ \\
\hline Day 1 - mean ( \pm SD) & $14(158)$ & $11(111)$ \\
\hline no. / total no. (\%) & $19 / 1102(2)$ & $22 / 1058(2)$ \\
\hline Day 2 - mean $( \pm S D)$ & $8(69)$ & $17(149)$ \\
\hline no. / total no. (\%) & $10 / 530(2)$ & $9 / 494(2)$ \\
\hline Day 3 - mean ( \pm SD) & $8(85)$ & $13(150)$ \\
\hline no. / total no. (\%) & $4 / 323(1)$ & $5 / 300(2)$ \\
\hline Day 4 to 90 - mean ( $\pm S D$ ) & $93(764)$ & $37(207)$ \\
\hline no. / total no. (\%) & $8 / 214(4)$ & 9/197 (5) \\
\hline \multicolumn{3}{|l|}{$5 \%$ dextrose } \\
\hline Day 0 - mean $( \pm S D)$ & $146(343)$ & $141(330)$ \\
\hline no. / total no. (\%) & $301 / 1152(26)$ & $283 / 1110(25)$ \\
\hline Day 1 - mean $( \pm S D)$ & $154(371)$ & $148(365)$ \\
\hline no. / total no. (\%) & $274 / 1102(25)$ & $249 / 1056(24)$ \\
\hline Day 2 - mean $( \pm S D)$ & $103(331)$ & $74(243)$ \\
\hline no. / total no. (\%) & $115 / 530(22)$ & $90 / 496$ (18) \\
\hline Day 3 - mean ( $\pm S D)$ & $50(214)$ & 48 (194) \\
\hline no. / total no. (\%) & $42 / 323(13)$ & $35 / 300(12)$ \\
\hline \multicolumn{3}{|l|}{$4 \%$ albumin } \\
\hline Day 0 - mean $( \pm S D)$ & 135 (459) & $113(384)$ \\
\hline no. / total no. (\%) & $159 / 1152(14)$ & $137 / 1110(12)$ \\
\hline Day 1 - mean ( $\pm S D)$ & 77 (303) & $60(270)$ \\
\hline no. / total no. (\%) & $100 / 1102$ (9) & $74 / 1056(7)$ \\
\hline Day 2 - mean $( \pm S D)$ & $36(172)$ & $26(187)$ \\
\hline no. / total no. (\%) & $29 / 530(5)$ & $16 / 494(3)$ \\
\hline Day 3 - mean $( \pm S D)$ & 22 (167) & $23(163)$ \\
\hline no. / total no. (\%) & $9 / 323(3)$ & $12 / 300(4)$ \\
\hline \multicolumn{3}{|l|}{$20 \%$ albumin } \\
\hline Day 0 - mean $( \pm S D)$ & $1(10)$ & $2(22)$ \\
\hline no. / total no. (\%) & $5 / 1152(0)$ & $11 / 1110(1)$ \\
\hline Day 1 - mean ( \pm SD) & $3(27)$ & $3(27)$ \\
\hline no. / total no. (\%) & $21 / 1102(2)$ & $17 / 1056(2)$ \\
\hline Day 2 - mean $( \pm S D)$ & $2(16)$ & $4(32)$ \\
\hline no. / total no. (\%) & $6 / 530(1)$ & $11 / 494(2)$ \\
\hline Day 3 - mean $( \pm S D)$ & $1(14)$ & $6(40)$ \\
\hline no. / total no. (\%) & $4 / 323(1)$ & $8 / 300(3)$ \\
\hline \multicolumn{3}{|l|}{ Gelofusine $^{\circledR}$} \\
\hline Day 0 - mean $( \pm S D)$ & $0(0)$ & $0(15)$ \\
\hline no. / total no. (\%) & $0 / 1152(0)$ & $1 / 1110(0)$ \\
\hline
\end{tabular}




\begin{tabular}{|c|c|c|}
\hline Day 1 - mean $( \pm S D)$ & $\begin{array}{c}0(0) \\
0 / 1102\end{array}$ & $\begin{array}{c}0(0) \\
0\end{array}$ \\
\hline no. / total no. (\%) & $0 / 1102(0)$ & $0 / 1056(0)$ \\
\hline Day 2 - mean ( $\pm S D)$ & $0(0)$ & $0(0)$ \\
\hline no. / total no. (\%) & $0 / 530(0)$ & 0/494 (0) \\
\hline Day 3 - mean ( $\pm S D)$ & $0(0)$ & $0(0)$ \\
\hline no. / total no. (\%) & $0 / 323(0)$ & $0 / 300(0)$ \\
\hline \multicolumn{3}{|l|}{ Voluven $^{\circledR}$ or volulyte ${ }^{\circledR}$} \\
\hline Day 0 - mean ( $\pm S D)$ & $0(0)$ & $2(60)$ \\
\hline no. / total no. (\%) & $0 / 1152(0)$ & $1 / 1110(0)$ \\
\hline Day 1 - mean ( $\pm S D)$ & $0(0)$ & $0(0)$ \\
\hline no. / total no. (\%) & $0 / 1102(0)$ & $0 / 1056(0)$ \\
\hline Day 2 - mean ( $\pm S D)$ & $0(0)$ & $0(0)$ \\
\hline no. / total no. (\%) & $0 / 530(0)$ & 0/494 (0) \\
\hline Day 3 - mean $( \pm S D)$ & $0(0)$ & $0(0)$ \\
\hline no. / total no. (\%) & $0 / 323(0)$ & $0 / 300(0)$ \\
\hline \multicolumn{3}{|l|}{ Other colloids } \\
\hline Day 0 - mean ( $\pm S D)$ & $2(48)$ & $3(68)$ \\
\hline no. / total no. (\%) & $2 / 1152(0)$ & $2 / 1110(0)$ \\
\hline Day 1 - mean ( $\pm S D)$ & $4(108)$ & $4(97)$ \\
\hline no. / total no. (\%) & $2 / 1102(0)$ & $4 / 1056(0)$ \\
\hline Day 2 - mean ( $\pm S D)$ & $6(148)$ & $10(145)$ \\
\hline no. / total no. (\%) & $1 / 530(0)$ & 4/494 (1) \\
\hline Day 3 - mean $( \pm S D)$ & $13(199)$ & $30(321)$ \\
\hline no. / total no. (\%) & $2 / 323(1)$ & $4 / 300(1)$ \\
\hline \multicolumn{3}{|l|}{ Packed red blood cells } \\
\hline Day 0 - mean ( $\pm S D$ ) & $54(220)$ & $30(144)$ \\
\hline no. / total no. (\%) & 103/1152 (9) & $75 / 1110(7)$ \\
\hline Day 1 - mean ( $\pm S D)$ & $37(143)$ & $27(176)$ \\
\hline no. / total no. (\%) & 93/1102 (9) & $64 / 1056(6)$ \\
\hline Day 2 - mean ( $\pm S D)$ & $36(122)$ & $37(258)$ \\
\hline no. / total no. (\%) (\%) & $54 / 530(10)$ & $39 / 494(8)$ \\
\hline Day 3 - mean $( \pm S D)$ & 39 (199) & $45(277)$ \\
\hline no. / total no. (\%)) & $29 / 323(9)$ & $26 / 300(9)$ \\
\hline \multicolumn{3}{|l|}{ Fresh frozen plasma } \\
\hline Day 0 - mean ( $\pm S D)$ & $33(171)$ & 20 (131) \\
\hline no. / total no. (\%) & $59 / 1152(5)$ & $36 / 1110(3)$ \\
\hline Day 1 - mean ( $\pm S D)$ & $8(74)$ & $9(128)$ \\
\hline no. / total no. (\%) & 14/1102 (1) & $10 / 1056(1)$ \\
\hline Day 2 - mean ( $\pm S D)$ & $6(65)$ & $7(78)$ \\
\hline no. / total no. (\%) & $5 / 530(1)$ & $5 / 494(1)$ \\
\hline Day 3 - mean $( \pm S D)$ & $8(100)$ & $13(120)$ \\
\hline no. / total no. (\%) & $3 / 323(1)$ & $5 / 300(2)$ \\
\hline \multicolumn{3}{|l|}{ Platelets } \\
\hline Day 0 - mean $( \pm S D)$ & $21(102)$ & $13(80)$ \\
\hline no. / total no. (\%) & $56 / 1152(5)$ & $36 / 1110(3)$ \\
\hline Day 1 - mean ( $\pm S D)$ & $4(53)$ & $6(67)$ \\
\hline no. / total no. (\%) & $8 / 1102(1)$ & $12 / 1056(1)$ \\
\hline Day 2 - mean $( \pm S D)$ & $5(46)$ & $12(116)$ \\
\hline no. / total no. (\%) & $8 / 530(2)$ & $10 / 494(2)$ \\
\hline Day 3 - mean $( \pm S D)$ & $8(61)$ & $17(132)$ \\
\hline no. / total no. (\%) & $6 / 323(2)$ & $9 / 300(3)$ \\
\hline \multicolumn{3}{|l|}{ Cryoprecipitate } \\
\hline Day 0 - mean ( $\pm S D$ ) & $5(42)$ & $3(30)$ \\
\hline no. / total no. (\%) & $24 / 1152(2)$ & $14 / 1110(1)$ \\
\hline Day 1 - mean $( \pm S D)$ & $2(47)$ & $1(23)$ \\
\hline no. / total no. (\%) & $5 / 1102(0)$ & 4/1056 (0) \\
\hline
\end{tabular}




\subsubsection{Primary outcome variable: the proportion of patients with either AKI or renal failure}

Overall, 102 of 1067 participants (9.6\%) in the Plasma-Lyte 148 group developed AKI or renal failure within 90 days of study enrolment compared with 94 of 1025 patients $(9.2 \%)$ in $0.9 \%$ saline group (absolute difference, $0.4 \%$; $95 \% \mathrm{Cl},-2.1 \%$ to $2.9 \%$; $\mathrm{RR}, 1.04,95 \% \mathrm{Cl}, 0.80$ to 1.36 ; $\mathrm{p}=0.77$ ) (Table 8.8).

\subsubsection{Primary outcome variable: missing data sensitivity analysis}

Primary outcome data were missing for 170 of the 2262 intention to treat population (7.5\%). There were no baseline creatinine values available for 19 of 1152 participants (1.6\%) in the Plasma-Lyte 148 group and 18 of 1110 (1.6\%) participants in the saline group. The peak serum creatinine in the ICU was not measured and missing for 68 of 1152 patients $(5.9 \%)$ in the Plasma-Lyte 148 group and 68 of 1110 patients (6.1\%) in the $0.9 \%$ saline group. $A$ sensitivity analysis was conducted assuming all patients with missing data had AKI and that all patients with missing data did not have AKI (Table 8.9). The sensitivity analysis did not yield any significant between-group differences. 
Table 8.8. Outcomes for study one.

\begin{tabular}{|c|c|c|c|c|c|}
\hline Variable & $\begin{array}{c}\text { Plasma-Lyte } \\
148\end{array}$ & $0.9 \%$ saline & $\begin{array}{l}\text { Absolute difference } \\
(95 \% \mathrm{Cl})\end{array}$ & $\begin{array}{c}\text { Relative Risk } \\
(95 \% \mathrm{Cl})\end{array}$ & $P$ value \\
\hline \multicolumn{6}{|l|}{ Primary outcome } \\
\hline $\begin{array}{l}\text { Acute kidney injury or } \\
\text { failureb, no./ total no. (\%) }\end{array}$ & $102 / 1067$ (9.6) & $94 / 1025$ (9.2) & $0.4(-2.1$ to 2.9$)$ & $1.04(0.80-1.36)$ & 0.77 \\
\hline \multicolumn{6}{|l|}{ Secondary outcomes } \\
\hline \multicolumn{6}{|c|}{ Renal outcomes, no./ total no. (\%) } \\
\hline \multicolumn{6}{|l|}{ RIFLE $^{\mathrm{C}}$} \\
\hline RIFLE-R & $123 / 1067(11.5)$ & $107 / 1025(10.4)$ & $1.1(-1.6$ to 3.8$)$ & $1.1(0.86-1.41)$ & 0.44 \\
\hline RIFLE-I & $46 / 1067(4.3)$ & $57 / 1025(5.6)$ & $-1.2(-3.1$ to 0.6$)$ & $0.78(0.53-1.13)$ & 0.19 \\
\hline RIFLE-F & $54 / 1067(5.1)$ & $36 / 1025(3.5)$ & $1.5(-0.2$ to 3.3$)$ & $1.44(0.95-2.18)$ & 0.09 \\
\hline RIFLE-L & $2 / 1067(0.2)$ & $1 / 1025(0.1)$ & $0(0$ to 0$)$ & $1.92(0.17-21.16)$ & 1.00 \\
\hline RIFLE-E & $0 / 1067(0)$ & $0 / 1025(0)$ & & & \\
\hline \multicolumn{6}{|l|}{$\mathrm{KDIGO}^{\mathrm{b}}$} \\
\hline Stage 1 & $194 / 1067(18.2)$ & 194/1025 (18.9) & $-0.7(-4.1$ to 2.6$)$ & $0.96(0.8-1.15)$ & 0.69 \\
\hline Stage 2 & $43 / 1067(4)$ & $46 / 1025(4.5)$ & $-0.5(-2.2$ to 1.3$)$ & $0.9(0.6-1.35)$ & 0.67 \\
\hline Stage 3 & $62 / 1067$ (5.8) & $58 / 1025(5.7)$ & $0.2(-1.8$ to 2.1$)$ & $1.03(0.73-1.45)$ & 0.93 \\
\hline \multicolumn{6}{|c|}{ RRT use and indications for RRT initiation } \\
\hline RRT use & $38 / 1152(3.3)$ & $38 / 1110(3.4)$ & $-0.1(-1.6$ to 1.4$)$ & $0.96(0.62-1.5)$ & 0.91 \\
\hline Oliguria & $10 / 1152(0.9)$ & $11 / 1110(1)$ & $-0.1(-0.9$ to 0.7$)$ & $0.88(0.37-2.05)$ & 0.83 \\
\hline $\begin{array}{l}\text { Hyperkalaemia with serum } \\
\text { potassium }>6.5 \mathrm{mEq} / \mathrm{L}\end{array}$ & $4 / 1152(0.3)$ & $2 / 1110(0.2)$ & $0.2(-0.3$ to 0.6$)$ & $1.93(0.35-10.50)$ & 0.69 \\
\hline Acidemia with $\mathrm{pH}<7.20$ & $13 / 1152(1.1)$ & $9 / 1110(0.8)$ & $0.3(-0.5$ to 1.1$)$ & $1.39(0.6-3.24)$ & 0.52 \\
\hline Serum urea $>70 \mathrm{mg} / \mathrm{dL}$ & $5 / 1152(0.4)$ & $10 / 1110(0.9)$ & $-0.5(-1.1$ to 0.2$)$ & $0.48(0.17-1.41)$ & 0.20 \\
\hline $\begin{array}{l}\text { Serum creatinine } \\
>3.39 \mathrm{mg} / \mathrm{dL}\end{array}$ & $16 / 1152(1.4)$ & $13 / 1110(1.2)$ & $0.2(-0.7$ to 1.1$)$ & $1.19(0.57-2.45)$ & 0.71 \\
\hline Organ oedema & $6 / 1152(0.5)$ & $11 / 1110(1)$ & $-0.5(-1.2$ to 0.2$)$ & $0.53(0.20-1.42)$ & 0.23 \\
\hline $\begin{array}{l}\text { Other renal failure related } \\
\text { indication }\end{array}$ & $3 / 1152(0.3)$ & $9 / 1110(0.8)$ & $-0.6(-1.2$ to 0.1$)$ & $0.32(0.09-1.18)$ & 0.09 \\
\hline $\begin{array}{l}\text { Other non-renal failure } \\
\text { related indication }\end{array}$ & $0 / 1152(0)$ & $2 / 1110(0.2)$ & $-0.2(-0.4$ to 0.1$)$ & & 0.24 \\
\hline \multirow[t]{2}{*}{$\begin{array}{l}\text { Ongoing use after hospital } \\
\text { discharge }\end{array}$} & $0 / 1152(0)$ & $0 / 1110(0)$ & & & \\
\hline & & & \multicolumn{2}{|c|}{ Mean difference $(95 \% \mathrm{Cl})$} & \\
\hline \multirow{2}{*}{$\begin{array}{l}\text { Delta creatinine }{ }^{c} \text {, mean } \\
(95 \% \mathrm{Cl}), \mathrm{mg} / \mathrm{dL}\end{array}$} & $0.21(0.16-0.25)$ & $0.18(0.13-0.23)$ & \multicolumn{2}{|c|}{$0.03(-0.04$ to 0.10$)$} & 0.42 \\
\hline & & & \multicolumn{2}{|c|}{ Ratio of geometric means ( $95 \% \mathrm{Cl})$} & \\
\hline \multicolumn{6}{|l|}{ Service utilisation } \\
\hline Days in ICU & $1.5[1.41-1.60]$ & $1.47[1.39-1.57]$ & \multicolumn{2}{|c|}{1.02 (0.94 to 1.11$)$} & 0.58 \\
\hline Days in hospital & $7.45[7.05-7.87]$ & $7.33[6.94-7.76]$ & \multicolumn{2}{|c|}{$1.01(0.94$ to 1.1$)$} & 0.72 \\
\hline \multirow[t]{2}{*}{$\begin{array}{l}\text { Hours of mechanical } \\
\text { ventilation }\end{array}$} & $\begin{array}{c}15.32[13.83- \\
16.97]\end{array}$ & $\begin{array}{c}14.24[12.82- \\
15.82]\end{array}$ & \multicolumn{2}{|c|}{1.05 (0.91 to 1.21$)$} & 0.48 \\
\hline & & & $\begin{array}{l}\text { Absolute difference } \\
\qquad(95 \% \mathrm{Cl})\end{array}$ & $\begin{array}{l}\text { Relative Risk } \\
\quad(95 \% \mathrm{Cl})\end{array}$ & \\
\hline $\begin{array}{l}\text { Use of mechanical } \\
\text { ventilation, no./ total no. } \\
\text { (\%) }\end{array}$ & $790 / 1152(68.6)$ & $751 / 1110(67.7)$ & $0.9(-2.9$ to 4.8$)$ & $1.01(0.96-1.07)$ & 0.65 \\
\hline $\begin{array}{l}\text { ICU readmission required } \\
\text { during index hospital } \\
\text { admission, no./ total no. } \\
\text { (\%) }\end{array}$ & $80 / 1152$ (6.9) & $57 / 1110(5.1)$ & $1.8(-0.2$ to 3.8$)$ & $1.35(0.97-1.88)$ & 0.08 \\
\hline \multicolumn{6}{|l|}{ Mortality } \\
\hline Death in ICU & $76 / 1152(6.6)$ & $80 / 1110(7.2)$ & $-0.6(-2.7$ to 1.5$)$ & $0.92(0.68-1.24)$ & 0.62 \\
\hline Death in hospital & $87 / 1152(7.6)$ & $95 / 1110(8.6)$ & $-1.0(-3.3$ to 1.5$)$ & $0.88(0.67-1.17)$ & 0.40 \\
\hline \multicolumn{6}{|c|}{$\begin{array}{l}\text { Abbreviations: RIFLE: Risk, Injury, Failure, Loss, End stage renal failure; KDIGO: Kidney Disease Improving } \\
\text { Global Outcomes; RRT: Renal Replacement Therapy; ICU: Intensive Care Unit } \\
\text { Plus-minus values are mean } \pm \text { SE. Values followed by square brackets are geometric mean }[95 \% \mathrm{CI}] \\
\text { b based on serum creatinine levels in accordance with RIFLE criteria } \\
\text { c Difference between the most recent pre-enrolment serum creatinine level and the peak serum creatinine level } \\
\text { measured during the ICU stay (censored at day 90) }\end{array}$} \\
\hline
\end{tabular}


Table 8.9. Sensitivity analysis for the missing serum creatinine data.

\begin{tabular}{|lccc|}
\hline & Acute kidney injury of failure $\mathrm{n} / \mathrm{N}$ (\%) & Relative Risk \\
Assumption & Plasma-Lyte $\mathbf{1 4 8}$ & $\mathbf{0 . 9 \%}$ saline & $\mathbf{( 9 5 \% )}$ \\
$\begin{array}{l}\text { Assume none have acute kidney } \\
\text { injury }\end{array}$ & $102 / 1152(8.9)$ & $94 / 1110(8.5)$ & 1.05 (0.78 to 1.41) \\
$\begin{array}{l}\text { Assume all have acute kidney } \\
\text { injury }\end{array}$ & $187 / 1152(16.2)$ & $179 / 1110(16.1)$ & $1.01(0.80$ to 1.26$)$ \\
\hline
\end{tabular}

\subsubsection{Secondary outcome variables: Renal outcomes}

There were no differences between treatment groups in any of the secondary renal outcome measures of interest (Table 8.8). There were no differences in the individual proportion of patients that developed AKI based on each category of the RIFLE classification categories or the KDIGO stages.

RRT was used in the ICU in 38 of 1152 patients (3.3\%) in the Plasma-Lyte 148 group and 38 of 1110 patients $(3.8 \%)$ in the $0.9 \%$ saline group ( $R R, 0.96 ; 95 \% \mathrm{Cl}, 0.62$ to $1.50 ; p=0.91$ ). There were no significant differences in probability of remaining RRT free to day 90 between patients allocated to Plasma-Lyte 148 compared to $0.9 \%$ saline $(p=0.85)$ (Figure 8.6). Both groups had similar indications for the initiation of RRT (Table 8.8). In the group of patients that required RRT in ICU there were no patients that required RRT after hospital discharge in either group.

The delta creatinine was similar in both groups (mean, $(95 \% \mathrm{Cl}), 0.21 \mathrm{mg} / \mathrm{dL}(0.16$ to 0.25$)$ in the Plasma-Lyte 148 group vs. $0.18 \mathrm{mg} / \mathrm{dL}$ (0.13 to 0.23); absolute difference, (95\%Cl), 0.03 (0.04 to 0.10$) ; p=0.42$ ). There were no differences between groups in the peak daily creatinine over the first seven days after study enrolment (Figure 8.7). 
Figure 8.6. Kaplan-Meier estimate of the probability of remaining RRT up to day 90.

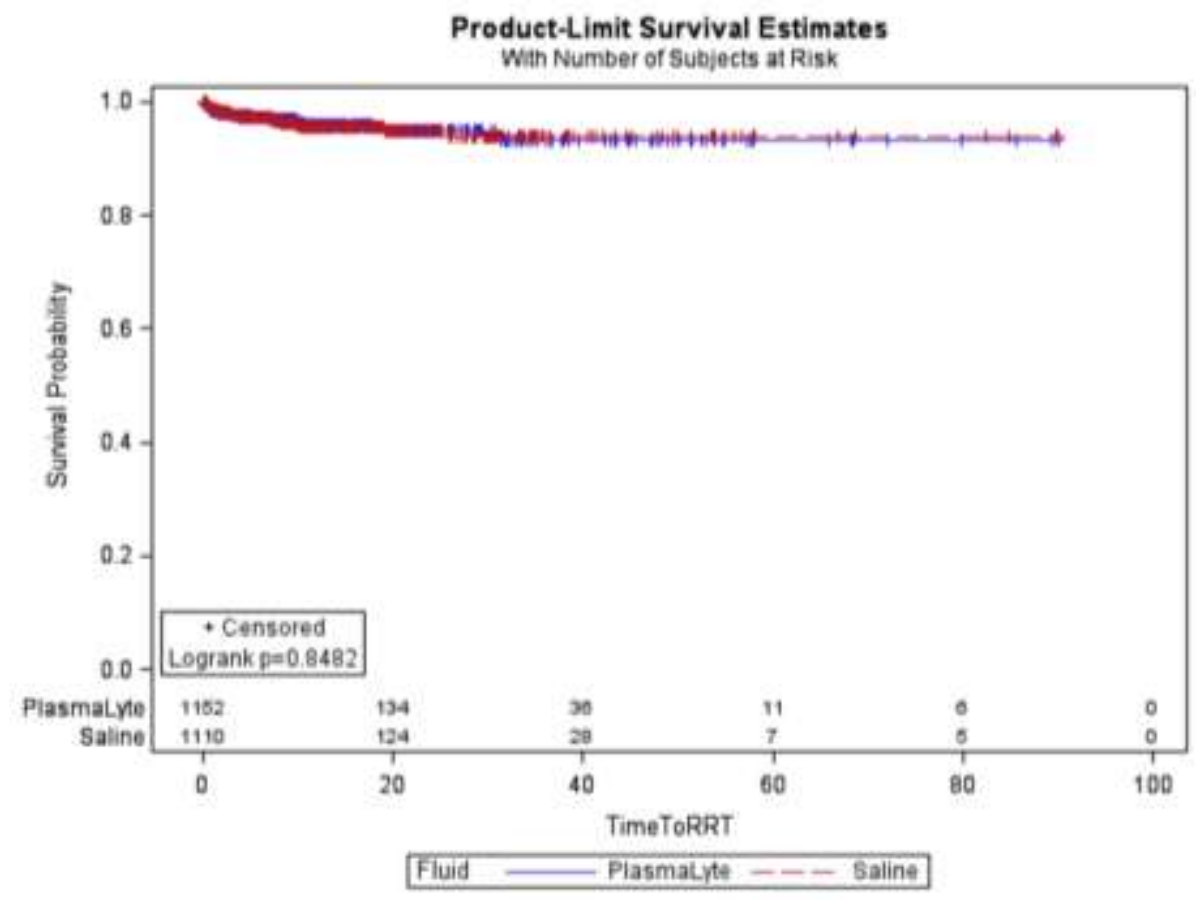

Figure 8.7. Daily serum creatinine by treatment group.

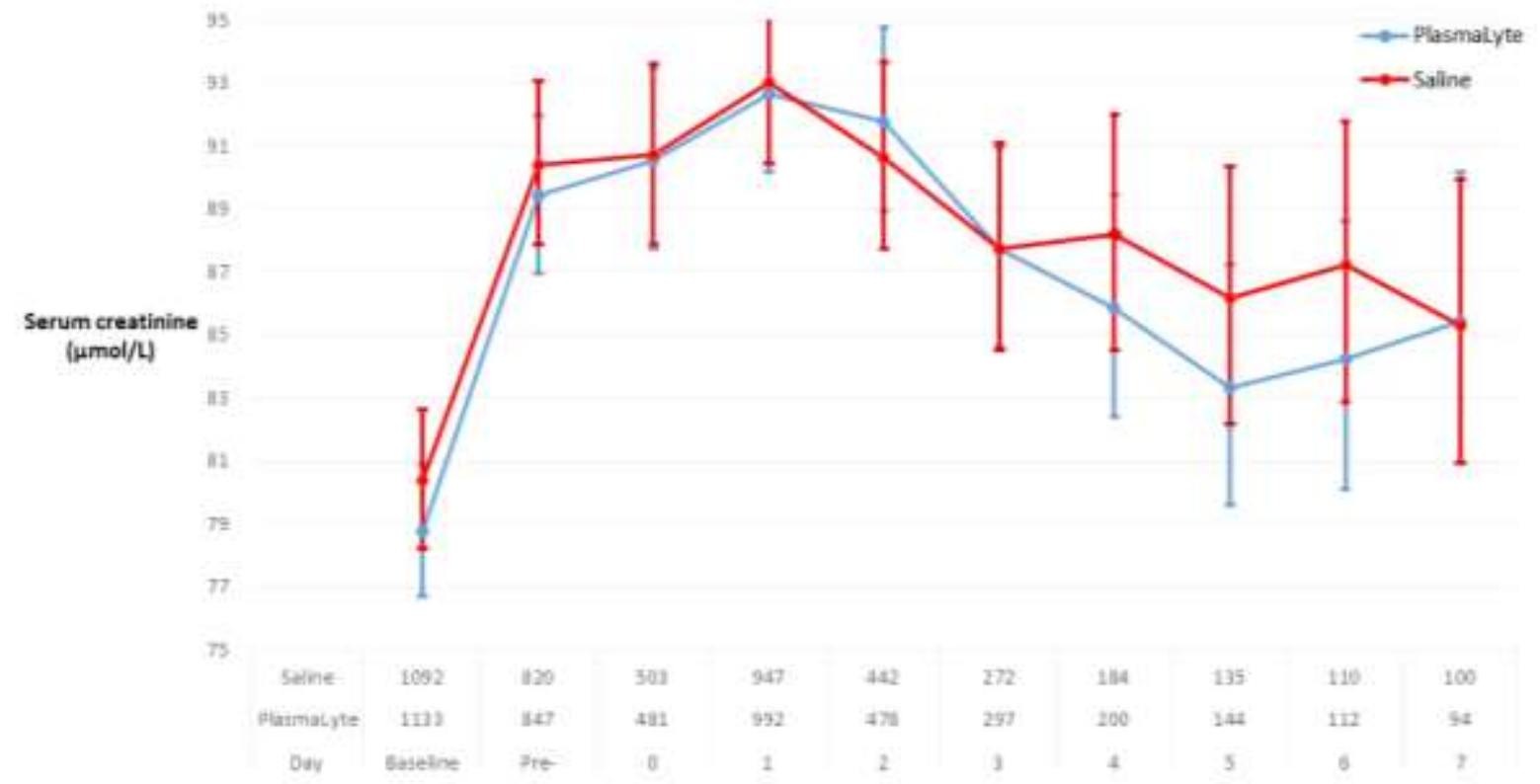

The number of patients contributing data on each study day is shown on the horizontal axis by treatment group. Serum creatinine values are presented as geometric means and error bars represent the $95 \%$ confidence intervals. 


\subsubsection{Secondary outcome variables: Service utilisation}

There were no differences between groups with respect to any of the "service utilisation" variables of interest (Table 8.8).

The ICU lengths of stay was similar in both groups (geometric mean, [95\% Cl], 1.50 days $[1.41$ to 1.60 days] in the Plasma-Lyte 148 group vs. 1.47 days [1.39-1.57 days] in the $0.9 \%$ saline group; ratio of geometric means, [95\%Cl], 1.02 (0.94 to 1.11); $p=0.58)$. There were no differences in hospital length of stay (geometric mean, [95\% Cl], 7.45 days [7.05 to 7.87 days] in the Plasma-Lyte 148 group vs. 7.33 days [6.94-7.76 days] in the $0.9 \%$ saline group; ratio of geometric means, [95\% Cl], 1.01 (0.91 to 1.21$) ; p=0.48$ ).

There was no between-group difference in the duration or proportion of people requiring mechanical ventilation (Table 8.8). 80 of 1152 participants (6.9\%) in the Plasma-Lyte 148 group required ICU readmission compared to 57 of 1110 participants (5.1\%) in $0.9 \%$ saline group (RR, [95\% Cl], 1.35 [0.97 to 1.88 ]; $p=0.08$ ).

\subsubsection{Secondary outcome variables: Mortality}

There was no significant difference in survival to day 90 between patients allocated to Plasma-Lyte 148 compared to $0.9 \%$ saline ( $p=0.32)$ (Figure 8.8). Overall, 87 of 1152 participants (7.6\%) in the Plasma-Lyte 148 group died in hospital (all causes) compared to 95 of 1110 participants (8.6\%) in $0.9 \%$ saline group (absolute difference, $-1.0 \% ; 95 \% \mathrm{Cl},-3.3 \%$ to 1.2.\%; RR, $0.88,95 \% \mathrm{Cl}, 0.67$ to $1.17 ; \mathrm{p}=0.40$ )(Table 8.8). The two groups had similar rates of cause specific mortality with cerebral cause being the leading cause of mortality in both followed by sepsis, cardiac, "other" and bleeding (Table 8.10). 
Figure 8.8. Kaplan-Meier estimate of the probability of probability of survival to day 90.

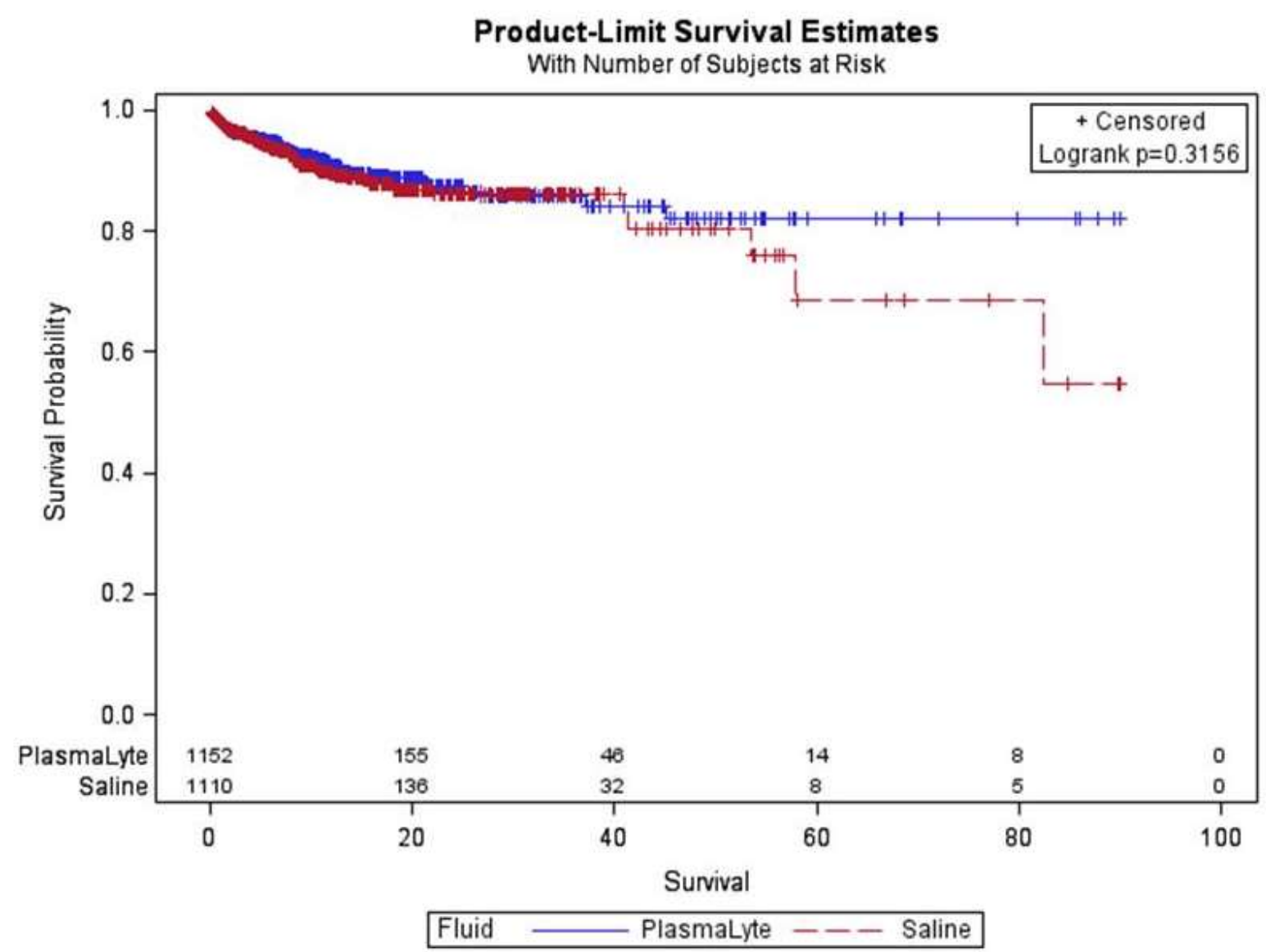

Table 8.10 Cause-specific in hospital mortality within the 90-day follow-up period

\begin{tabular}{|lcccc|}
\hline & Plasma-Lyte $\mathbf{1 4 8}$ & $\mathbf{0 . 9 \%}$ saline & $\begin{array}{c}\text { Relative Risk } \\
\text { (95\% Cl) }\end{array}$ & P value \\
Categories - no. / total no. (\%) & & & & \\
Bleeding & $3 / 1152$ & $2 / 1110$ & 1.45 & 1.00 \\
Cardiac & $(0.3)$ & $(0.2)$ & $(0.24$ to 8.63$)$ & 0.67 \\
Cerebral & $14 / 1152$ & $20 / 1110$ & $(0.34$ to 1.33$)$ & 0.30 \\
Sepsis & $(1.2)$ & $(1.8)$ & 0.79 & 0.34 \\
Other & $32 / 1152$ & $39 / 1110$ & $(0.5$ to 1.25$)$ & 0.41 \\
\hline
\end{tabular}




\subsubsection{Primary and secondary outcomes variables: Adjusted analyses}

There were no significant differences in primary or key secondary outcomes with hierarchical analysis adjusting for patients nested within study site and multivariable hierarchical analysis adjusting for baseline covariates (APACHE-III admission diagnosis, age, ICU admission source, and APACHE-II score) with patients nested within study site (Table 8.11).

Table 8.11: Raw and Adjusted analyses with patients nested within study site.

\begin{tabular}{|c|c|c|c|c|c|c|}
\hline Outcome & $\begin{array}{l}\text { OR 95\% Cl } \\
\text { (unadjusted) }\end{array}$ & $\begin{array}{c}\mathbf{P} \\
\text { Value }\end{array}$ & $\begin{array}{l}\text { OR 95\% CI } \\
\text { (nested }^{\text {al }}\end{array}$ & $\begin{array}{l}\text { Nested } \\
\mathbf{P} \\
\text { Value }\end{array}$ & $\begin{array}{l}\text { OR } 95 \% \mathrm{Cl} \\
\text { (nested and } \\
\text { adjusted }^{\mathrm{b}} \text { ) }\end{array}$ & $\begin{array}{c}\text { nested } \\
\text { and } \\
\text { adjusted } \\
P \text { Value }\end{array}$ \\
\hline $\begin{array}{l}\text { Acute kidney } \\
\text { injury or } \\
\text { failure }\end{array}$ & $\begin{array}{c}1.05 \text { (0.78 to } \\
1.41)\end{array}$ & 0.76 & $\begin{array}{c}1.05 \text { (0.78 to } \\
1.41)\end{array}$ & 0.76 & $\begin{array}{c}1.01(0.74 \text { to } \\
1.39)\end{array}$ & 0.95 \\
\hline RIFLE-R & $\begin{array}{c}1.12(0.85 \text { to } \\
1.47)\end{array}$ & 0.43 & $\begin{array}{c}1.12(0.19 \text { to } \\
6.65)\end{array}$ & 0.57 & $\begin{array}{c}1.13(0.19 \text { to } \\
6.83)\end{array}$ & 0.54 \\
\hline RIFLE-I & $\begin{array}{c}0.77(0.51 \text { to } \\
1.14)\end{array}$ & 0.19 & $\begin{array}{c}0.76(0.06 \text { to } \\
10.07)\end{array}$ & 0.41 & $\begin{array}{c}0.74(0.49 \text { to } \\
1.12)\end{array}$ & 0.15 \\
\hline RIFLE-F & $\begin{array}{c}1.46(0.95 \text { to } \\
2.25)\end{array}$ & 0.08 & $\begin{array}{c}1.48(0.96 \text { to } \\
2.29)\end{array}$ & 0.08 & $\begin{array}{c}1.45(0.9 \text { to } \\
2.32)\end{array}$ & 0.12 \\
\hline KDIGO-1 & $\begin{array}{c}0.95(0.76 \text { to } \\
1.19)\end{array}$ & 0.66 & $\begin{array}{c}0.95(0.23 \text { to } \\
3.98)\end{array}$ & 0.74 & $\begin{array}{c}0.98(0.23 \text { to } \\
4.17)\end{array}$ & 0.89 \\
\hline KDIGO-2 & $\begin{array}{c}0.89(0.58 \text { to } \\
1.37)\end{array}$ & 0.60 & $\begin{array}{c}0.88(0.06 \text { to } \\
13.93)\end{array}$ & 0.67 & $\begin{array}{c}0.87(0.57 \text { to } \\
1.35)\end{array}$ & 0.54 \\
\hline KDIGO-3 & $\begin{array}{c}1.03(0.71 \text { to } \\
1.49)\end{array}$ & 0.88 & $\begin{array}{c}1.04(0.72 \text { to } \\
1.51)\end{array}$ & 0.83 & $\begin{array}{c}0.99(0.66 \text { to } \\
1.48)\end{array}$ & 0.96 \\
\hline RRT in ICU & $\begin{array}{c}0.96(0.61 \text { to } \\
1.52)\end{array}$ & 0.87 & $\begin{array}{c}0.98(0.62 \text { to } \\
1.55)\end{array}$ & 0.93 & $\begin{array}{c}0.91(0.56 \text { to } \\
1.47)\end{array}$ & 0.69 \\
\hline Died in ICU & $\begin{array}{c}0.91(0.66 \text { to } \\
1.26)\end{array}$ & 0.57 & $\begin{array}{c}0.92(0.66 \text { to } \\
1.28)\end{array}$ & 0.62 & $\begin{array}{c}0.88(0.61 \text { to } \\
1.27)\end{array}$ & 0.51 \\
\hline $\begin{array}{l}\text { Died in } \\
\text { Hospital }\end{array}$ & $\begin{array}{c}0.87(0.64 \text { to } \\
1.18)\end{array}$ & 0.38 & $\begin{array}{c}0.88(0.65 \text { to } \\
1.19)\end{array}$ & 0.41 & $\begin{array}{c}0.85(0.60 \text { to } \\
1.19)\end{array}$ & 0.34 \\
\hline
\end{tabular}

${ }^{a}$ hierarchical analysis with patients nested within study site.

b multivariable hierarchical analysis adjusting for APACHE-III admission diagnosis, age, ICU admission source, and APACHE-II score with patients nested within study site.

\subsubsection{Subgroup analyses: Renal outcomes}

There was a significant interaction between the effect of treatment on AKI and the ICU study site $(p=0.05)$ (Figure 8.9).There was no significant heterogeneity in the effect of treatment on any of the predefined subgroups (Figure 8.9). 
Figure 8.9. Risk of acute kidney injury and subgroup.

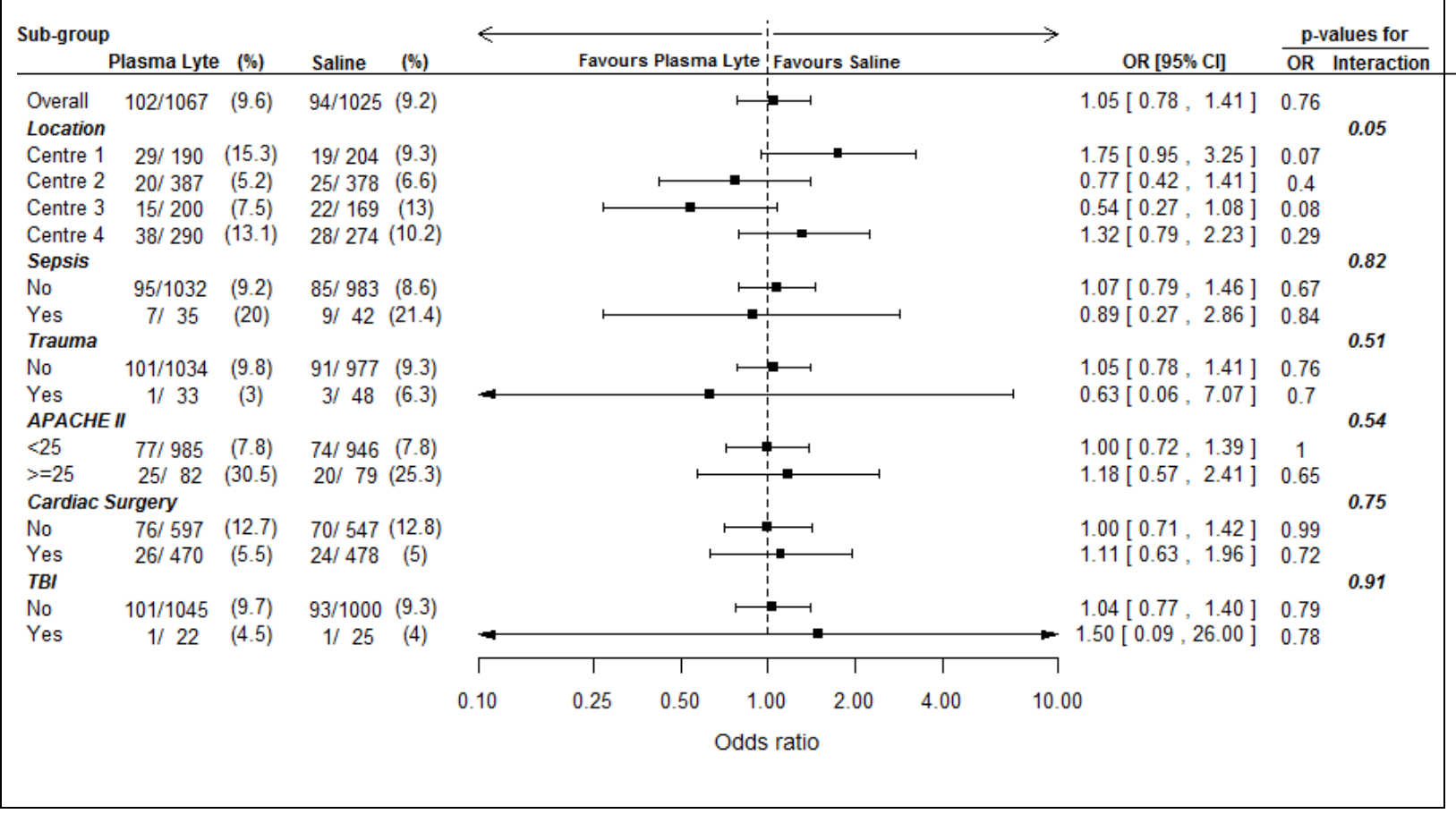

\subsubsection{Subgroup analyses: In-hospital mortality}

There was no significant heterogeneity or interaction in the effect of treatment on all cause in-hospital mortality in any of the predefined subgroups (Figure 8.10).

Figure 8.10. Risk of in-hospital mortality by subgroup.

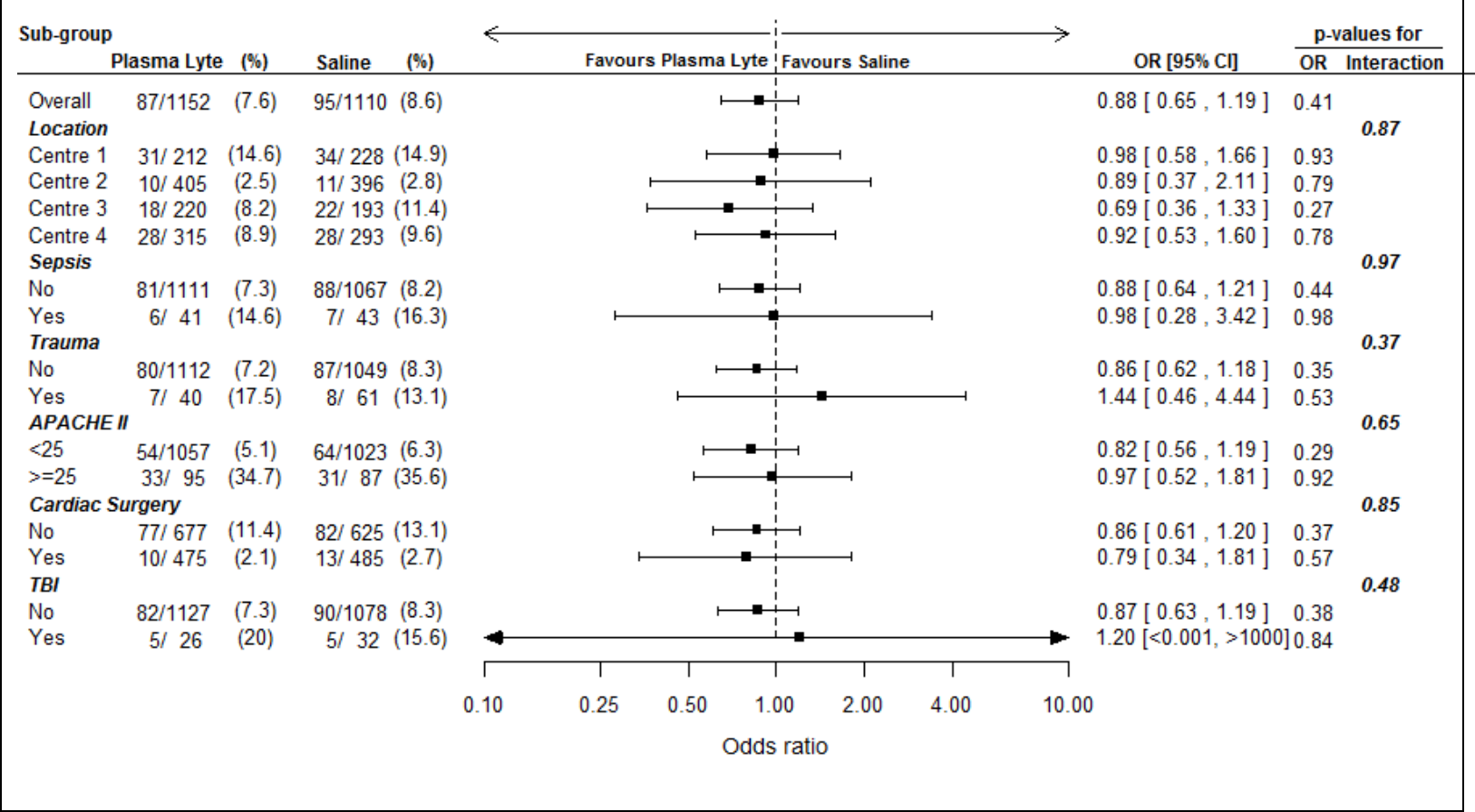




\subsubsection{Protocol deviations}

In total, there were six patients $(0.27 \%)$ from the intention to treat population that did not receive study fluid as per protocol, five patients allocated to the Plasma-Lyte 148 group and one patient allocated to the $0.9 \%$ saline group (Figure 8.4 ).

\subsubsection{Adverse events}

There was one serious adverse event of lactic acidosis associated with death that was reported in a patient allocated to the Plasma-Lyte 148 group that was deemed potentially related to the study treatment (see appendix 3). This occurred in a patient admitted to ICU post live donor renal transplantation. Prior to study enrolment they had already developed a lactic acidosis which was presumed to be secondary to poor tissue perfusion. The patient received fluid resuscitation with study fluid however they developed a rapidly worsening lactic acidosis. The patient was commenced on dialysis and had a laparotomy that excluded ischaemic bowel as the cause of the lactic acidosis. The patient continued to deteriorate despite maximal medical therapy and developed multi-organ failure leading to circulatory arrest and death 26 hours after admission to ICU. A post-mortem found no cause for death. This event was reviewed by the DSMB and the study management committee. The DSMB recommended that the study continued without modification of the study protocol. 


\subsection{Discussion for study one}

\subsubsection{Statement of principal findings}

In this multicentre, cluster, double-blind, double-crossover study there were no significant differences in the incidence of AKI or renal failure within 90 days of study enrolment in a heterogeneous population of critically ill patients allocated to receive Plasma-Lyte 148 or $0.9 \%$ saline. There were no differences between groups in any of the secondary renal outcomes including the individual proportion of patients that developed AKI based on each category of the RIFLE and KDIGO classification, the requirements for RRT and change in serum creatinine while in ICU. There were no significant differences between groups in service utilisation or mortality outcomes.

\subsubsection{Significance of the findings}

No previous prospective interventional trials have evaluated the comparative effectiveness of a buffered crystalloid fluid compared to $0.9 \%$ saline for intravenous fluid therapy in critically unwell patients.

Amongst observational studies in critically ill patients, the renal outcomes from this study were consistent with a large propensity matched observational study conducted by Raghunathan et al. (2014) in non-surgical sepsis patients receiving vasopressor in ICU. The authors reported no difference in ICD-9-CM defined AKI (both with and without the need for RRT) in a group of patients that had received balanced crystalloids compared to a group of patients that received no-balanced crystalloid fluids. In contrast, the authors did report a lower mortality rate in patients in the balanced crystalloid groups.

Study one's findings were at variance to a single centre, observational cohort study by Yunos et al. (2012) that had reported a 40\% reduction in RIFLE-defined AKI following a change from a standard chloride-liberal fluids strategy to chloride-restrictive fluids strategy. As multiple changes in intravenous fluid therapy occurred simultaneously, such as a decreased use of $0.9 \%$ saline; decreased use of $4 \%$ succinylate gelatin; decreased use of albumin $4 \%$; increased use of Hartmann's solution; increased use of Plasma-Lyte 148 and increased use of $20 \%$ albumin, it is difficult to determine what individual component of the fluid change (if 
any) strategy was responsible for the observed difference in AKI risk. This is compounded by observational evidence to suggest that merely switching intravenous fluids from gelatin to crystalloid fluids in critically unwell septic shock patients is associated with reduced rates of AKI (Bayer et al., 2011). Additionally, a recently published extended analysis (doubling that of the observation period to 12 months, $n=2,994$ ) of the Yunos et al. (2015) cohort reported fluctuations in the incidence of AKI over time and a significant interaction between treatment and the treatment period $(p=0.01)$ suggesting unidentified confounders or a Hawthorne effect may have contributed to some of the observed findings.

Study one's results are supported by the findings of a recently published systematic review and meta-analysis $(n=411)$ that reported no difference in serum creatinine after the first 24 hours of fluid administration in patients randomised to receive to buffered crystalloids (Ringer's lactate) or $0.9 \%$ saline (Orbegozo Cortes et al., 2014). Furthermore, interventional studies in surgical and trauma patients have reported no difference in the incidence of AKI, requirements for RRT or postoperative creatinine levels in patients randomised to PlasmaLyte compared to $0.9 \%$ saline (Hadimioglu et al., 2008; Kim et al., 2013; J. B. Young et al., 2014). A retrospective study by Shaw et al. (2012) in patients undergoing major abdominal surgery also reported no difference in the incidence of AKI in patients that only received Plasma-Lyte compared to $0.9 \%$ saline; however, the authors did report an increased risk of requiring dialysis with the use of $0.9 \%$ saline.

\subsubsection{Strengths and limitations}

Study one was a large pragmatic, multicentre study. Compared to previous observational research study one's design incorporates a number of features that reduced the risk of bias. A study protocol and statistical analysis plan were reported before the study recruitment was completed which mitigated the risk of analysis bias (Reddy et al., 2014; Reddy et al., 2015; P. Young et al., 2014).

Study fluids were labelled as "fluid A" or "fluid B" to minimise the risk of ascertainment bias. Despite the blinding, $2 / 3$ of clinicians were able to correctly identify that "fluid $A$ " was Plasma-Lyte 148 . The use of $0.9 \%$ saline in appreciable volumes has been associated with the development of a hyperchloraemic and metabolic acidosis (Scheingraber et al., 1999). As allocation of patients to fluid A or fluid B was not concealed, it is plausible that the 
development of metabolic and/or acid/base derangements may have led clinicians to correctly deduce which fluid was assigned to each treatment block. Although this may potentially have led to ascertainment bias, there were no major differences in any cointerventions between treatment groups that were able to be detected. However, details on all co-interventions administered in ICU, biochemical data (other than serum creatinine) or physiological data were not collected in this study as they were cost prohibitive.

Our primary endpoint was derived from serum creatinine which is routinely used in clinical practice, unambiguous, not subject to observe bias. This outcome had also been previously used in studies exploring renal impairment with crystalloid fluid therapy (Yunos et al., 2015; Yunos et al., 2012; Zhou et al., 2014). There was $100 \%$ monitoring of all the serum creatinine for each patient and therefore complete monitoring of the AKI outcomes which increased the validity of the findings.

The use of a double crossover design improved the balance of confounders between the two groups and may have contributed to the baseline characteristics of the patients being similar. Despite multiple crossovers, there were very few protocol deviations and this compares favourably to previous RCTs on fluids in ICU that have reported a protocol violation rate of approximately 10\% (Finfer et al., 2004; Myburgh et al., 2012). The efficient study design meant that the total cost of the trial, excluding the cost of the study fluid, was less than USD\$150,000 and that study recruitment was completed at the planned 28 week point.

The risk of selection bias was negligible as $99.3 \%$ of eligible patients were enrolled and analysed. One notable feature of study one is that all ICU patients who received crystalloid fluid therapy, except for those with established renal failure, and those patients admitted to ICU for palliative care, were eligible for study participation. This gives the study's results a high degree of generalisability. However, this study was only conducted in New Zealand centres which may reduce the external validity of the findings.

The most important limitation of study one was that prospective sample size calculations were not able to be performed. Study one's results are consistent with a treatment effect that lies between a relative decrease of $20 \%$ and a relative increase of $36 \%$ in AKI arising from use of Plasma-Lyte 148 for crystalloid fluid therapy instead of $0.9 \%$ saline. Although the 
confidence intervals of the treatment effect in relation to the risk of AKI did not encompass the large treatment effect suggested by previous observational data (Yunos et al., 2012) the confidence intervals are wide and the possibility of a clinically significant effect on AKI is not excluded by study one. Additionally, there was a significant interaction found between study treatment and study centre. Although there were no known variations in care or differences in patient populations between study sites there may have been unmeasured differences between centres in the use of cointerventions that may have accounted for the heterogeneity of the response observed between centres.

More than $90 \%$ of patients had received intravenous fluid prior to study enrolment with most patients having received Plasma-Lyte 148. The use of a broad inclusion criteria and narrow exclusion criteria, which included elective surgery patients, may have contributed to the low APACHE II score and lower-risk of AKI. The study's findings do not preclude the possibility of potential harm or benefit in renal outcomes in specific high-risk populations. Although the average volume of study fluids administered to patients in study one was modest (median, two litres), they were similar to the volumes reported in a detailed nested cohort within the study conducted by Yunos et al. (2012). This study reported a reduced risk of RIFLE-defined AKI with the use of a chloride restrictive fluid strategy compared to a chloride liberal strategy. Additionally, the volume of study fluid used in study one was also similar to the volumes administered in the crystalloid versus hydroxyethyl starch trial that which reported that the use of hydroxyethyl starch for fluid resuscitation in critically ill patients significantly increased the use of RRT compared to $0.9 \%$ saline (Myburgh et al., 2012).

Study one does not exclude the possibility of a clinically important increase or decrease in the risk of in-hospital mortality with the use of Plasma-Lyte 148 compared $0.9 \%$ saline. Study one was conducted in a heterogeneous population of critically ill patients with a low overall mortality. The study findings are consistent with a treatment effect that lies between a relative decrease of $33 \%$ and a relative increase of $17 \%$ in in-hospital mortality arising from the use of Plasma-Lyte 148 for crystalloid fluid therapy compared to $0.9 \%$ saline. The observed point estimate of a $12 \%$ relative risk reduction in the in-hospital mortality, which did not differ significantly in five predefined subgroup pairs, provides new information that may inform the design of a pivotal randomised controlled trial designed to definitively 
establish the relative safety and efficacy of Plasma-Lyte 148 and $0.9 \%$ saline in ICU patients requiring IV fluid therapy.

\subsubsection{Conclusions}

Among a heterogeneous population of adult patients receiving crystalloid fluid in ICU, the use of Plasma-Lyte 148 compared to $0.9 \%$ saline was not associated with a reduced risk of AKI. For clinicians, prescribing fluids in ICU Plasma-Lyte 148 and $0.9 \%$ saline can be considered equipotent treatments with regard to renal outcomes for intravascular volume replacement. Further large RCTs are needed to assess the comparative effectiveness of Plasma-Lyte 148 and $0.9 \%$ saline in higher-risk populations and a clinically relevant outcome measure such as mortality. 


\section{Study two: A post-hoc exploratory subgroup analysis and single centre pilot study nested cohort within study one to evaluate the effects of $0.9 \%$ saline and Plasma-Lyte-148 on blood product use and post-operative bleeding.}

\subsection{Rationale}

As detailed in the introduction chapter there is emerging evidence to suggest that crystalloid fluids may have a complex interaction with haemostasis that goes beyond passive haemodilution. There is also evidence to suggest that there may be increased blood transfusion requirements in postoperative patients that received $0.9 \%$ saline compared to Plasma-Lyte 148 (Shaw et al., 2012). As most patients that were enrolled into study one were admitted following surgery, this allowed an opportunity to conduct an exploratory subgroup analysis, within a high patient risk population, into the blood transfusion requirements and bleeding in patients allocated to 0.9\% saline vs. Plasma-Lyte 148.

Within study one, the most common surgery being performed on patients admitted to ICU was cardiac surgery. Abnormal bleeding, defined as diffuse oozing after cardiopulmonary bypass, occurs in greater than $10 \%$ of patients undergoing cardiac surgery and between 5 to $7 \%$ of all patients will have a postoperative blood loss of more than 2 litres within the first 24 hours (Yavari \& Becker, 2009). Re-operation for bleeding after coronary artery bypass graft (CABG) surgery is required in between 2.3 and $8 \%$ of patients and is associated with a 4.5 fold increased risk of death (R. H. Mehta et al., 2009; Yavari \& Becker, 2009). Even modest increases in chest drain losses following surgery are associated with an increased risk of death, higher re-operation rates, an increased need for blood products, and prolonged requirements for intensive care (Dixon et al., 2014; Hartmann et al., 2006).

Patients undergoing cardiac surgery use $10-25 \%$ of the total blood products transfused annually in the United States (Ferraris \& Ferraris, 1995; Hartmann et al., 2006; Makar et al., 2010). However, a minority of patients (10-20\%) consume $80 \%$ of these blood products. This has led to an increasing desire to identify both modifiable and non-modifiable risk factors for bleeding (Ferraris \& Ferraris, 1995; Makar et al., 2010). Patient-specific factors such as older 
age, non-white ethnicity, greater body surface area, elevated pre-operative creatinine, preoperative anaemia, hereditary coagulopathy and operative factors such as urgency of surgery, complexity of surgery, surgeon experience, degree of systemic hypothermia, duration of extracorporeal circulation, and use of an intra-aortic balloon pump are all associated with increased bleeding, blood transfusion requirements, and re-operation rates in cardiac surgery (G. Despotis, Avidan, \& Eby, 2009; Ferraris \& Ferraris, 1995; Hartmann et al., 2006; R. H. Mehta et al., 2009). Frequently, a combination of factors contribute to excessive bleeding in surgical patients and there is now a growing acceptance of the importance of multi-modal strategies to reduce blood loss and requirements for allogenic blood transfusion (G. Despotis et al., 2009; Dixon et al., 2014; Theusinger, Felix, \& Spahn, 2012).

Intravenous fluid therapy is a ubiquitous, modifiable component of peri-operative cardiac surgical care (Myburgh, 2014; Schumacher \& Klotz, 2009). Cardiac surgical patients receive large volumes of intravenous fluids. On average, these patients are given around $4000 \mathrm{~mL}$ of combined colloid and crystalloid intravenous fluids intraoperatively and around $2500 \mathrm{~mL}$ in first 24 hours following surgery (Mueller et al., 2002; Parke, McGuinness, Gilder, \& McCarthy, 2014; Pradeep et al., 2010; Staton et al., 2005). There is marked heterogeneity in clinical practice and no consensus on the appropriate choice of fluid to use in cardiac surgical patients (Finfer et al.; Gu \& Boonstra, 2006; Kastrup et al., 2007). The absence of robust evidence in specific patient populations, the presence of academic fraud, and the marketing endeavours of manufacturers have resulted in an on-going debate on the appropriate use of intravenous fluids in cardiac surgical populations (Bion et al., 2014; Reilly). There has never been a study that has assessed the comparative effectiveness of $0.9 \%$ saline compared to a buffered crystalloid fluid in cardiac surgical patients.

\subsection{Primary aim}

To provide preliminary data on the comparative effectiveness of $0.9 \%$ saline vs. Plasma-Lyte 148 on the need for blood and blood product in adult cardiac surgical patients admitted to ICU following cardiac surgery. 


\subsection{Secondary aims}

The secondary aims were to determine whether, in adult cardiac surgical patients admitted to ICU following cardiac surgery randomised to receive $0.9 \%$ saline or Plasma-Lyte 148 , there were differences between treatment groups in terms of the:

1. Proportions of patients and volume of PRBC, FFP, platelets and cryoprecipitate administered to patients

2. Chest drain losses at 12 and 24 hours after surgery

3. Proportion of patients returning to theatre for bleeding

4. Proportion of patients developing a major post-operative complication (death, myocardial infarction, renal failure requiring dialysis, or a new focal neurological deficit)

5. Lowest daily haemoglobin

6. Daily fluid balance level while in ICU

7. Time until free from inotropes/vasopressors

8. Highest INR after enrolment on the ICU day of admission

9. Duration of mechanical ventilation

10. Proportion of patients requiring ICU readmission during their index hospital admission

11. Length of ICU admission from the time of study enrolment

12. Length of hospital admission from the time study of enrolment

\subsection{Overview}

An overview of the protocol for the nested cohort portion of study two was published in a peer-reviewed journal (Reddy et al., 2015) and was also prospectively registered on the Australian and New Zealand Clinical Trial Registry (Registration number: 12614000289617). 
Study two involved an exploratory subgroup analysis of cardiac surgical patients enrolled in study one to compare the effects of $0.9 \%$ saline vs. Plasma-Lyte 148 on the need for blood product and post-operative bleeding. A copy of the study protocol was provided to the ANZICS-CTG. The CTG has determined that this study did not require formal ANZICS-CTG review.

\subsection{Study design and treatment allocation}

In study two a post-hoc analyses of adult patients enrolled into study one and admitted to ICU after cardiac surgery was undertaken (this group will be referred to as "overall cohort"). Of the four ICUs that participated in study one, only three ICUs admitted patients after cardiac surgery (Auckland Hospital's Cardiac and Vascular ICU, Christchurch ICU, and Wellington Regional Hospital ICU). Patients admitted to ICU following cardiac surgery from Auckland Hospital's Cardiac and Vascular ICU and Christchurch ICU was identified based on their APACHE III admission diagnostic codes entered into the study one database (no additional data were collected from these patients). However, patients admitted following cardiac surgery at Wellington Regional Hospital ICU were prospectively identified and coenrolled into a single nested cohort study in which additional data were collected (this group will be referred to as the "nested cohort").

\subsubsection{Study design: Details of nested cohort}

A single centre nested cohort on all adult patients admitted following cardiac surgery was run concurrently with study one at Wellington Regional Hospital ICU. Only patients from Wellington Regional Hospital ICU were assessed for eligibility. This nested cohort study allowed for a more detailed to look at bleeding and blood transfusion requirements.

The study ran during the same 28 week period as study one. Patients received either blinded $0.9 \%$ saline or blinded Plasma-Lyte 148. The actual treatment allocation order for the study ICU was Plasma-Lyte 148, 0.9\% saline, Plasma-Lyte 148 and $0.9 \%$ saline (Figure 9.1). Any patient that remained in the ICU after a crossover period continued to receive the study fluid to which they were originally assigned up to 90 days after enrolment. 
Figure 9.1. Overview of crossover design nested cohort portion of study two.

\begin{tabular}{|c|c|c|c|c|}
\hline & 7 weeks & 7weeks & 7 weeks & 7 weeks \\
\hline $\begin{array}{c}\text { Wellington } \\
\text { ICU }\end{array}$ & trial fluid A & trial fluid $B$ & trial fluid A & trial fluid B \\
\hline
\end{tabular}

\subsection{Primary outcome: Overall cohort}

The primary outcome for the overall cohort was the proportion of patients that required any of the following blood products in ICU over the first three days after study enrolment; PRBC, FFP, platelets, and cryoprecipitate.

A composite outcome combining the total proportion of patients needing blood transfusion has been reported in previous studies conducted in cardiac surgical populations (Weightman, Gibbs, Sheminant, Newman, \& Grey, 2009). Additionally, the proportion of patients requiring blood transfusion has been previously used by Shaw et al. (2012) in a study that reported a higher proportion of patients that received $0.9 \%$ saline needed blood transfusions when compared to Plasma-Lyte 148 or Plasma-Lyte A.

\subsection{Primary outcome: Nested cohort}

For the nested cohort, in order to explore the relationship between the choice of crystalloid fluid and bleeding, the primary outcome was chest drain losses between ICU admission and 12 hours later.

We did not include patients who had been discharged from the ICU before 12 hours in this analysis. We made no assumptions about missing data and we report the number of available observations. If patients required a return back to theatre for post-operative bleeding the chest drain losses before return to theatre were added to the chest drain losses after returning back from theatre up to 12 hours after the first admission to ICU.

Quantitative measure of blood loss has been previously used as an outcome measure in meta-analyses that have explored the comparative effectiveness of different fluids and the 
risk of bleeding/haemostasis (Burdett et al., 2012; Orbegozo Cortes et al., 2014). Chest drain losses following cardiac surgery are used in clinical practice as a surrogate marker of bleeding and have been previously reported as a measure of postoperative blood loss following cardiac surgery (Dixon et al., 2014). 12 hours was deemed to be an appropriate time point for our study as most patients would still have chest drains in place and patients would still likely be in the study ICU.

\subsection{Secondary outcomes: Overall cohort}

Secondary outcomes within the 90-day follow-up period were:

1) The proportions of patients that required each of PRBC, FFP, platelets and cryoprecipitate during the first three ICU days after study enrolment.

2) The volume of PRBC, FFP, platelets and cryoprecipitate administered in ICU over the first three days after study enrolment.

3) Duration of mechanical ventilation.

4) The proportion of patients requiring ICU readmission during their index hospital admission.

5) The ICU length of stay from the time of first receiving study fluid (days).

6) The hospital length of stay from the time of first receiving study fluid (days).

7) ICU all-cause mortality.

8) In-hospital all-cause mortality.

ICU data were only collected for the index ICU admission.

\subsection{Secondary outcomes: Nested cohort}

Secondary outcomes within the 90-day follow-up period were:

1) The chest tube losses from the time of arrival to 24 hours post-operative if still in ICU.

2) The proportion of patients requiring blood products post-operatively in ICU. 
3) The proportions of patients that required each of PRBC, FFP, platelets and cryoprecipitate in ICU.

4) The total proportion of patients developing a major post-operative complication (death, myocardial infarction, renal failure requiring dialysis, or a new focal neurological deficit). Defined as if was listed as an event on the clinical discharge summary.

5) The proportion of patients developing each of; death, myocardial infarction, renal failure requiring dialysis, or a new focal neurological deficit. Defined as if was listed as an event on the clinical discharge summary.

6) The proportion of patients returning to theatre for bleeding during index ICU admission.

7) Highest INR after enrolment on the ICU day of admission.

8) The proportion of patients with INR> 1.5 after enrolment on the ICU day of admission.

9) The proportion of patients with a haemoglobin $<80 \mathrm{~g} / \mathrm{L}$ during the first three days after study enrolment.

10) The time until free from inotropes (hours).

11) Duration of mechanical ventilation (hours).

12) The ICU length of stay from the time of first receiving study fluid (days).

13) The hospital length of stay from the time of first receiving study fluid (days).

ICU data were only collected for the index ICU admission.

\subsection{Study participants: Overall cohort}

\subsubsection{Inclusion criteria}

All patients enrolled in study one were assessed for eligibility for this study. Patients who met the eligibility criteria were those aged 18 years and had an APACHE III admission diagnosis of cardiac surgery. 


\subsubsection{Exclusion criteria}

As in study one, patients were excluded if they were usually on dialysis for end-stage renal failure, currently receiving renal replacement therapy or expected to require renal replacement therapy within six hours, were admitted to the ICU solely for consideration of organ donation or for palliative care, or were previously enrolled in study one.

\subsection{Study participants: Nested cohort}

\subsubsection{Inclusion criteria}

Patients enrolled in the study one at Wellington ICU were assessed for eligibility for this study. Patients who met the eligibility criteria were those aged 18 years or older and admitted to the study ICU following cardiac surgery.

\subsubsection{Exclusion criteria}

There were no further exclusion criteria for this study than those listed above for the overall cohort study.

\subsubsection{Approach to blood transfusions in cardiac surgical patients in the nested cohort study.}

The study protocol did not specify triggers for transfusion of blood or blood products as such the decisions to transfuse patients were left to the treating clinicians. However, within the study ICU there was a standardised approach to monitoring of bleeding and thresholds for transfusion of blood products after cardiac surgery (Figure 9.2). 
Figure 9.2. Guidelines for bleeding and transfusion after cardiac surgery at study ICU.

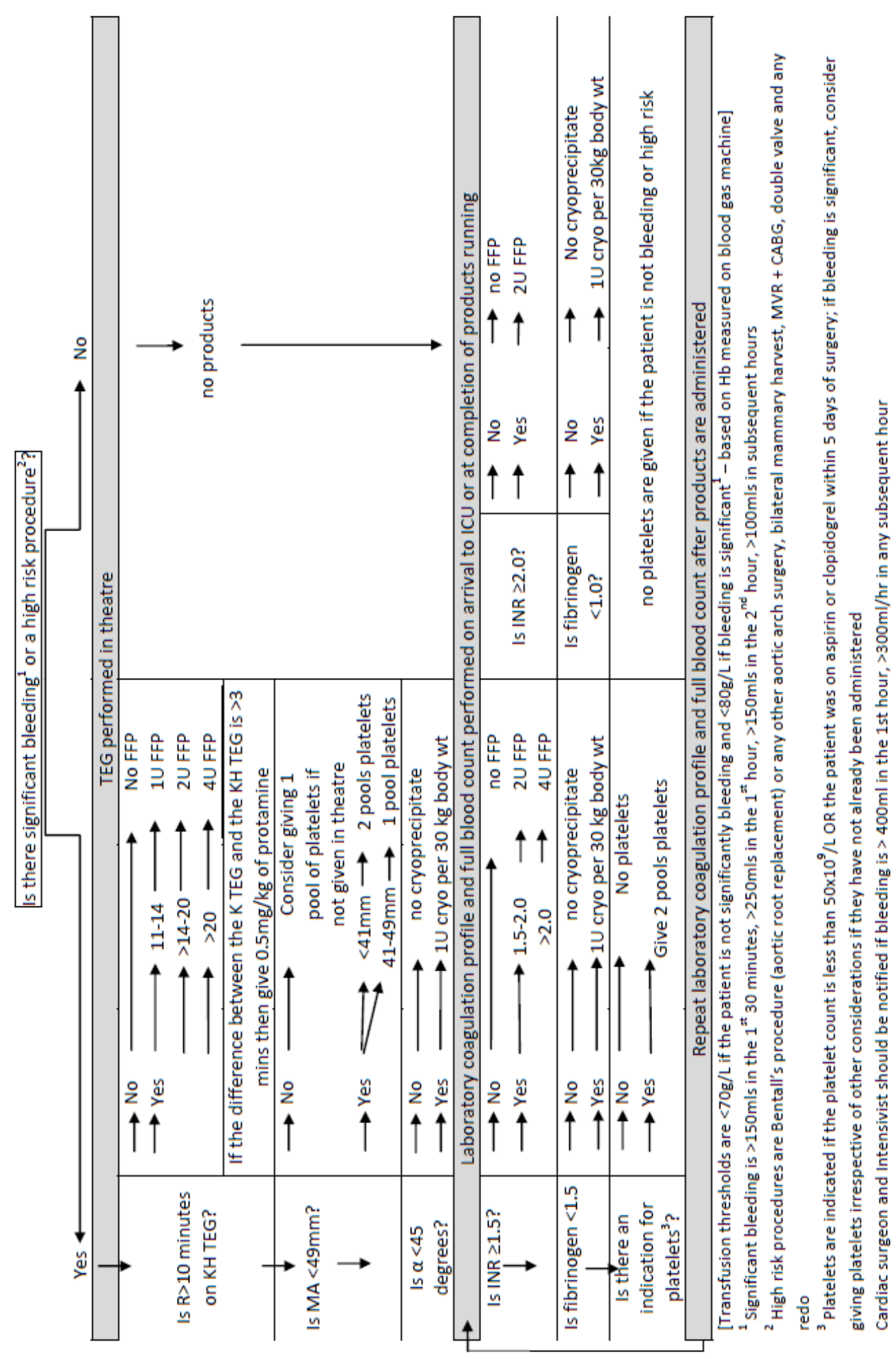




\subsection{Data collection and Management}

Data for the overall cohort was obtained from the study one database (Table 9.1). An excel spreadsheet was exported from the web application created for study one.

Table 9.1. Data collected in study two for the overall cohort.

\section{Baseline information}

Age, sex, ethnicity, weight

ICU admission source

Baseline APACHE II score

APACHE III diagnostic code

Comorbidities (chronic respiratory disease, chronic cardiovascular disease, leukaemia/ myeloma, immunosuppression by disease, immunosuppression by therapy, hepatic failure, cirrhosis, lymphoma, AIDS, metastatic cancer)

Mechanical ventilation at study enrolment

Type and amount of IV fluids ${ }^{a}$ in the 24 prior to study enrolment

\section{Daily Data}

Total volume and type of IV fluids ${ }^{*}$ received on Day 0 to Day 3 inclusive

\section{Hospital discharge data and Day 90 follow-up}

Total amount of study fluid, open label Plasma-Lyte $148^{\circledR}$, open label $0.9 \%$ saline, received in ICU up until day 90 from study enrolment

Need for ICU readmission during index hospitalisation

Duration of mechanical ventilation

ICU length of stay from time of study enrolment

Hospital length of stay from time of study enrolment

Vital status (alive / dead) at ICU and hospital discharge

APACHE = Acute physiology and chronic health evaluation; $A I D S=$ Acquired Immunodeficiency Syndrome; IV = intravenous; ICU = Intensive Care Unit; RRT = renal replacement therapy

a Specific IV fluids recorded will include; 1 ) Crystalloid fluids : Plasma-Lyte $148^{\circledR}, 0.9 \%$ saline, $5 \%$ dextrose, paediatric maintenance fluid, and 'other crystalloids', 2) Colloids : $4 \%$ albumin, $20 \%$ albumin, gelofusion, voluven/volulyte, and 'other colloids' 3) Blood products : packed red blood cells, fresh frozen plasma, platelets, and cryoprecipitate.

For the nested cohort data was collected by the study investigator. The specific additional data for study two was entered onto a paper CRF. Table 9.2 shows details of the data that was collected. 
Table 9.2. Data collected in the study two for the nested cohort.

\section{Baseline information}

Age, sex, ethnicity*

Body mass index

Baseline APACHE II score*

Baseline euroSCORE II score ${ }^{\dagger}$

Comorbidities (diabetes, hypercholeterolemia, hypertension, perpheral vascular disease, cerebrovascular disease, smoking history, family history of ischaemic heart disease)

Use of anti-platelet/anti-thrombotic medication (aspirin on the day of surgery, aspirin within 5 days, clopidogrel on the day of surgery, clopidogrel within 5 days, and therapeutic heparin on the day of surgery)

Prior cardiac surgery

Type of operation (Coronary artery bypass surgery, valve surgery and other cardiac) Operative urgency (Elective, urgent, emergency, salavage)

Cardiopulmonary bypass used

Cumulative cross-clamp time (minutes)

Cumulative cardiopulmonary bypass time (minutes)

Pre-operative haemoglobin $(\mathrm{g} / \mathrm{L})$

ICU admission haemoglobin $(\mathrm{g} / \mathrm{L})$

Time from ICU admission to first fluid (hours)

Chest tube losses on arrival to ICU $(\mathrm{mL})$

Type and amount of IV fluids $s^{\mathrm{a}}$ in the 24 hours prior to study enrolment*

\section{Daily Data}

Chest losses at 12 hours and 24 hours after ICU admission

Total volume and type of IV fluids ${ }^{*}$ received on Day 0 to Day 3 inclusive*

Fluid balance in ICU on Day 0 to Day 2 inclusive

Lowest haemoglobin ( $\mathrm{g} / \mathrm{L}$ ) in ICU on Day 0 to Day 3 inclusive

Highest INR after enrolment on ICU day of

Hospital discharge data and Day $\mathbf{9 0}$ follow-up

Total amount of study fluid, open label Plasma-Lyte $148^{\circledR}$, open label $0.9 \%$ saline, received in ICU up until day 90 from study enrolment

Need for PBRC's in ICU

Need for FFP in ICU

Need for platelets in ICU

Need for cryoprecipitate in ICU

Had a myocardial infarction

Developed renal failure requiring dialysis

Developed new focal neurological deficit

In-hospital death 


Returning to theatre for bleeding
Time until free from inotropes (hours)
Duration of mechanical ventilation*
ICU length of stay from time of study enrolment*
Hospital length of stay from time of study enrolment*
APACHE = Acute physiology and chronic health evaluation; ICU = Intensive Care Unit;
* These data were already collected as part of study one. $^{\text {+ European System for Cardiac Operative Risk Evaluation (euroSCORE) II is a risk model that }}$
calculates the preoperative risk of death.
a Specific IV fluids recorded will include; 1 ) Crystalloid fluids : Plasma-Lyte $148^{\circledR}, 0.9 \%$ saline,
$5 \%$ dextrose, paediatric maintenance fluid, and 'other crystalloids', 2) Colloids : $4 \%$ albumin,
20\% albumin, gelofusion, voluven/volulyte ,and 'other colloids' 3) Blood products : packed
red blood cells, fresh frozen plasma, platelets, and cryoprecipitate.

\subsection{Assessment of safety}

As this was a post-hoc analysis and a nested cohort study within study one there were no additional safety monitoring mechanisms beyond that of study one. In the event of an $A E$ and SAE this would have been reported as per the protocol for study one. The investigator was responsible for detecting, documenting and reporting of $A E$ and SAE.

\subsection{Ethical issues: nested cohort}

As per study one, this study was performed in accordance with World Medical Association Declaration of Helsinki: Ethical principles for medical research involving human subjects (World Medical Association, 2013) and the NEAC Ethical guidelines for interventional studies and operational standards for ethic committees (National Ethics Advisory Committee, 2006, 2012). This study was granted ethical approval by the New Zealand Health and Disability Northern B Ethics Committee (reference: 14/NTB/12) on the basis of the provision of information to patients and/or their next of kin and the opportunity for them to opt-out of the use of their data if they wish. A separate opt consent form was designed for this study which gave a brief overview of the study. 


\subsection{Process of obtaining opt-out consent: nested cohort}

As soon as was reasonably possible and appropriate patients, their families, and/or legal representatives were provided with an opt-out form/information sheet for both study one and study two. If patients or next of kin were not able to receive an opt-out form prior to hospital discharge or patient death a letter detailing the study along with a copy of the opt form were sent to the patient/next of kin.

\subsection{Data handling and confidentiality: nested cohort}

A site file containing a data dictionary and paper versions of the data collection forms were keep at the study site. Study documents were stored in secure locked cabinets.

The investigator maintained the confidentiality of all study documentation. The unique study number given to patients for study one were used for study two. A separate enrolment log was created for this study that included the NHI number and the unique study number. The enrolment log and the study data were kept separately in a locked office. Data from the paper CRF was double data entered into an excel spreadsheet and the patient data were identified by the unique study number only.

\subsection{Sample size and power}

A statistical analysis plan for the nested cohort study was reported prior to any statistical analyses (Reddy et al., 2015). As recruitment for this study was dependent on enrolment into study one it was unknown how many patients would be included in the overall cohort and the nested cohort at the studies' commencements. The number of cardiac surgeries performed during this period of time is not fixed, however Wellington Regional Hospital ICU admits approximately $800-850$ patients every 28 weeks. Of these patients 260 patients have undergone major cardiac surgery and will be eligible for the nested cohort study.

\subsection{Statistical analysis}

All analysis was on an intention-to-treat basis and there was no imputation for missing values. 
All continuous variables were assessed for normality and log-transformed where appropriate. Comparisons between groups were determined using chi-square test or Fischer exact test when numbers were small. Student's t-test was used for normally distributed variables and Wilcoxon rank sum test used otherwise. Binomial outcome variables were analysed using logistic regression. All analyses were performed using SPSS version 22.0 (IBM Corp., Armonk, NY) and a two-sided p-value of 0.05 was considered to be statistically significant.

Hierarchical logistic regression was performed for the total proportion of patients receiving blood products adjusting for study site, baseline characteristics that had a $p$-value of below 0.20 (gender, age, chronic cardiovascular disease, APACHE II score, volume of $0.9 \%$ saline administered 24 hour prior to randomisation, volume of other crystalloids administered 24 hour prior to randomisation and volume of Voluven or Volulyte administered 24 hour prior to randomisation,) and variables collected that have been associated with increased blood transfusions requirements (ethnicity, elective/emergency surgery and isolated CABG surgery/other than isolated CABG)(Ferraris et al., 2007; R. H. Mehta et al., 2009).

For the nested cohort a multivariate logistic regression analysis was conducted on the total proportion of patients receiving blood products. The variables were selected from the baseline characteristics that had a p-value of below 0.10 when compared between treatment groups (APACHE II score, euroSCORE II, Clopidogrel within 5 days) and variables that have been associated with increased bleeding and blood transfusions requirements after cardiac surgery (age, gender, extracorporeal circulation time and preoperative haemoglobin)(G. Despotis et al., 2009; G. J. Despotis et al., 1996; Ferraris et al., 2007).

\subsection{Funding and support}

This study is an investigator-initiated study. Sumeet Reddy has received a Clinical Research Training Fellowship from the HRC of New Zealand. The additional costs of this study have been underwritten by the MRINZ. The study fluid was supplied and distributed by Baxter Healthcare Corporation. Baxter Healthcare Corporation was not involved in the study design, conduct, data collection, statistical analysis, or writing of the manuscript/thesis for this study. 


\subsection{Results}

\subsubsection{Baseline characteristics}

From April 2014 through to October 2014, a total of 954 cardiac surgical patients representing $42 \%$ of the 2262 patients enrolled in study one were included in this analysis. 475 patients were assigned to receive Plasma-Lyte 148 and 479 were assigned to receive $0.9 \%$ saline. Demographic data were available for $100 \%$ of the intention to treat population.

For the nested cohort 251 patients of the 611 patient (41\%) enrolled into study one at the study site were analysed, with 131 assigned to receive Plasma-Lyte 148 and 120 to receive $0.9 \%$ saline.

Overall, Plasma-Lyte 148 patients had lower APACHE II scores $(p<0.01)$ and were less likely to be male $(p<0.01)$ than $0.9 \%$ saline patients (Table 9.3$)$.

Table 9.3. Characteristics of the patients at baseline in the overall cohort.

\begin{tabular}{|c|c|c|c|}
\hline Baseline characteristics & $\begin{array}{c}\text { Plasma-Lyte } 148 \\
(n=475)\end{array}$ & $\begin{array}{c}0.9 \% \text { saline } \\
(n=479)\end{array}$ & p-value \\
\hline Male sex, no. / total no. (\%) & $323 / 475(68)$ & $368 / 479(77)$ & 0.002 \\
\hline Age, median [IQR], years & $\begin{array}{c}65.0[55.0- \\
74.0]\end{array}$ & $\begin{array}{c}67.0[57.0- \\
74.0]\end{array}$ & 0.16 \\
\hline Weight, median [IQR], kgs & $\begin{array}{c}82.0[71.0- \\
106.0]\end{array}$ & $\begin{array}{c}81.0[71.0- \\
95.0]\end{array}$ & 0.5 \\
\hline APACHE II score $\dagger$, median [IQR] & $10.0[8.0-13.0]$ & $\begin{array}{c}11.0[8.0- \\
14.0]\end{array}$ & 0.006 \\
\hline \multicolumn{4}{|l|}{ Ethnicity, no. / total no. (\%) } \\
\hline - European & 292/475 (61) & $286 / 479(60)$ & 0.58 \\
\hline - Maori & $44 / 475(9)$ & 43/479 (9) & 0.88 \\
\hline - Pacific Islander & $51 / 475(11)$ & $52 / 479(11)$ & 0.95 \\
\hline - Other & $88 / 475$ (19) & $98 / 479(20)$ & 0.45 \\
\hline $\begin{array}{l}\text { Non-emergency surgery, no. / total no. } \\
\text { (\%) }\end{array}$ & $435 / 475(92)$ & $437 / 479(91)$ & 0.85 \\
\hline $\begin{array}{l}\text { Isolated coronary artery bypass surgery, } \\
\text { no. / total no. (\%) }\end{array}$ & $236 / 475(50)$ & $250 / 479(52)$ & 0.44 \\
\hline \multicolumn{4}{|l|}{ Comorbidities, no. / total no. (\%) } \\
\hline - Chronic respiratory disease & $4 / 475(<1)$ & $9 / 479(2)$ & 0.26 \\
\hline - Chronic cardiovascular disease & $3 / 475(<1)$ & $15 / 479(3)$ & 0.007 \\
\hline - Immunosuppression by therapy & $2 / 475(<1)$ & $2 / 479(<1)$ & 1 \\
\hline - Hepatic failure & $0 / 475(0)$ & $2 / 479(<1)$ & 0.5 \\
\hline
\end{tabular}




\begin{tabular}{|c|c|c|c|}
\hline - Lymphoma & $4 / 475(<1)$ & $2 / 479(<1)$ & 0.45 \\
\hline - Metastatic cancer & $1 / 475(<1)$ & $2 / 479(<1)$ & 0.58 \\
\hline $\begin{array}{l}\text { Time from ICU admission to first fluid, } \\
\text { median }[I Q R] \text {, hours }\end{array}$ & $0.8[0-2.3]$ & $0.8[0-2.0]$ & 0.29 \\
\hline \multicolumn{4}{|c|}{$\begin{array}{l}\text { Crystalloids administered in the } 24 \mathrm{hr} \text { before randomisation, median [IQR], mean +/- SD, } \\
\text { no. / total no. }(\%), \mathrm{mL} .++\end{array}$} \\
\hline - Plasma-Lyte $148^{\circledR}$ & $\begin{array}{c}2000[1000- \\
3000] \\
2367+/-1764 \\
412 / 475(87)\end{array}$ & $\begin{array}{c}2000[1000- \\
3300], \\
2355+/-1888 \\
389 / 479(82)\end{array}$ & 0.71 \\
\hline - $\quad 0.9 \%$ saline & $\begin{array}{c}0[0-0] \\
49+/-305 \\
23 / 475(5)\end{array}$ & $\begin{array}{c}\text { 0[0-0], } \\
89+/-356, \\
44 / 479(9)\end{array}$ & 0.02 \\
\hline - $5 \%$ dextrose & $\begin{array}{c}0[0-0] \\
11+/-76 \\
27 / 475(6)\end{array}$ & $\begin{array}{c}0[0-0] \\
8+/-49 \\
21 / 479(4)\end{array}$ & 0.29 \\
\hline - Other crystalloids & $\begin{array}{c}0[0-0] \\
284+/-930, \\
57 / 475(12)\end{array}$ & $\begin{array}{c}0[0-0] \\
377+/-1025 \\
74 / 479(16)\end{array}$ & 0.13 \\
\hline
\end{tabular}

Colloids administered in the $24 \mathrm{hr}$ before randomisation, median [IQR], mean +/- SD, no. / total no. (\%), mL. $+\dagger$

\begin{tabular}{|l|c|c|c|}
\hline \multirow{2}{*}{$4 \%$ albumin } & $0[0-0]$, & $0[0-0]$, & \\
& $3+/-51$, & $1+/-23$, & 0.56 \\
& $2 / 475(<1)$ & $1 / 479(<1)$ & \\
\hline \multirow{3}{*}{$20 \%$ albumin } & $0[0-0]$, & $0[0-0]$, & \\
& $47+/-87$, & $45+/-122$, & 0.31 \\
\hline \multirow{3}{*}{ Gelofusine } & $108 / 475(23)$ & $96 / 479(20)$ & \\
\hline \multirow{3}{*}{ Voluven or Volulyte } & $0[0-0]$, & $0[0-0]$, & \\
& $<1+/-9$, & $0+/-0$, & 0.32 \\
\hline & $1 / 475(<1)$ & $0 / 479(0)$ & \\
\hline & $0[0-0]$, & $0[0-0]$, & \multirow{2}{*}{0.16} \\
\hline & $2+/-3$, & $0+/-0$, & \\
\hline & $2 / 475(<1)$ & $0 / 479(0)$ & 1 \\
\hline
\end{tabular}

Blood products administered in the $24 \mathrm{hr}$ before randomisation, median [IQR], mean +/SD, no. / total no. (\%), mL. ††

- Packed red cells

$$
0 \text { [0-0], }
$$
$89+/-270$, $66 / 475(14)$ 0 [0-0], $70+/-242$, $48 / 475(10)$

$$
0[0-0] \text {, }
$$
$91+/-263$, $70 / 479(15)$ 0[0-0], $83+/-294$, $52 / 479$ (11)
0.79

0.67 
- Platelets

- Cryoprecipitate

\begin{tabular}{c|c|c}
\hline $0[0-0]$, & $0[0-0]$, & \\
$79+/-266$, & $64+/-199$, & \\
$68 / 475(14)$ & $60 / 479(13)$ & 0.43 \\
$0[0-0]$, & $0[0-0]$, & \\
$23+/-84$, & $25+/-92$, & \\
$40 / 475(8)$ & $40 / 479(8)$ & 0.98
\end{tabular}

+ Scores on the Acute Physiology and Chronic Health Evaluation (APACHE) II range from 0 to 71 , with higher scores indicating an increased risk of death.

†† $\mathrm{P}$ value for comparison of volume of fluid administered calculated using Wilcoxon Rank Sum test.

Within the nested cohort, Plasma-Lyte 148 patients also had significantly lower APACHE II scores than $0.9 \%$ saline patients $(p=0.04)$. In this cohort, Plasma-Lyte 148 patients also had higher euroSCORE II scores and were less likely to have received Clopidogrel within 5 days of surgery $(p<0.01)$ (Table 9.4). There were no additional patients that withdrew consents from this study.

Table 9.4. Characteristic of the patients at baseline in the nested cohort.*

\begin{tabular}{|c|c|c|c|}
\hline Characteristics & $\begin{array}{l}\text { Plasma-Lyte } 148 \\
\qquad(n=131)\end{array}$ & $\begin{array}{c}0.9 \% \text { saline } \\
(n=120)\end{array}$ & p-value \\
\hline Age (years) & $65.3+/-12.9$ & $65.9+/-10.2$ & 0.79 \\
\hline Male sex - no. / total no. (\%) & $95 / 131(73)$ & $97 / 120(81)$ & 0.12 \\
\hline Body mass index & $28.7+/-5.6$ & $29.0+/-5.9$ & 0.78 \\
\hline \multicolumn{4}{|l|}{ Ethnicity - no. / total no. (\%) } \\
\hline - New Zealand European & $99 / 131(76)$ & $91 / 120(76)$ & 0.96 \\
\hline - Maori & $16 / 131(12)$ & $12 / 120(10)$ & 0.58 \\
\hline - Pacific Island people & $8 / 131(6)$ & $7 / 120(6)$ & 0.93 \\
\hline - Other & $8 / 131(6)$ & $10 / 120(8)$ & 0.50 \\
\hline APACHE II score ${ }^{\dagger}$ & $13.8+/-3.7$ & $14.6+/-3.2$ & 0.04 \\
\hline euroSCORE II score †† & $1.9+/-1.5$ & $1.5+/-1.1$ & 0.008 \\
\hline \multicolumn{4}{|l|}{ Comorbidities - no. / total no. (\%) } \\
\hline - Diabetes & 25/131 (19) & $31 / 120(26)$ & 0.20 \\
\hline - Hypercholesterolemia & $86 / 131(66)$ & $85 / 120(71)$ & 0.38 \\
\hline - Hypertension & $86 / 131(66)$ & $89 / 120(74)$ & 0.14 \\
\hline - Peripheral vascular disease & $9 / 131(7)$ & $5 / 120(4)$ & 0.35 \\
\hline
\end{tabular}


- Cerebrovascular disease

$13 / 131(10)$

$8 / 120(7)$

0.35

- Smoking history

$59 / 131(45)$

$46 / 120(38)$

0.28

- Family history of ischaemic heart disease

$46 / 131(35)$

$54 / 120(45)$

0.11

Use of anti-platelet/anti-

thrombotic medication - no. /

total no. (\%)

$68 / 131(52)$

$71 / 120(59) \quad 0.25$

- Aspirin on the day of surgery

$$
6 / 131(5)
$$

$4 / 120(3)$

0.75

- Aspirin within 5 days

$59 / 131(45) \quad 63 / 120(53) \quad 0.24$

- Clopidogrel on the day of surgery

$0 / 131(0) \quad 1 / 120(<1) \quad 0.48$

- Clopidogrel within 5 days

$4 / 131(3) \quad 18 / 120(15) \quad 0.001$

- Therapeutic heparin on the day of surgery

$3 / 131(2)$

$1 / 120(<1) \quad 0.62$

Prior cardiac surgery - no. / total no. (\%)

4/131 (3)

$3 / 120(3)$

1.00

Type of operation- no. / total no.

(\%)

- $\quad$ CABG

$81 / 131(62)$

$84 / 120(70)$

0.17

- Valve

$52 / 131(40)$

$49 / 120(41)$

0.85

- Other cardiac

$16 / 131(12)$

$12 / 120(10)$

0.58

Operative urgency - no. / total no.

(\%)

- Elective

$56 / 131(43)$

$60 / 120(50)$

0.25

- Urgent

$65 / 131(50)$

$51 / 120(43)$

0.26

- Emergency

9/131 (7)

$9 / 120(8)$

0.85

- Salvage

$1 / 131(<1)$

$0 / 120(0)$

1.00

Cardiopulmonary bypass used no. / total no. (\%)

129/131 (99)

$120 / 120(100)$

0.50

Cumulative cross-clamp time

(minutes)

$81.0[58.0-104.0]$

$87.0[61.0-113.0] \quad 0.56$

Cumulative cardiopulmonary

bypass time (minutes)

$108.0[79.0-137.0] \quad 113.0[84.5-141.5] \quad 0.40$

\begin{tabular}{|llll}
\hline Pre-operative haemoglobin (g/L) & $139.2+/-15.9$ & $135.7+/-19.2$ & 0.11 \\
\hline ICU admission haemoglobin (g/L) & $103.3+/-15.2$ & $103.7+/-16.5$ & 0.88
\end{tabular}


Time from ICU admission to first

$\begin{array}{llll}\text { fluid (hours) } & 1.0[0-3.5] & 1.0[0-3.1] & 0.92\end{array}$

Chest tube losses on arrival to ICU $110.5[62.3-186.2] \quad 118.5[65.0-183.0] \quad 0.69$

* Plus-minus values are mean \pm SD. Values followed by ranges in square brackets are the median [IQR].

+ Scores on the Acute Physiology and Chronic Health Evaluation (APACHE) II range from 0 to 71, with higher scores indicating an increased risk of death.

t† European System for Cardiac Operative Risk Evaluation (euroSCORE) II is a risk model that calculates the preoperative risk of death.

Patients in the overall cohort had lower APACHE-II scores compared to those in the nested pilot study (median [IQR], 11.0 [8.0-14.0] in the overall cohort vs. 14.0 [12.0-16.0] in the nested cohort, $\mathrm{p}<0.001$ ) (see Table 9.5). In the 24 hours prior to study enrolment, PlasmaLyte 148, 20\% albumin, FFP, platelets and cryoprecipitate were all used more in the nested cohort than overall cohort while other crystalloids were used less $(p<0.01$ for all comparisons) (Table 9.5). 
Table 9.5. Characteristics of the patients at baseline in the overall cohort compared to the nested cohort.

\begin{tabular}{|c|c|c|c|}
\hline Baseline characteristics & Overall cohort $(n=954)$ & Nested pilot ( $n=251)$ & $p$-value \\
\hline Male sex, no. / total no. (\%) & $691 / 954(72)$ & $192 / 251(77)$ & 0.2 \\
\hline Age, median [IQR], years & $66.0[56.8-74.0]$ & $68.0[60.0-74.0]$ & 0.16 \\
\hline Weight, median [IQR], kgs & $81.0[71.0-94.00]$ & $80.0[71.0-95.0]$ & 0.99 \\
\hline APACHE score + , median [IQR] & $11.0[8.0-14.0]$ & $14.0[12.0-16.0]$ & $<0.001$ \\
\hline Elective surgery, no. / total no. (\%) & $872 / 954(91)$ & $230 / 251(92)$ & 0.91 \\
\hline $\begin{array}{l}\text { Isolated coronary artery bypass } \\
\text { surgery, } \\
\text { no. / total no. (\%) }\end{array}$ & $486 / 954(51)$ & $128 / 251(51)$ & 0.99 \\
\hline \multicolumn{4}{|l|}{ Comorbidities, no. / total no. (\%) } \\
\hline Chronic respiratory disease & $13 / 954(1)$ & $0 / 251(0)$ & 0.08 \\
\hline $\begin{array}{l}\text { Chronic cardiovascular } \\
\text { disease }\end{array}$ & $18 / 954(2)$ & $0 / 251(0)$ & 0.02 \\
\hline $\begin{array}{l}\text { Immunosuppression by } \\
\text { therapy }\end{array}$ & $4 / 954(<1)$ & $0 / 251(0)$ & 0.59 \\
\hline Hepatic failure & $2 / 954(<1)$ & $0 / 251(0)$ & 1 \\
\hline Lymphoma & $9 / 954(<1)$ & $0 / 251(0)$ & 0.35 \\
\hline Metastatic cancer & $3 / 954(<1)$ & $0 / 251(0)$ & 1 \\
\hline $\begin{array}{l}\text { Time from ICU admission to first } \\
\text { fluid, median [IQR], hours }\end{array}$ & $0.83[0-2.08]$ & $1.00[0.08-2.33]$ & 0.05 \\
\hline \multicolumn{4}{|c|}{$\begin{array}{l}\text { Crystalloids administered in the } 24 \mathrm{hr} \text { before randomisation, median [IQR], mean +/- SD, no. / total } \\
\text { no. (\%), } \mathrm{mL} . \dagger \dagger\end{array}$} \\
\hline Plasma-Lyte $148{ }^{\circledR}$ & $\begin{array}{c}2000[1000-3000] \\
2361+/-2826 \\
801 / 952(84)\end{array}$ & $\begin{array}{c}3000 \text { [2000-3600], } \\
2958+/-1306 \\
250 / 251(99.6)\end{array}$ & $<0.001$ \\
\hline $0.9 \%$ saline & $\begin{array}{l}0[0-0], 69+/-332 \\
67 / 952(7)\end{array}$ & $\begin{array}{l}0[0-0], 60+/-307 \\
12 / 251(5)\end{array}$ & 0.26 \\
\hline $5 \%$ dextrose & $\begin{array}{l}0[0-0], 10+/-64 \\
48 / 952(5)\end{array}$ & $\begin{array}{l}0[0-0], 37+/-121 \\
47 / 251(19)\end{array}$ & $<0.001$ \\
\hline Other crystalloids & $\begin{array}{l}0[0-0], 329+/-978 \\
131 / 952(14)\end{array}$ & $\begin{array}{l}0[0-0], 9+/-127 \\
2 / 251(<1)\end{array}$ & $<0.001$ \\
\hline
\end{tabular}

Colloids administered in the $24 \mathrm{hr}$ before randomisation, median [IQR], mean +/- SD, no. / total no. (\%), mL. ††

\begin{tabular}{|l|c|c|c|}
\hline \multirow{2}{*}{$4 \%$ albumin } & $\begin{array}{c}0[0-0], 2+/-40,3 / 952 \\
(<1)\end{array}$ & $\begin{array}{c}0[0-0], 0+/-0,0 / 251 \\
(0)\end{array}$ & 0.37 \\
\hline \multirow{2}{*}{$20 \%$ albumin } & $0[0-0], 46+/-106$, & $0[0-0], 173+/-143$, & $<0.001$ \\
\hline \multirow{2}{*}{ Gelofusine } & $204 / 952(21)$ & $204 / 251(81)$ & \\
\hline Voluven or Volulyte & $0[0-0], 0.2+/-6$, & $0[0-0], 0+/-0$, & 0.31 \\
& $1 / 952(<1)$ & $0 / 251(0)$ & \\
\hline Other colloids & $0[0-0], 1+/-23$, & $0[0-0], 0+/-0$, & 0.47 \\
& $2 / 952(<1)$ & $0 / 251(0)$ & \\
\hline & $0[0-0], 0+/-0$, & $0[0-0], 0+/-0$, & 1 \\
\hline
\end{tabular}


Blood products administered in the $24 \mathrm{hr}$ before randomisation, median [IQR], mean +/- SD, no. / total no. (\%), mL. ††

\begin{tabular}{|c|c|c|c|}
\hline Packed red cells & $0[0-0], 90+/-266$, & $0[0-0], 109+/-276$, & 0.15 \\
\hline & $136 / 954(14)$ & $45 / 251(18)$ & \\
\hline Fresh frozen plasma & $0[0-0], 77+/-269$, & $0[0-0], 109+/-266$, & 0.005 \\
\hline & $100 / 954(10)$ & $43 / 251(17)$ & \\
\hline Platelets & $0[0-0], 71+/-234$, & $0[0-0], 109+/-233$, & 0.001 \\
\hline Cryoprecipitate & $128 / 954(13)$ & $56 / 251(22)$ & \\
\hline
\end{tabular}

+ Scores on the Acute Physiology and Chronic Health Evaluation (APACHE) II range from 0 to 71 , with higher scores indicating an increased risk of death.

†† $\mathrm{P}$ value for comparison of volume of fluid administered calculated using Wilcoxon Rank Sum test.

\subsubsection{Fluid therapy}

In the 24 hours prior to enrolment patients in the Plasma-Lyte 148 and $0.9 \%$ saline groups received similar volumes of crystalloid, colloid and blood products (Table 9.3 and Table 9.6). Within the overall cohort and the nested cohort patients allocated to Plasma-Lyte 148 and $0.9 \%$ saline received similar volumes of study fluids and other fluids with most study fluid administered on the first day in ICU (Table 9.7, Table 9.8, Table 9.9 and Table 9.10).

However, smaller total volumes of study fluid were administered to the patients in the nested cohort than overall cohort (median [IQR], 2000mL [1000-3000mL] Plasma-Lyte 148 for nested cohort patients vs. 2500mL [1440-3500mL] Plasma-Lyte 148 overall cohort; $\mathrm{P}=0.01$ and median [IQR], 2000mL [1285-2993mL] 0.9\% saline for nested cohort patients vs. $2500 \mathrm{~mL}[1500-3500 \mathrm{~mL}]$ overall cohort; $p=0.03)$. 
Table 9.6. Fluids received in the 24 hours before randomisation in the nested cohort.*

\begin{tabular}{|c|c|c|}
\hline Fluid - mL & Plasma-Lyte 148 & $0.9 \%$ saline \\
\hline \multicolumn{3}{|c|}{ Plasma-Lyte 148 (study fluid) - median [IQR], mean \pm SD, no. / total no. (\%), mL } \\
\hline Day 0 & $\begin{array}{c}1250[540-2000], 1428 \pm \\
874,131 / 131(100)\end{array}$ & $0[0-0], 0 \pm 0,0 / 120(0)$ \\
\hline Day 1 & $\begin{array}{c}500[0-1000], 648 \pm 799 \\
83 / 130(64)\end{array}$ & $0[0-0], 0 \pm 0,0 / 117(0)$ \\
\hline Day 2 & $\begin{array}{c}120[0-500], 325 \pm 347 \\
39 / 71(55)\end{array}$ & $0[0-0], 0 \pm 0,0 / 50(0)$ \\
\hline Day 3 & $\begin{array}{c}0[0-205], 94 \pm 153 \\
13 / 37(35)\end{array}$ & $0[0-0], 0 \pm 0,0 / 23(0)$ \\
\hline Day 4 to 90 & $\begin{array}{c}0[0-125], 116 \pm 239 \\
6 / 18(33)\end{array}$ & $0[0-0], 0 \pm 0,0 / 16(0)$ \\
\hline \multicolumn{3}{|c|}{$0.9 \%$ saline (study fluid) - median [IQR], mean $\pm \mathrm{SD}$, no. / total no. (\%), mL } \\
\hline Day 0 & $0[0-0], 0 \pm 0,0(0)$ & $\begin{array}{c}1500[1000-2000], 1506 \pm \\
929,120 / 120(100)\end{array}$ \\
\hline Day 1 & $0[0-0],<1 \pm 4,1 / 130(0.8)$ & $\begin{array}{c}500[0-1000], 746 \pm 989 \\
75 / 117(64)\end{array}$ \\
\hline Day 2 & $0[0-0], 0 \pm 0,0 / 71(0)$ & $\begin{array}{c}0[0-500], 370 \pm 581 \\
23 / 50(46)\end{array}$ \\
\hline Day 3 & $0[0-0], 0 \pm 0,0 / 37(0)$ & $\begin{array}{c}0[0-150], 197 \pm 443, \\
10 / 23(43)\end{array}$ \\
\hline Day 4 to 90 & $0[0-0], 0 \pm 0,0 / 18(0)$ & $\begin{array}{c}0[0-0], 257 \pm 773 \\
3 / 16(19)\end{array}$ \\
\hline
\end{tabular}

*There were no significant $(p<0.05)$ differences between the groups for the volume of study fluid received. Comparisons for volume of fluid was tested using Wilcoxon Rank Sum test. 
Table 9.7. Study fluids administered in the overall cohort.*

\begin{tabular}{|c|c|c|}
\hline Fluid - mL & Plasma-Lyte 148 & $0.9 \%$ saline \\
\hline \multicolumn{3}{|c|}{ Plasma-Lyte 148 (study fluid) - median [IQR], mean +/- SD, no. / total no. (\%), mL } \\
\hline \multicolumn{3}{|c|}{2000 [1000-3000], $2105+/-$} \\
\hline Day 0 & $\begin{array}{c}1295 \\
475 / 475(100)\end{array}$ & $\begin{array}{c}0 \text { [0-0], } 0+/-0 \\
0 / 479(0)\end{array}$ \\
\hline Day 1 & $\begin{array}{c}0[0-500], 382+/-641 \\
226 / 471(48)\end{array}$ & $\begin{array}{c}0[0-0], 0+/-0 \\
0 / 472(0)\end{array}$ \\
\hline Day 2 & $\begin{array}{c}0 \text { [0-250], } 156+/-295 \\
68 / 195(35)\end{array}$ & $\begin{array}{c}0 \text { [0-0], } 0+/-0 \\
0 / 188(0))\end{array}$ \\
\hline Day 3 & $\begin{array}{c}0 \text { [0-60], } 83+/-173 \\
28 / 107(26)\end{array}$ & $\begin{array}{c}0[0-0], 0+/-0 \\
0 / 95\end{array}$ \\
\hline Day 4 to 90 & $\begin{array}{c}0[0-250], 273+/-631 \\
21 / 65(32)\end{array}$ & $\begin{array}{c}0[0-0], 0+/-0 \\
0 / 58(0)\end{array}$ \\
\hline \multicolumn{3}{|c|}{$0.9 \%$ saline (study fluid) - median [IQR], mean +/- SD, no. / total no. (\%), mL } \\
\hline Day 0 & $\begin{array}{c}0[0-0], 0+/-0 \\
0 / 475(0)\end{array}$ & $\begin{array}{c}2000[1000,3000], 2074+/- \\
1224,478 / 479(99.8)\end{array}$ \\
\hline Day 1 & $\begin{array}{c}0[0-0],<1+/-2 \\
1 / 471(<1)\end{array}$ & $\begin{array}{c}40[0-500], 426+/-714 \\
249 / 472(53)\end{array}$ \\
\hline Day 2 & $\begin{array}{c}0[0-0], 0+/-0 \\
0 / 195(0)\end{array}$ & $\begin{array}{c}0[0-206], 174+/-372 \\
56 / 188(30)\end{array}$ \\
\hline Day 3 & $\begin{array}{c}0[0-0], 0+/-0 \\
0 / 107(0)\end{array}$ & $\begin{array}{c}0[0-120], 175+/-489 \\
29 / 95(31)\end{array}$ \\
\hline Day 4 to 90 & $\begin{array}{c}0[0-0], 0+/-0 \\
0 / 65(0)\end{array}$ & $\begin{array}{c}0[0-250], 429+/-1098 \\
17 / 58(29)\end{array}$ \\
\hline
\end{tabular}

*There were no significant $(p<0.05)$ differences between the groups for the volume of study fluid received. Comparison for volume of fluid was tested using Wilcoxon Rank Sum test. 
Table 9.8: Study fluids administered in nested cohort. *

Fluid - $\mathrm{mL}$

Plasma-Lyte 148 Group

$0.9 \%$ saline Group

Plasma-Lyte 148 (study fluid) - median [IQR], mean +/- SD, no. / total no. (\%), mL

\begin{tabular}{|c|c|c|}
\hline Day 0 & $\begin{array}{c}1250[540-2000], 1428+/- \\
874,131 / 131(100)\end{array}$ & $0[0-0], 0+/-0,0 / 120(0)$ \\
\hline Day 1 & $\begin{array}{c}500[0-1000], 648+/-799 \\
83 / 130(64)\end{array}$ & $0[0-0], 0+/-0,0 / 117(0)$ \\
\hline Day 2 & $\begin{array}{c}120[0-500], 325+/-347 \\
39 / 71(55)\end{array}$ & $0[0-0], 0+/-0,0 / 50(0)$ \\
\hline Day 3 & $\begin{array}{c}0[0-205], 94+/-153 \\
13 / 37(35)\end{array}$ & $0[0-0], 0+/-0,0 / 23(0)$ \\
\hline Day 4 to 90 & $\begin{array}{c}0[0-125], 116+/-239 \\
6 / 18(33)\end{array}$ & $0[0-0], 0+/-0,0 / 16(0)$ \\
\hline \multicolumn{3}{|c|}{$0.9 \%$ saline (study fluid) - median [IQR], mean +/- SD, no. / total no. (\%), mL } \\
\hline Day 0 & $0[0-0], 0+/-0,0 / 131(0)$ & $\begin{array}{c}1500[1000-2000], 1506+/- \\
929,120 / 120(100)\end{array}$ \\
\hline Day 1 & $0[0-0],<1+/-4,1 / 130(0.8)$ & $\begin{array}{c}500[0-1000], 746+/-989 \\
75 / 117(64)\end{array}$ \\
\hline Day 2 & $0[0-0], 0+/-0,0 / 71(0)$ & $\begin{array}{c}0[0-500], 370+/-581 \\
23 / 50(46)\end{array}$ \\
\hline Day 3 & $0[0-0], 0+/-0,0 / 37(0)$ & $\begin{array}{c}0[0-150], 197+/-443, \\
10 / 23(43)\end{array}$ \\
\hline Day 4 to 90 & $0[0-0], 0+/-0,0 / 18(0)$ & $\begin{array}{c}0[0-0], 257+/-773, \\
3 / 16(19)\end{array}$ \\
\hline
\end{tabular}

*There were no significant $(p<0.05)$ differences between the groups for the volume of study fluid received. Comparison for volume of fluid was tested using Wilcoxon Rank Sum test. 
Table 9.9. Non- Study fluids and blood products administered in overall cohort.*

$\begin{array}{lll}\text { Fluid }-\mathrm{mL} & \text { Plasma-Lyte } 148 & 0.9 \% \text { saline }\end{array}$

\begin{tabular}{|c|c|c|}
\hline \multicolumn{3}{|l|}{ Plasma-Lyte 148 (open label) } \\
\hline $\begin{array}{l}\text { Day } 0 \text { - median [IQR] } \\
\text { no./total no. (\%) }\end{array}$ & $\begin{array}{l}0[0-0] \\
7 / 475(1)\end{array}$ & $\begin{array}{l}0[0-0] \\
9 / 479(2)\end{array}$ \\
\hline $\begin{array}{l}\text { Day } 1 \text { - median [IQR]) } \\
\text { no./total no. (\%) }\end{array}$ & $\begin{array}{l}0[0-0] \\
4 / 471(<1)\end{array}$ & $\begin{array}{l}0[0-0] \\
0 / 472(0)\end{array}$ \\
\hline $\begin{array}{l}\text { Day } 2 \text { - median [IQR]) } \\
\text { no./total no. (\%) }\end{array}$ & $\begin{array}{l}0[0-0] \\
1 / 195(<1)\end{array}$ & $\begin{array}{l}0[0-0] \\
0 / 188(0)\end{array}$ \\
\hline $\begin{array}{l}\text { Day } 3 \text { - median [IQR]) } \\
\text { no./total no. (\%) }\end{array}$ & $\begin{array}{l}0[0-0] \\
2 / 107(2)\end{array}$ & $\begin{array}{l}0[0-0] \\
1 / 95(1)\end{array}$ \\
\hline $\begin{array}{l}\text { Day } 4 \text { to } 90 \text { - median [IQR] } \\
\text { no./total no. (\%) }\end{array}$ & $\begin{array}{l}0[0-0] \\
0 / 65(0)\end{array}$ & $\begin{array}{l}0[0-0] \\
3 / 58(5)\end{array}$ \\
\hline \multicolumn{3}{|l|}{$0.9 \%$ saline (open label) } \\
\hline $\begin{array}{l}\text { Day } 0 \text { - median [IQR] } \\
\text { no./total no. (\%) }\end{array}$ & $\begin{array}{l}0[0-0] \\
2 / 475(<1)\end{array}$ & $\begin{array}{l}0[0-0] \\
13 / 479(3)\end{array}$ \\
\hline $\begin{array}{l}\text { Day } 1 \text { - median [IQR] } \\
\text { no./total no. (\%) }\end{array}$ & $\begin{array}{l}0[0-0] \\
3 / 471(<1)\end{array}$ & $\begin{array}{l}0[0-0] \\
8 / 472(2)\end{array}$ \\
\hline $\begin{array}{l}\text { Day } 2 \text { - median [IQR] } \\
\text { no./total no. (\%) }\end{array}$ & $\begin{array}{l}0[0-0] \\
3 / 195(2)\end{array}$ & $\begin{array}{l}0[0-0] \\
0 / 188(0)\end{array}$ \\
\hline $\begin{array}{l}\text { Day } 3 \text { - median [IQR] } \\
\text { no./total no. (\%) }\end{array}$ & $\begin{array}{l}0[0-0] \\
1 / 107(<1)\end{array}$ & $\begin{array}{l}0[0-0] \\
1 / 95(1)\end{array}$ \\
\hline $\begin{array}{l}\text { Day } 4 \text { to } 90 \text { - median [IQR] } \\
\text { no./total no. (\%) }\end{array}$ & $\begin{array}{l}0[0-0] \\
1 / 65(2)\end{array}$ & $\begin{array}{l}0[0-0] \\
0 / 58(0)\end{array}$ \\
\hline
\end{tabular}

\begin{tabular}{|l|l|l|}
\hline 5\% Dextrose & & \\
\hline $\begin{array}{l}\text { Day 0 - median [IQR] } \\
\text { no./total no. (\%) }\end{array}$ & $0[0-0]$ & $0[0-0]$ \\
\hline $\begin{array}{l}\text { Day 1 - median [IQR] } \\
\text { no./total no. (\%) }\end{array}$ & $87 / 475(18)$ & $89 / 479(19)$ \\
\hline $\begin{array}{l}\text { Day 2 - median [IQR] } \\
\text { no./total no. (\%) }\end{array}$ & $0[0-0]$ & $0[0-0]$ \\
\hline & $84 / 471(18)$ & $81 / 472(17)$ \\
\hline & $0[0-0]$ & $0[0-0]$ \\
\hline
\end{tabular}




\begin{tabular}{|c|c|c|}
\hline $\begin{array}{l}\text { Day } 3 \text { - median [IQR] } \\
\text { no./total no. (\%) }\end{array}$ & $\begin{array}{l}0[0-0] \\
15 / 107(14)\end{array}$ & $\begin{array}{l}0[0-0] \\
11 / 95(12)\end{array}$ \\
\hline \multicolumn{3}{|l|}{ 4\% Albumin } \\
\hline $\begin{array}{l}\text { Day } 0 \text { - median [IQR] } \\
\text { no./total no. (\%) }\end{array}$ & $\begin{array}{l}0[0-0] \\
105 / 475(22)\end{array}$ & $\begin{array}{l}0[0-0] \\
97 / 479(20)\end{array}$ \\
\hline $\begin{array}{l}\text { Day } 1 \text { - median [IQR] } \\
\text { no./total no. (\%) }\end{array}$ & $\begin{array}{l}0[0-0] \\
45 / 471(10)\end{array}$ & $\begin{array}{l}0[0-0] \\
29 / 472(6)\end{array}$ \\
\hline $\begin{array}{l}\text { Day } 2 \text { - median [IQR] } \\
\text { no./total no. (\%) }\end{array}$ & $\begin{array}{l}0[0-0] \\
10 / 195(5)\end{array}$ & $\begin{array}{l}0[0-0] \\
5 / 188(3)\end{array}$ \\
\hline $\begin{array}{l}\text { Day } 3 \text { - median [IQR] } \\
\text { no./total no. (\%) }\end{array}$ & $\begin{array}{l}0[0-0] \\
4 / 107(4)\end{array}$ & $\begin{array}{l}0 \text { [0-0] } \\
7 / 95(7)\end{array}$ \\
\hline \multicolumn{3}{|l|}{$20 \%$ Albumin } \\
\hline $\begin{array}{l}\text { Day } 0 \text { - median [IQR] } \\
\text { no./total no. (\%) }\end{array}$ & $\begin{array}{l}0[0-0] \\
1 / 475(<1)\end{array}$ & $\begin{array}{l}0[0-0] \\
6 / 479(1)\end{array}$ \\
\hline $\begin{array}{l}\text { Day } 1 \text { - median [IQR] } \\
\text { no./total no. (\%) }\end{array}$ & $\begin{array}{l}0[0-0] \\
8 / 471(2)\end{array}$ & $\begin{array}{l}0[0-0] \\
7 / 472(1)\end{array}$ \\
\hline $\begin{array}{l}\text { Day } 2 \text { - median [IQR] } \\
\text { no./total no. (\%) }\end{array}$ & $\begin{array}{l}0[0-0] \\
1 / 195(<1)\end{array}$ & $\begin{array}{l}0[0-0] \\
4 / 188(2)\end{array}$ \\
\hline $\begin{array}{l}\text { Day } 3 \text { - median [IQR] } \\
\text { no./total no. (\%) }\end{array}$ & $\begin{array}{l}0[0-0] \\
1 / 107(<1)\end{array}$ & $\begin{array}{l}0 \text { [0-0] } \\
1 / 95(1)\end{array}$ \\
\hline \multicolumn{3}{|l|}{ Gelofusine } \\
\hline $\begin{array}{l}\text { Day } 0 \text { - median [IQR] } \\
\text { no./total no. (\%) }\end{array}$ & $\begin{array}{l}0[0-0] \\
0 / 475(0)\end{array}$ & $\begin{array}{l}0[0-0] \\
0 / 479(0)\end{array}$ \\
\hline $\begin{array}{l}\text { Day } 1 \text { - median [IQR] } \\
\text { no./total no. (\%) }\end{array}$ & $\begin{array}{l}0[0-0] \\
0 / 471(0)\end{array}$ & $\begin{array}{l}0[0-0] \\
0 / 472(0)\end{array}$ \\
\hline $\begin{array}{l}\text { Day } 2 \text { - median [IQR] } \\
\text { no./total no. (\%) }\end{array}$ & $\begin{array}{l}0[0-0] \\
0 / 195(0)\end{array}$ & $\begin{array}{l}0[0-0] \\
0 / 188(0)\end{array}$ \\
\hline $\begin{array}{l}\text { Day } 3 \text { - median [IQR] } \\
\text { no./total no. (\%) }\end{array}$ & $\begin{array}{l}0[0-0] \\
0 / 107(0)\end{array}$ & $\begin{array}{l}0[0-0] \\
0 / 95(0)\end{array}$ \\
\hline \multicolumn{3}{|l|}{ Voluven or Volulyte } \\
\hline $\begin{array}{l}\text { Day } 0 \text { - median [IQR] } \\
\text { no./total no. (\%) }\end{array}$ & $\begin{array}{l}0[0-0] \\
0 / 475(0)\end{array}$ & $\begin{array}{l}0[0-0] \\
0 / 479(0)\end{array}$ \\
\hline
\end{tabular}




\begin{tabular}{|c|c|c|}
\hline $\begin{array}{l}\text { Day } 1 \text { - median [IQR] } \\
\text { no./total no. (\%) }\end{array}$ & $\begin{array}{l}0[0-0] \\
0 / 471(0)\end{array}$ & $\begin{array}{l}0[0-0] \\
0 / 472(0)\end{array}$ \\
\hline $\begin{array}{l}\text { Day } 2 \text { - median [IQR] } \\
\text { no./total no. (\%) }\end{array}$ & $\begin{array}{l}0[0-0] \\
0 / 195(0)\end{array}$ & $\begin{array}{l}0[0-0] \\
0 / 188(0)\end{array}$ \\
\hline $\begin{array}{l}\text { Day } 3 \text { - median [IQR] } \\
\text { no./total no. (\%) }\end{array}$ & $\begin{array}{l}0[0-0] \\
0 / 107(0)\end{array}$ & $\begin{array}{l}0[0-0] \\
0 / 95(0)\end{array}$ \\
\hline \multicolumn{3}{|l|}{ Other colloids } \\
\hline $\begin{array}{l}\text { Day } 0 \text { - median [IQR] } \\
\text { no./total no. (\%) }\end{array}$ & $\begin{array}{l}0[0-0] \\
0 / 475(0)\end{array}$ & $\begin{array}{l}0[0-0] \\
0 / 479(0)\end{array}$ \\
\hline $\begin{array}{l}\text { Day } 1 \text { - median [IQR] } \\
\text { no./total no. (\%) }\end{array}$ & $\begin{array}{l}0[0-0] \\
0 / 471(0)\end{array}$ & $\begin{array}{l}0[0-0] \\
1 / 472(<1)\end{array}$ \\
\hline $\begin{array}{l}\text { Day } 2 \text { - median [IQR] } \\
\text { no./total no. (\%) }\end{array}$ & $\begin{array}{l}0[0-0] \\
0 / 195(0)\end{array}$ & $\begin{array}{l}0[0-0] \\
0 / 188(0)\end{array}$ \\
\hline $\begin{array}{l}\text { Day } 3 \text { - median [IQR] } \\
\text { no./total no. (\%) }\end{array}$ & $\begin{array}{l}0[0-0] \\
0 / 107(0)\end{array}$ & $\begin{array}{l}0[0-0] \\
0 / 95(0)\end{array}$ \\
\hline \multicolumn{3}{|l|}{ Packed red blood cells } \\
\hline $\begin{array}{l}\text { Day } 0 \text { - median [IQR] } \\
\text { no./total no. (\%) }\end{array}$ & $\begin{array}{l}0[0-0] \\
60 / 475(13)\end{array}$ & $\begin{array}{l}0[0-0] \\
42 / 479(9)\end{array}$ \\
\hline $\begin{array}{l}\text { Day } 1 \text { - median [IQR] } \\
\text { no./total no. (\%) }\end{array}$ & $\begin{array}{l}0[0-0] \\
47 / 471(10)\end{array}$ & $\begin{array}{l}0[0-0] \\
31 / 472(7)\end{array}$ \\
\hline $\begin{array}{l}\text { Day } 2 \text { - median [IQR] } \\
\text { no./total no. (\%) }\end{array}$ & $\begin{array}{l}0[0-0] \\
27 / 195(14)\end{array}$ & $\begin{array}{l}0[0-0] \\
24 / 188(13)\end{array}$ \\
\hline $\begin{array}{l}\text { Day } 3 \text { - median [IQR] } \\
\text { no./total no. (\%) }\end{array}$ & $\begin{array}{l}0[0-0] \\
14 / 107(13)\end{array}$ & $\begin{array}{l}0[0-0] \\
14 / 95(15)\end{array}$ \\
\hline \multicolumn{3}{|l|}{ Fresh frozen plasma } \\
\hline $\begin{array}{l}\text { Day } 0 \text { - median [IQR] } \\
\text { no./total no. (\%) }\end{array}$ & $\begin{array}{l}0[0-0] \\
39 / 475(8)\end{array}$ & $\begin{array}{l}0[0-0] \\
25 / 479(5)\end{array}$ \\
\hline $\begin{array}{l}\text { Day } 1 \text { - median [IQR] } \\
\text { no./total no. (\%) }\end{array}$ & $\begin{array}{l}0[0-0] \\
5 / 471(1)\end{array}$ & $\begin{array}{l}0[0-0] \\
3 / 472(<1)\end{array}$ \\
\hline $\begin{array}{l}\text { Day } 2 \text { - median [IQR] } \\
\text { no./total no. (\%) }\end{array}$ & $\begin{array}{l}0[0-0] \\
2 / 195(1)\end{array}$ & $\begin{array}{l}0[0-0] \\
1 / 188(<1)\end{array}$ \\
\hline Day 3 - median [IQR] & $0[0-0]$ & $0[0-0]$ \\
\hline
\end{tabular}


no./total no. (\%)

$0 / 107(0)$

$2 / 95(2)$

Platelets

\begin{tabular}{|c|c|c|}
\hline $\begin{array}{l}\text { Day } 0 \text { - median [IQR] } \\
\text { no./total no. (\%) }\end{array}$ & $\begin{array}{l}0[0-0] \\
46 / 475(10)\end{array}$ & $\begin{array}{l}0[0-0] \\
29 / 479(6)\end{array}$ \\
\hline $\begin{array}{l}\text { Day } 1 \text { - median [IQR] } \\
\text { no./total no. (\%) }\end{array}$ & $\begin{array}{l}0[0-0] \\
3 / 471(<1)\end{array}$ & $\begin{array}{l}0[0-0] \\
2 / 472(<1)\end{array}$ \\
\hline $\begin{array}{l}\text { Day } 2 \text { - median [IQR] } \\
\text { no./total no. (\%) }\end{array}$ & $\begin{array}{l}0[0-0] \\
5 / 195(3)\end{array}$ & $\begin{array}{l}0[0-0] \\
6 / 188(3)\end{array}$ \\
\hline $\begin{array}{l}\text { Day } 3 \text { - median [IQR] } \\
\text { no./total no. (\%) }\end{array}$ & $\begin{array}{l}0[0-0] \\
4 / 107(4)\end{array}$ & $\begin{array}{l}0[0-0] \\
6 / 95(6)\end{array}$ \\
\hline \multicolumn{3}{|l|}{ Cryoprecipitate } \\
\hline $\begin{array}{l}\text { Day } 0 \text { - median [IQR] } \\
\text { no./total no. }(\%)\end{array}$ & $\begin{array}{l}0[0-0] \\
19 / 475(4)\end{array}$ & $\begin{array}{l}0[0-0] \\
11 / 479(2)\end{array}$ \\
\hline $\begin{array}{l}\text { Day } 1 \text { - median [IQR] } \\
\text { no./total no. (\%) }\end{array}$ & $\begin{array}{l}0[0-0] \\
1 / 471(<1)\end{array}$ & $\begin{array}{l}0[0-0] \\
1 / 472(<1)\end{array}$ \\
\hline $\begin{array}{l}\text { Day } 2 \text { - median [IQR] } \\
\text { no./total no. (\%) }\end{array}$ & $\begin{array}{l}0[0-0] \\
0 / 195(0)\end{array}$ & $\begin{array}{l}0[0-0] \\
0 / 188(0)\end{array}$ \\
\hline $\begin{array}{l}\text { Day } 3 \text { - median [IQR] } \\
\text { no./total no. (\%) }\end{array}$ & $\begin{array}{l}0[0-0] \\
0 / 107(0)\end{array}$ & $\begin{array}{l}0[0-0] \\
1 / 95(1)\end{array}$ \\
\hline
\end{tabular}

* Greater volumes of day 0 packed red blood cells $(P=0.04)$, day 0 platelets $(P=0.04)$, day 1 open label Plasma-Lyte $148(P=0.05)$ and day 1 other crystalloids $(P=0.05)$ were administered in the Plasma-Lyte 148 group. Greater volumes of day 0 saline $(P=0.004)$ were administered in the saline group.

There were no other significant $(p<0.05)$ between group differences in non-study fluid or blood products received per day. Comparison for volume of fluid was tested using Wilcoxon Rank Sum test. 
Table 9.10. Non- Study fluids and blood products administered to nested cohort

\begin{tabular}{|c|c|c|}
\hline Fluid - $\mathrm{mL}$ & Plasma-Lyte 148 & $0.9 \%$ saline \\
\hline \multicolumn{3}{|l|}{ Plasma-Lyte 148 (open label) } \\
\hline Day 0 - median [IQR] & $0[0-0]$ & $0[0-0]$ \\
\hline no./total no. (\%) & $1 / 131(1)$ & $2 / 120(2)$ \\
\hline Day 1 - median [IQR]) & $0[0-0]$ & $0[0-0]$ \\
\hline no./total no. (\%) & $0 / 130(0)$ & $0 / 117(0)$ \\
\hline Day 2 - median [IQR]) & $0[0-0]$ & $0[0-0]$ \\
\hline no./total no. (\%) & $0 / 71(0)$ & $0 / 50(0)$ \\
\hline Day 3 - median [IQR]) & $0[0-0]$ & $0[0-0]$ \\
\hline no./total no. (\%) & $0 / 37(0)$ & $0 / 23(0)$ \\
\hline Day 4 to 90 - median [IQR] & $0[0-0]$ & $0[0-0]$ \\
\hline no./total no. (\%) & $0 / 18(0)$ & $0 / 16(0)$ \\
\hline \multicolumn{3}{|l|}{$0.9 \%$ saline (open label) } \\
\hline Day 0 - median [IQR] & $0[0-0]$ & $0[0-0]$ \\
\hline no./total no. (\%) & $0 / 131(0)$ & $4 / 120(3)$ \\
\hline Day 1 - median [IQR] & $0[0-0]$ & $0[0-0]$ \\
\hline no./total no. (\%) & $1 / 130(1)$ & $1 / 117(1)$ \\
\hline Day 2 - median [IQR] & $0[0-0]$ & $0[0-0]$ \\
\hline no./total no. (\%) & $1 / 71(1)$ & $0 / 50(0)$ \\
\hline Day 3 - median [IQR] & $0[0-0]$ & $0[0-0]$ \\
\hline no./total no. (\%) & $0 / 37(0)$ & $0 / 23(0)$ \\
\hline Day 4 to 90 - median [IQR] & $0[0-0]$ & $0[0-0]$ \\
\hline no./total no. (\%) & $0 / 18(0)$ & $0 / 16(0)$ \\
\hline \multicolumn{3}{|l|}{ 5\% Dextrose } \\
\hline Day 0 - median [IQR] & $320[70-570]$ & $298[58-538]$ \\
\hline no./total no. (\%) & $87 / 131(66)$ & $84 / 120(70)$ \\
\hline Day 1 - median [IQR] & $170[0-658]$ & $460[0-910]$ \\
\hline no./total no. (\%) & $84 / 130(65)$ & 74/117 (63) \\
\hline Day 2 - median [IQR] & $70[0-215]$ & $140.0[0-300]$ \\
\hline
\end{tabular}




\begin{tabular}{|c|c|c|}
\hline no./total no. (\%) & $41 / 71(58)$ & $31 / 50(62)$ \\
\hline Day 3 - median [IQR] & $0[0-60]$ & $140[0-300]$ \\
\hline no./total no. (\%) & $15 / 37(41)$ & $8 / 23(35)$ \\
\hline \multicolumn{3}{|l|}{$4 \%$ Albumin } \\
\hline Day 0 - median [IQR] & $0[0-0]$ & $0[0-0]$ \\
\hline no./total no. (\%) & $1 / 131(1)$ & $1 / 120(1)$ \\
\hline Day 1 - median [IQR] & $0[0-0]$ & $0[0-0]$ \\
\hline no./total no. (\%) & $0 / 130(0)$ & $0 / 117(0)$ \\
\hline Day 2 - median [IQR] & $0[0-0]$ & $0[0-0]$ \\
\hline no./total no. (\%) & $0 / 71(0)$ & $0 / 50(0)$ \\
\hline Day 3 - median [IQR] & $0[0-0]$ & $0[0-0]$ \\
\hline no./total no. (\%) & $0 / 37(0)$ & $0 / 23(0)$ \\
\hline \multicolumn{3}{|l|}{$20 \%$ Albumin } \\
\hline Day 0 - median [IQR] & $0[0-0]$ & $0[0-0]$ \\
\hline no./total no. (\%) & $1 / 131(1)$ & $3 / 120(4)$ \\
\hline Day 1 - median [IQR] & $0[0-0]$ & $0[0-0]$ \\
\hline no./total no. (\%) & $5 / 130(4)$ & $4 / 117(3.4)$ \\
\hline Day 2 - median [IQR] & $0[0-0]$ & $0[0-0]$ \\
\hline no./total no. (\%) & $0 / 71(0)$ & $0 / 50(0)$ \\
\hline Day 3 - median [IQR] & $0[0-0]$ & $0[0-0]$ \\
\hline no./total no. (\%) & $0 / 37(0)$ & $0 / 23(0)$ \\
\hline \multicolumn{3}{|l|}{ Gelofusine } \\
\hline Day 0 - median [IQR] & $0[0-0]$ & $0[0-0]$ \\
\hline no./total no. (\%) & $0 / 131(0)$ & $0 / 120(0)$ \\
\hline Day 1 - median [IQR] & $0[0-0]$ & $0[0-0]$ \\
\hline no./total no. (\%) & $0 / 130(0)$ & $0 / 117(0)$ \\
\hline Day 2 - median [IQR] & $0[0-0]$ & $0[0-0]$ \\
\hline no./total no. (\%) & $0 / 71(0)$ & $0 / 50(0)$ \\
\hline Day 3 - median [IQR] & $0[0-0]$ & $0[0-0]$ \\
\hline no./total no. (\%) & $0 / 37(0)$ & $0 / 23(0)$ \\
\hline
\end{tabular}




\begin{tabular}{|c|c|c|}
\hline \multicolumn{3}{|l|}{ Voluven or Volulyte } \\
\hline Day 0 - median [IQR] & $0[0-0]$ & $0[0-0]$ \\
\hline no./total no. (\%) & $0 / 131(0)$ & $0 / 120(0)$ \\
\hline Day 1 - median [IQR] & $0[0-0]$ & $0[0-0]$ \\
\hline no./total no. (\%) & $0 / 130(0)$ & $0 / 117(0)$ \\
\hline Day 2 - median [IQR] & $0[0-0]$ & $0[0-0]$ \\
\hline no./total no. (\%) & 0/71 (0) & $0 / 50(0)$ \\
\hline Day 3 - median [IQR] & $0(0)$ & $0(0)$ \\
\hline no./total no. (\%) & $0 / 37(0)$ & $0 / 23(0)$ \\
\hline \multicolumn{3}{|l|}{ Other colloids } \\
\hline Day 0 - median [IQR] & $0[0-0]$ & $0[0-0]$ \\
\hline no./total no. (\%) & $0 / 131(0)$ & $0 / 120(0)$ \\
\hline Day 1 - median [IQR] & $0[0-0]$ & $0[0-0]$ \\
\hline no./total no. (\%) & $0 / 130(0)$ & $0 / 117(0)$ \\
\hline Day 2 - median [IQR] & $0[0-0]$ & $0[0-0]$ \\
\hline no./total no. (\%) & $0 / 71(0)$ & $0 / 50(0)$ \\
\hline Day 3 - median [IQR] & $0[0-0]$ & $0[0-0]$ \\
\hline no./total no. (\%) & $0 / 37(0)$ & $0 / 23(0)$ \\
\hline \multicolumn{3}{|l|}{ Packed red blood cells } \\
\hline Day 0 - median [IQR] & $0[0-0]$ & $0[0-0]$ \\
\hline no./total no. (\%) & 13/131 (10) & $7 / 120(6)$ \\
\hline Day 1 - median [IQR] & $0[0-0]$ & $0[0-0]$ \\
\hline no./total no. (\%) & $10 / 130(8)$ & $6 / 117(5)$ \\
\hline Day 2 - median [IQR] & $0[0-0]$ & $0[0-0]$ \\
\hline no./total no. (\%) & $7 / 71(10)$ & $3 / 50(6)$ \\
\hline Day 3 - median [IQR] & $0[0-0]$ & $0[0-0]$ \\
\hline no./total no. (\%) & $5 / 37(14)$ & $2 / 23(9)$ \\
\hline Day 4 to 90 - median [IQR] & $0[0-0]$ & $0[0-0]$ \\
\hline no./total no. (\%) & $2 / 18(11)$ & $2 / 16(13)$ \\
\hline
\end{tabular}




\begin{tabular}{|c|c|c|}
\hline Day 0 - median [IQR] & $0[0-0]$ & $0[0-0]$ \\
\hline no./total no. (\%) & $15 / 131(11)$ & $7 / 120(6)$ \\
\hline Day 1 - median [IQR] & $0[0-0]$ & $0[0-0]$ \\
\hline no./total no. (\%) & $3 / 130(2)$ & $2 / 117(2)$ \\
\hline Day 2 - median [IQR] & $0[0-0]$ & $0[0-0]$ \\
\hline no./total no. (\%) & 2/71 (3) & $0 / 50(0)$ \\
\hline Day 3 - median [IQR] & $0[0-0]$ & $0[0-0]$ \\
\hline no./total no. (\%) & $0 / 37(0)$ & $0 / 23(0)$ \\
\hline Day 4 to 90 - median [IQR] & $0[0-0]$ & $0[0-0]$ \\
\hline no./total no. (\%) & $0 / 18(0)$ & $0 / 16(0)$ \\
\hline \multicolumn{3}{|l|}{ Platelets } \\
\hline Day 0 - median [IQR] & $0[0-0]$ & $0[0-0]$ \\
\hline no./total no. (\%) & 23/131 (18) & $11 / 120(9)$ \\
\hline Day 1 - median [IQR] & $0[0-0]$ & $0(0)$ \\
\hline no./total no. (\%) & $1 / 130(1)$ & $0 / 117(0)$ \\
\hline Day 2 - median [IQR] & $0[0-0]$ & $0[0-0]$ \\
\hline no./total no. (\%) & $0 / 71(0)$ & $0 / 50(0)$ \\
\hline Day 3 - median [IQR] & $0[0-0]$ & $0[0-0]$ \\
\hline no./total no. (\%) & $0 / 37(0)$ & $0 / 23(0)$ \\
\hline Day 4 to 90 - median [IQR] & $0[0-0]$ & $0[0-0]$ \\
\hline no./total no. (\%) & $0 / 18(0)$ & $0 / 16(0)$ \\
\hline \multicolumn{3}{|l|}{ Cryoprecipitate } \\
\hline Day 0 - median [IQR] & $0[0-0]$ & $0[0-0]$ \\
\hline no./total no. (\%) & $13 / 131(10)$ & $10 / 120(12)$ \\
\hline Day 1 - median [IQR] & $0[0-0]$ & $0[0-0]$ \\
\hline no./total no. (\%) & $0 / 130(0)$ & $1 / 117(1)$ \\
\hline Day 2 - median [IQR] & $0[0-0]$ & $0[0-0]$ \\
\hline no./total no. (\%) & $0 / 71(0)$ & $0 / 50(0)$ \\
\hline Day 3 - median [IQR] & $0[0-0]$ & $0[0-0]$ \\
\hline no./total no. (\%) & $0 / 37(0)$ & $0 / 23(0)$ \\
\hline
\end{tabular}


Day 4 to 90 - median [IQR]

$0[0-0]$

$0[0-0]$

no./total no. (\%)

$0 / 18(0)$

$0 / 16(0)$

*There were no significant $(p<0.05)$ differences in between the groups for the volume of non-study fluid received except for day 0 saline $(p=0.04)$. Comparison for volume of fluid was tested using Wilcoxon Rank Sum test.

\subsubsection{Primary outcome variable-overall cohort: the proportion} of patients receiving blood products

128 of 475 patients [26.9\%] in the Plasma-Lyte 148 group received blood or a blood product compared with 94 of 479 [19.6\%] patients in the 0.9\% saline group (OR [95\% Cl], 1.51 [1.112.05], $p=0.008$ ) (Table 9.11). This result remained significant after multivariable sensitivity analysis.

Table 9.11. Outcomes for overall cohort.

\begin{tabular}{|c|c|c|c|c|c|c|}
\hline Outcome & $\begin{array}{l}\text { Plasma- } \\
\text { Lyte } 148 \\
(n=475)\end{array}$ & $\begin{array}{c}0.9 \% \\
\text { saline } \\
(n=479)\end{array}$ & $\begin{array}{l}\text { Unadjusted } \\
\text { Odds ratio } \\
(95 \% \mathrm{Cl})\end{array}$ & P-value & $\begin{array}{l}\text { Adjusted } \\
\text { Odds } \\
\text { ratio } \\
(95 \% \mathrm{Cl}) \\
+\end{array}$ & $\begin{array}{l}\text { Adjusted } \\
\text { P-value }\end{array}$ \\
\hline \multicolumn{7}{|l|}{ Blood transfusion requirements* } \\
\hline $\begin{array}{l}\text { - Total proportion of patient } \\
\text { requiring blood products in } \\
\text { ICU, no./total no. (\%) }\end{array}$ & $\begin{array}{c}128 / 475 \\
(26.9)\end{array}$ & $\begin{array}{c}94 / 479 \\
(19.6)\end{array}$ & $\begin{array}{c}1.51 \\
(1.11,2.05)\end{array}$ & 0.008 & $\begin{array}{r}1.63 \\
(1.18 \\
2.23)\end{array}$ & 0.003 \\
\hline $\begin{array}{l}\text { Proportion of patients } \\
\text { requiring PRBC in ICU, } \\
\text { no./total no. (\%) }\end{array}$ & $\begin{array}{c}105 / 475 \\
(22.1)\end{array}$ & $\begin{array}{c}73 / 479 \\
(15.2)\end{array}$ & $\begin{array}{c}1.58 \\
(1.13,2.20)\end{array}$ & 0.007 & $\begin{array}{r}1.74 \\
(1.22 \\
2.46)\end{array}$ & 0.002 \\
\hline $\begin{array}{l}\text { Proportion of patients } \\
\text { requiring FFP in ICU, } \\
\text { no./total no. (\%) }\end{array}$ & $\begin{array}{c}46 / 475 \\
(9.7)\end{array}$ & $\begin{array}{c}32 / 479 \\
(6.7)\end{array}$ & $\begin{array}{c}1.50 \\
(0.94,2.40)\end{array}$ & 0.09 & $\begin{array}{l}1.56 \\
(0.96 \\
2.54)\end{array}$ & 0.07 \\
\hline $\begin{array}{l}\text { Proportion of patients } \\
\text { requiring platelets in ICU, } \\
\text { no./total no. (\%) }\end{array}$ & $\begin{array}{l}51 / 475 \\
(10.7)\end{array}$ & $\begin{array}{c}35 / 479 \\
(7.3)\end{array}$ & $\begin{array}{c}1.53 \\
(0.97,2.39)\end{array}$ & 0.07 & $\begin{array}{l}1.57 \\
(0.98 \\
2.50)\end{array}$ & 0.06 \\
\hline $\begin{array}{l}\text { - Proportion of patients } \\
\text { requiring cryoprecipitate in } \\
\text { ICU, no./total no. (\%) }\end{array}$ & $\begin{array}{l}19 / 475 \\
(4.0)\end{array}$ & $\begin{array}{c}13 / 479 \\
(2.7)\end{array}$ & $\begin{array}{c}1.49 \\
(0.73,3.06)\end{array}$ & 0.27 & $\begin{array}{c}1.33 \\
(0.63 \\
2.82)\end{array}$ & 0.46 \\
\hline $\begin{array}{l}\text { - Volume of PRBC } \\
\text { administered in ICU, mean } \\
\text { +/- standard deviation, } \\
\text { median [IQR], mL§. }\end{array}$ & $\begin{array}{c}78+/-216 \\
0[0-0]\end{array}$ & $\begin{array}{l}66+/- \\
311,0[0- \\
\quad 0]\end{array}$ & & 0.04 & & \\
\hline $\begin{array}{l}\text { - Volume of FFP administered } \\
\text { in ICU, mean +/- standard } \\
\text { deviation, median [IQR], } \\
\text { mL§. }\end{array}$ & $\begin{array}{c}47+/-198 \\
0[0-0]\end{array}$ & $\begin{array}{l}28+/- \\
148,0[0- \\
0]\end{array}$ & & 0.04 & & \\
\hline $\begin{array}{l}\text { Volume of platelets } \\
\text { administered in ICU - mean }\end{array}$ & $\begin{array}{c}45+/-145 \\
0[0-0]\end{array}$ & $\begin{array}{c}34+/- \\
170,0[0-\end{array}$ & & 0.03 & & \\
\hline
\end{tabular}




\begin{tabular}{|c|c|c|c|c|}
\hline $\begin{array}{l}\text { +/- standard deviation, } \\
\text { median [IQR], mL§. }\end{array}$ & & 0] & & \\
\hline $\begin{array}{l}\text { Volume of cryoprecipitate } \\
\text { administered in ICU - mean } \\
\text { +/- standard deviation, } \\
\text { median [IQR], mL§. }\end{array}$ & $\begin{array}{c}8+/-53 \\
0[0-0]\end{array}$ & $\begin{array}{c}5+/-37 \\
0[0-0]\end{array}$ & & 0.13 \\
\hline \multicolumn{5}{|l|}{ Service utilisation } \\
\hline $\begin{array}{l}\text { Duration of Mechanical } \\
\text { ventilation, median [IQR], } \\
\text { hours§. }\end{array}$ & $\begin{array}{c}7.0 \\
{[4.0-15.0]}\end{array}$ & $\begin{array}{c}7.0 \\
4.0-14.0]\end{array}$ & & 0.46 \\
\hline $\begin{array}{l}\text { - ICU readmission, no./total } \\
\text { no. (\%) }\end{array}$ & $\begin{array}{c}25 / 475 \\
(5.3)\end{array}$ & $\begin{array}{c}23 / 479 \\
(4.8)\end{array}$ & $\begin{array}{c}1.10 \\
(0.62,1.97)\end{array}$ & 0.74 \\
\hline $\begin{array}{l}\text { - ICU length of stay, median } \\
\text { [IQR], days }+\dagger, \S .\end{array}$ & $\begin{array}{c}1.0 \\
{[0.8-2.0]}\end{array}$ & $\begin{array}{c}1.0 \\
{[0.8-2.0]}\end{array}$ & & 0.95 \\
\hline $\begin{array}{l}\text { Hospital length of stay, } \\
\text { median [IQR], days }{ }^{\dagger}, \S \text {. }\end{array}$ & $\begin{array}{c}6.4 \\
{[5.2-8.7]}\end{array}$ & $\begin{array}{c}6.7 \\
{[5.2-8.8]}\end{array}$ & & 0.96 \\
\hline \multicolumn{5}{|l|}{ Mortality } \\
\hline $\begin{array}{l}\text { - Death in ICU, no./total no. } \\
\text { (\%) }\end{array}$ & $\begin{array}{c}6 / 475 \\
(1.3)\end{array}$ & $\begin{array}{c}13 / 479 \\
(2.7)\end{array}$ & $\begin{array}{c}2.18 \\
(0.82,5.79)\end{array}$ & 0.12 \\
\hline $\begin{array}{l}\text { - Death in Hospital, no./total } \\
\text { no. (\%) }\end{array}$ & $\begin{array}{c}10 / 475 \\
(2.1)\end{array}$ & $\begin{array}{c}13 / 479 \\
(2.7)\end{array}$ & $\begin{array}{c}1.30 \\
(0.56,2.99)\end{array}$ & 0.54 \\
\hline
\end{tabular}

*Blood transfusion requirement data only collected for ICU calendar day $0,1,2$, and 3 after study enrolment.

† Hierarchical logistic regression was performed adjusting for study site as a fixed variable than gender, age, ethnicity, Acute Physiology and Chronic Health Evaluation (APACHE) II score, volume of $0.9 \%$ saline administered 24 hours prior to randomisation, volume of Voluven or Volulyte administered 24 hours prior to randomisation, volume of other crystalloids saline administered 24 hours prior to randomisation, chronic cardiovascular disease, elective/emergency surgery and isolated coronary artery bypass (CABG) surgery/other than isolated CABG.

+† Days in ICU and days in hospital have been calculated from the time that patients first received study fluid in ICU until ICU and hospital discharge. PRBC packed red blood cells, FFP fresh frozen plasma.

$\S . P-$ Values for comparisons were calculated using the Wilcoxon Rank Sum test.

\subsubsection{Secondary outcome variables: overall cohort}

Allocation to Plasma-Lyte 148 was associated with a significantly increased use of PRBC: 105 of 475 patients [22.1\%] in the Plasma-Lyte 148 group received at least one unit of PRBCs compared with 73 of 479 [15.2\%] in the $0.9 \%$ saline group, OR [95\% Cl] 1.58 [1.13-2.20], $p=0.007)$. This difference remained significant in the multivariable sensitivity analysis adjusting for baseline imbalances (see Table 9.11). Allocation to Plasma-Lyte 148 was associated with significantly increased volumes of PRBC, FFP and platelets compared with allocation to $0.9 \%$ saline (see Table 9.11 ). 


\subsubsection{Primary outcome variable-nested cohort: the chest drain losses at 12 hours}

In the nested cohort there were no between-group differences in chest drain losses at 12 hours (Table 9.12). Chest drain losses between ICU admission and 12 hours post-operative were not available for four patients (3\%) in the $0.9 \%$ saline group. Two patients died and one patient was discharged prior to this endpoint. There was also one patient whose chest drain losses were missing from the clinical records.

Table 9.12. Outcomes for nested cohort.*

\begin{tabular}{|c|c|c|c|c|}
\hline \multirow[t]{2}{*}{ Outcome } & Plasma-Lyte 148 & $0.9 \%$ saline & & P-value \\
\hline & & & \multicolumn{2}{|l|}{$\begin{array}{l}\text { Ratio of geometric } \\
\text { means }(95 \% \mathrm{Cl})\end{array}$} \\
\hline \multicolumn{5}{|c|}{ Chest tube losses - Geometric mean $(95 \% \mathrm{Cl})$ no./total no. (\%) } \\
\hline \multirow{2}{*}{$\begin{array}{l}\text { From time of arrival to } 12 \text { hours } \\
\text { post-operative }\end{array}$} & $566(521-617)$ & $547(496-604)$ & \multirow{2}{*}{$1.04(0.91-1.18)$} & \multirow{2}{*}{0.6} \\
\hline & $131 / 131(100)$ & $116 / 120$ (96.7) & & \\
\hline \multirow{4}{*}{$\begin{array}{l}\text { From time of arrival to } 24 \text { hours } \\
\text { post-operative }\end{array}$} & $905(826-991)$ & $878(790-976)$ & \multirow{2}{*}{$1.03(0.90-1.18)$} & \multirow{2}{*}{0.7} \\
\hline & $82 / 131(62.6)$ & $66 / 120(55.0)$ & & \\
\hline & & \multirow{2}{*}{\multicolumn{3}{|c|}{$\begin{array}{l}\text { Odds ratio } \\
(95 \% \mathrm{Cl})\end{array}$}} \\
\hline & & & & \\
\hline $\begin{array}{l}\text { Proportion of patient requiring } \\
\text { blood products post-operatively } \\
\text { in ICU - no./total no. (\%) }\end{array}$ & $40 / 131(30.5)$ & $22 / 120(18.3)$ & $1.96(1.08-3.54)$ & 0.03 \\
\hline $\begin{array}{l}\text { Proportion of patients } \\
\text { requiring PRBC post- } \\
\text { operatively in ICU }\end{array}$ & 28/131 (21.4) & $15 / 120(12.5)$ & $1.90(0.96-3.77)$ & 0.07 \\
\hline $\begin{array}{l}\text { Proportion of patients } \\
\text { requiring FFP post- } \\
\text { operatively in ICU }\end{array}$ & $18 / 131(13.7)$ & $9 / 120(7.5)$ & $1.97(0.85-4.56)$ & 0.12 \\
\hline $\begin{array}{l}\text { Proportion of patients } \\
\text { requiring platelets post- } \\
\text { operatively in ICU }\end{array}$ & 23/131 (17.6) & $11 / 120(9.2)$ & $2.11(0.98-4.54)$ & 0.06 \\
\hline $\begin{array}{l}\text { Proportion of patients } \\
\text { requiring } \\
\text { cryoprecipitate post- } \\
\text { operatively in ICU }\end{array}$ & $13 / 131(9.9)$ & $11 / 120(9.2)$ & $1.09(0.47-2.54)$ & 0.84 \\
\hline $\begin{array}{l}\text { Composite outcome of } \\
\text { proportion of patients } \\
\text { developing a major post- } \\
\text { operative complication - } \\
\text { no./total no. (\%) }\end{array}$ & $8 / 131(6.1)$ & $8 / 120(6.7)$ & $0.91(0.33-2.51)$ & 0.86 \\
\hline $\begin{array}{l}\text { - Proportion of patients } \\
\text { developing a myocardial }\end{array}$ & $1 / 131(0.8)$ & $1 / 120(0.8)$ & $0.92(0.06-14.80)$ & 0.95 \\
\hline
\end{tabular}




\begin{tabular}{|c|c|c|c|c|}
\hline $\begin{array}{l}\text { Proportion of patients } \\
\text { developing a renal } \\
\text { failure requiring dialysis }\end{array}$ & $2 / 131$ (1.5) & $1 / 120(0.8)$ & $\begin{array}{c}1.85 \\
(0.17-20.61)\end{array}$ & 0.62 \\
\hline $\begin{array}{l}\text { Proportion of patients } \\
\text { developing a new focal } \\
\text { neurological deficit }\end{array}$ & $6 / 131(4.6)$ & $3 / 120(2.5)$ & $1.87(0.46-7.66)$ & 0.38 \\
\hline $\begin{array}{l}\text { Proportion of patients } \\
\text { dying during hospital } \\
\text { admission (all causes) }\end{array}$ & $2 / 131(1.5)$ & $3 / 120(2.5)$ & $0.61(0.10-3.68)$ & 0.59 \\
\hline $\begin{array}{l}\text { Proportion of patient returning } \\
\text { to theatre for bleeding - no./total } \\
\text { no. (\%) }\end{array}$ & 4/131 (3.1) & $5 / 120(4.2)$ & $0.72(0.19-2.76)$ & 0.64 \\
\hline $\begin{array}{l}\text { Time until free from inotropes } \\
\text { (hours) }+\end{array}$ & $17.0[4.9-29.2]$ & $17.3[6.4-28.9]$ & & 0.68 \\
\hline $\begin{array}{l}\text { Duration of mechanical } \\
\text { ventilation (hours) - median } \\
{[I Q R]^{\dagger}}\end{array}$ & $6.0[1.0-11.0]$ & $5.0[1.0-9.0]$ & & 0.48 \\
\hline $\begin{array}{l}\text { Length of ICU stay (days) †,††- } \\
\text { median [IQR] }\end{array}$ & $1.8[0.8-2.8]$ & $1.2[0.7-1.7]$ & & 0.06 \\
\hline $\begin{array}{l}\text { Length of hospital stay (days) } \\
\dagger,+\dagger \text { - median [IQR] }\end{array}$ & $6.4[5.4-7.5]$ & $6.0[5.0-7.0]$ & & 0.04 \\
\hline
\end{tabular}

+ P-Values for comparisons were calculated using the Wilcoxon Rank Sum test.

†† Days in ICU and days in hospital have been calculated from the time that patients first received study fluid in ICU until ICU and hospital discharge. PRBC packed red blood cells, FFP fresh frozen plasma.

\subsubsection{Secondary outcome variables: nested cohort}

In the Plasma-Lyte 148 group, 40 of 131 patients (30.5\%) required blood or a blood product in ICU compared with 22 of 120 patients (18.3\%) in the 0.9\% saline group (OR [95\% CI] 1.96 [1.08-3.54], $p=0.03)$. This result remained significant after multivariable sensitivity analysis (Table 9.13).

Allocation to Plasma-Lyte 148 was associated with a significantly increased hospital length of stay compared to allocation to saline in the nested cohort (median [IQR], 6.4 days [5.4-7.5 days] for the Plasma-Lyte 148 group vs. 6.0 days [5.0-7.0] for 0.9\% saline group; $p=0.04$ ); however, this difference was not evident in the larger overall cohort (median [IQR], 6.4 days [5.2-8.7 days] for the Plasma-Lyte 148 group vs. 6.7 days [5.2- 8.8 days] for $0.9 \%$ saline group; $p=0.96)$. In the nested cohort there was a significant between-group difference in the highest INR on the day of ICU admission (median [IQR], 1.4 [1.3-1.5] in the Plasma-Lyte 148 group vs. 1.3 [1.3-1.4] in the $0.9 \%$ saline group; $p=0.04$ ) and in the proportion of patients with an INR> 1.5 on the day of study ICU admission (11 of 58 patients (19\%) in the Plasma- 
Lyte 148 group vs. 2 of 50 patients $(4 \%)$ in the $0.9 \%$ saline group, OR $[95 \% \mathrm{Cl}] 5.62$ [1.1826.70]; $p=0.03$ ) (see Table 9.14). There were no other significant between-group differences in other secondary outcome measures (Table 9.12 and Table 9.15). 
Table 9.13. Unadjusted and adjusted analysis of the key secondary outcomes for nested cohort.* $^{*}$

\begin{tabular}{|c|c|c|c|c|c|c|}
\hline Outcome & $\begin{array}{l}\text { Plasma- } \\
\text { Lyte } 148\end{array}$ & $\begin{array}{c}0.9 \% \\
\text { saline }\end{array}$ & $\begin{array}{c}\text { Unadjusted } \\
\text { Odds ratio } \\
(95 \% \mathrm{Cl})\end{array}$ & $\begin{array}{c}\text { P- } \\
\text { value }\end{array}$ & $\begin{array}{l}\text { Adjusted* } \\
\text { Odds ratio } \\
(95 \% \mathrm{Cl})\end{array}$ & $\begin{array}{c}\text { Adjusted* } \\
\text { P-value }\end{array}$ \\
\hline $\begin{array}{l}\text { Proportion of patient } \\
\text { requiring blood } \\
\text { products post- } \\
\text { operatively in ICU - } \\
\text { no./total no. (\%) }\end{array}$ & $\begin{array}{c}40 / 131 \\
(30.5)\end{array}$ & $\begin{array}{c}22 / 120 \\
(18.3)\end{array}$ & $\begin{array}{c}1.96 \\
(1.08-3.54)\end{array}$ & 0.03 & $\begin{array}{c}2.41 \\
(1.22-4.77)\end{array}$ & 0.01 \\
\hline \begin{tabular}{l}
\multicolumn{1}{c}{ Proportion of } \\
patients requiring PRBC \\
post-operatively in ICU
\end{tabular} & $\begin{array}{c}28 / 131 \\
(21.4)\end{array}$ & $\begin{array}{c}15 / 120 \\
(12.5)\end{array}$ & $\begin{array}{c}1.90 \\
(0.96-3.77)\end{array}$ & 0.07 & $\begin{array}{c}2.34 \\
(1.05-5.24)\end{array}$ & 0.04 \\
\hline \begin{tabular}{l}
\multicolumn{1}{c}{ Proportion of } \\
patients requiring FFP \\
post-operatively in ICU
\end{tabular} & $\begin{array}{c}18 / 131 \\
(13.7)\end{array}$ & $\begin{array}{c}9 / 120 \\
(7.5)\end{array}$ & $\begin{array}{c}1.97 \\
(0.85-4.56)\end{array}$ & 0.12 & $\begin{array}{c}2.05 \\
(0.08-5.25)\end{array}$ & 0.13 \\
\hline $\begin{array}{l}\quad \text { Proportion of } \\
\text { patients requiring } \\
\text { platelets post- } \\
\text { operatively in ICU }\end{array}$ & $\begin{array}{c}23 / 131 \\
(17.6)\end{array}$ & $\begin{array}{c}11 / 120 \\
(9.2)\end{array}$ & $\begin{array}{c}2.11 \\
(0.98-4.54)\end{array}$ & 0.06 & $\begin{array}{c}2.22 \\
(0.96-5.12)\end{array}$ & 0.06 \\
\hline $\begin{array}{l}\quad \text { Proportion of } \\
\text { patients requiring } \\
\text { cryoprecipitate post- } \\
\text { operatively in ICU }\end{array}$ & $\begin{array}{c}13 / 131 \\
(9.9)\end{array}$ & $\begin{array}{c}11 / 120 \\
(9.2)\end{array}$ & $\begin{array}{c}1.09 \\
(0.47-2.54)\end{array}$ & 0.84 & $\begin{array}{c}0.96 \\
(0.38-2.42)\end{array}$ & 0.92 \\
\hline
\end{tabular}

* Adjusted analyses performed using logistic regression. Variables included were gender, age, Acute Physiology and Chronic Health Evaluation (APACHE) II score, European System for Cardiac Operative Risk Evaluation (euroSCORE) II, Clopidogrel within 5 days, extracorporeal circulation time and preoperative haemoglobin. 
Table 9.14. Post-operative INR and proportion of patients with haemoglobin $<80 \mathrm{~g} / \mathrm{L}$ in nested cohort study.

\begin{tabular}{|c|c|c|c|c|}
\hline & Plasma-Lyte 148 & $0.9 \%$ saline & & P-value \\
\hline \multirow[t]{2}{*}{$\begin{array}{l}\text { Highest INR after enrolment on ICU } \\
\text { day of admission- median [IQR], no. } \\
\text { available observations / total no. (\%) } \\
+\end{array}$} & $\begin{array}{c}1.4[1.3-1.5] \\
58 / 131(44)\end{array}$ & $\begin{array}{c}1.3[1.3-1.4] \\
50 / 120(42)\end{array}$ & & 0.04 \\
\hline & & & $\begin{array}{l}\text { Odds } \\
\text { ratio } \\
{[95 \% \mathrm{Cl}]}\end{array}$ & \\
\hline $\begin{array}{l}\text { Proportion of patients with INR>1.5 } \\
\text { after enrolment on ICU day of } \\
\text { admission- no. / total no. (\%) }\end{array}$ & $11 / 58(19)$ & $2 / 50(4.0)$ & $\begin{array}{l}5.62 \\
(1.18- \\
26.7)\end{array}$ & 0.03 \\
\hline $\begin{array}{l}\text { Proportion of patients with } \mathrm{Hb}<80 \\
\text { during first three ICU days- no. / } \\
\text { total no. (\%), }\end{array}$ & $31 / 131$ (23.7) & $21 / 120$ (17.5) & $\begin{array}{l}1.46 \\
(0.79- \\
2.72)\end{array}$ & 0.23 \\
\hline
\end{tabular}

Table 9.15. Post-operative fluid balance and lowest haemoglobin in nested cohort.

\begin{tabular}{|c|c|c|c|c|}
\hline Outcome & Plasma-Lyte 148 & $0.9 \%$ saline & & P-value \\
\hline \multicolumn{5}{|l|}{$\begin{array}{l}\text { Fluid balance }(\mathrm{mL}) \text { - } \\
\text { median [IQR] }\end{array}$} \\
\hline - ICU chart day 0 & 821 [75 - 1568] & $889[218-1560]$ & & 0.90 \\
\hline - ICU chart day 1 & $655[-12-1322]$ & 874 [200- 1548] & & 0.33 \\
\hline - ICU chart day 2 & $190[-262-642]$ & $131[-376-638]$ & & 0.94 \\
\hline \multicolumn{2}{|c|}{ Lowest haemoglobin $(\mathrm{g} / \mathrm{L})$-mean $\pm \mathrm{SE}$} & \multicolumn{3}{|c|}{$\begin{array}{c}\text { Mean difference } \\
\quad(95 \% \mathrm{Cl})\end{array}$} \\
\hline - ICU chart day 0 & $102.3+/-1.4$ & $102.1+/-1.6$ & $0.2(-3.9-4.2)$ & 0.94 \\
\hline - ICU chart day 1 & $104.6+/-1.5$ & $104.3+/-1.4$ & $0.3(-3.8-4.4)$ & 0.89 \\
\hline - ICU chart day 2 & $92.1+/-1.7$ & $90.0+/-1.8$ & $2.1(-2.8-7.0)$ & 0.40 \\
\hline - ICU chart day 3 & $87.0+/-2.3$ & $82.6+/-2.0$ & $4.4(-1.8-10.7)$ & 0.16 \\
\hline
\end{tabular}




\subsubsection{Subgroup analyses nested cohort: chest drain losses at}

\section{2 hours}

In the nested cohort patients who had emergency cardiac surgery and were allocated to Plasma-Lyte 148 had a larger volume of chest drain losses at 12 hours compared to those allocated to $0.9 \%$ saline (geometric mean [95\% Cl], $904 \mathrm{~mL}$ [640-1277 mL] for the PlasmaLyte 148 group vs. $570 \mathrm{~mL}$ [ $470-691 \mathrm{~mL}$ ] in the $0.9 \%$ saline group; $p=0.02$ ) (Table 9.16)

Table 9.16. Subgroup analysis of chest tube losses from time of arrival to 12 hours postoperative if still in ICU within nested cohort.

\begin{tabular}{|c|c|c|c|c|}
\hline & Plasma-Lyte 148 & $0.9 \%$ saline & & \\
\hline Subgroup & $\begin{array}{r}\text { Geometric mean ( } \\
\text { patient with ou } \\
\text { available/ total no. } \\
\text { subgrc }\end{array}$ & $\begin{array}{l}\text { L) }[95 \% \mathrm{Cl}] \text {, no. } \\
\text { tcome data } \\
\text { patient in each } \\
\text { up }\end{array}$ & $\begin{array}{c}\text { Ratio of } \\
\text { Geometric } \\
\text { Means }(95 \% \mathrm{Cl})\end{array}$ & P value \\
\hline Overall & $\begin{array}{l}566(521-617) \\
131 / 131(100)\end{array}$ & $\begin{array}{l}547(496-604) \\
116 / 120(96.7)\end{array}$ & $1.04(0.91-1.18)$ & 0.60 \\
\hline Operative group & & & & \\
\hline - Elective & $\begin{array}{l}542[471,623] \\
56 / 56\end{array}$ & $\begin{array}{l}491[418,576] \\
58 / 60\end{array}$ & $1.10(0.89,1.36)$ & 0.36 \\
\hline - Urgent & $\begin{array}{l}546[490,608] \\
65 / 65\end{array}$ & $\begin{array}{l}618[543,702] \\
50 / 51\end{array}$ & $0.89(0.75,1.04)$ & 0.14 \\
\hline - Emergency & $\begin{array}{l}904[640,1277] \\
9 / 9\end{array}$ & $\begin{array}{l}570[470,691] \\
8 / 9\end{array}$ & $1.58(1.09,2.31)$ & 0.02 \\
\hline - Salvage & $\begin{array}{l}1200[\mathrm{NA}] \\
1 / 1\end{array}$ & - & - & \\
\hline Euro II score & & & & \\
\hline - $<3$ & $\begin{array}{l}547[499,598] \\
114 / 114\end{array}$ & $\begin{array}{l}541[488,600] \\
107 / 111\end{array}$ & $1.01(0.88,1.16)$ & 0.88 \\
\hline - $\quad \geq 3$ & $\begin{array}{l}724[570,920] \\
17 / 17\end{array}$ & $\begin{array}{l}633[414,968] \\
9 / 9\end{array}$ & $1.34(0.98,1.84)$ & 0.52 \\
\hline
\end{tabular}




\begin{tabular}{|c|c|c|c|c|}
\hline \multicolumn{5}{|l|}{ Age } \\
\hline - $\quad \geq 65$ & $\begin{array}{l}536[478,601] \\
78 / 78\end{array}$ & $\begin{array}{l}519[451,596] \\
70 / 73\end{array}$ & $1.03(0.86,1.24)$ & 0.71 \\
\hline - $\quad<65$ & $\begin{array}{l}615[534,700] \\
53 / 53\end{array}$ & $\begin{array}{l}595[522,678] \\
46 / 47\end{array}$ & $1.04(0.86,1.23)$ & 0.71 \\
\hline \multicolumn{5}{|c|}{ Preoperative clopidogrel or aspirin use within 5 days of surgery } \\
\hline - Yes & $\begin{array}{l}566(527,640) \\
66 / 66\end{array}$ & $\begin{array}{l}589[527,658] \\
69 / 71\end{array}$ & $0.96(0.82,1.13)$ & 0.64 \\
\hline - No & $\begin{array}{l}567(503,640) \\
65 / 65\end{array}$ & $\begin{array}{l}492[411,590] \\
47 / 49\end{array}$ & $1.15(0.94,1.42)$ & 0.18 \\
\hline \multicolumn{5}{|l|}{ Gender } \\
\hline - Male & $\begin{array}{l}561(508,620) \\
95 / 95\end{array}$ & $\begin{array}{l}563[506,626] \\
94 / 97\end{array}$ & $1.00(0.86,1.15)$ & 0.97 \\
\hline - Female & $\begin{array}{l}582(490,691) \\
36 / 36\end{array}$ & $\begin{array}{l}487[374,634] \\
22 / 23\end{array}$ & $1.20(0.89,1.61)$ & 0.23 \\
\hline \multicolumn{5}{|c|}{ Prior Cardiac surgery } \\
\hline - Yes & $\begin{array}{l}709(390,1287) \\
4 / 4\end{array}$ & $\begin{array}{l}576[400,829] \\
3 / 3\end{array}$ & $1.23(0.68,2.24)$ & 0.41 \\
\hline - No & $\begin{array}{l}563(516,605] \\
127 / 127\end{array}$ & $\begin{array}{l}547[494,605] \\
113 / 117\end{array}$ & $1.03(0.90,1.17)$ & 0.67 \\
\hline
\end{tabular}




\subsubsection{Subgroup analyses nested cohort: risk of requiring blood products following surgery}

In the nested cohort within patients that had emergency cardiac surgery there were a higher proportion of patients that needed blood or blood product in those allocated to Plasma-Lyte 148 compared to those allocated to $0.9 \%$ saline (6 of 9 patients [66.7\%] in Plasma-Lyte 148 group vs. 1 of 9 [11.1\%] patients in the 0.9\% saline group, OR [95\% Cl] 15.9 [1.31-200.0]; $\mathrm{p}=0.03$ ) (Table 9.17).

Table 9.17. Subgroup analysis of the use of blood or blood products in the ICU within the nested cohort.

\begin{tabular}{|c|c|c|c|c|}
\hline Subgroup & $\begin{array}{c}\text { Plasma-Lyte } \\
148\end{array}$ & $0.9 \%$ saline & $\begin{array}{l}\text { Odds Ratio } \\
\text { [95\% Cl] }\end{array}$ & $\begin{array}{l}\text { P value } \\
\text { for OR }\end{array}$ \\
\hline & $\begin{array}{c}\text { no. of } \\
\text { events/total } \\
\text { no. }(\%)\end{array}$ & no. of events/total no. (\%) & & \\
\hline Overall & $40 / 131(30.5)$ & $22 / 120(18.3)$ & $1.96[1.09,3.57]$ & 0.03 \\
\hline \multicolumn{5}{|l|}{ Operative group } \\
\hline - Elective & $17 / 56(30.4)$ & $11 / 60(18.3)$ & $1.94[0.82,4.62]$ & 0.13 \\
\hline - Urgent & $16 / 65(24.6)$ & $10 / 51(19.6)$ & $1.34[0.55,3.27]$ & 0.52 \\
\hline - Emergency & $6 / 9(66.7)$ & $1 / 9(11.1)$ & $15.9[1.31,200.0]$ & 0.03 \\
\hline - Salvage & $1 / 1(100)$ & - & - & - \\
\hline \multicolumn{5}{|l|}{ Euro II score } \\
\hline - $<3$ & $31 / 114(27.2)$ & $21 / 111(18.9)$ & $1.60[0.85,3.00]$ & 0.14 \\
\hline - $\quad \geq 3$ & $9 / 17$ (52.9) & $1 / 9(11.1)$ & $9.09[0.91,90.91]$ & 0.06 \\
\hline \multicolumn{5}{|l|}{ Age } \\
\hline - $\quad \geq 65$ & $24 / 78(30.8)$ & $15 / 73(20.5)$ & $1.72[0.82,3.57]$ & 0.15 \\
\hline - $\quad<65$ & $16 / 53(30.2)$ & $7 / 47$ (14.9) & $2.44[0.92,6.67]$ & 0.08 \\
\hline \multicolumn{5}{|c|}{ Preoperative clopidogrel or aspirin use within 5 days of surgery } \\
\hline - Yes & $18 / 66(27.2)$ & $17 / 71(23.9)$ & $1.19[0.55,2.56]$ & 0.66 \\
\hline - No & $22 / 65(33.8)$ & $5 / 49(10.2)$ & $4.55[1.56,13.0]$ & 0.01 \\
\hline
\end{tabular}




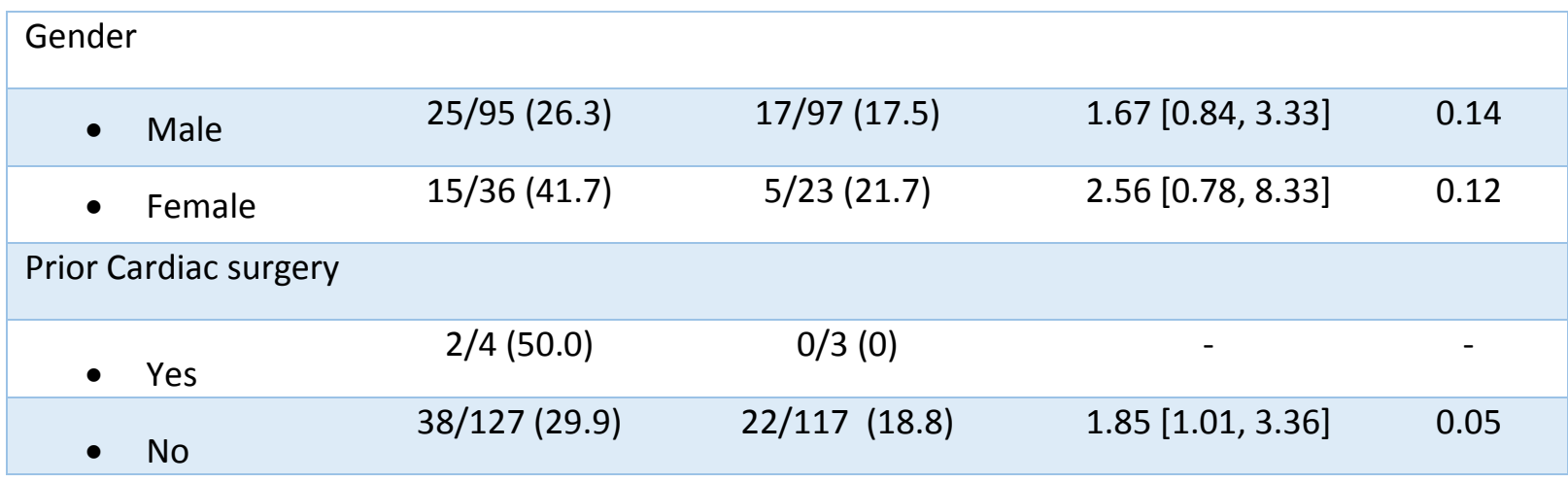

\subsubsection{Protocol deviations}

In the nested cohort study one participant allocated to the Plasma-Lyte 148 group had received a $0.9 \%$ saline study fluid in error during the study.

\subsubsection{Adverse events}

There were no reported serious events that were judged to be potentially related to study treatment. 


\subsection{Discussion study two}

\subsubsection{Statement of principal findings}

In this post-hoc exploratory subgroup analysis of cardiac surgical patients that were enrolled into study one, the primary outcome of patients that received blood or blood products in ICU occurred in a significantly higher proportion of patients assigned to Plasma-Lyte 148 compared to $0.9 \%$ saline. This difference remained after adjustment for baseline imbalances. Allocation to Plasma-Lyte 148 was associated with a significantly increased proportion of patients that received PRBC and volumes of PRBC, FFP and platelets while in ICU compared with allocation to $0.9 \%$ saline.

Within the single centre nested cohort group, there were no between-group differences in chest drain losses at 12 hours following admission to ICU. However, there was a significantly higher proportion of patients that were allocated to Plasma-Lyte 148 that received blood products and had a higher median INR on the day of ICU admission compared to patients allocated to $0.9 \%$ saline. In a subgroup analysis of patients in the nested cohort who had emergency cardiac surgery, both the chest drain losses at 12 hours and the use of blood and blood products were significantly higher in the group allocated to Plasma-Lyte 148.

\subsubsection{Significance of the findings}

There have been no previous studies that have assessed the comparative effectiveness of using balanced crystalloids versus unbalanced crystalloids in cardiac surgery patients. The results from study two were contrary to the study hypothesis and differ from previous research in non-cardiac surgery populations on the effect of blood transfusion requirements and bleeding with the use of buffered crystalloids compared to $0.9 \%$ saline (Krajewski, Raghunathan, Paluszkiewicz, Schermer, \& Shaw, 2015; Orbegozo Cortes et al., 2014; Shaw et al., 2012). We had speculated that in patients admitted to ICU after cardiac surgery, the administration of Plasma-Lyte 148 would decrease the proportion of patients requiring blood products and also decrease postoperative bleeding compared to $0.9 \%$ saline. However, allocation to Plasma-Lyte 148 was associated with a significantly increased blood 
transfusion requirement compared to allocation to $0.9 \%$ saline which has not been previously reported.

Study two findings are unexpected and may represent a type one error. Within the overall cohort, there were some imbalances in the measured characteristics of the patients at baseline, notably the APACHE II score. However, after adjustment of the baseline imbalances, the proportion of patients requiring blood products remained significantly higher in the Plasma-Lyte 148 group. The primary outcome for the overall cohort was a composite-end-point that combined the proportion of people that required blood and any blood product following cardiac surgery. The specific criteria to transfuse blood and blood products for the overall cohort were not outlined in the study protocol, and hence, the decision to transfuse patients was left to the discretion of the treating clinicians at each study site. It is acknowledged that the decision to transfuse patients following cardiac surgery has multiple triggers and that there may also be a variation in blood transfusions practices amongst the treating clinicians (Bennett-Guerrero et al., 2010; Hajjar et al., 2010). However, as the study fluid was blinded to clinicians and the results remained significant after adjusting for study site it is unlikely that the differences observed were caused by variations in thresholds for initiating blood transfusions.

Within the nested cohort there were no significant differences found in chest drain losses at 12 hours after admission to ICU, however, there was a significantly higher proportion of patients allocated to Plasma-Lyte 148 that received blood or blood products. Although chest drain losses are used in clinical practice as a surrogate marker for bleeding and may be used by clinicians in deciding when to transfuse patients following cardiac surgery there are multiple factors, which were not recorded in this study, that can commonly influence its accuracy in monitoring for bleeding including chest tube blockage and incomplete evacuation of intrathoracic blood (Kwiatt et al., 2014; Velmahos et al., 1999). Further, the cumulative volume of chest drain losses was used to assess for bleeding whereas the rate of chest drain output, especially within the first few hours after admission to ICU, may be a more important factor in triggering transfusion of blood products (Woodman \& Harker, 1990; Wynne, Botti, Copley, \& Bailey, 2007) 
The biological mechanisms explaining why allocation to Plasma-Lyte 148 may have led to increased transfusion of blood and blood products are largely speculative. Haemostasis is complex and pathways are influenced by numerous factors. In the overall cohort, most of the study fluid as well as most blood products were administered on the day of ICU admission. Patients allocated to Plasma-Lyte 148 received a median volume of $5000 \mathrm{~mL}$ of Plasma-Lyte 148 on the day of ICU admission ( $3000 \mathrm{~mL}$ prior to study enrolment and 2000 $\mathrm{mL}$ of study fluid in ICU). It is currently unknown what the adverse effects (if any) are of moderately-large volume administrations of Plasma-Lyte 148. In particular, the clinical effects of acetate and gluconate are not fully understood and it has been reported that blood levels of acetate and gluconate remain at supraphysiological concentrations for several hours after administration of two litres of Plasma-Lyte 148 in cardiac surgical populations (Davies et al., 2011). Within the nested cohort there were significant differences in the median INR and the proportion of patients with an INR> 1.5 on the ICU day of admission. Although these results may suggest greater impairment of coagulation in the group allocated to Plasma-Lyte 148 this finding should be interpreted with caution as INR results were only available for less than half the patients.

There have been few in-vivo studies comparing the effect on haemostasis of different types of crystalloid fluid. The nested cohort's findings were at variance to a small RCT conducted by J. B. Young et al. (2014) in severe trauma patients that reported no difference in INR levels 24 hours after fluid resuscitation with Plasma-Lyte A compared to $0.9 \%$ saline. However, Plasma-Lyte may indirectly affect coagulation by influencing mediators of inflammation. In an animal study by Zhou et al. (2014), the use of Plasma-Lyte compared to $0.9 \%$ saline was associated with a significantly lower level of interleukin 6 which has been reported to promote coagulation through endothelial cell activation, platelet production, increased expression of clotting factors and reducing levels of anticoagulants (anti-thrombin and protein S) (Kerr, Stirling, \& Ludlam, 2001; Stouthard et al., 1996). Further in-vivo research into the specific haemostatic pathways that may be influenced by different types of crystalloid fluid is required.

The secondary outcome of an increased portion and volume of PRBCs given to patients allocated to $0.9 \%$ saline were at odds with a recently published meta-analysis conducted by Krajewski et al. (2015) which combined the results from 4 RCT's $(n=221)$ that compared the 
intraoperative and ED trauma resuscitation with low chloride fluid (Ringer's lactate and Plasma-Lyte A) to high chloride fluid ( $0.9 \%$ saline). This meta-analysis reported greater volumes of PRBC's transfusion in patients receiving high chloride fluid compared to low chloride fluid (standardised mean difference, $0.35 ; 95 \% \mathrm{Cl}, 0.07$ to $0.63 ; \mathrm{p}=0.014$ ). However, all studies included in this meta-analysis were small, only one of the studies was blinded, studies had markedly different study populations and had differing intravenous fluid regimens. The meta-analysis also combined studies using different types of buffered crystalloid fluid which may have led to misleading results as acetate/gluconate containing buffered crystalloid fluids (Plasma-Lyte 148) and lactate containing buffered crystalloid (Hartmann's and Ringer's lactate) are not biologically equivalent and there is emerging evidence to suggest that they may not be clinically equivalent with regard to risk of bleeding and haemostasis (Weinberg et al., 2015). Additionally, calcium containing buffered crystalloid fluids (Ringer's lactate and Hartmann's) are contraindicated for co-infusion with blood or blood related products (Shaw et al., 2012) and therefore, calcium containing buffered crystalloid fluid may not be appropriate to use in cardiac surgical patients who are at a high-risk for blood transfusions.

\subsubsection{Strengths and limitations}

Study one is the only study that has included a cardiac surgical population and compared a buffered crystalloid solution to $0.9 \%$ saline. As blood products administered in ICU were included in the data collected for study one, this allowed for an exploratory analysis for a clinically important outcome measure (need for blood transfusion) in a high-risk sub-group of patients (cardiac surgical patients). The blinding of study groups and publication of a prespecified statistical analysis plan minimised the risk of bias (Reddy et al., 2015). As 99.7\% of all eligible patients were included and analysed in study one and all of the patients undergoing cardiac surgery were included this study, the data were not subject to selection bias.

Study two had a number of limitations. Firstly, as this was a post-hoc exploratory analysis there is a high-risk of a type one error and a causal relationship cannot be determined. Therefore, all observations should only be regarded as hypothesis-generating. The analysis of the overall cohort was only limited to data that were collected as part of study one. There 
may have been a variety of unmeasured co-interventions as well as patient and operative specific factors that may have influenced the proportion of patients that required blood or blood products which were not collected in study one. To mitigate against this, a single centre nested cohort study was also conducted for study two. Although the overall cohort and nested were similar in baseline demographics and case-mix, there were imbalances between the nested cohort and overall cohort in the crystalloid fluid and blood products received in the 24 hours prior to enrolment which may suggest variation in fluid prescribing and transfusion practices between study sites. Therefore, the findings of the nested cohort may not be generalisable to the overall cohort.

For the overall cohort, data on blood and blood products received was only collected for the first three days after study enrolment. It is possible that differences between groups in transfusion may have occurred beyond the transfusion data collection period, however there were less than $15 \%$ of patients still in the ICU beyond this time and previous data from cardiac surgical patients suggest that most transfusions are given in the first three days after surgery (Hajjar et al., 2010).

Another limitation of this study was the pre-study enrolment administration of crystalloid fluids, mainly Plasma-Lyte 148. Within the cardiac surgical population, most of the pre-study enrolment fluid was given intraoperatively. The volumes of pre-study fluid administered intraoperatively were appreciable and also close to the total volume of study fluid given to patients. However, this study was designed to be pragmatic which may better reflect a real world setting, where it is rare that patients receive only one type of intravenous fluid during the perioperative period (Shaw et al., 2012). There were also no additional biochemical tests, measurements of coagulation factors or use tests for global haemostatic function such as thromboelastography. The inclusion of these investigations may have been useful in identification of the potential mechanisms by which crystalloid fluids may influence haemostasis, however, additional testing was cost prohibitive.

\subsubsection{Conclusions}

In an exploratory subgroup analysis of patients admitted to ICU after undergoing cardiac surgery, allocation to Plasma-Lyte 148 was associated with an increased proportion of patients receiving blood or blood products compared to allocation to $0.9 \%$ saline. These 
findings are of concern to clinicians prescribing intravenous fluids to patients in ICU following cardiac surgery and support the need for further clinical investigation in this area. 
10 Study three: A single centre pilot study nested within study one to evaluate the effect of using $0.9 \%$ saline or Plasma-Lyte $148{ }^{\circledR}$ as crystalloid fluid therapy on gastrointestinal feeding intolerance in mechanically ventilated patients receiving nasogastric enteral nutrition.

\subsection{Rationale}

As mentioned in the introduction of the thesis there is currently a paucity of research on the gastrointestinal effects of different crystalloid fluids. Study one created an opportunity for the concurrent investigation of the gastrointestinal effects of $0.9 \%$ saline vs. Plasma-Lyte 148 in a high-risk and previously uninvestigated patient population.

Critical illness is associated with a catabolic stress state in which patients commonly demonstrate a systematic inflammatory response and frequently develop multi-organ failure (Martindale et al., 2009). To date, much of the research has been focussed on the functional changes in the cardiovascular, respiratory, and renal systems in critically unwell patients (Meier, 2010). Much less is known about gastrointestinal dysfunction, although observational data suggests that gastrointestinal feeding intolerance in ICU patients is associated with decreased nutrient intake and adverse clinical outcomes (Mentec et al., 2001; Nguyen, Ng, Chapman, Fraser, \& Holloway, 2007). Consensus international guidelines now recommend commencement of enteral nutrition within 24-48 hours of admission to the ICU (Martindale et al., 2009) to decrease physiological stress, promote healing, and enhance immunocompetence (Marik \& Zaloga, 2001). Despite the importance of adequate enteral nutrition, patients in ICU often receive less energy intake than recommended (De Jonghe et al., 2001; Dvir, Cohen, \& Singer, 2006; McClave et al., 1999).

Gastrointestinal feeding intolerance (vomiting, diarrhoea, high gastric residual volumes) of enteral nutrition is the most frequent gastrointestinal complication occurring in $50-60 \%$ of patients during the course of feeding in the ICU (Montejo et al., 2010) and is the most common reason for unwanted cessation of enteral nutrition (McClave \& Snider, 2002). Cohort studies in mechanically ventilated patients have shown patients with gastrointestinal 
feeding intolerance receive less volume of diet and have a worse prognosis in terms of ICU stay and mortality (Mentec et al., 2001; Montejo, 1999).

Only recently has the technology been available to identify the magnitude of the abnormalities in gastrointestinal motor function in critical illness (Deane, Chapman, Fraser, \& Horowitz, 2010). In a capsule endoscopy study of critically unwell trauma patients, there was a statistically significant delayed gastric emptying and small bowel transit time resulting in a median time until the passage of capsule of 10 days versus 1.2 days in healthy control patients (Rauch et al., 2012). Absorption of nutrients is also substantially impaired and early research suggests impaired gastrointestinal mucosal function may be responsible (Chapman et al., 2009; Deane et al., 2010). The aetiology of impaired motility and absorption in critical illness remains unclear, although factors like inotropic support, cytokine release, hormonal imbalance, electrolyte disturbance and sedative agents have all been implicated (Nguyen et al., 2008). The effect of different intravenous fluids has never been assessed.

\subsection{Primary aim}

To provide preliminary data on the comparative effectiveness of $0.9 \%$ saline compared to Plasma-Lyte 148 on the risk of developing gastrointestinal feeding intolerance in adult mechanically ventilated patients receiving enteral nutrition via nasogastric feeding.

\subsection{Secondary aims}

The secondary aims were to determine whether there were, in adult mechanically ventilated patients receiving enteral nutrition via nasogastric feeding randomised to receive $0.9 \%$ saline or Plasma-Lyte 148, differences between treatment groups in terms of the:

1. Cumulative incidence of patients with each of following: high gastric residual volume (GRV), diarrhoea, and vomiting.

2. Diet volume ratio (administered volume of diet/ prescribed volume of diet) at 48 hours after study enrolment.

3. Duration of nasogastric feeding.

4. Reason for cessation of nasogastric feeding. 
5. Duration of mechanical ventilation.

6. Length of ICU admission from the time of study enrolment.

7. Length of hospital admission from the time of study enrolment.

\subsection{Overview}

An overview of the protocol for study three was published in a peer-reviewed journal (Reddy et al., 2015) and the study was also prospectively registered on the Australian and New Zealand Clinical Trial Registry (Registration number:12614000269639). Study three was a single centre pilot study nested within study one conducted over 28 weeks comparing $0.9 \%$ saline to Plasma-Lyte 148 as the routine IV crystalloid fluid therapy. Study three has been accepted for publication in the journal of Critical Care and Resuscitation. A copy of the study protocol was provided to the ANZICS -CTG. The CTG has determined that this study did not require formal CTG review.

\subsection{Study design and treatment allocation}

Study three recruited patients that were already enrolled into study one. Only patients from Wellington Regional Hospital ICU were assessed for eligibility. The study ran during the same 28 week period as study one. As per study one, patients received either blinded Plasma-Lyte 148 or $0.9 \%$ saline. The treatment allocation for the study ICU was Plasma-Lyte $148,0.9 \%$ saline, Plasma-Lyte 148 and $0.9 \%$ saline (Figure 10.1).

Figure 10.1. Overview of crossover design for study three

\begin{tabular}{|c|c|c|c|c|}
\hline & 7 weeks & 7weeks & 7 weeks & 7 weeks \\
\hline $\begin{array}{c}\text { Wellington } \\
\text { ICU }\end{array}$ & trial fluid A & trial fluid B & trial fluid A & trial fluid B \\
\hline
\end{tabular}

Any patient that remained in the ICU after a crossover period continued to receive the study fluid to which they were originally assigned up to 90 days after enrolment. Any patients 
readmitted to the ICU within the index hospital admission continued to receive the fluid they were originally assigned even if unit-wide crossover had occurred. If patients were readmitted to the ICU beyond their index hospital admission, they were not required to receive study fluid.

\subsection{Primary outcome}

The primary outcome was the proportion of patients with gastrointestinal feeding intolerance, as defined by having any of the following: high GRV (a single nasogastric aspirate volume of greater than $500 \mathrm{~mL}$ ) (Montejo et al., 2010), diarrhoea (three or more loose or liquid stools per day)(Reintam Blaser et al., 2012) or vomiting (enteral formula ejected from mouth irrespective of amount)(Reintam Blaser et al., 2012) while receiving nasogastric feeding in the ICU.

We acknowledge that definitions of gastrointestinal feeding intolerance and gastrointestinal dysfunction are varied and largely based on expert opinion. Nonetheless, vomiting, diarrhoea and high GRV are considered to be valid symptoms of gastrointestinal feeding intolerance in critically ill patients (Reintam Blaser et al., 2012). Composite outcomes that combine both upper and lower gastrointestinal symptoms have been previously used in ICU studies exploring gastrointestinal dysfunction in the critically ill (Montejo, 1999; Montejo et al., 2010). Our definition for diarrhoea and vomiting were based on the European Society of Intensive Care Medicine recommendations (Reintam Blaser et al., 2012). While there is controversy on the use of GRV monitoring and marked variation in GRV measurement technique, frequency and cut-off value, $500 \mathrm{~mL}$ was chosen as our cut-off value as this was in line with our established nasogastric enteral feeding protocol and we contend that most Intensivists would regard a single GRV of $>500 \mathrm{~mL}$ as abnormal (Martindale et al., 2009; Montejo et al., 2010).

\subsection{Secondary outcomes and co-interventions}

Secondary outcomes within the 90-day follow-up period were:

1) The proportion of patients with each of high GRV, diarrhoea, and vomiting. 
2) The diet volume ratio (administered volume of diet/ prescribed volume of diet)(Montejo et al., 2010) at 48 hours after study enrolment. 48 hours was deemed an appropriate time endpoint for our study as for the first 48 hours after commencing nasogastric feeding patients have specific time points for gastric aspiration ( 4 hourly). After 48 hours there is potential for differences in the frequency of GRV measurement which may influence the administered nasogastric feeding rate.

3) The duration of nasogastric feeding (days).

4) The duration of mechanical ventilation (days).

5) Reason for cessation of nasogastric feeding (pre-specified indications for cessation of nasogastric feeding were as follows: (1) Commencement of oral diet; (2) Gastrointestinal complication (high GRV, diarrhoea, and vomiting); (3) Other complications ; (4) ICU discharge; (5) ICU death).

6) Total daily GRV from day 0 to day 7. This outcome was added following study completion as it was requested on peer review following submission of the manuscript to Critical Care and Resuscitation.

7) Mean lowest and mean highest blood $\mathrm{pH}, \mathrm{CO}_{2}$, bicarbonate, glucose, sodium or potassium on day 0 , day 1 , day 2 or day 3 if still in ICU. These outcomes were added following study completion as it was requested on peer review following submission of the manuscript to Critical Care and Resuscitation.

8) The ICU length of stay from the time of first receiving study fluid (days).

9) The hospital length of stay from the time of first receiving study fluid (days).

We also recorded the proportion of patients in each treatment group who received prokinetic drugs (metoclopramide or erythromycin), opiates, or catecholamines postrandomisation as we considered these to be important co-interventions.

As per study one, all outcome data were censored at day 90 from the time of study enrolment. ICU data were only collected for the index ICU admission. 


\subsection{Study participants}

\subsubsection{Inclusion criteria}

Patients enrolled in study one at Wellington ICU were assessed for eligibility for this study. Patients who met the eligibility criteria were those aged 18 years or older, expected to require mechanical ventilation for greater than 48 hours and receiving enteral nutrition exclusively by nasogastric tube.

\subsubsection{Exclusion criteria}

As in study one, patients were excluded if they were usually on dialysis for end-stage renal failure, currently receiving renal replacement therapy or expected to require renal replacement therapy within six hours, were admitted to the ICU solely for consideration of organ donation or for palliative care, or were previously enrolled in study one.

\subsubsection{Approach to enteral feeding in mechanically ventilated patients.}

Within the study ICU there was a standardised approach to nutritional support and nasogastric feeding. Enteral nutrition was commenced as early as clinically possible with the aim of achieving the nutritional goal rate within 48 hours. Nasogastric feeding was the preferred feeding method for mechanically ventilated patients and whenever possible patients were nursed in a semi-recumbent position (30-45 head-up). Once the intragastric position of the nasogastric tube was radiographically verified, $1.28 \mathrm{kcal} / \mathrm{mL}$ feeds were commenced at a rate of $30 \mathrm{~mL} /$ hour and increased by a rate of $30 \mathrm{~mL} /$ hour every four hours until the goal rate was achieved. The initial goal rate was prescribed by the treating clinician and was subsequently adjusted in collaboration with the ICU dietician if necessary. Measurement of GRV was performed at four hourly intervals via syringe aspiration through the nasogastric tube with volumes below $500 \mathrm{~mL}$ returned to the patient. Once the goal feeding rate was tolerated for 24 hours, the frequency of nasogastric aspiration was decreased to 12 hourly. The size of the nasogastric tube inserted, changes to type of 
nasogastric feed used, and use of prokinetic agents were at the discretion of the treating clinicians.

\subsection{Data collection and Management}

Baseline data and outcome data were collected by the study investigator. Relevant data that were collected as part of study one and entered into the web based CRF were combined with additional data required for study three. Data were collected from the patient's medical records and entered into paper forms. Table 10.1 shows details of the data that were collected.

Table 10.1. Data collected in the study three.

\section{Baseline information}

Age, sex, ethnicity*

Body mass index

Diagnosis admission category (Medical, surgical and trauma)

Baseline APACHE II score*

Pre-randomisation blood glucose

Received opiates in the $24 \mathrm{hr}$ before randomisation

Received catecholamine's in the $24 \mathrm{hr}$ before randomisation

Comorbidities (chronic respiratory disease, chronic cardiovascular disease, leukaemia/ myeloma, immunosuppression by disease, immunosuppression by therapy, hepatic failure, cirrhosis, lymphoma, AIDS, metastatic cancer)* Mechanical ventilation at study enrolment*

Type and amount of IV fluids ${ }^{\mathrm{a}}$ in the 24 prior to study enrolment*

\section{Daily Data}

Total volume and type of IV fluids ${ }^{*}$ received on Day 0 to Day 3 inclusive*

Total gastric residual volume recorded in ICU on Day 0 to Day 7 inclusive

Lowest and highest blood $\mathrm{pH}, \mathrm{CO}_{2}$, bicarbonate, glucose, sodium or potassium in ICU on Day 0 to Day 7 inclusive

\section{Hospital discharge data and Day 90 follow-up}

Developed high gastric residual volume while receiving nasogastric feeding Developed vomiting while receiving nasogastric feeding

Developed diarrhoea while receiving nasogastric feeding

Total amount of study fluid, open label Plasma-Lyte $148^{\circledR}$, open label $0.9 \%$ saline, received in ICU up until day 90 from study enrolment*

Duration of nasogastric feeding

Reason for cessation of nasogastric feeding

Duration of mechanical ventilation* 


Need for metoclopramide while receiving nasogastric feeding
Need for erythromycin while receiving nasogastric feeding
Need for opiates while receiving nasogastric feeding
Need for catecholamine's while receiving nasogastric feeding
ICU length of stay from time of study enrolment*
Hospital length of stay from time of study enrolment*
APACHE = Acute physiology and chronic health evaluation; AIDS = Acquired
Immunodeficiency Syndrome; IV = intravenous; ICU = Intensive Care Unit;
* These data were already collected as part of study one.
a Specific IV fluids recorded will include; 1 ) Crystalloid fluids : Plasma-Lyte $148^{\circledR}, 0.9 \%$ saline,
$5 \%$ dextrose, paediatric maintenance fluid, and 'other crystalloids', 2) Colloids : $4 \%$ albumin,
20\% albumin, gelofusion, voluven/volulyte ,and 'other colloids' 3) Blood products : packed
red blood cells, fresh frozen plasma, platelets, and cryoprecipitate.

\subsection{Assessment of safety}

As this was a nested cohort study there were no additional safety monitoring mechanisms beyond that of study one. In the event of an AE and SAE this would have been reported as per the protocol for study one. The investigator was responsible for detecting, documenting and reporting of $\mathrm{AE}$ and SAE.

\subsection{Ethical issues}

As per study one, this study was performed in accordance with World Medical Association Declaration of Helsinki: Ethical principles for medical research involving human subjects (World Medical Association, 2013) and the NEAC Ethical guidelines for interventional studies and operational standards for ethic committees (National Ethics Advisory Committee, 2006, 2012). This study was granted ethical approval by the New Zealand Health and Disability Northern B Ethics Committee (reference: 14/NTB/10) on the basis of the provision of information to patients and/or their next of kin and the opportunity for them to opt-out of the use of their data if they wish. 


\subsection{Process of obtaining opt-out consent}

Given this was a low-risk cohort study within study one as soon as is reasonably possible and appropriate patients, their families, and/or legal representatives were provided with an optout form/information sheet. This form was given in addition to the form given in study one. If patients or next of kin were not able to receive an opt-out form prior to hospital discharge or patient death a letter detailing the study along with a copy of the opt form were sent to the patient/next of kin.

\subsection{Data handling and confidentiality}

A site file containing a data dictionary and paper versions of the data collection forms were keep at the study site. Study documents were stored in secure locked cabinets.

The investigator maintained the confidentiality of all study documentation. The unique study number given to patients for study one was used for this study. A separate enrolment log was created that included the NHI number and the unique study number. The enrolment log and the study data were kept separately in a locked office. Data from the paper CRF entered was double data entered into an excel spreadsheet, and patient data were identified by the unique study number only.

\subsection{Sample size and power}

A detailed statistical analysis plan was reported prior to any statistical analyses (Reddy et al., 2015).

As study three was dependent on recruitment of study one, which was set to run for a specific period of time, there were no prospective sample size numbers or power calculations. Additionally, no previous clinical trial has compared the effect of $0.9 \%$ saline with a buffered crystalloid on gastrointestinal feeding intolerance therefore the possible magnitude of effect size is unknown. However, this study will provide preliminary data to allow for the planning of a larger study. 


\subsection{Statistical analysis}

All analysis was on an intention-to-treat basis and there was no imputation for missing values. The lead investigator (Sumeet Reddy) performed the data analyses in collaboration with Michael Bailey from the Australian and New Zealand Research Centre, Melbourne, Australia.

All continuous variables were assessed for normality and log-transformed where appropriate. Comparison between groups was performed using chi-square tests for equal proportion, Student's t-test for normally distributed variables and Wilcoxon rank sum tests otherwise, with results reported as numbers (\%), means (standard deviation) or median (interquartile range) respectively. Binomial outcome variables were analysed using logistic regression and reported as odds ratios ( $95 \%$ confidence interval).

The primary outcome was also examined in 5 subgroups on the basis of baseline characteristics: the admission diagnosis group (medical, surgical, trauma), the score ( $<25$ vs. $\geq 25$ ) on the Acute Physiology and Chronic Health Evaluation (APACHE) II score, age (<65 vs. $\geq 65$ ), body mass index (<30 vs. $\geq 30$ ) and gender (male or female)

Additional multivariable sensitivity analyses were conducted for the primary outcome and the key secondary outcomes (the proportion of patients with each of high GRV, diarrhoea, and vomiting) considering the baseline characteristics that were imbalanced between groups (sex, trauma admission diagnosis and time until NG feeding commencement) as given by a pvalue $<0.10$.

All analyses were performed using SPSS version 22.0 (IBM Corp., Armonk, NY) and a twosided $p$-value of 0.05 were considered to be statistically significant.

\subsection{Funding and support}

This study is an investigator-initiated study. Sumeet Reddy has received a Clinical Research Training Fellowship from the Health Research Council of New Zealand. The additional costs of this study were underwritten by the Medical Research Institute of New Zealand. The study fluid was supplied and distributed by Baxter Healthcare Corporation. Baxter Healthcare 
Corporation was not involved in the study design, conduct, data collection, statistical analysis, or writing of the manuscript/thesis for this study. 


\subsection{Results}

\subsubsection{Baseline characteristics}

From April 2014 through to October 2014, 69 participants were enrolled and analysed, with 35 assigned to receive Plasma-Lyte 148 group and 34 to receive $0.9 \%$ saline (Figure 10.2). Amongst those participants at the study site that were enrolled into study one $(n=611) 182$ patients $(29.8 \%)$ did not require ventilation and 360 patients (58.9\%) were not expected to require ventilation for greater than 48 hours or receive enteral nutrition exclusively by nasogastric tube.

There were no additional patients that withdrew consent from this study. Demographic and primary/secondary outcome data were available for $100 \%$ of the intention to treat population. 
Figure 10.2. Flow of participants through the study three

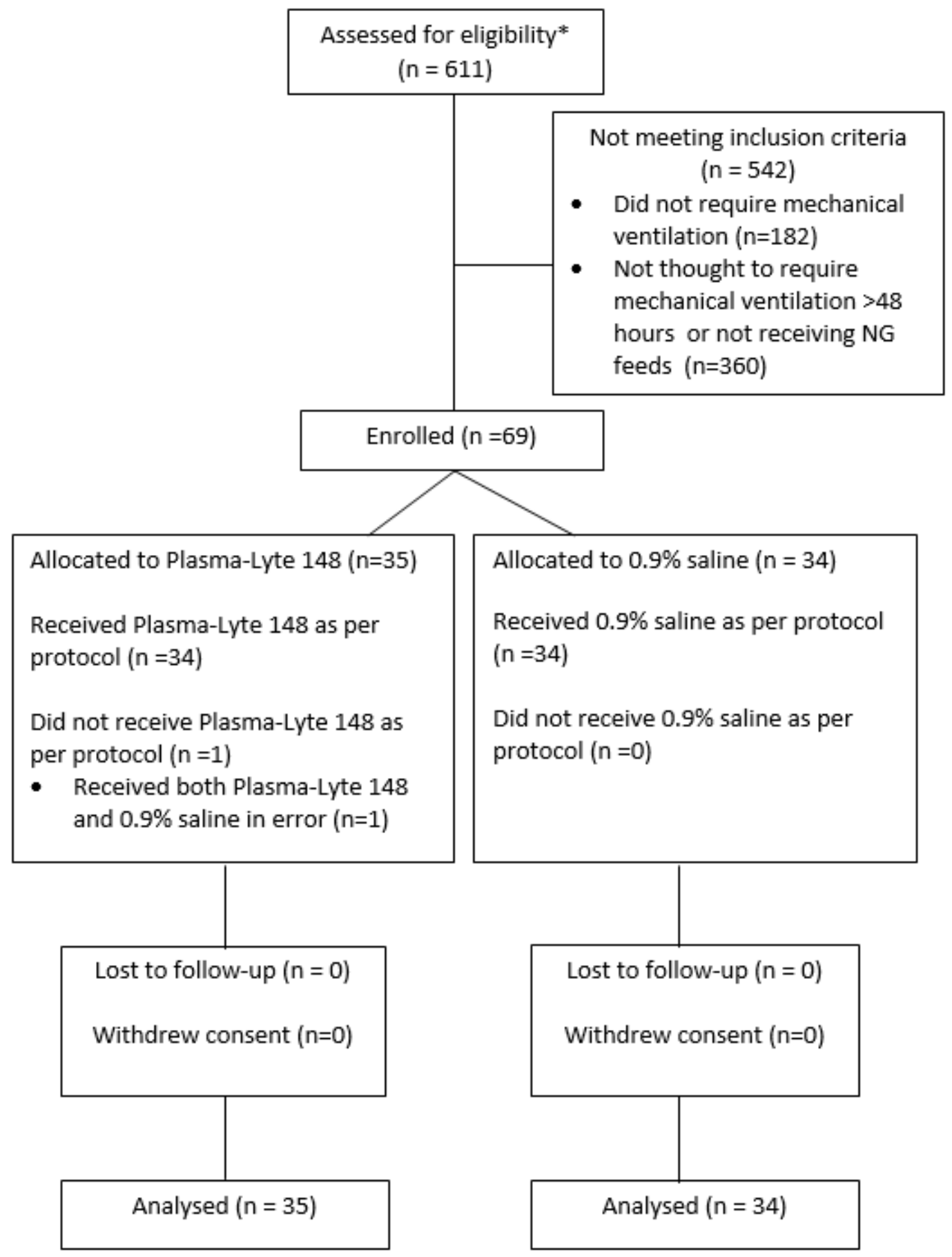

*All adult patients admitted to the Wellington ICU and that had been enrolled in study one were screened for study enrolment. 
Participants in both groups had similar baseline characteristics. Demographic and clinical characteristics at baseline are shown in Table 10.2. The mean (SD) ages of study participants were 55.2 (16.7) years old in the Plasma-Lyte 148 group and 51.4 (18.5) years old in the $0.9 \%$ saline group ( $p=0.48)$. The mean (SD) APACHE II scores were 17.9 (6.1) Plasma-Lyte 148 group and $16.9(5.6)$ in the $0.9 \%$ saline group $(p=0.48)$. There were few comorbidities amongst study participants and no significant between-group differences.

There was no significant difference between-groups in diagnostic admission category for patients. 6 of 35 participants (17.1\%) in the Plasma-Lyte 148 group had a trauma admission diagnosis and 12 of 34 participants (35.2\%) in the $0.9 \%$ saline group had a trauma admission diagnosis $(p=0.09)$. There was no difference in the proportion of participants that received opiates or catecholamines prior to study enrolment.

There were no significant differences in the volumes of crystalloids, colloids or blood products received by participants in the 24 hours prior to study enrolment. 
Table 10.2. Characteristics of the participants in study three.

\begin{tabular}{|c|c|c|c|}
\hline Characteristics & $\begin{array}{l}\text { Plasma-Lyte } 148 \\
\quad(n=35)\end{array}$ & $\begin{array}{c}0.9 \% \text { saline } \\
(n=34)\end{array}$ & $p$-value \\
\hline Age (years) & $55.2 \pm 16.7$ & $51.4 \pm 18.5$ & 0.48 \\
\hline Male sex - no. / total no. (\%) & $20 / 35(57)$ & $27 / 34(79)$ & 0.07 \\
\hline Body mass index & $27.54[24.5-30.2]$ & $26.02[24.2-32.0]$ & 0.14 \\
\hline \multicolumn{4}{|l|}{ Ethnicity - no. / total no. (\%) } \\
\hline - New Zealand European & $26 / 35(74)$ & $22(65)$ & 0.39 \\
\hline - Maori & $3 / 35(9)$ & $6(18)$ & 0.49 \\
\hline - Pacific Island People & $3 / 35(9)$ & $3(9)$ & 0.99 \\
\hline - Other & $3 / 35(9)$ & $3(9)$ & 0.99 \\
\hline \multicolumn{4}{|l|}{ Diagnostic admission category - no. / total no. (\%) } \\
\hline - Medical & $14 / 35(40)$ & 9/34 (27) & 0.23 \\
\hline - Surgical & $15 / 35(43)$ & $13 / 34(39)$ & 0.70 \\
\hline - Trauma & $6 / 35(17)$ & $12 / 34(35)$ & 0.09 \\
\hline \multicolumn{4}{|l|}{ Comorbidities - no. / total no. (\%) } \\
\hline - Chronic respiratory disease & $1 / 35(3)$ & $0 / 34(0)$ & 1.00 \\
\hline - Chronic cardiovascular disease & $0 / 35(0)$ & $0 / 34(0)$ & 1.00 \\
\hline - Leukaemia / myeloma & $0 / 35(0)$ & $1 / 34(3)$ & 0.49 \\
\hline - Immunosuppression by disease & $0 / 35(0)$ & $1 / 34(3)$ & 0.49 \\
\hline - Immunosuppression by therapy & $0 / 35(0)$ & $1 / 34(3)$ & 0.49 \\
\hline - Hepatic failure & $0 / 35(0)$ & $0 / 34(0)$ & 1.00 \\
\hline - Cirrhosis & $0 / 35(0)$ & $1 / 34(3)$ & 0.49 \\
\hline - Lymphoma & $0 / 35(0)$ & $0 / 34(0)$ & 1.00 \\
\hline - $\quad$ AIDS & $0 / 35(0)$ & $0 / 34(0)$ & 1.00 \\
\hline - Metastatic cancer & $0 / 35(0)$ & $0 / 34(0)$ & 1.00 \\
\hline APACHE II score $\geq 25$ & $6 / 35(17)$ & $3 / 34(9)$ & 0.48 \\
\hline APACHE II score & $17.9 \pm 6.1$ & $16.9 \pm 5.6$ & 0.48 \\
\hline Time from ICU admission to receiving first study fluid - hour & $2.3[1.0-16.8]$ & $2.1[0.5-6.8]$ & 0.26 \\
\hline Time for ICU admission to commencement of NG feeding & $13.8[5.3-30.7]$ & $19.3[14.2-32.2]$ & 0.07 \\
\hline Pre-randomisation blood glucose & $8.9 \pm 4.1$ & $8.0 \pm 3.4$ & 0.30 \\
\hline $\begin{array}{l}\text { Received opiates in the } 24 \mathrm{hr} \text { before randomisation - no. / } \\
\text { total no. (\%) }\end{array}$ & $35(100)$ & $33(97)$ & 0.31 \\
\hline $\begin{array}{l}\text { Received catechloamine's in the } 24 \mathrm{hr} \text { before } \\
\text { randomisation - no. / total no. (\%) }\end{array}$ & $27(77)$ & $23(68)$ & 0.38 \\
\hline \multicolumn{4}{|l|}{ Crystalloids received in the $24 \mathrm{hr}$ before randomisation - $\mathrm{mL}$} \\
\hline - Plasma-Lyte $148^{\circledR}$ & $0[0-2000]$ & $0[0-1625]$ & 0.48 \\
\hline - $\quad 0.9 \%$ saline & $1000[0-3000]$ & $1000[0-3000]$ & 0.42 \\
\hline - $5 \%$ dextrose & $0[0-0]$ & $0[0-550]$ & 0.52 \\
\hline - Other crystalloids & $0[0-0]$ & $0[0-0]$ & 1.00 \\
\hline \multicolumn{4}{|l|}{ Colloids received in the $24 \mathrm{hr}$ before randomisation $-\mathrm{mL}$} \\
\hline - $4 \%$ albumin & $0[0-0]$ & $0[0-0]$ & 1.00 \\
\hline - $20 \%$ albumin & $0[0-0]$ & $0[0-0]$ & 1.00 \\
\hline - Gelofusine & $0[0-0]$ & $0[0-0]$ & 1.00 \\
\hline - Voluven or Volulyte & $0[0-0]$ & $0[0-0]$ & 1.00 \\
\hline - Other colloids & $0[0-0]$ & $0[0-0]$ & 1.00 \\
\hline \multicolumn{4}{|l|}{ Blood products received in the $24 \mathrm{hr}$ before randomisation $-\mathrm{mL}$} \\
\hline - $\quad$ Packed red cells & $0[0-0]$ & $0[0-0]$ & 0.24 \\
\hline
\end{tabular}




\begin{tabular}{|c|c|c|c|}
\hline - $\quad$ Fresh frozen plasma & $0[0-0]$ & $0[0-0]$ & 0.36 \\
\hline - $\quad$ Platelets & $0[0-0]$ & $0[0-0]$ & 0.62 \\
\hline - Cryoprecipitate & $0[0-0]$ & $0[0-0]$ & 0.99 \\
\hline
\end{tabular}

Abbreviations: AIDS: acquired immunodeficiency syndrome; ICU: Intensive Care Unit.

a plus-minus values are mean $\pm S D$. Values followed by ranges in square brackets are median [IQR].

${ }^{b}$ Scores on the Acute Physiology and Chronic Health Evaluation (APACHE) II range from 0 to 71, with higher scores indicating an increased risk of death.

c Subgroups are based on the Acute Physiology and Chronic Health Evaluation (APACHE) III admission diagnostic codes.

\subsubsection{Fluid therapy}

The median time from ICU admission to receiving study fluid was just over two hours in both groups (Table 10.2).

The median total volume of study fluid given in the Plasma-Lyte 148 group was $2500 \mathrm{~mL}$ [IQR: $1000-5200 \mathrm{~mL}$ ] compared with the $3155 \mathrm{~mL}$ in the $0.9 \%$ saline group [IQR: $2154-5266$ $\mathrm{mL}$; however, the difference was not significant $(\mathrm{P}=0.21)$. The majority of the study fluid was given over the first two days after study enrolment and there was also no differences in the volume of study fluid, non-study fluid and blood products administered to patients per day while in ICU (Table 10.3 and Table 10.4). Very few patients were administered non-study crystalloid fluids and no patients required colloid fluids (Table 10.4).

Table 10.3. Volume of study fluid administered $(\mathrm{mL})$ and proportion of patients receiving fluid.*

\begin{tabular}{|c|c|c|}
\hline Fluid - mls & $\begin{array}{l}\text { Plasma-Lyte } 148 \\
\quad(n=35)\end{array}$ & $\begin{array}{c}0.9 \% \text { saline } \\
(n=34)\end{array}$ \\
\hline \multicolumn{3}{|c|}{ Proportion of patients receiving fluid } \\
\hline \multicolumn{3}{|l|}{ Plasma-Lyte 148 (study fluid) } \\
\hline $\begin{array}{l}\text { Day } 0 \text { - median [IQR] } \\
\text { no./total no. (\%) }\end{array}$ & $\begin{array}{c}1000[0-2000] 35 / 35 \\
(100)\end{array}$ & $\begin{array}{c}0[0-0] \\
0 / 34(0)\end{array}$ \\
\hline $\begin{array}{l}\text { Day } 1 \text { - median [IQR] } \\
\text { no./total no. (\%) }\end{array}$ & $\begin{array}{c}220[0-1080] \\
21 / 35(60)\end{array}$ & $\begin{array}{c}0[0-0] \\
0 / 34(0)\end{array}$ \\
\hline $\begin{array}{l}\text { Day } 2 \text { - median [IQR] } \\
\text { no./total no. (\%) }\end{array}$ & $0[0-500] 14 / 35(40)$ & $\begin{array}{c}0[0-0] \\
0 / 34(0)\end{array}$ \\
\hline $\begin{array}{l}\text { Day } 3 \text { - median [IQR] } \\
\text { no./total no. (\%) }\end{array}$ & $\begin{array}{c}0[0-0] \\
6 / 35(17)\end{array}$ & $\begin{array}{c}0[0-0] \\
0 / 34(0)\end{array}$ \\
\hline $\begin{array}{l}\text { Day } 4 \text { to } 90 \text { - median [IQR] } \\
\text { no./total no. (\%) }\end{array}$ & $\begin{array}{l}0[0-1200] \\
12 / 35(34)\end{array}$ & $\begin{array}{c}0[0-0] \\
0 / 34(0)\end{array}$ \\
\hline
\end{tabular}




\begin{tabular}{|l|c|c|}
\hline Day 0 - median [IQR] & $0[0-0]$ & $1020[0-2673]$ \\
\hline no./total no. (\%) & $0 / 35(0)$ & $34 / 34(100)$ \\
\hline Day 1 - median [IQR] & $0[0-0]$ & $500[0-1670]$ \\
\hline no./total no. $\%$ ) & $0 / 35(0)$ & $22 / 34(65)$ \\
\hline Day 2 - median [IQR] & $0[0-0]$ & $0[0-620]$ \\
no./total no. (\%) & $0 / 35(0)$ & $13 / 34(38)$ \\
\hline Day 3 - median [IQR] & $0[0-0]$ & $0[0-0]$ \\
no./total no. (\%) & $0 / 35(0)$ & $5 / 34(15)$ \\
\hline Day 4 to 90 - median [IQR] & $0[0-0]$ & $0[0-1000]$ \\
no./total no. $(\%)$ & $1 / 35(3)$ & $15 / 34(44)$ \\
\hline
\end{tabular}

*There were no significant differences in between the groups for the volume of study fluid received. Comparisons for volume of fluid administered by treatment group tested using Wilcoxon Rank Sum test.

Table 10.4 Non-Study fluids and blood products administered.

\begin{tabular}{|c|c|c|}
\hline & Plasma-Lyte 148 (n=35) & $0.9 \%$ saline $(n=34)$ \\
\hline \multicolumn{3}{|l|}{ Plasma-Lyte 148 (open label) } \\
\hline Day 0 - median [IQR] no./total no. (\%) & $0[0-0] 2 / 35(6)$ & $0[0-0] 1 / 34(3)$ \\
\hline Day 1 - median [IQR] no./total no. (\%) & $0[0-0] 3 / 35(9)$ & $0[0-0] 2 / 34(6)$ \\
\hline Day 2 - median [IQR] no./total no. (\%) & $0[0-0] 0 / 35(0)$ & $0[0-0] 0 / 34(0)$ \\
\hline Day 3 - median [IQR] no./total no. (\%) & $0[0-0] 0 / 35(0)$ & $0[0-0] 1 / 34(3)$ \\
\hline Day 4 to 90 - median [IQR] no./total no. (\%) & $0[0-0] 0 / 35(0)$ & $0[0-0] 2 / 34(6)$ \\
\hline \multicolumn{3}{|l|}{$0.9 \%$ saline (open label) } \\
\hline Day 0 - median [IQR] no./total no. (\%) & $0[0-0] 1 / 35(3)$ & $0[0-0] 3 / 34(9)$ \\
\hline Day 1 - median [IQR] no./total no. (\%) & $0[0-0] 2 / 35(6)$ & $0[0-0] 2 / 34(6)$ \\
\hline Day 2 - median [IQR] no./total no. (\%) & $0[0-0] 0 / 35(0)$ & $0[0-0] 0 / 34(0)$ \\
\hline Day 3 - median [IQR] no./total no. (\%) & $0[0-0] 0 / 35(0)$ & $0[0-0] 0 / 34(0)$ \\
\hline Day 4 to 90 - median [IQR] no./total no. (\%) & $0[0-0] 0 / 35(0)$ & $0[0-0] 2 / 34(6)$ \\
\hline \multicolumn{3}{|l|}{ 5\% Dextrose } \\
\hline Day 0 - median [IQR] no./total no. (\%) & $0[0-0] 4 / 35(11)$ & $0[0-0](12)$ \\
\hline Day 1 - median [IQR] no./total no. (\%) & $0[0-0] 3 / 35(9)$ & $0[0-0] 5 / 34(15)$ \\
\hline Day 2 - median [IQR] no./total no. (\%) & $0[0-0] 5 / 35(14)$ & $0[0-0] 3 / 34(9)$ \\
\hline Day 3 - median [IQR] no./total no. (\%) & $0[0-0] 2 / 35(6)$ & $0[0-0] 0 / 34(0)$ \\
\hline \multicolumn{3}{|l|}{$4 \%$ Albumin } \\
\hline Day 0 - median [IQR] no./total no. (\%) & $0[0-0] 0 / 35(0)$ & $0[0-0] 0 / 34(0)$ \\
\hline Day 1 - median [IQR] no./total no. (\%) & $0[0-0] 0 / 35(0)$ & $0[0-0] 0 / 34(0)$ \\
\hline Day 2 - median [IQR] no./total no. (\%) & $0[0-0] 0 / 35(0)$ & $0[0-0] 0 / 34(0)$ \\
\hline Day 3 - median [IQR] no./total no. (\%) & $0[0-0] 0 / 35(0)$ & $0[0-0] 0 / 34(0)$ \\
\hline \multicolumn{3}{|l|}{$20 \%$ Albumin } \\
\hline Day 0 - median [IQR] no./total no. (\%) & $0[0-0] 0 / 35(0)$ & $0[0-0] 0 / 34(0)$ \\
\hline Day 1 - median [IQR] no./total no. (\%) & $0[0-0] 0 / 35(0)$ & $0[0-0] 0 / 34(0)$ \\
\hline Day 2 - median [IQR] no./total no. (\%) & $0[0-0] 0 / 35(0)$ & $0[0-0] 0 / 34(0)$ \\
\hline Day 3 - median [IQR] no./total no. (\%) & $0[0-0] 1 / 35(3)$ & $0[0-0] 0 / 34(0)$ \\
\hline \multicolumn{3}{|l|}{ Gelofusine } \\
\hline Day 0 - median [IQR] no./total no. (\%) & $0[0-0] 0 / 35(0)$ & $0[0-0] 0 / 34(0)$ \\
\hline Day 1 - median [IQR] no./total no. (\%) & $0[0-0] 0 / 35(0)$ & $0[0-0] 0 / 34(0)$ \\
\hline
\end{tabular}




\begin{tabular}{|c|c|c|}
\hline Day 2 - median [IQR] no./total no. (\%) & $0[0-0] 0 / 35(0)$ & $0[0-0] 0 / 34(0)$ \\
\hline Day 3 - median [IQR] no./total no. (\%) & $0[0-0] 0 / 35(0)$ & $0[0-0] 0 / 34(0)$ \\
\hline \multicolumn{3}{|l|}{ Voluven or Volulyte } \\
\hline Day 0 - median [IQR] no./total no. (\%) & $0[0-0] 0 / 35(0)$ & $0[0-0] 0 / 34(0)$ \\
\hline Day 1 - median [IQR] no./total no. (\%) & $0[0-0] 0 / 35(0)$ & $0[0-0] 0 / 34(0)$ \\
\hline Day 2 - median [IQR] no./total no. (\%) & $0[0-0] 0 / 35(0)$ & $0[0-0] 0 / 34(0)$ \\
\hline Day 3 - median [IQR] no./total no. (\%) & $0[0-0] 0 / 35(0)$ & $0[0-0] 0 / 34(0)$ \\
\hline \multicolumn{3}{|l|}{ Other colloids } \\
\hline Day 0 - median [IQR] no./total no. (\%) & $0[0-0] 0 / 35(0)$ & $0[0-0] 0 / 34(0)$ \\
\hline Day 1 - median [IQR] no./total no. (\%) & $0[0-0] 0 / 35(0)$ & $0[0-0] 0 / 34(0)$ \\
\hline Day 2 - median [IQR] no./total no. (\%) & $0[0-0] 0 / 35(0)$ & $0[0-0] 0 / 34(0)$ \\
\hline Day 3 - median [IQR] no./total no. (\%) & $0[0-0] 0 / 35(0)$ & $0[0-0] 0 / 34(0)$ \\
\hline \multicolumn{3}{|l|}{ Packed red blood cells } \\
\hline Day 0 - median [IQR] no./total no. (\%) & $0[0-0] 3 / 35(9)$ & $0[0-0] 0 / 34(0)$ \\
\hline Day 1 - median [IQR] no./total no. (\%) & $0[0-0] 3 / 35(9)$ & $0[0-0] 1 / 34(3)$ \\
\hline Day 2 - median [IQR] no./total no. (\%) & $0[0-0] 6 / 35(17)$ & $0[0-0] 2 / 34(6)$ \\
\hline Day 3 - median [IQR] no./total no. (\%) & $0[0-0] 3 / 35(9)$ & $0[0-0] 2 / 34(6)$ \\
\hline \multicolumn{3}{|l|}{ Fresh frozen plasma } \\
\hline Day 0 - median [IQR] no./total no. (\%) & $0[0-0] 3 / 35(9)$ & $0[0-0] 2 / 34(6)$ \\
\hline Day 1 - median [IQR] no./total no. (\%) & $0[0-0] 1 / 35(3)$ & $0[0-0] 1 / 34(3)$ \\
\hline Day 2 - median [IQR] no./total no. (\%) & $0[0-0] 0 / 35(0)$ & $0[0-0] 0 / 34(0)$ \\
\hline Day 3 - median [IQR] no./total no. (\%) & $0[0-0] 1 / 35(3)$ & $0[0-0] 1 / 34(3)$ \\
\hline \multicolumn{3}{|l|}{ Platelets } \\
\hline Day 0 - median [IQR] no./total no. (\%) & $0[0-0] 2 / 35(6)$ & $0[0-0] 1 / 34(3)$ \\
\hline Day 1 - median [IQR] no./total no. (\%) & $0[0-0] 1 / 35(3)$ & $0[0-0] 2 / 34(6)$ \\
\hline Day 2 - median [IQR] no./total no. (\%) & $0[0-0] 0 / 35(0)$ & $0[0-0] 0 / 34(0)$ \\
\hline Day 3 - median [IQR] no./total no. (\%) & $0[0-0] 0 / 35(0)$ & $0[0-0] 0 / 34(0)$ \\
\hline \multicolumn{3}{|l|}{ Cryoprecipitate } \\
\hline Day 0 - median [IQR] no./total no. (\%) & $0[0-0] 1 / 35(3)$ & $0[0-0] 0 / 34(0)$ \\
\hline Day 1 - median [IQR] no./total no. (\%) & $0[0-0] 1 / 35(3)$ & $0[0-0] 0 / 34(0)$ \\
\hline Day 2 - median [IQR] no./total no. (\%) & $0[0-0] 0 / 35(0)$ & $0[0-0] 0 / 34(0)$ \\
\hline Day 3 - median [IQR] no./total no. (\%) & $0[0-0] 0 / 35(0)$ & $0[0-0] 0 / 34(0)$ \\
\hline
\end{tabular}




\subsubsection{Co-interventions}

There were no significant differences between groups in the proportion of patients requiring prokinetics (metoclopramide and erythromycin), opiates or catecholamines (Table 10.5).

Table 10.5. Co-intervention use during the study.

\begin{tabular}{|l|c|c|r|}
\hline Co-intervention & Plasma-Lyte 148 & $\mathbf{0 . 9 \%}$ saline & p-value \\
\hline Metoclopramide no./total no. (\%) & $8 / 35(22.9)$ & $15 / 34(44.1)$ & 0.06 \\
\hline Erythromycin no./total no. (\%) & $1 / 35(2.9)$ & $4 / 34(11.8)$ & 0.15 \\
\hline Opiates no./total no. (\%) & $25 / 35(100)$ & $33 / 34(97.1)$ & 0.3 \\
\hline Catecholamines no./total no. (\%) & $29 / 35(82.9)$ & $28 / 34(82.4)$ & 0.96 \\
\hline
\end{tabular}

\subsubsection{Primary outcome variable: the proportion of patients with gastrointestinal feeding intolerance}

There were no significant between group differences in the proportion of patients that developed gastrointestinal feeding intolerance. In the Plasma-Lyte 148 group, 21 of 35 patients (60.0\%) developed gastrointestinal feeding intolerance as compared to 22 of 34 patients $(64.7 \%)$ in the $0.9 \%$ saline group (odds ratio in the Plasma-Lyte 148 group, 0.82; 95\% confidence interval [Cl], 0.31 to $2.17 ; \mathrm{P}=0.69$ ).

\subsubsection{Secondary outcome variables: gastrointestinal outcomes}

GRV >500 mL was observed in 4 of 35 patients (11.4\%) in the Plasma-Lyte 148 group and 11 of 34 patients (32.4\%) in the $0.9 \%$ saline group (odds ratio in the Plasma-Lyte 148 group, $0.27 ; 95 \% \mathrm{Cl}, 0.08$ to $0.96 ; \mathrm{P}=0.04$ ) (Table 10.6). There were no differences between treatment groups in the individual proportion of patients that developed vomiting or diarrhoea.

There was a significantly lower median GRV on day 7 in the Plasma-Lyte 148 group (median [IQR], $15 \mathrm{~mL}$ [1-46mL] in the Plasma-Lyte 148 group compared to $50 \mathrm{~mL}$ [15-870mL] in the $0.9 \%$ saline group, $p=0.049$ ) (Table 10.6). There was no significant difference between groups with respect to the reason for cessation of nasogastric feeding, in diet/volume ratio received and the duration of nasogastric feeds (Table 10.6). 
In both groups, the two most common reasons for cessation of nasogastric feeding were the commencement of oral diet and ICU discharge. Within the Plasma-Lyte 148 group, there were 4 of 35 participants (11.4\%) who required cessation of nasogastric feeding due to a gastrointestinal feeding intolerance complications compared to 0 of 34 participants in the $0.9 \%$ saline group ( $p=0.11$ ). Two patients had nasogastric feeding stopped for post-operative ileus with vomiting after abdominal surgery and one patient each had nasogastric feeding stopped due to vomiting and diarrhoea.

Table 10.6. Outcomes for study three.

\begin{tabular}{|c|c|c|c|c|}
\hline Outcome & Plasma-Lyte 148 & $0.9 \%$ saline & $\begin{array}{l}\text { Odds ratio } \\
\text { (95\% Cl) }\end{array}$ & P-Value \\
\hline $\begin{array}{l}\text { Total number of patients with GI } \\
\text { feed intolerance - no./ total no. } \\
\text { (\%) }\end{array}$ & $21 / 35(60.0)$ & $22 / 34(64.7)$ & $\begin{array}{c}0.82 \\
(0.31,2.17)\end{array}$ & 0.69 \\
\hline $\begin{array}{l}\text { Patients with high GRV- } \\
\text { no./ total no. (\%) }\end{array}$ & $4 / 35(11.4)$ & $11 / 34(32.4)$ & $\begin{array}{c}0.27 \\
(0.08,0.96)\end{array}$ & 0.04 \\
\hline $\begin{array}{l}\text { - Patients with vomiting- no./ } \\
\text { total no. (\%) }\end{array}$ & $9 / 35(25.7)$ & $6 / 34(17.6)$ & $\begin{array}{c}1.62 \\
(0.51,5.12)\end{array}$ & 0.42 \\
\hline $\begin{array}{l}\text { Patients with diarrhoea- } \\
\text { no./ total no. (\%) }\end{array}$ & $16 / 35(45.7)$ & $15 / 34(44.1)$ & $\begin{array}{c}1.07 \\
(0.41,2.76)\end{array}$ & 0.89 \\
\hline Diet volume ratio & $0.86+/-0.03$ & $0.93+/-0.04$ & & 0.10 \\
\hline Duration NG feeding - days & $8.4+/-1.3$ & $10.1+/-1.2$ & & 0.23 \\
\hline $\begin{array}{l}\text { Duration of mechanical } \\
\text { ventilation - days }\end{array}$ & $7.8+/-1.2$ & $8.5+/-1.1$ & & 0.36 \\
\hline \multicolumn{3}{|c|}{ Reason for cessation of NG feeding - no./ total no. (\%) } & \multicolumn{2}{|l|}{$\begin{array}{c}\text { Odds ratio } \\
(95 \% \mathrm{Cl})\end{array}$} \\
\hline $\begin{array}{l}\text { - Commencement of oral } \\
\text { diet }\end{array}$ & $13 / 35(37.1)$ & $8 / 34(23.5)$ & $\begin{array}{c}1.92 \\
(0.67,5,48)\end{array}$ & 0.22 \\
\hline - $\quad$ GI complication & $4 / 35(11.4)$ & $0 / 34(0)$ & & 0.99 \\
\hline Other complication & $0 / 35(0)$ & $1 / 34(2.9)$ & & 0.99 \\
\hline - ICU discharge & $12 / 35(34.3)$ & $16 / 34(47.1)$ & $\begin{array}{c}0.59 \\
(0.22,1.55)\end{array}$ & 0.28 \\
\hline \multirow[t]{2}{*}{ - ICU death } & 6/35 (17.1) & $9 / 34(26.5)$ & $\begin{array}{c}0.58 \\
(0.18,1.84)\end{array}$ & 0.35 \\
\hline & & \multicolumn{3}{|c|}{$\begin{array}{c}\text { Ratio of } \\
\text { geometric means }(95 \% \mathrm{Cl})\end{array}$} \\
\hline Days in ICUt & $8.1[6.5-9.8]$ & $10.0[8.1-12.4]$ & $\begin{array}{c}0.80 \\
(0.60-1.08)\end{array}$ & 0.24 \\
\hline Days in Hospitalt & $13.1[10.4-16.6]$ & $14.0[11.0-17.8]$ & $\begin{array}{c}0.54 \\
(0.67-1.31)\end{array}$ & 0.71 \\
\hline
\end{tabular}

\footnotetext{
* Plus-minus values are mean $\pm \mathrm{SE}$. Values followed by ranges in square brackets are geometric mean [95\% Cl]. GI gastrointestinal, GRV gastric residual volume, $N G$ nasogastric.

† Days in ICU and days in hospital have been calculated from the time that patients first received study fluid in ICU until ICU and hospital discharge.

P-values for continuous outcome measures calculated using a Student's t-test.
} 
Table 10.7. Daily total gastric residual volumes $(\mathrm{mL})$ day 0 to day 7 .

\begin{tabular}{|c|c|c|c|}
\hline Gastric residual volume & Plasma-Lyte 148 & $0.9 \%$ saline & P-Value* \\
\hline Day 0 - median [IQR] no./total no. (\%) & $\begin{array}{c}140[5-285] \\
35 / 35\end{array}$ & $\begin{array}{c}68[0-328] \\
34 / 34\end{array}$ & 0.48 \\
\hline Day 1 - median [IQR] no./total no. (\%) & $\begin{array}{c}340[41-530] \\
35 / 35\end{array}$ & $\begin{array}{c}281[83-1085] \\
34 / 34\end{array}$ & 0.27 \\
\hline Day 2 - median [IQR] no./total no. (\%) & $\begin{array}{c}185[49-500] \\
35 / 35\end{array}$ & $\begin{array}{c}300[59-564] \\
34 / 34\end{array}$ & 0.32 \\
\hline Day 3 - median [IQR] no./total no. (\%) & $\begin{array}{c}100[25-434] \\
34 / 35\end{array}$ & $\begin{array}{c}167[43-450] \\
31 / 34\end{array}$ & 0.57 \\
\hline Day 4 - median [IQR] no./total no. (\%) & $\begin{array}{c}43[14-268] \\
26 / 35\end{array}$ & $\begin{array}{c}238[28-603] \\
26 / 34\end{array}$ & 0.06 \\
\hline Day 5 - median [IQR] no./total no. (\%) & $\begin{array}{c}43[6-256] \\
20 / 35\end{array}$ & $\begin{array}{c}138[24-375] \\
24 / 34\end{array}$ & 0.36 \\
\hline Day 6 - median [IQR] no./total no. (\%) & $\begin{array}{c}35[11-188] \\
14 / 35\end{array}$ & $\begin{array}{c}138[19-315] \\
21 / 34\end{array}$ & 0.18 \\
\hline Day 7 - median [IQR] no./total no. (\%) & $\begin{array}{c}15[1-46] \\
12 / 35\end{array}$ & $\begin{array}{c}50[15-870] \\
21 / 34\end{array}$ & 0.049 \\
\hline
\end{tabular}

* $P$ value for comparison of daily gastric residual volume by treatment group calculated using Wilcoxon Rank Sum test.

\subsubsection{Multivariable sensitivity analyses of primary and key secondary gastrointestinal outcome variables.}

Multivariable sensitivity analyses (adjusting for sex, trauma admission diagnosis and time until nasogastric feeding commencement) did not result in any meaningful change to the total proportion of patients developing gastrointestinal feeding intolerance (Table 10.8). The proportion of patients with GRV $>500 \mathrm{~mL}$ remained significant on multivariable sensitivity analysis (adjusted OR (95\% Cl) for the Plasma-Lyte 148 group, $0.26(0.07$ to 0.99$), p=0.049$ ). There were no significant changes to the proportion of patients that developed vomiting or diarrhoea on multivariable analysis. 
Table 10.8. Unadjusted and adjusted analysis of the primary outcome and key secondary outcomes.*

\begin{tabular}{|c|c|c|c|c|c|c|}
\hline Outcome & $\begin{array}{c}\text { Plasma-Lyte } \\
148, \mathrm{n} / \mathrm{N} \\
\text { (\%) }\end{array}$ & $\begin{array}{c}0.9 \% \\
\text { saline, } \\
\mathrm{n} / \mathrm{N}(\%)\end{array}$ & $\begin{array}{l}\text { OR } 95 \% \mathrm{Cl} \\
\text { (unadjusted) }\end{array}$ & $\begin{array}{l}\text { P- } \\
\text { value }\end{array}$ & $\begin{array}{l}\text { OR 95\%Cl } \\
\text { (adjusted)* }\end{array}$ & $\begin{array}{l}\text { Adjusted } \\
\text { P-Value }\end{array}$ \\
\hline $\begin{array}{l}\text { Total number of } \\
\text { patients with a } \\
\text { gastrointestinal } \\
\text { feeding } \\
\text { intolerance }\end{array}$ & $\begin{array}{l}21 / 35 \\
(60.0)\end{array}$ & $\begin{array}{l}22 / 34 \\
(64.7)\end{array}$ & $\begin{array}{l}0.82 \\
(0.31,2.17)\end{array}$ & 0.69 & $\begin{array}{c}1.00 \\
(0.35,2.89)\end{array}$ & 0.994 \\
\hline $\begin{array}{l}\text { Patients with GRV } \\
>500 \mathrm{~mL}\end{array}$ & $\begin{array}{l}4 / 35 \\
(11.4)\end{array}$ & $\begin{array}{l}11 / 34 \\
(32.4)\end{array}$ & $\begin{array}{l}0.27 \\
(0.08,0.96)\end{array}$ & 0.04 & $\begin{array}{c}0.26 \\
(0.07,0.99)\end{array}$ & 0.049 \\
\hline $\begin{array}{l}\text { Patients with } \\
\text { vomiting }\end{array}$ & $\begin{array}{c}9 / 35 \\
(25.7)\end{array}$ & $\begin{array}{c}6 / 34 \\
(17.6)\end{array}$ & $\begin{array}{l}1.62 \\
(0.51,5.12)\end{array}$ & 0.42 & $\begin{array}{c}2.92 \\
(0.71,12.09)\end{array}$ & 0.137 \\
\hline $\begin{array}{l}\text { Patients with } \\
\text { diarrhoea }\end{array}$ & $\begin{array}{l}16 / 35 \\
(45.7)\end{array}$ & $\begin{array}{l}15 / 34 \\
(44.1)\end{array}$ & $\begin{array}{l}1.07 \\
(0.41,2.76)\end{array}$ & 0.89 & $\begin{array}{c}1.13 \\
(0.41,3.15)\end{array}$ & 0.811 \\
\hline
\end{tabular}

* Adjusted analyses performed using logistic regression. Variables that were included are sex, trauma admission diagnosis and time until nasogastric feeding commencement.

\subsubsection{Secondary outcome variables: Service utilisation}

There were no differences between groups with respect to any of the service utilisation variables of interest (Table 10.6).

The ICU length of stay was similar in both groups (geometric mean, [95\% Cl], 8.1 days [6.5 to 9.8 days] in the Plasma-Lyte 148 group vs. 10.0 days [8.1-12.4 days] in the $0.9 \%$ saline group; ratio of geometric means for the Plasma-Lyte 148 group, [95\% Cl], $0.80(0.60$ to 1.08); $\mathrm{p}=0.24$ ). There were no differences in hospital length of stay (geometric mean, $[95 \% \mathrm{Cl}], 13.1$ days [10.4 to 16.6 days] in the Plasma-Lyte 148 group vs. 14.0 days [11.0-17.8 days] in the $0.9 \%$ saline group; ratio of geometric means for the Plasma-Lyte 148 group, [ $95 \% \mathrm{Cl}], 0.54$ (0.67 to 1.31); $p=0.71)$. There were no between-group differences the duration of mechanical ventilation. 


\subsubsection{Secondary outcome variables: Biochemical data}

There were no significant differences between groups found in the mean lowest and mean highest blood $\mathrm{pH}, \mathrm{CO}_{2}$, bicarbonate, glucose, sodium or potassium on day 0 , day 1 , day 2 or day 3 (Table 10.9).

Table 10.9. Biochemical data from day 0 to day 3.

\begin{tabular}{|c|c|c|c|}
\hline $\begin{array}{l}\text { Values followed by brackets are } \\
\text { mean (Standard error). }\end{array}$ & Plasma-Lyte 148 & $0.9 \%$ saline & P-value \\
\hline \multicolumn{4}{|l|}{ Lowest bicarbonate } \\
\hline - Day 0 & $21.9(0.8)$ & $21.0(0.8)$ & 0.40 \\
\hline - Day 1 & $22.6(0.7)$ & $22.1(0.7)$ & 0.64 \\
\hline - Day 2 & $24.2(0.7)$ & $24.6(0.8)$ & 0.71 \\
\hline - Day 3 & $24.7(0.6)$ & $24.3(0.8)$ & 0.73 \\
\hline \multicolumn{4}{|l|}{ Highest bicarbonate } \\
\hline - Day 0 & $24.2(0.8)$ & $23.4(0.8)$ & 0.50 \\
\hline - Day 1 & $25.5(0.5)$ & $24.9(0.7)$ & 0.53 \\
\hline - Day 2 & $26.8(0.7)$ & $26.5(0.7)$ & 0.75 \\
\hline - Day 3 & $27.2(0.7)$ & $26.2(0.7)$ & 0.29 \\
\hline \multicolumn{4}{|l|}{ Lowest potassium } \\
\hline - Day 0 & $3.7(0.1)$ & $3.8(0.1)$ & 0.75 \\
\hline - Day 1 & $3.7(0.1)$ & $3.7(0.1)$ & 0.60 \\
\hline - Day 2 & $3.7(0.1)$ & $3.7(0.8)$ & 0.66 \\
\hline - Day 3 & $3.7(0.1)$ & $3.6(0.1)$ & 0.47 \\
\hline \multicolumn{4}{|l|}{ Highest potassium } \\
\hline - Day 0 & $4.3(0.1)$ & $4.4(0.1)$ & 0.57 \\
\hline - Day 1 & $4.6(0.1)$ & $4.4(0.1)$ & 0.40 \\
\hline - Day 2 & $4.3(0.1)$ & $4.2(0.1)$ & 0.64 \\
\hline - Day 3 & $4.2(0.1)$ & $4.1(0.1)$ & 0.48 \\
\hline \multicolumn{4}{|l|}{ Lowest sodium } \\
\hline - Day 0 & $138.5(1.0)$ & $138.6(0.7)$ & 0.93 \\
\hline - Day 1 & $138.2(0.9)$ & $138.6(0.6)$ & 0.72 \\
\hline - Day 2 & $138.4(0.9)$ & $139.9(0.8)$ & 0.66 \\
\hline - Day 3 & $139.4(0.9)$ & $141.0(1.0)$ & 0.47 \\
\hline \multicolumn{4}{|l|}{ Highest sodium } \\
\hline - Day 0 & $142.1(1.1)$ & $141.7(0.7)$ & 0.77 \\
\hline - Day 1 & $142.4(0.9)$ & $142.3(0.6)$ & 0.89 \\
\hline - Day 2 & $142.5(0.8)$ & $143.5(0.9)$ & 0.42 \\
\hline - Day 3 & $143.0(0.9)$ & $144.3(1.1)$ & 0.38 \\
\hline \multicolumn{4}{|l|}{ Lowest glucose } \\
\hline - Day 0 & $7.4(0.4)$ & $7.2(0.3)$ & 0.66 \\
\hline - Day 1 & $7.2(0.2)$ & $6.9(0.3)$ & 0.40 \\
\hline - Day 2 & $7.3(0.2)$ & $7.4(0.4)$ & 0.90 \\
\hline - Day 3 & $7.3(0.2)$ & $7.0(0.3)$ & 0.36 \\
\hline Highest glucose & & & \\
\hline
\end{tabular}




\begin{tabular}{|c|c|c|c|}
\hline - Day 0 & $9.7(0.6)$ & $9.4(0.4)$ & 0.62 \\
\hline - Day 1 & $10.6(0.7)$ & $9.1(0.3)$ & 0.07 \\
\hline - $\quad$ Day 2 & $10.0(0.4)$ & $9.2(0.4)$ & 0.14 \\
\hline - Day 3 & $9.7(0.4)$ & $9.1(0.4)$ & 0.32 \\
\hline \multicolumn{4}{|l|}{ Lowest pH } \\
\hline - Day 0 & $7.31(0.02)$ & $7.31(0.02)$ & 0.94 \\
\hline - Day 1 & $7.34(0.02)$ & $7.35(0.01)$ & 0.60 \\
\hline - $\quad$ Day 2 & $7.37(0.01)$ & $7.38(0.01)$ & 0.25 \\
\hline - Day 3 & $7.41(0.01)$ & $7.39(0.01)$ & 0.24 \\
\hline \multicolumn{4}{|l|}{ Highest $\mathrm{pH}$} \\
\hline - Day 0 & $7.38(0.02)$ & $7.39(0.01)$ & 0.83 \\
\hline - $\quad$ Day 1 & $7.42(0.01)$ & $7.43(0.01)$ & 0.39 \\
\hline - Day 2 & $7.45(0.01)$ & $7.44(0.01)$ & 0.20 \\
\hline - Day 3 & $7.46(0.01)$ & $7.45(0.01)$ & 0.30 \\
\hline \multicolumn{4}{|c|}{ Lowest carbon dioxide } \\
\hline - Day 0 & 49.1 (3.0) & $46.5(2.3)$ & 0.50 \\
\hline - Day 1 & $45.7(1.3)$ & $43.9(1.4)$ & 0.34 \\
\hline - Day 2 & 46.0 (1.7) & $43.0(1.3)$ & 0.17 \\
\hline - Day 3 & $42.6(1.5)$ & $42.7(1.7)$ & 0.97 \\
\hline \multicolumn{4}{|c|}{ Highest carbon dioxide } \\
\hline - Day 0 & 38.5 (1.3) & $37.5(1.5)$ & 0.61 \\
\hline - Day 1 & $37.0(1.1)$ & $34.8(1.0)$ & 0.12 \\
\hline - Day 2 & $37.2(1.4)$ & $36.7(1.0)$ & 0.78 \\
\hline - Day 3 & 36.5 (1.3) & $36.2(1.3)$ & 0.87 \\
\hline
\end{tabular}




\subsubsection{Subgroup analyses: total proportion of patients with gastrointestinal feeding intolerance}

There was no significant between-group difference in the effect of treatment in the total proportion of participants developing gastrointestinal feeding intolerance in any of the predefined subgroups (Table 10.10).

Table 10.10. Subgroup analysis on the risk of developing gastrointestinal feeding intolerance.

\begin{tabular}{|c|c|c|c|c|}
\hline \multirow[t]{2}{*}{ Subgroup } & Plasma-Lyte 148 & $0.9 \%$ saline & \multirow[t]{2}{*}{ Odds Ratio $(95 \% \mathrm{Cl})$} & \multirow[t]{2}{*}{$P$ value for $O R$} \\
\hline & \multicolumn{2}{|c|}{ no. of events/total no. (\%) } & & \\
\hline Overall & $21 / 35(60.0)$ & $22 / 34(64.7)$ & $0.82(0.31-2.17)$ & 0.69 \\
\hline \multicolumn{5}{|c|}{ Diagnostic Group } \\
\hline - Medical & $9 / 14(64.3)$ & $5 / 9(55.6)$ & $1.44(0.26,7.96)$ & 0.68 \\
\hline - Surgical & $8 / 15(53.3)$ & $6 / 12(50.0)$ & $1.14(0.25,5.22)$ & 0.86 \\
\hline - Trauma & $4 / 6(66.7)$ & $11 / 13(84.6)$ & $0.36(0.04,3.51)$ & 0.38 \\
\hline \multicolumn{5}{|c|}{ APACHE II score } \\
\hline - $\quad \geq 25$ & $5 / 6(83.3)$ & $3 / 3(100)$ & & 0.99 \\
\hline - $\quad<25$ & $16 / 29(55.2)$ & $19 / 31(61.3)$ & $0.78(0.28,2.17)$ & 0.63 \\
\hline \multicolumn{5}{|l|}{ Age } \\
\hline - $\quad \geq 65$ & $7 / 10(70.0)$ & $6 / 8(75.0)$ & $0.78(0.10,6.32)$ & 0.81 \\
\hline - $\quad<65$ & $14 / 25(56.0)$ & $16 / 26(61.5)$ & $0.80(0.26,2.43)$ & 0.69 \\
\hline \multicolumn{5}{|l|}{ BMI } \\
\hline - $\quad \geq 30$ & $4 / 9(44.4)$ & $7 / 13(53.8)$ & $0.69(0.12,3.78)$ & 0.67 \\
\hline - $\quad<30$ & $17 / 26(65.4)$ & $15 / 21(71.4)$ & $0.76(0.22,2.62)$ & 0.66 \\
\hline \multicolumn{5}{|l|}{ Gender } \\
\hline - Male & $12 / 20(60.0)$ & $19 / 27(70.4)$ & $0.63(0.19,2.13)$ & 0.46 \\
\hline - $\quad$ Female & $9 / 15(60.0)$ & $3 / 7$ (42.9) & $2.00(0.32,12.33)$ & 0.46 \\
\hline
\end{tabular}

\subsubsection{Protocol deviations}

One participant allocated to the Plasma-Lyte 148 group had received a $500 \mathrm{~mL}$ bolus of $0.9 \%$ saline study fluid in error during the study.

\subsubsection{Adverse events}

There were no reported serious events that were judged to be potentially related to study treatment. 


\subsection{Discussion for study three}

\subsubsection{Statement of principal findings}

In this single centred nested cohort study, there was no difference in the primary outcome: of the proportion of patients developing gastrointestinal feeding intolerance in a population of mechanically ventilated patients receiving nasogastric feeding given either Plasma-Lyte 148 compared with $0.9 \%$ saline. However, the secondary endpoint of GRV $>500 \mathrm{~mL}$ in isolation, occurred in a significantly higher proportion of patients assigned to $0.9 \%$ saline. This difference remained after adjustment for baseline imbalance.

\subsubsection{Significance of the findings}

No previous clinical trials have assessed the gastrointestinal effects of different crystalloid fluids in critically ill patients. Prospective studies that have investigated the influence of different crystalloid fluids of gastrointestinal symptoms have largely been performed in selective surgical populations with conflicting results.

Study three's results were at variance with a recent propensity matched observational study of patients undergoing major abdominal surgery that reported that the odds of having a minor gastrointestinal complication (defined as nausea, vomiting and ileus) were significantly higher in patients that had received exclusively Plasma-Lyte 148 or Plasma-Lyte $A^{\circledR}$ compared with those that had exclusively received $0.9 \%$ saline $(O R=1.45, P<0.05)$ (Shaw et al., 2012).

High GRV and vomiting are considered valid surrogate markers for upper gastrointestinal feeding intolerance (Mentec et al., 2001). The stomach is under complex intrinsic neurohormonal control and normal function has been reported to be sensitive to external influences with a number of agents commonly used in the ICU such as opiates, sedatives and vasopressors thought to significantly affect gastric emptying and feeding tolerance (Deane et al., 2007). Significant differences in intraoperative gastric tonometry $\mathrm{CO}_{2}$ gradient, a surrogate measure for gastric mucosal perfusion, in addition to significantly lower rates of hyperchloremia and metabolic acidosis, have been observed with the use of buffered fluids compared with saline in elective surgical patients (Wilkes et al., 2001). Our findings of no 
significant metabolic differences between groups indicate that intravenous fluid may impair upper GI function by an alternative mechanism to acid/base disturbance.

Rat models have reported that crystalloid fluid resuscitation can cause acute hydrostatic gut oedema and delayed intestinal transit time (Moore-Olufemi, Xue, Attuwaybi, et al., 2005). In healthy volunteers, a two litre infusion of saline has been shown to cause significantly increased extracellular fluid expansion when compared to a two litre infusion of Plasma-Lyte 148 (Chowdhury et al., 2012). These findings raise the possibility that increased interstitial oedema caused by intravenous fluid administration may have some effect on upper gastrointestinal motility. Study three's findings are consistent with this possibility. Alternatively, the composition of the different crystalloid fluids may have differential effects on splanchnic perfusion. Low volumes of Plasma-Lyte compared to $0.9 \%$ saline has been associated with reduced visceral blood flow and vasoactive properties; with a significantly increased renal artery blood flow velocity, increased renal cortical perfusion and increased saphenous vein graft relaxation (Chowdhury et al., 2012; Sanchez et al., 1994). However, no direct vasoactive effect has been demonstrated with splanchnic perfusion.

\subsubsection{Strengths and limitations}

This pilot study was an opportunistic, pragmatic study that allowed for co-enrolment and concurrent investigation of the impact of a ubiquitous intervention used in the ICU on gastrointestinal function in a high-risk but previously unstudied population. The risk of bias was minimised through allocation concealment, blinding of study groups and publication of a pre-specified statistical analysis plan (Reddy et al., 2015).

The main limitations of the study are the small sample size and that it was not possible to perform prospective sample size calculations. This was due to two reasons; first as recruitment of this study was dependent on enrolment into study one, which was set to run for a specific duration of time, the final recruitment number for this study was unknown at its commencement. Secondly, there are no previous studies that had been performed within this population that would allow for appropriate power calculations. Based on the results from our study we estimate that 1665 patients per group would need to be enrolled for a study to have $80 \%$ power to detect a proportion of patients with gastrointestinal feeding 
intolerance of $60.0 \%$ in the Plasma-Lyte 148 and $64.7 \%$ in the $0.9 \%$ saline, at an overall twosided alpha of 0.05 .

No adjustment was made for multiple comparisons in the analysis plan, and, the observed difference in GRV between treatment groups may therefore represent a type one error and should be regarded as hypothesis-generating. The numerically higher proportion of patients who were given prokinetics in the saline group may, in part, explain the lower proportion of patients in the saline group with vomiting but a significantly higher proportion of patients with high GRV.

Our primary outcome was a composite outcome which contained clinical signs and symptoms that indicate gastrointestinal feeding intolerance. As mentioned previously we acknowledge that definitions in this field are varied and the use of GRV monitoring in critically ill patients is a contentious topic.

No physiological tests of gastrointestinal function were conducted as these were cost prohibitive. However, in any case, there are no accurate markers to assess gastrointestinal function in daily clinical practice and no validated system for grading the severity of gastrointestinal dysfunction (Martindale et al., 2009; McClave et al., 2009; Reintam Blaser et al., 2012).

The study has a number of strengths. Because $99.7 \%$ of all eligible patients were included and analysed in study one and all these patients were screened for eligibility and, where eligible, were included in this study, our data were not subject to selection bias. The use of a specific feeding protocol allowed for a standardised approach to enteral feeding that may have reduced the risk of bias.

\subsubsection{Conclusions}

A single centre nested cohort study within a randomised, double blind, double crossover study was conducted to compare the gastrointestinal effects of Plasma-Lyte -148 versus $0.9 \%$ saline, for crystalloid fluid therapy in a population of nasogastric fed mechanically ventilated patients in a multidisciplinary tertiary ICU. No difference in the combined proportion of patients with gastrointestinal feeding intolerance was found, however, a higher proportion of patients in the saline group developed high GRV. These findings support 
the need for further clinical investigation in this area to determine if the use of $0.9 \%$ saline versus Plasma-Lyte 148 leads to differences in upper gastrointestinal dysmotility. 


\section{Implications and future directions}

After 180 years of using intravenous fluid therapy, this research programme provides the first body of evidence from interventional studies on the comparative effectiveness of two different types of crystalloid fluids in critically unwell patients.

The primary aims of this research programme were to provide preliminary data on the comparative effectiveness of $0.9 \%$ saline compared Plasma-Lyte 148 with respect to the:

- risk of developing AKI in critically ill patients based on creatinine levels.

- need for blood and blood products in adult cardiac surgical patients admitted to ICU following cardiac surgery.

- risk of developing gastrointestinal feeding intolerance in adult mechanically ventilated patients receiving enteral nutrition via nasogastric feeding.

The novel study design used for study one allowed for near complete enrolment and analysis of all eligible patients. There was high protocol adherence and near complete follow-up which supports the feasibility and reliability of large-scale cluster double-crossover trial design in the ICU. However, future investigators need to be aware of the major weakness of this study design which is the lack of statistical methodologies to allow for accurate prospective power calculations.

Study one's findings, which observed no difference in risk of AKI between Plasma-Lyte 148 and $0.9 \%$ saline, provide the best available evidence to suggest equipoise in renal outcomes with the use of these fluids in the ICU. This is reassuring for the prescribers of intravenous fluids in the ICU. Criticism can be drawn on the low acuity of study one's patient population (a large proportion of elective surgical patients) that received a moderate amount of study fluid and the lack of supporting biochemical data (Kellum \& Shaw, 2015). However, study one was a pragmatic study which used similar volumes of fluid to an observational study that had reported benefit in renal outcomes after switching from high chloride to low chloride intravenous fluids (Yunos et al., 2012). There is evidence from observational data to suggest that there may be a mortality benefit with the use of buffered crystalloid solutions in patient populations that require large volume fluid resuscitation i.e. septic patients 
(Raghunathan et al., 2014). Study one had insufficient power to examine effects on mortality between fluids, although there was a non-significant $12.8 \%$ trend towards lower in patients assigned Plasma-Lyte 148 ( $5 \%$ vs. 8.6\%; RR 0.87; 95\% 0.66 to 1.55; $p=0.36$ ). Differences in mortality may exist with the use of Plasma-Lyte 148 compared to $0.9 \%$ saline and warrant further investigation through a large randomised trial within a higher risk patient population. Additionally, from a health economic perspective further research on the comparative safety of intravenous fluids is important. A cost sensitivity analysis on the different types of intravenous fluids used for resuscitation conducted by the NICE advisory committee calculated that only less than one extra major complication per 1000 patients would need to be avoided for Plasma-Lyte 148 to be cost neutral compared with $0.9 \%$ saline (Padhi et al., 2013).

Study two and study three were opportunistic and allowed for concurrent investigation of outcomes that would have otherwise been unlikely to be independently investigated. Although the study findings of increased blood transfusion requirements and low GRV observed in patients allocated to Plasma-Lyte 148 are unique they are at risk of a type one error and should only be viewed as hypothesis generating. These sub-studies are important as they demonstrate that there may be significant and differing effects with the use of $0.9 \%$ saline compared to Plasma-Lyte 148 in different body systems and patient populations. Study two and study three support the need for further research into specific sub-groups of patients and support further research into the haemostatic and gastrointestinal effects of crystalloid fluid resuscitation in critically unwell patients.

Intravenous fluids are an essential but modifiable part of the care for the majority of critical unwell patients. Each type of intravenous fluid has a unique preparation with different properties. Among the buffered crystalloid fluids there are differences in composition and they should therefore not be considered as biologically equivalent. Hence, research using acetate/gluconate containing buffered crystalloids (Plasma-Lyte 148) may not be generalisable to lactate based buffered crystalloids (Ringer's lactate and Hartmann's fluid). As a consequence, there are still many areas of ongoing uncertainty about their comparative safety. 
This research programme provides preliminary data on the comparative effectiveness of 0.9\% saline compared to Plasma-Lyte 148 on AKI, post-operative blood transfusion requirements and gastrointestinal dysfunction in critically unwell patients. Caution needs to be taken in the generalisation of these study results and further research is required to confirm or refute the research programmes findings. There is still a paucity of evidence to guide clinical practice in the safe use of intravenous fluids. In the absence of robust evidence, clinicians should justify their prescribing based on the clinical context and each fluids unique physiochemical properties and known side effect profile. 


\section{References}

Akanji, A. O., Bruce, M. A., \& Frayn, K. N. (1989). Effect of acetate infusion on energy expenditure and substrate oxidation rates in non-diabetic and diabetic subjects. Eur $J$ Clin Nutr, 43(2), 107-115. Retrieved from http://www.ncbi.nlm.nih.gov/entrez/query.fcgi?cmd=Retrieve\&db=PubMed\&dopt=C itation\&list uids $=2651106$

Akanji, A. O., \& Hockaday, T. D. (1990). Acetate tolerance and the kinetics of acetate utilization in diabetic and nondiabetic subjects. Am J Clin Nutr, 51(1), 112-118. Retrieved from http://www.ncbi.nlm.nih.gov/entrez/query.fcgi?cmd=Retrieve\&db=PubMed\&dopt=C itation\&list uids $=2153334$

Aoki, K., Yoshino, A., Yoh, K., Sekine, K., Yamazaki, M., \& Aikawa, N. (2010). A comparison of Ringer's lactate and acetate solutions and resuscitative effects on splanchnic dysoxia in patients with extensive burns. Burns, 36(7), 1080-1085. doi:S0305-4179(10)000914 [pii]

10.1016/j.burns.2010.04.002

Austin, P. C. (2011). An Introduction to Propensity Score Methods for Reducing the Effects of Confounding in Observational Studies. Multivariate Behav Res, 46(3), 399-424. doi:10.1080/00273171.2011.568786

Awad, S., Allison, S. P., \& Lobo, D. N. (2008). The history of 0.9\% saline. Clin Nutr, 27(2), 179188. doi:S0261-5614(08)00028-9 [pii]

10.1016/j.clnu.2008.01.008

Bayer, O., Reinhart, K., Sakr, Y., Kabisch, B., Kohl, M., Riedemann, N. C., . . . Hartog, C. S. (2011). Renal effects of synthetic colloids and crystalloids in patients with severe sepsis: a prospective sequential comparison. Crit Care Med, 39(6), 1335-1342. doi:10.1097/CCM.0b013e318212096a

Bellomo, R., Ronco, C., Kellum, J. A., Mehta, R. L., \& Palevsky, P. (2004). Acute renal failure definition, outcome measures, animal models, fluid therapy and information technology needs: the Second International Consensus Conference of the Acute Dialysis Quality Initiative (ADQI) Group. Crit Care, 8(4), R204-212. doi:10.1186/cc2872

cc2872 [pii]

Bennett-Guerrero, E., Zhao, Y., O'Brien, S. M., Ferguson, T. B., Jr., Peterson, E. D., Gammie, J. S., \& Song, H. K. (2010). Variation in use of blood transfusion in coronary artery bypass graft surgery. JAMA, 304(14), 1568-1575. doi:10.1001/jama.2010.1406

Berger, N. G., Ridolfi, T. J., \& Ludwig, K. A. (2015). Delayed gastrointestinal recovery after abdominal operation - role of alvimopan. Clin Exp Gastroenterol, 8, 231-235. doi:10.2147/CEG.S64029

Bion, J., Bellomo, R., Myburgh, J., Perner, A., Reinhart, K., \& Finfer, S. (2014). Hydroxyethyl starch: putting patient safety first. Intensive Care Med, 40(2), 256-259. doi:10.1007/s00134-013-3167-6

Blantz, R. C., Deng, A., Miracle, C. M., \& Thomson, S. C. (2007). Regulation of kidney function and metabolism: a question of supply and demand. Trans Am Clin Climatol Assoc, 118, 23-43. Retrieved from http://www.ncbi.nlm.nih.gov/pubmed/18528487 
Brummel-Ziedins, K., Whelihan, M. F., Ziedins, E. G., \& Mann, K. G. (2006). The resuscitative fluid you choose may potentiate bleeding. J Trauma, 61(6), 1350-1358. doi:10.1097/01.ta.0000235525.64176.01

00005373-200612000-00009 [pii]

Bullivant, E. M., Wilcox, C. S., \& Welch, W. J. (1989). Intrarenal vasoconstriction during hyperchloremia: role of thromboxane. Am J Physiol, 256(1 Pt 2), F152-157. Retrieved from http://www.ncbi.nlm.nih.gov/pubmed/2912160

Burdett, E., Dushianthan, A., Bennett-Guerrero, E., Cro, S., Gan, T. J., Grocott, M. P., . . . Rowan, K. (2012). Perioperative buffered versus non-buffered fluid administration for surgery in adults. Cochrane Database Syst Rev, 12, CD004089. doi:10.1002/14651858.CD004089.pub2

Chanimov, M., Gershfeld, S., Cohen, M. L., Sherman, D., \& Bahar, M. (2006). Fluid preload before spinal anaesthesia in Caesarean section: the effect on neonatal acid-base status. Eur J Anaesthesiol, 23(8), 676-679. doi:S0265021506000044 [pii]

\section{$10.1017 / \mathrm{S} 0265021506000044$}

Chapman, M. J., Fraser, R. J., Matthews, G., Russo, A., Bellon, M., Besanko, L. K., . . . Horowitz, M. (2009). Glucose absorption and gastric emptying in critical illness. Crit Care, 13(4), R140. doi:cc8021 [pii]

\section{$10.1186 /$ cc8021}

Chee, Y. L., Crawford, J. C., Watson, H. G., \& Greaves, M. (2008). Guidelines on the assessment of bleeding risk prior to surgery or invasive procedures. British Committee for Standards in Haematology. Br J Haematol, 140(5), 496-504. doi:10.1111/j.1365-2141.2007.06968.x

Chin, K. J., Macachor, J., Ong, K. C., \& Ong, B. C. (2006). A comparison of $5 \%$ dextrose in $0.9 \%$ normal saline versus non-dextrose-containing crystalloids as the initial intravenous replacement fluid in elective surgery. Anaesth Intensive Care, 34(5), 613-617. Retrieved

from http://www.ncbi.nlm.nih.gov/entrez/query.fcgi?cmd=Retrieve\&db=PubMed\&dopt=C itation\&list uids $=17061636$

Cho, Y. S., Lim, H., \& Kim, S. H. (2007). Comparison of lactated Ringer's solution and $0.9 \%$ saline in the treatment of rhabdomyolysis induced by doxylamine intoxication. Emerg Med J, 24(4), 276-280. doi:24/4/276 [pii]

\subsection{6/emj.2006.043265}

Chowdhury, A. H., Cox, E. F., Francis, S. T., \& Lobo, D. N. (2012). A randomized, controlled, double-blind crossover study on the effects of $2-L$ infusions of $0.9 \%$ saline and plasma-lyte(R) 148 on renal blood flow velocity and renal cortical tissue perfusion in healthy volunteers. Ann Surg, 256(1), 18-24. doi:10.1097/SLA.0b013e318256be72

Cieza, J. A., Hinostroza, J., Huapaya, J. A., \& Leon, C. P. (2013). Sodium chloride $0.9 \%$ versus Lactated Ringer in the management of severely dehydrated patients with choleriform diarrhoea. J Infect Dev Ctries, 7(7), 528-532. Retrieved from http://www.ncbi.nlm.nih.gov/entrez/query.fcgi?cmd=Retrieve\&db=PubMed\&dopt=C itation\&list uids $=23857387$

Coll, E., Perez-Garcia, R., Rodriguez-Benitez, P., Ortega, M., Martinez Miguel, P., Jofre, R., \& Lopez-Gomez, J. M. (2007). Clinical and analytical changes in hemodialysis without acetate. Nefrologia, 27(6), 742-748. Retrieved from 
http://www.ncbi.nlm.nih.gov/entrez/query.fcgi?cmd=Retrieve\&db=PubMed\&dopt=C itation\&list uids $=18336105$

Corcoran, T., Rhodes, J. E., Clarke, S., Myles, P. S., \& Ho, K. M. (2012). Perioperative fluid management strategies in major surgery: a stratified meta-analysis. Anesth Analg, 114(3), 640-651. doi:ANE.0b013e318240d6eb [pii]

\subsection{3/ANE.0b013e318240d6eb}

Davies, P. G., Venkatesh, B., Morgan, T. J., Presneill, J. J., Kruger, P. S., Thomas, B. J., . . . Mundy, J. (2011). Plasma acetate, gluconate and interleukin- 6 profiles during and after cardiopulmonary bypass: a comparison of Plasma-Lyte 148 with a bicarbonatebalanced solution. Crit Care, 15(1), R21. doi:cc9966 [pii]

\section{$10.1186 /$ cc9966}

De Jonghe, B., Appere-De-Vechi, C., Fournier, M., Tran, B., Merrer, J., Melchior, J. C., \& Outin, $H$. (2001). A prospective survey of nutritional support practices in intensive care unit patients: what is prescribed? What is delivered? Crit Care Med, 29(1), 8-12. Retrieved from http://www.ncbi.nlm.nih.gov/entrez/query.fcgi?cmd=Retrieve\&db=PubMed\&dopt=C itation\&list uids $=11176150$

Deane, A., Chapman, M. J., Fraser, R. J., Bryant, L. K., Burgstad, C., \& Nguyen, N. Q. (2007). Mechanisms underlying feed intolerance in the critically ill: implications for treatment. World J Gastroenterol, 13(29), 3909-3917. Retrieved from http://www.ncbi.nlm.nih.gov/pubmed/17663503

Deane, A., Chapman, M. J., Fraser, R. J., \& Horowitz, M. (2010). Bench-to-bedside review: the gut as an endocrine organ in the critically ill. Crit Care, 14(5), 228. doi:cc9039 [pii]

$10.1186 /$ cc9039

Despotis, G., Avidan, M., \& Eby, C. (2009). Prediction and management of bleeding in cardiac surgery. J Thromb Haemost, 7 Suppl 1, 111-117. doi:JTH3412 [pii]

10.1111/j.1538-7836.2009.03412.x

Despotis, G. J., Filos, K. S., Zoys, T. N., Hogue, C. W., Jr., Spitznagel, E., \& Lappas, D. G. (1996). Factors associated with excessive postoperative blood loss and hemostatic transfusion requirements: a multivariate analysis in cardiac surgical patients. Anesth Analg, 82(1), 13-21. Retrieved from http://www.ncbi.nlm.nih.gov/pubmed/8712388

Dixon, B., Reid, D., Collins, M., Newcomb, A. E., Rosalion, A., Yap, C. H., . . . Campbell, D. J. (2014). The operating surgeon is an independent predictor of chest tube drainage following cardiac surgery. J Cardiothorac Vasc Anesth, 28(2), 242-246. doi:S10530770(13)00517-X [pii]

10.1053/j.jvca.2013.09.010

Dvir, D., Cohen, J., \& Singer, P. (2006). Computerized energy balance and complications in critically ill patients: an observational study. Clin Nutr, 25(1), 37-44. doi:S02615614(05)00187-1 [pii]

10.1016/j.clnu.2005.10.010

Ekblad, H., Kero, P., \& Takala, J. (1985). Slow sodium acetate infusion in the correction of metabolic acidosis in premature infants. Am J Dis Child, 139(7), 708-710. Retrieved from 
http://www.ncbi.nlm.nih.gov/entrez/query.fcgi?cmd=Retrieve\&db=PubMed\&dopt=C itation\&list uids $=4014095$

Eliahou, H. E., Feng, P. H., Weinberg, U., laina, A., \& Reisin, E. (1970). Acetate and bicarbonate in the correction of uraemic acidosis. $\mathrm{Br}$ Med J, 4(5732), 399-401. Retrieved from http://www.ncbi.nIm.nih.gov/entrez/query.fcgi?cmd=Retrieve\&db=PubMed\&dopt=C itation\&list uids $=5481517$

Ferraris, V. A., \& Ferraris, S. P. (1995). Limiting excessive postoperative blood transfusion after cardiac procedures. A review. Tex Heart Inst J, 22(3), 216-230. Retrieved from http://www.ncbi.nlm.nih.gov/entrez/query.fcgi?cmd=Retrieve\&db=PubMed\&dopt=C itation \&list uids $=7580359$

Ferraris, V. A., Ferraris, S. P., Saha, S. P., Hessel, E. A., 2nd, Haan, C. K., Royston, B. D., . . . Body, S. (2007). Perioperative blood transfusion and blood conservation in cardiac surgery: the Society of Thoracic Surgeons and The Society of Cardiovascular Anesthesiologists clinical practice guideline. Ann Thorac Surg, 83(5 Suppl), S27-86. doi:S0003-4975(07)00495-X [pii]

10.1016/j.athoracsur.2007.02.099

Finfer, S., Bellomo, R., Boyce, N., French, J., Myburgh, J., \& Norton, R. (2004). A comparison of albumin and saline for fluid resuscitation in the intensive care unit. $N$ Engl J Med, 350(22), 2247-2256. doi:10.1056/NEJMoa040232

350/22/2247 [pii]

Finfer, S., Liu, B., Chittock, D. R., Norton, R., Myburgh, J. A., McArthur, C., . . Robinson, B. G. Hypoglycemia and risk of death in critically ill patients. N Engl J Med, 367(12), 11081118. doi:10.1056/NEJMoa1204942

Finfer, S., Liu, B., Taylor, C., Bellomo, R., Billot, L., Cook, D., . . . Myburgh, J. (2010). Resuscitation fluid use in critically ill adults: an international cross-sectional study in 391 intensive care units. Crit Care, 14(5), R185. doi:cc9293 [pii]

$10.1186 / \operatorname{cc} 9293$

Gu, Y. J., \& Boonstra, P. W. (2006). Selection of priming solutions for cardiopulmonary bypass in adults. Multimed Man Cardiothorac Surg, 2006(109), mmcts 2005001198. doi:mmcts.2005.001198 [pii]

10.1510/mmcts.2005.001198

Hadimioglu, N., Saadawy, I., Saglam, T., Ertug, Z., \& Dinckan, A. (2008). The effect of different crystalloid solutions on acid-base balance and early kidney function after kidney transplantation. Anesth Analg, 107(1), 264-269. doi:107/1/264 [pii]

10.1213/ane.0b013e3181732d64

Hajjar, L. A., Vincent, J. L., Galas, F. R., Nakamura, R. E., Silva, C. M., Santos, M. H., . . Auler, J. O., Jr. (2010). Transfusion requirements after cardiac surgery: the TRACS randomized controlled trial. JAMA, 304(14), 1559-1567. doi:10.1001/jama.2010.1446

Hamada, T., Yamamoto, M., Nakamaru, K., Iwaki, K., Ito, Y., \& Koizumi, T. (1997). The pharmacokinetics of D-lactate, L-lactate and acetate in humans. Masui, 46(2), 229236.

Retrieved

from http://www.ncbi.nlm.nih.gov/entrez/query.fcgi?cmd=Retrieve\&db=PubMed\&dopt=C itation\&list uids $=9071107$ 
Hartmann, M., Sucker, C., Boehm, O., Koch, A., Loer, S., \& Zacharowski, K. (2006). Effects of cardiac surgery on hemostasis. Transfus Med Rev, 20(3), 230-241. doi:S08877963(06)00015-0 [pii]

10.1016/j.tmrv.2006.03.003

Hasman, H., Cinar, O., Uzun, A., Cevik, E., Jay, L., \& Comert, B. (2012). A randomized clinical trial comparing the effect of rapidly infused crystalloids on acid-base status in dehydrated patients in the emergency department. Int J Med Sci, 9(1), 59-64. Retrieved from http://www.ncbi.nlm.nih.gov/entrez/query.fcgi?cmd=Retrieve\&db=PubMed\&dopt=C itation\&list uids $=22211091$

Healey, M. A., Davis, R. E., Liu, F. C., Loomis, W. H., \& Hoyt, D. B. (1998). Lactated ringer's is superior to normal saline in a model of massive hemorrhage and resuscitation. $J$ Trauma, 45(5), 894-899. Retrieved from http://www.ncbi.nlm.nih.gov/pubmed/9820700

Heidari SM, Saryazdi H, Shafa A, \& Arefpour R. (2011). Comparison of the effect of preoperative administration of Ringer's solution, normal saline and hypertonic saline $5 \%$ on postoperative nausea and vomiting: a randomized, double blinded clinical study. Pak J Med, 27, 771-774.

Hoffman, M., \& Monroe, D. M., 3rd. (2001). A cell-based model of hemostasis. Thromb Haemost, 85(6), 958-965. doi:01060958 [pii]

Jacob, A. D., Elkins, N., Reiss, O. K., Chan, L., \& Shapiro, J. I. (1997). Effects of acetate on energy metabolism and function in the isolated perfused rat heart. Kidney Int, 52(3), 755-760.

Retrieved

from

http://www.ncbi.nlm.nih.gov/entrez/query.fcgi?cmd=Retrieve\&db=PubMed\&dopt=C itation\&list uids $=9291197$

Johansson, P. I., Stensballe, J., Oliveri, R., Wade, C. E., Ostrowski, S. R., \& Holcomb, J. B. (2014). How I treat patients with massive hemorrhage. Blood, 124(20), 3052-3058. doi:blood-2014-05-575340 [pii]

10.1182/blood-2014-05-575340

Karaca B, S. M., Yildiz TS, Ozkarakas H, Toker K. (2006). Effects of various loading solutions on postspinal hearing loss. J Turk Anesthesiol Reanim Soc, 36, 156-161.

Kastrup, M., Markewitz, A., Spies, C., Carl, M., Erb, J., Grosse, J., \& Schirmer, U. (2007). Current practice of hemodynamic monitoring and vasopressor and inotropic therapy in post-operative cardiac surgery patients in Germany: results from a postal survey. Acta Anaesthesiol Scand, 51(3), 347-358. doi:AAS1190 [pii]

10.1111/j.1399-6576.2006.01190.x

Kellum, J. A., Lameire, N., \& KDIGO AKI Guideline Work Group. (2013). Diagnosis, evaluation, and management of acute kidney injury: a KDIGO summary (Part 1). Crit Care, 17(1), 204. doi:10.1186/cc11454

Kellum, J. A., \& Shaw, A. D. (2015). Assessing Toxicity of Intravenous Crystalloids in Critically III Patients. JAMA, 314(16), 1695-1697. doi:10.1001/jama.2015.12390

Kerr, R., Stirling, D., \& Ludlam, C. A. (2001). Interleukin 6 and haemostasis. Br J Haematol, 115(1), 3-12. Retrieved from http://www.ncbi.nlm.nih.gov/pubmed/11722403 
Khajavi, M. R., Etezadi, F., Moharari, R. S., Imani, F., Meysamie, A. P., Khashayar, P., \& Najafi, A. (2008). Effects of normal saline vs. lactated ringer's during renal transplantation. Ren Fail, 30(5), 535-539. doi:794015825 [pii]

\section{$10.1080 / 08860220802064770$}

Kim, S. Y., Huh, K. H., Lee, J. R., Kim, S. H., Jeong, S. H., \& Choi, Y. S. (2013). Comparison of the effects of normal saline versus Plasmalyte on acid-base balance during living donor kidney transplantation using the Stewart and base excess methods. Transplant Proc, 45(6), 2191-2196. doi:S0041-1345(13)00499-5 [pii]

10.1016/j.transproceed.2013.02.124

Kiraly, L. N., Differding, J. A., Enomoto, T. M., Sawai, R. S., Muller, P. J., Diggs, B., . . . Schreiber, M. A. (2006). Resuscitation with normal saline (NS) vs. lactated ringers (LR) modulates hypercoagulability and leads to increased blood loss in an uncontrolled hemorrhagic shock swine model. J Trauma, 61(1), 57-64; discussion 64-55. doi:10.1097/01.ta.0000220373.29743.69

00005373-200607000-00008 [pii]

Kirkendol, P. L., Starrs, J., \& Gonzalez, F. M. (1980). The effects of acetate, lactate, succinate and gluconate on plasma $\mathrm{pH}$ and electrolytes in dogs. Trans Am Soc Artif Intern Organs, 26, 323-327. Retrieved from http://www.ncbi.nlm.nih.gov/entrez/query.fcgi?cmd=Retrieve\&db=PubMed\&dopt=C itation\&list uids $=7245507$

Kirkendol, R. L., Pearson, J. E., Bower, J. D., \& Holbert, R. D. (1978). Myocardial depressant effects of sodium acetate. Cardiovasc Res, 12(2), 127-136. Retrieved from http://www.ncbi.nlm.nih.gov/entrez/query.fcgi?cmd=Retrieve\&db=PubMed\&dopt=C itation\&list uids $=647712$

Knaus, W. A., Draper, E. A., Wagner, D. P., \& Zimmerman, J. E. (1985). APACHE II: a severity of disease classification system. Crit Care Med, 13(10), 818-829. Retrieved from http://www.ncbi.nlm.nih.gov/entrez/query.fcgi?cmd=Retrieve\&db=PubMed\&dopt=C itation\&list uids $=3928249$

Kogan, A., Preisman, S., Bar, A., Sternik, L., Lavee, J., Malachy, A., . . Raanani, E. (2012). The impact of hyperlactatemia on postoperative outcome after adult cardiac surgery. $J$ Anesth, 26(2), 174-178. doi:10.1007/s00540-011-1287-0

Krajewski, M. L., Raghunathan, K., Paluszkiewicz, S. M., Schermer, C. R., \& Shaw, A. D. (2015). Meta-analysis of high- versus low-chloride content in perioperative and critical care fluid resuscitation. Br J Surg, 102(1), 24-36. doi:10.1002/bjs.9651

Kveim, M., \& Nesbakken, R. (1979). Utilization of exogenous acetate during canine haemorrhagic shock. Scand J Clin Lab Invest, 39(7), 653-658. Retrieved from http://www.ncbi.nlm.nih.gov/entrez/query.fcgi?cmd=Retrieve\&db=PubMed\&dopt=C itation\&list uids $=43582$

Kwiatt, M., Tarbox, A., Seamon, M. J., Swaroop, M., Cipolla, J., Allen, C., . . Stawicki, S. P. (2014). Thoracostomy tubes: A comprehensive review of complications and related topics. Int J Crit IIIn Inj Sci, 4(2), 143-155. doi:10.4103/2229-5151.134182

Levey, A. S., Bosch, J. P., Lewis, J. B., Greene, T., Rogers, N., \& Roth, D. (1999). A more accurate method to estimate glomerular filtration rate from serum creatinine: a new prediction equation. Modification of Diet in Renal Disease Study Group. Ann Intern Med, 130(6), 461-470. doi:199903160-00002 [pii] 
Lira, A., \& Pinsky, M. R. (2014). Choices in fluid type and volume during resuscitation: impact on patient outcomes. Ann Intensive Care, 4, 38. doi:10.1186/s13613-014-0038-4

s13613-014-0038-4 [pii]

Liskaser, F. J., Bellomo, R., Hayhoe, M., Story, D., Poustie, S., Smith, B., . . . Bennett, M. (2000). Role of pump prime in the etiology and pathogenesis of cardiopulmonary bypass-associated acidosis. Anesthesiology, 93(5), 1170-1173. Retrieved from http://www.ncbi.nlm.nih.gov/entrez/query.fcgi?cmd=Retrieve\&db=PubMed\&dopt=C itation\&list uids $=11046201$

Lobo, D. N., \& Awad, S. (2014). Should chloride-rich crystalloids remain the mainstay of fluid resuscitation to prevent 'pre-renal' acute kidney injury?: con. Kidney Int, 86(6), 10961105. doi:ki2014105 [pii]

10.1038/ki.2014.105

Lopes, J. A., \& Jorge, S. (2013). The RIFLE and AKIN classifications for acute kidney injury: a critical and comprehensive review. Clin Kidney J., 6, 8-14.

Mahler, S. A., Conrad, S. A., Wang, H., \& Arnold, T. C. (2011). Resuscitation with balanced electrolyte solution prevents hyperchloremic metabolic acidosis in patients with diabetic ketoacidosis. Am J Emerg Med, 29(6), 670-674. doi:S0735-6757(10)00089-6 [pii]

10.1016/j.ajem.2010.02.004

Makar, M., Taylor, J., Zhao, M., Farrohi, A., Trimming, M., \& D'Attellis, N. (2010). Perioperative Coagulopathy, Bleeding, and Hemostasis During Cardiac Surgery A Comprehensive Review. ICU Director, 1(1), 17-27.

Marik, P. E., \& Zaloga, G. P. (2001). Early enteral nutrition in acutely ill patients: a systematic review. Crit Care Med, 29(12), 2264-2270. Retrieved from http://www.ncbi.nlm.nih.gov/entrez/query.fcgi?cmd=Retrieve\&db=PubMed\&dopt=C itation\&list uids $=11801821$

Martindale, R. G., McClave, S. A., Vanek, V. W., McCarthy, M., Roberts, P., Taylor, B., . . . Cresci, G. (2009). Guidelines for the provision and assessment of nutrition support therapy in the adult critically ill patient: Society of Critical Care Medicine and American Society for Parenteral and Enteral Nutrition: Executive Summary. Crit Care Med, 37(5), 1757-1761. doi:10.1097/CCM.0b013e3181a40116

00003246-200905000-00031 [pii]

Martini, W. Z., Cortez, D. S., \& Dubick, M. A. (2013). Comparisons of normal saline and lactated Ringer's resuscitation on hemodynamics, metabolic responses, and coagulation in pigs after severe hemorrhagic shock. Scand J Trauma Resusc Emerg Med, 21, 86. doi:1757-7241-21-86 [pii]

10.1186/1757-7241-21-86

McCague, A., Dermendjieva, M., Hutchinson, R., Wong, D. T., \& Dao, N. (2011). Sodium acetate infusion in critically ill trauma patients for hyperchloremic acidosis. Scand J Trauma Resusc Emerg Med, 19, 24. doi:1757-7241-19-24 [pii]

10.1186/1757-7241-19-24

McClave, S. A., Martindale, R. G., Vanek, V. W., McCarthy, M., Roberts, P., Taylor, B., . . . Cresci, G. (2009). Guidelines for the Provision and Assessment of Nutrition Support 
Therapy in the Adult Critically III Patient: Society of Critical Care Medicine (SCCM) and American Society for Parenteral and Enteral Nutrition (A.S.P.E.N.). JPEN J Parenter Enteral Nutr, 33(3), 277-316. doi:33/3/277 [pii]

$10.1177 / 0148607109335234$

McClave, S. A., Sexton, L. K., Spain, D. A., Adams, J. L., Owens, N. A., Sullins, M. B., . . Snider, H. L. (1999). Enteral tube feeding in the intensive care unit: factors impeding adequate delivery. Crit Care Med, 27(7), 1252-1256. Retrieved from http://www.ncbi.nlm.nih.gov/entrez/query.fcgi?cmd=Retrieve\&db=PubMed\&dopt=C itation\&list uids $=10446815$

McClave, S. A., \& Snider, H. L. (2002). Clinical use of gastric residual volumes as a monitor for patients on enteral tube feeding. JPEN J Parenter Enteral Nutr, 26(6 Suppl), S43-48; discussion S49-50. Retrieved from http://www.ncbi.nlm.nih.gov/entrez/query.fcgi?cmd=Retrieve\&db=PubMed\&dopt=C itation\&list uids $=12405622$

McLoughlin, P. D., \& Bell, D. A. (2010). Hartmann's solution--osmolality and lactate. Anaesth Intensive Care, 38(6), 1135-1136. Retrieved from http://www.ncbi.nlm.nih.gov/entrez/query.fcgi?cmd=Retrieve\&db=PubMed\&dopt=C itation\&list uids $=21229667$

Mehta, R. H., Sheng, S., O'Brien, S. M., Grover, F. L., Gammie, J. S., Ferguson, T. B., \& Peterson, E. D. (2009). Reoperation for bleeding in patients undergoing coronary artery bypass surgery: incidence, risk factors, time trends, and outcomes. Circ Cardiovasc Qual Outcomes, 2(6), 583-590. doi:CIRCOUTCOMES.109.858811 [pii]

10.1161/CIRCOUTCOMES.109.858811

Mehta, R. L., Kellum, J. A., Shah, S. V., Molitoris, B. A., Ronco, C., Warnock, D. G., . . Acute Kidney Injury, N. (2007). Acute Kidney Injury Network: report of an initiative to improve outcomes in acute kidney injury. Crit Care, 11(2), R31. doi:10.1186/cc5713

Meier, J. J. (2010). Waking up the gut in critically ill patients. Crit Care, 14(5), 183. doi:cc9079 [pii]

\section{$10.1186 /$ cc9079}

Mentec, H., Dupont, H., Bocchetti, M., Cani, P., Ponche, F., \& Bleichner, G. (2001). Upper digestive intolerance during enteral nutrition in critically ill patients: frequency, risk factors, and complications. Crit Care Med, 29(10), 1955-1961. Retrieved from http://www.ncbi.nlm.nih.gov/entrez/query.fcgi?cmd=Retrieve\&db=PubMed\&dopt=C itation\&list uids $=11588461$

Modi, M. P., Vora, K. S., Parikh, G. P., \& Shah, V. R. (2012). A comparative study of impact of infusion of Ringer's Lactate solution versus normal saline on acid-base balance and serum electrolytes during live related renal transplantation. Saudi J Kidney Dis Transpl, 23(1), 135-137. doi:SaudiJKidneyDisTranspl_2012_23_1_135_91320 [pii]

Montejo, J. C. (1999). Enteral nutrition-related gastrointestinal complications in critically ill patients: a multicenter study. The Nutritional and Metabolic Working Group of the Spanish Society of Intensive Care Medicine and Coronary Units. Crit Care Med, 27(8), 1447-1453.

Retrieved

from

http://www.ncbi.nlm.nih.gov/entrez/query.fcgi?cmd=Retrieve\&db=PubMed\&dopt=C itation\&list uids $=10470748$ 
Montejo, J. C., Minambres, E., Bordeje, L., Mesejo, A., Acosta, J., Heras, A., . . Manzanedo, R. (2010). Gastric residual volume during enteral nutrition in ICU patients: the REGANE study. Intensive Care Med, 36(8), 1386-1393. doi:10.1007/s00134-010-1856$Y$

Moon, P. F., Hollyfield-Gilbert, M. A., Myers, T. L., \& Kramer, G. C. (1994). Effects of isotonic crystalloid resuscitation on fluid compartments in hemorrhaged rats. Shock, 2(5), 355-361. Retrieved from http://www.ncbi.nlm.nih.gov/pubmed/7743362

Moore-Olufemi, S. D., Xue, H., Allen, S. J., Moore, F. A., Stewart, R. H., Laine, G. A., \& Cox, C. S., Jr. (2005). Inhibition of intestinal transit by resuscitation-induced gut edema is reversed by L-NIL. J Surg Res, 129(1), 1-5. doi:10.1016/j.jss.2005.04.041

Moore-Olufemi, S. D., Xue, H., Attuwaybi, B. O., Fischer, U., Harari, Y., Oliver, D. H., . . Cox, C. S., Jr. (2005). Resuscitation-induced gut edema and intestinal dysfunction. J Trauma, 58(2), 264-270. doi:00005373-200502000-00007 [pii]

Morgan, T. J. (2013). The ideal crystalloid - what is 'balanced'? Curr Opin Crit Care, 19(4), 299-307. doi:10.1097/MCC.0b013e3283632d46

Morgan, T. J., Power, G., Venkatesh, B., \& Jones, M. A. (2008). Acid-base effects of a bicarbonate-balanced priming fluid during cardiopulmonary bypass: comparison with Plasma-Lyte 148. A randomised single-blinded study. Anaesth Intensive Care, 36(6), 822-829. Retrieved from http://www.ncbi.nlm.nih.gov/entrez/query.fcgi?cmd=Retrieve\&db=PubMed\&dopt=C itation\&list uids $=19115651$

Morgan, T. J., \& Venkatesh, B. (2003). Designing 'balanced' crystalloids. Crit Care Resusc, 5(4), 284-291. doi:AACCM-JDecember03.10 [pii]

Mudge, G. H., Manning, J. A., \& Gilman, A. (1949). Sodium acetate as a source of fixed base. Proc Soc Exp Biol Med, 71(1), 136-138. Retrieved from http://www.ncbi.nlm.nih.gov/entrez/query.fcgi?cmd=Retrieve\&db=PubMed\&dopt=C itation\&list uids $=18151504$

Mueller, X. M., Chassot, P. G., Zhou, J., Eisa, K. M., Chappuis, C., Tevaearai, H. T., \& von Segesser, L. K. (2002). Hemodynamics optimization during off-pump coronary artery bypass: the 'no compression' technique. Eur J Cardiothorac Surg, 22(2), 249-254. doi:S1010794002002701 [pii]

Murney, P. (2008). To mix or not to mix - compatibilities of parenteral drug solutions. Aust Prescr, 31, 98-101.

Murthi, S. B., Wise, R. M., Weglicki, W. B., Komarov, A. M., \& Kramer, J. H. (2003). Mggluconate provides superior protection against postischemic dysfunction and oxidative injury compared to Mg-sulfate. Mol Cell Biochem, 245(1-2), 141-148. Retrieved

from http://www.ncbi.nlm.nih.gov/entrez/query.fcgi?cmd=Retrieve\&db=PubMed\&dopt=C itation\&list uids $=12708753$

Myburgh, J. A. (2014). Fluid resuscitation in acute medicine: what is the current situation? J Intern Med, 277(1), 58-68. doi:10.1111/joim.12326

Myburgh, J. A., Finfer, S., Bellomo, R., Billot, L., Cass, A., Gattas, D., . . Webb, S. A. (2012). Hydroxyethyl starch or saline for fluid resuscitation in intensive care. N Engl J Med, 367(20), 1901-1911. doi:10.1056/NEJMoa1209759

Myburgh, J. A., \& Mythen, M. G. (2013). Resuscitation fluids. N Engl J Med, 369(25), 24622463. doi:10.1056/NEJMc1313345 
National Clinical Guideline Centre. (2013). Acute kidney injury: prevention, detection and management of acute kidney injury up to the point of renal replacement therapy. Retrieved from https://www.nice.org.uk/guidance/cg169/evidence/acute-kidneyinjury-full-guideline-191530621

National Ethics Advisory Committee. (2006). Operational Standard for Ethics Committees. Retrieved from

National Ethics Advisory Committee. (2012). Ethical Guidelines for Intervention Studies: Revised edition Retrieved from

Naylor, J. M., \& Forsyth, G. W. (1986). The alkalinizing effects of metabolizable bases in the healthy calf. Can J Vet Res, 50(4), 509-516. Retrieved from http://www.ncbi.nlm.nih.gov/entrez/query.fcgi?cmd=Retrieve\&db=PubMed\&dopt=C itation\&list uids $=3024796$

Ng, K. F., Lam, C. C., \& Chan, L. C. (2002). In vivo effect of haemodilution with saline on coagulation: a randomized controlled trial. Br J Anaesth, 88(4), 475-480. Retrieved from http://www.ncbi.nlm.nih.gov/pubmed/12066721

Nguyen, N. Q., Chapman, M. J., Fraser, R. J., Bryant, L. K., Burgstad, C., Ching, K., . . . Holloway, R. H. (2008). The effects of sedation on gastric emptying and intra-gastric meal distribution in critical illness. Intensive Care Med, 34(3), 454-460. doi:10.1007/s00134-007-0942-2

Nguyen, N. Q., Ng, M. P., Chapman, M., Fraser, R. J., \& Holloway, R. H. (2007). The impact of admission diagnosis on gastric emptying in critically ill patients. Crit Care, 11(1), R16. doi:cc5685 [pii]

$10.1186 /$ cc5685

O'Carroll-Kuehn, B., \& Meeran, H. (2007). Management of coagulation during cardiopulmonary bypass. Contin Educ Anaesth Crit Care Pain, 7(6), 195-198. doi:10.1093/bjaceaccp/mkm036

O'Malley, C. M., Frumento, R. J., Hardy, M. A., Benvenisty, A. I., Brentjens, T. E., Mercer, J. S., \& Bennett-Guerrero, E. (2005). A randomized, double-blind comparison of lactated Ringer's solution and $0.9 \% \mathrm{NaCl}$ during renal transplantation. Anesth Analg, 100(5), 1518-1524, table of contents. doi:100/5/1518 [pii]

10.1213/01.ANE.0000150939.28904.81

Orbegozo Cortes, D., Rayo Bonor, A., \& Vincent, J. L. (2014). Isotonic crystalloid solutions: a structured review of the literature. Br J Anaesth, 112(6), 968-981. doi:aeu047 [pii]

10.1093/bja/aeu047

Ostermann, M., \& Chang, R. W. (2007). Acute kidney injury in the intensive care unit according to RIFLE. Crit Care Med, 35(8), 1837-1843; quiz 1852. doi:10.1097/01.CCM.0000277041.13090.0A

Padhi, S., Bullock, I., Li, L., \& Stroud, M. (2013). Intravenous fluid therapy for adults in hospital: summary of NICE guidance. BMJ, 347, f7073. Retrieved from http://www.ncbi.nlm.nih.gov/entrez/query.fcgi?cmd=Retrieve\&db=PubMed\&dopt=C itation\&list uids $=24326887$

Parke, R. L., McGuinness, S. P., Gilder, E., \& McCarthy, L. W. (2014). Intravenous fluid use after cardiac surgery: a multicentre, prospective, observational study. Crit Care Resusc, 16(3), 164-169. Retrieved from 
http://www.ncbi.nlm.nih.gov/entrez/query.fcgi?cmd=Retrieve\&db=PubMed\&dopt=C itation\&list uids $=25161017$

Pilcher, D., Hicks, P., Slater, A., Huckson, S., \& O'Sullivan, E. (2013). APD Data Dictionary for Software Programmers. Retrieved from http://www.anzics.com.au/Downloads/ANZICS\%20APD\%20Dictionary\%20V4 Progra $\underline{\mathrm{mmer} . p d f}$

Pradeep, A., Rajagopalam, S., Kolli, H. K., Patel, N., Venuto, R., Lohr, J., \& Nader, N. D. (2010). High volumes of intravenous fluid during cardiac surgery are associated with increased mortality. HSR Proc Intensive Care Cardiovasc Anesth, 2(4), 287-296. Retrieved

from http://www.ncbi.nlm.nih.gov/entrez/query.fcgi?cmd=Retrieve\&db=PubMed\&dopt=C itation\&list uids $=23439737$

Raghunathan, K., Shaw, A., Nathanson, B., Sturmer, T., Brookhart, A., Stefan, M. S., . . . Lindenauer, P. K. (2014). Association between the choice of IV crystalloid and inhospital mortality among critically ill adults with sepsis*. Crit Care Med, 42(7), 15851591. doi:10.1097/CCM.0000000000000305

Raghunathan, K., Shaw, A. D., \& Bagshaw, S. M. (2013). Fluids are drugs: type, dose and toxicity. Curr Opin Crit Care, 19(4), 290-298. doi:10.1097/MCC.0b013e3283632d77

Ramanathan, S., Masih, A. K., Ashok, U., Arismendy, J., \& Turndorf, H. (1984). Concentrations of lactate and pyruvate in maternal and neonatal blood with different intravenous fluids used for prehydration before epidural anesthesia. Anesth Analg, 63(1), 69-74. Retrieved

from http://www.ncbi.nlm.nih.gov/entrez/query.fcgi?cmd=Retrieve\&db=PubMed\&dopt=C itation\&list uids $=6691565$

Rauch, S., Krueger, K., Turan, A., You, J., Roewer, N., \& Sessler, D. I. (2012). Use of wireless motility capsule to determine gastric emptying and small intestinal transit times in critically ill trauma patients. J Crit Care, 27(5), 534 e537-512. doi:S08839441(11)00501-6 [pii]

10.1016/j.jcrc.2011.12.002

Reddy, S. K., Bailey, M. J., Beasley, R. W., Bellomo, R., Henderson, S. J., Mackle, D. M., . . . Young, P. J. (2014). A protocol for the $0.9 \%$ saline versus Plasma-Lyte 148 for intensive care fluid therapy (SPLIT) study. Crit Care Resusc, 16(4), 274-279. Retrieved from

http://www.ncbi.nlm.nih.gov/entrez/query.fcgi?cmd=Retrieve\&db=PubMed\&dopt=C itation\&list uids $=25437221$

Reddy, S. K., Young, P. J., Beasley, R. W., Mackle, D. M., McGuinness, S. P., McArthur, C. J., . . . Bellomo, R. (2015). Overview of the study protocols and statistical analysis plan for the Saline versus Plasma-Lyte 148 for Intravenous Fluid Therapy (SPLIT) research program. Crit Care Resusc, 17(1), 29-36. Retrieved from http://www.ncbi.nlm.nih.gov/entrez/query.fcgi?cmd=Retrieve\&db=PubMed\&dopt=C itation\&list uids $=25702759$

Reilly, C. Retraction. Notice of formal retraction of articles by Dr. Joachim Boldt. Br J Anaesth, 107(1), 116-117. doi:aer068 [pii]

10.1093/bja/aer068

Reintam Blaser, A., Malbrain, M. L., Starkopf, J., Fruhwald, S., Jakob, S. M., De Waele, J., . . . Spies, C. (2012). Gastrointestinal function in intensive care patients: terminology, 
definitions and management. Recommendations of the ESICM Working Group on Abdominal Problems. Intensive Care Med, 38(3), 384-394. doi:10.1007/s00134-0112459-y

Ricci, Z., Ronco, C., D'Amico, G., De Felice, R., Rossi, S., Bolgan, I., . . . Piccinni, P. (2006). Practice patterns in the management of acute renal failure in the critically ill patient: an international survey. Nephrol Dial Transplant, 21(3), 690-696. doi:10.1093/ndt/gfi296

Roche, A. M., James, M. F., Bennett-Guerrero, E., \& Mythen, M. G. (2006). A head-to-head comparison of the in vitro coagulation effects of saline-based and balanced electrolyte crystalloid and colloid intravenous fluids. Anesth Analg, 102(4), 12741279. doi:102/4/1274 [pii]

10.1213/01.ane.0000197694.48429.94

Ropper, A. H. (2012). Management of raised intracranial pressure and hyperosmolar therapy. Pract Neurol. doi:practneurol-2014-000811 [pii]

10.1136/practneurol-2014-000811

Ruttmann, T. G., James, M. F., \& Viljoen, J. F. (1996). Haemodilution induces a hypercoagulable state. $\mathrm{Br} J$ Anaesth, 76(3), 412-414. Retrieved from http://www.ncbi.nlm.nih.gov/entrez/query.fcgi?cmd=Retrieve\&db=PubMed\&dopt=C itation\&list uids $=8785143$

Sanchez, A. M., Wooldridge, T. A., Boerboom, L. E., Olinger, G. N., Almassi, G. H., \& Rusch, N. J. (1994). Comparison of saphenous vein graft relaxation between Plasma-Lyte solution and normal saline solution. J Thorac Cardiovasc Surg, 107(6), 1445-1453. Retrieved from http://www.ncbi.nlm.nih.gov/pubmed/8196386

Scheingraber, S., Rehm, M., Sehmisch, C., \& Finsterer, U. (1999). Rapid saline infusion produces hyperchloremic acidosis in patients undergoing gynecologic surgery. Anesthesiology, 90(5), 1265-1270. Retrieved from http://www.ncbi.nlm.nih.gov/entrez/query.fcgi?cmd=Retrieve\&db=PubMed\&dopt=C itation\&list uids $=10319771$

Schnermann, J., \& Briggs, J. P. (1999). The macula densa is worth its salt. J Clin Invest, 104(8), 1007-1009. doi:10.1172/JCl8539

Schnermann, J., Ploth, D. W., \& Hermle, M. (1976). Activation of tubulo-glomerular feedback by chloride transport. Pflugers Arch, 362(3), 229-240. Retrieved from http://www.ncbi.nlm.nih.gov/pubmed/944430

Schrander-vd Meer, A. M., ter Wee, P. M., Kan, G., Donker, A. J., \& van Dorp, W. T. (1999). Improved cardiovascular variables during acetate free biofiltration. Clin Nephrol, 51(5), 304-309. Retrieved from http://www.ncbi.nlm.nih.gov/entrez/query.fcgi?cmd=Retrieve\&db=PubMed\&dopt=C itation\&list uids $=10363631$

Schumacher, J., \& Klotz, K., F. (2009). Fluid therapy in cardiac surgery patients Applied Cardiopulmonary Pathophysiology, 12, 138-142.

Shaw, A. D., Bagshaw, S. M., Goldstein, S. L., Scherer, L. A., Duan, M., Schermer, C. R., \& Kellum, J. A. (2012). Major complications, mortality, and resource utilization after open abdominal surgery: 0.9\% saline compared to Plasma-Lyte. Ann Surg, 255(5), 821-829. doi:10.1097/SLA.0b013e31825074f5

Shin, W. J., Kim, Y. K., Bang, J. Y., Cho, S. K., Han, S. M., \& Hwang, G. S. (2011). Lactate and liver function tests after living donor right hepatectomy: a comparison of solutions 
with and without lactate. Acta Anaesthesiol Scand, 55(5), 558-564. doi:10.1111/j.1399-6576.2011.02398.x

Skutches, C. L., Holroyde, C. P., Myers, R. N., Paul, P., \& Reichard, G. A. (1979). Plasma acetate turnover and oxidation. J Clin Invest, 64(3), 708-713. doi:10.1172/JCI109513

Srinivasa, S., \& Hill, A. G. (2012). Perioperative fluid administration: historical highlights and implications for practice. Ann Surg, 256(6), 1113-1118. doi:10.1097/SLA.0b013e31825a2f22

Srinivasa, S., Singh, S. P., Kahokehr, A. A., Taylor, M. H., \& Hill, A. G. (2012). Perioperative fluid therapy in elective colectomy in an enhanced recovery programme. ANZ J Surg, 82(7-8), 535-540. doi:10.1111/j.1445-2197.2012.06122.x

Staton, G. W., Williams, W. H., Mahoney, E. M., Hu, J., Chu, H., Duke, P. G., \& Puskas, J. D. (2005). Pulmonary outcomes of off-pump vs on-pump coronary artery bypass surgery in a randomized trial. Chest, 127(3), 892-901. doi:127/3/892 [pii]

10.1378/chest.127.3.892

Stouthard, J. M., Levi, M., Hack, C. E., Veenhof, C. H., Romijn, H. A., Sauerwein, H. P., \& van der Poll, T. (1996). Interleukin-6 stimulates coagulation, not fibrinolysis, in humans. Thromb Haemost, 76(5), 738-742. Retrieved from http://www.ncbi.nlm.nih.gov/pubmed/8950783

Takil, A., Eti, Z., Irmak, P., \& Yilmaz Gogus, F. (2002). Early postoperative respiratory acidosis after large intravascular volume infusion of lactated ringer's solution during major spine surgery. Anesth Analg, 95(2), 294-298, table of contents. Retrieved from http://www.ncbi.nlm.nih.gov/entrez/query.fcgi?cmd=Retrieve\&db=PubMed\&dopt=C itation\&list uids $=12145036$

Theusinger, O. M., Felix, C., \& Spahn, D. R. (2012). Strategies to reduce the use of blood products: a European perspective. Curr Opin Anaesthesiol, 25(1), 59-65. doi:10.1097/ACO.0b013e32834dec98

Thomas, D. J., \& Alberti, K. G. (1978). Hyperglycaemic effects of Hartmann's solution during surgery in patients with maturity onset diabetes. Br J Anaesth, 50(2), 185-188. Retrieved

from http://www.ncbi.nlm.nih.gov/entrez/query.fcgi?cmd=Retrieve\&db=PubMed\&dopt=C itation\&list uids $=626700$

Tocantins, L. M., Carroll, R. T., \& Holburn, R. H. (1951). The clot accelerating effect of dilution on blood and plasma. Relation to the mechanism of coagulation of normal and hemophilic blood. Blood, 6(8), 720-739. Retrieved from http://www.ncbi.nlm.nih.gov/pubmed/14858438

Todd, S. R., Malinoski, D., Muller, P. J., \& Schreiber, M. A. (2007). Lactated Ringer's is superior to normal saline in the resuscitation of uncontrolled hemorrhagic shock. $J$ Trauma, 62(3), 636-639. doi:10.1097/TA.0b013e31802ee521

00005373-200703000-00014 [pii]

Tournadre, J. P., Allaouchiche, B., Malbert, C. H., \& Chassard, D. (2000). Metabolic acidosis and respiratory acidosis impair gastro-pyloric motility in anesthetized pigs. Anesth Analg, 90(1), 74-79. Retrieved from http://www.ncbi.nlm.nih.gov/entrez/query.fcgi?cmd=Retrieve\&db=PubMed\&dopt=C itation\&list uids $=10624982$

Traverso, L. W., Lee, W. P., \& Langford, M. J. (1986). Fluid resuscitation after an otherwise fatal hemorrhage: I. Crystalloid solutions. J Trauma, 26(2), 168-175. Retrieved from 
http://www.ncbi.nlm.nih.gov/entrez/query.fcgi?cmd=Retrieve\&db=PubMed\&dopt=C itation\&list uids $=3080602$

Uchino, S., Bellomo, R., Goldsmith, D., Bates, S., \& Ronco, C. (2006). An assessment of the RIFLE criteria for acute renal failure in hospitalized patients. Crit Care Med, 34(7), 1913-1917. doi:10.1097/01.CCM.0000224227.70642.4F

Van Zyl, D. G., Rheeder, P., \& Delport, E. (2012). Fluid management in diabetic-acidosis-Ringer's lactate versus normal saline: a randomized controlled trial. QJM, 105(4), 337-343. doi:hcr226 [pii]

10.1093/qjmed/hcr226

Velmahos, G. C., Demetriades, D., Chan, L., Tatevossian, R., Cornwell, E. E., 3rd, Yassa, N., .. . Berne, T. V. (1999). Predicting the need for thoracoscopic evacuation of residual traumatic hemothorax: chest radiograph is insufficient. J Trauma, 46(1), 65-70. Retrieved from http://www.ncbi.nlm.nih.gov/pubmed/9932685

Waikar, S. S., \& Bonventre, J. V. (2009). Creatinine kinetics and the definition of acute kidney injury. J Am Soc Nephrol, 20(3), 672-679. doi:10.1681/ASN.2008070669

Waikar, S. S., \& Winkelmayer, W. C. (2012). Saving the kidneys by sparing intravenous chloride? JAMA, 308(15), 1583-1585. doi:1383220 [pii]

10.1001/jama.2012.14076

Wakim, K. G. (1970). "Normal" 0.9 per cent salt solution is neither "normal" nor physiological. JAMA, 214(9), $1710 . \quad$ Retrieved from http://www.ncbi.nlm.nih.gov/entrez/query.fcgi?cmd=Retrieve\&db=PubMed\&dopt=C itation\&list uids $=5536543$

Waters, J. H., Gottlieb, A., Schoenwald, P., Popovich, M. J., Sprung, J., \& Nelson, D. R. (2001). Normal saline versus lactated Ringer's solution for intraoperative fluid management in patients undergoing abdominal aortic aneurysm repair: an outcome study. Anesth Analg, 93(4), 817-822. Retrieved from http://www.ncbi.nlm.nih.gov/entrez/query.fcgi?cmd=Retrieve\&db=PubMed\&dopt=C itation\&list uids=11574339

Weber, C. F., Klages, M., \& Zacharowski, K. (2013). Perioperative coagulation management during cardiac surgery. Curr Opin Anaesthesiol, 26(1), 60-64. doi:10.1097/ACO.0b013e32835afd28

Weightman, W. M., Gibbs, N. M., Sheminant, M. R., Newman, M. A., \& Grey, D. E. (2009). Moderate exposure to allogeneic blood products is not associated with reduced longterm survival after surgery for coronary artery disease. Anesthesiology, 111(2), 327333. doi:10.1097/ALN.0b013e3181ab6743

Weinberg, L., Pearce, B., Sullivan, R., Siu, L., Scurrah, N., Tan, C., . . Bellomo, R. (2015). The effects of plasmalyte-148 vs. Hartmann's solution during major liver resection: a multicentre, double-blind, randomized controlled trial. Minerva Anestesiol, 81(12), 1288-1297. Retrieved from http://www.ncbi.nlm.nih.gov/pubmed/25407026

Wilcox, C. S. (1983). Regulation of renal blood flow by plasma chloride. J Clin Invest, 71(3), 726-735. Retrieved from http://www.ncbi.nlm.nih.gov/entrez/query.fcgi?cmd=Retrieve\&db=PubMed\&dopt=C itation\&list uids $=6826732$

Wilcox, C. S. (1988). Renal haemodynamics during hyperchloraemia in the anaesthetized dog: effects of captopril. J Physiol, 406, 27-34. Retrieved from http://www.ncbi.nlm.nih.gov/pubmed/3075984 
Wilkes, N. J., Woolf, R., Mutch, M., Mallett, S. V., Peachey, T., Stephens, R., \& Mythen, M. G. (2001). The effects of balanced versus saline-based hetastarch and crystalloid solutions on acid-base and electrolyte status and gastric mucosal perfusion in elderly surgical patients. Anesth Analg, 93(4), 811-816. Retrieved from http://www.ncbi.nlm.nih.gov/entrez/query.fcgi?cmd=Retrieve\&db=PubMed\&dopt=C itation\&list uids $=11574338$

Williams, E. L., Hildebrand, K. L., McCormick, S. A., \& Bedel, M. J. (1999). The effect of intravenous lactated Ringer's solution versus $0.9 \%$ sodium chloride solution on serum osmolality in human volunteers. Anesth Analg, 88(5), 999-1003. Retrieved from http://www.ncbi.nlm.nih.gov/entrez/query.fcgi?cmd=Retrieve\&db=PubMed\&dopt=C itation\&list uids $=10320158$

Woodman, R. C., \& Harker, L. A. (1990). Bleeding complications associated with cardiopulmonary bypass. Blood, 76(9), 1680-1697. Retrieved from http://www.ncbi.nlm.nih.gov/pubmed/2224118

World Medical Association. (2013). WorldMedical Association Declaration of Helsinki Ethical Principles for Medical Research Involving Human Subjects. Retrieved from https://www.chemie.uni-hamburg.de/studium/wma declaration.pdf

Wu, B. U., Hwang, J. Q., Gardner, T. H., Repas, K., Delee, R., Yu, S., . . Conwell, D. L. (2011). Lactated Ringer's solution reduces systemic inflammation compared with saline in patients with acute pancreatitis. Clin Gastroenterol Hepatol, 9(8), 710-717 e711. doi:S1542-3565(11)00454-X [pii]

10.1016/j.cgh.2011.04.026

Wynne, R., Botti, M., Copley, D., \& Bailey, M. (2007). The normative distribution of chest tube drainage volume after coronary artery bypass grafting. Heart Lung, 36(1), 35-42. doi:10.1016/j.hrtlng.2006.05.006

Yavari, M., \& Becker, R. C. (2009). Coagulation and fibrinolytic protein kinetics in cardiopulmonary bypass. J Thromb Thrombolysis, 27(1), 95-104. doi:10.1007/s11239007-0187-5

Young, J. B., Utter, G. H., Schermer, C. R., Galante, J. M., Phan, H. H., Yang, Y., . . Scherer, L. A. (2014). Saline versus Plasma-Lyte $A$ in initial resuscitation of trauma patients: a randomized trial. Ann Surg, 259(2), 255-262. doi:10.1097/SLA.0b013e318295feba

Young, P., Bailey, M., Beasley, R., Henderson, S., Mackle, D., McArthur, C., . . . the, A. C. (2014). The statistical analysis plan for the 0.9\% Saline vs. Plasma-Lyte $148^{\circledR}$ for Intensive care fluid Therapy (SPLIT) study. Retrieved from http://wellingtonicu.com/Data/Trials/SPLITSAP.pdf

Young, P., Bailey, M., Beasley, R., Henderson, S., Mackle, D., McArthur, C., ... . the, A. C. (2015). Effect of a Buffered Crystalloid Solution vs Saline on Acute Kidney Injury Among Patients in the Intensive Care Unit: The SPLIT Randomized Clinical Trial. JAMA, 1-10. doi:10.1001/jama.2015.12334

Yunos, N. M., Bellomo, R., Glassford, N., Sutcliffe, H., Lam, Q., \& Bailey, M. (2015). Chlorideliberal vs. chloride-restrictive intravenous fluid administration and acute kidney injury: an extended analysis. Intensive Care Med, 41(2), 257-264. doi:10.1007/s00134-014-3593-0

Yunos, N. M., Bellomo, R., Hegarty, C., Story, D., Ho, L., \& Bailey, M. (2012). Association between a chloride-liberal vs chloride-restrictive intravenous fluid administration 
strategy and kidney injury in critically ill adults. JAMA, 308(15), 1566-1572. doi:1383234 [pii]

10.1001/jama.2012.13356

Zhou, F., Peng, Z. Y., Bishop, J. V., Cove, M. E., Singbartl, K., \& Kellum, J. A. (2014). Effects of fluid resuscitation with $0.9 \%$ saline versus a balanced electrolyte solution on acute kidney injury in a rat model of sepsis*. Crit Care Med, 42(4), e270-278. doi:10.1097/CCM.0000000000000145

Zimmer, H. G. (2005). Sydney Ringer, serendipity, and hard work. Clin Cardiol, 28(1), 55-56. Retrieved from http://www.ncbi.nlm.nih.gov/entrez/query.fcgi?cmd=Retrieve\&db=PubMed\&dopt=C itation\&list uids $=15704534$ 


\section{Appendix 1: Data monitoring committee charter}

\section{9\% Saline vs. Plasma Lyte ${ }^{\circledR} 148$ for Intensive Care Fluid Therapy}

The SPLIT study

\section{DATA MONITORING COMMITTEE CHARTER}

1. Introduction 3

1.1 Primary objective 3

1.2 Secondary objective $\quad 3$

1.3 Scope of this charter 3

2. Roles and responsibilities 3

2.1 Aims of the committee 3

2.2 Specific roles of the DMC 3

3. Responsibilities pre-trial commencement 4

3.1 Input into the study protocol 4

3.2 DMC first meeting 4

4. Responsibilities during the trial 4

4.1 Stopping rules $\quad 4$

4.2 Specific regulatory issues 4

5. Obligations of the DMC members 4

5.1 General $\quad 4$

6 Composition 5

6.1 Membership $\quad 5$

6.2 The responsibilities of the DMC statistician 5

7. Organisation of DMC meetings and communication pathways 5 
7.1 General 5

7.2 Communication 5

7.3 Decision-making 5

7.4 Disagreements between the DMC and the management committee 6

8. Other matters 6

8.1 Payments to DMC members 6

8.2 Disclosure of conflicts of interest 6

8.3 Information about the DMC in published trial reports 6 


\section{Introduction}

\subsection{Primary objective}

The primary objective of this study is to establish whether a large scale cluster cross over trial of $0.9 \%$ saline vs. PL-148 as routine fluid therapy in ICU is feasible. This will be achieved by:

1. Determining the likely recruitment rate for a large scale study

2. Establishing that the intervention can be administered in accordance with the study protocol

3. Providing data to allow statistical modelling of the number of clusters required and the overall sample size for large scale double cluster cross over study

4. Allowing real-world testing of web-based data collection tools

5. Establishing the amount of time required to collect study data

\subsection{Secondary objective}

The secondary objective of the current study is to provide preliminary data regarding the relative efficacy and safety of using $0.9 \%$ saline vs. PL-148 as routine fluid therapy in the ICU with respect to:

1. The risk of developing AKI in ICU based on creatinine levels in accordance with RIFLE criteria;

2. Requirements for dialysis and other forms of renal replacement therapy

3. Requirements for dialysis after acute hospital discharge;

4. Requirements for life support (invasive mechanical ventilation) in ICU;

5. ICU and hospital length of stay; and,

6. ICU and in-hospital mortality

1.3 Scope of this charter 
The purpose of this document is to describe the roles and responsibilities of the independent DMC for the SPLIT study, including the timing of meetings, methods of communication between the DMC and the management committee, frequency and format of meetings, and statistical issues.

\section{Roles and responsibilities}

\subsection{Aims of the committee}

The role of the DMC is to undertake general safety and study conduct monitoring and to make recommendations to the management committee on specific issues on request. The DMC does not make decisions about the trial, but rather makes recommendations to the study management committee.

\subsection{Specific roles of the DMC}

The DMC will review the progress of the trial including figures on recruitment, protocol violations, and adverse events. Specific roles for the DMC include reviewing:

1. information provided in relation to withdrawal of consent for the use of data by study participants or their next of kin

2. protocol deviations

3. adverse events

4. all requests for unblinding by study investigators

\section{Responsibilities pre-trial commencement}

\subsection{Input into the study protocol}

All potential DMC members will be provided with the protocol before finalising their agreement to join the committee. The trial protocol has been approved by a New Zealand Health and Disability Ethics Committee and is the product of substantial peer-review including that involved in obtaining endorsement from the Australian and New Zealand Intensive Care Society Clinical Trials Group and that involved in obtaining funding from the New Zealand Health Research Council. If a potential DMC member has reservations about the trial protocol or trial logastrointestinalstics, they should report these to the management 
committee. If these reservations are not addressed to the satisfaction of the potential DMC member, they should not accept the invitation to join the DMC because, while the DMC should provide independent advice the to management committee, it is important that the DMC members are supportive of the overall aims and methodology of the trial at the outset.

\subsection{DMC first meeting}

The DMC should meet prior to the trial commencing to discuss the protocol, future meetings, and to raise any issues that need to be clarified with the study management committee.

\section{Responsibilities during the trial}

\subsection{Stopping rules}

Gastrointestinalven the design of the current study, the only opportunity for interim analyses would be after the second cross-over when each of the four centres will have used each treatment once. Such an interim analysis is not planned because stopping a relatively small trial utilising a novel design on the basis of an interim analysis is likely to lead to scepticism about the reliability of the results and is unlikely to lead to practice change. The short timeframe for recruitment also means that by the time data from the mid-point of the study are available (allowing for censoring which occurs at day 90 post enrolment), recruitment is likely to be finished.

\subsection{Specific regulatory issues}

All adverse reactions will be reported to the trial co-ordination centre and will be provided to the DMC for their consideration.

\section{Obligations of the DMC members}

\subsection{General}

Members of the DMC are required to:

o Confirm their agreement to take on the responsibilities of membership as outlined in this charted 
- Agree to maintain the confidentiality of the data provided to them and of the deliberations of the committee

- Declare any conflicts of interest.

\section{Composition}

\subsection{Membership}

The DMC includes members with expertise in fluid therapy in critical illness and in statistical methods for cluster cross-over trials. The members of the DMC are:

o Prof Anders Perner (Chair)

o Dr John Morgan

- Prof Andrew Forbes (Statistician)

\section{Organisation of DMC meetings and communication pathways}

\subsection{General}

The DMC will determine the frequency of their meetings. Meetings will be held by teleconference and will be organised by the SPLIT project officer on request.

\subsection{Communication}

The DMC should report its recommendations in writing to the study management committee within 3 weeks of a meeting. These recommendations should be copied to the Chief Investigator by e-mail and to the co-ordinating centre for the trial master file.

\subsection{Decision-making}

Possible recommendations open to the DMC include:

- No action need; continue trial as planned

o Stopping recruitment

o Proposing protocol changes 
It is recommended that every effort should be made for the DMC to reach a unanimous decision. If the DMC cannot achieve this, a vote may be taken. It is important that the ethical, statistical, practical, and regulatory implications for the trial by considered before any recommendation is made. The role of the Chair is to summarise discussions and encourage consensus.

If possible all members of the DMC should attend all DMC meetings; however, the chair and one other member will constitute a quorum. If the $\mathrm{DMC}$ is considering a major recommendation after a meeting where one member was absent, the DMC chair should talk with the absent member to check they agree. If they do not, a further teleconference should be arranged with the full DMC.

\subsection{Disagreements between the DMC and the management committee}

The management committee undertake to review and discuss all recommendations made by the DMC; however, implementation of any recommendation is solely the responsibility of the management committee who are free to reject (in whole or in part) the recommendations of the DMC.

If the DMC has serious concerns with a decision made by the study management committee, a meeting of the DMC and the management committee should be held. If possible, any concerns should be resolved by discussion of the issues involved.

\section{Other matters}

\subsection{Payments to DMC members}

The costs of teleconferences will be the responsibility of the co-ordinating centre. The services of the DMC members are voluntary. There will be no payments made to DMC members.

\subsection{Disclosure of conflicts of interest}

All competing interests should be disclosed prior to agreeing to this Charter. These are no restricted to financial matters - involvement in other trials or intellectual investment could be relevant. Although members may well be able to act objectively despite such connections, complete disclosure helps to enhance credibility. 


\subsection{Information about the DMC in published trial reports}

The DMC members will be named and their affiliations listed in trial publications unless they specifically request otherwise.

This Charter was agreed by all members of the DMC:

Name Signature Date

Prof Anders Perner

Dr John Morgan

Prof Andrew Forbes 
14 Appendix 2: Study monitoring plan

\author{
$0.9 \%$ Saline vs. Plasma-Lyte ${ }^{\circledR} 148$ for Intensive Care Fluid Therapy \\ (The SPLIT study)
}

\title{
MONITORING PLAN \& PROCEDURES
}

\author{
Version 1.0, 14 March 2014
}

A multi-centre, cluster randomised, double cross over, feasibility trial comparing $0.9 \%$ saline with Plasma-Lyte ${ }^{\circledR} 148$ for all crystalloid fluid therapy in intensive care patients 


\section{Table of contents}

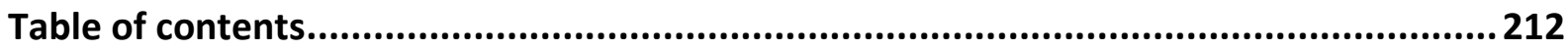

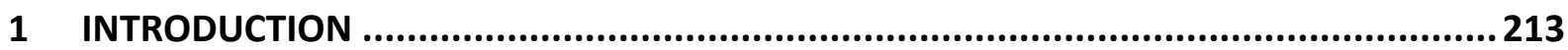

1.1 Objectives of Monitoring Plan 213

1.2 Coordinating Centres Study Team and Roles 214

1.3 Participating Sites 214

1.4 Study Timelines $\quad 215$

1.5 Patient recruitment and termination $\quad 215$

2 Monitoring Activities: Set up, ongoing and closure ..........................................216

2.1 Site Selection 216

2.2 Site Initiation 216

2.3 Monitoring Visit 217

2.4 Close-out Visit222

3 Interim analyses and Data Monitoring Committee ............................................222

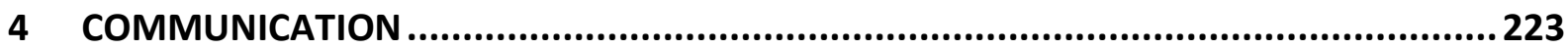

5 appendix ONE - monitoring visit report template / EXAMPLE..............................2225 


\subsection{INTRODUCTION}

\subsection{Objectives of Monitoring Plan}

- To define the study-specific requirements and the agreed upon commitments of the clinical study team involved in SPLIT clinical trial operations.

- To define the expectations regarding the scheduling, conduct and follow up of initiation, monitoring and close out visits conducted by the Medical Research Institute of New Zealand.

- To establish procedures for ensuring protocol adherence, the highest quality, completeness and the timeliness of data that is submitted to the study database, through on site and remote monitoring and through support, corrections and education of site staff.

- To establish procedures for ensuring rights and safety of patients are protected and safety reporting is made to relevant authorities.

This monitoring plan describes the extent and nature of monitoring which is based on the study design, sample size and number of data points, primary and secondary endpoints of the trial and study budget. On-site monitoring and central monitoring in conjunction with site staff training and meetings, and extensive written guidance assures appropriate conduct of the trial in accordance with GCP. Both convenience and random sampling will be used to select the data to be verified (Ref ICH GCP 5.18.3). The monitoring plan will be updated as needed during the course of the study in order to reflect changes to the protocol, monitoring requirements, or other study processes. 


\subsection{Coordinating Centres Study Team and Roles}

The Medical Research Institute of New Zealand (MRINZ) will assume the role of the coordinating centre for all 4 New Zealand sites.

\begin{tabular}{|c|c|c|c|}
\hline Name & Title & Role(s) & Based \\
\hline Diane Mackle & $\begin{array}{l}\text { Project Manager } \\
\text { and study monitor } \\
\text { (PM) }\end{array}$ & $\begin{array}{l}\text { - } \quad \text { Study site set up } \\
\text { - } \quad \text { Study procedures } \\
\text { - } \quad \text { Study treatment logistics } \\
\text { - } \quad \text { Management and Co-ordination of } \\
\text { NZ ethics and regulatory } \\
\text { - Initiation, Monitoring, Close Out }\end{array}$ & MRINZ \\
\hline Paul Young & $\begin{array}{l}\text { Chief Investigator } \\
\text { (Cl) }\end{array}$ & $\begin{array}{l}\text { - Oversight of study (will liaise with } \\
\text { PM) }\end{array}$ & $\mathrm{CCDHB} / \mathrm{MRINZ}$ \\
\hline Maureen Stretch & $\begin{array}{l}\text { Administrative } \\
\text { Assistant }\end{array}$ & $\begin{array}{l}\text { - } \text { Administrator } \\
\text { - } \text { Meeting organisation } \\
\text { - Travel arrangements }\end{array}$ & MRINZ \\
\hline Alison Pritchard & IT \& data manager & $\begin{array}{l}\text { - } \quad \text { IT support } \\
\text { - } \quad \text { Data management }\end{array}$ & MRINZ \\
\hline Denise Fabian & $\begin{array}{l}\text { Administration } \\
\text { Manager }\end{array}$ & - Site payments and related finances & MRINZ \\
\hline
\end{tabular}

\subsection{Participating Sites}

\begin{tabular}{|l|l|l|l|}
\hline Site & Abbreviation & Location & CRA \\
\hline Auckland City Hospital - CVICU & CVIN & NZ & DM \\
\hline Auckland City Hospital - DCCM & DCCN & NZ & DM \\
\hline Christchurch Hospital & CHCN & NZ & DM \\
\hline Wellington Hospital & WGTN & NZ & DM \\
\hline
\end{tabular}




\subsection{Study Timelines}

\begin{tabular}{|c|c|}
\hline Milestones & Timeline \\
\hline Start-up meeting & 26 March 2014 \\
\hline Block 1 begin at all sites & 1 April 2014 \\
\hline $\begin{array}{l}1^{\text {st }} \text { monitoring visits at each site, within 1-4 weeks from commencement of } \\
\text { recruitment }\end{array}$ & April/May 2014 \\
\hline 1st crossover and Block 2 begins & 20 May 2014 \\
\hline 2nd crossover and Block 3 begins & 8 July 2014 \\
\hline 3rd crossover and Block 4 begins & 26 August 2014 \\
\hline End of study enrolment (and end of Block 4) & $14^{\text {th }}$ October 2014 \\
\hline Last eCRF entered & Nov 2014 \\
\hline Monitoring visit \& last source document verified (SDV'd). $100 \%$ queries resolved & Dec 2014 \\
\hline Complete all data cleaning & Dec 2014 \\
\hline Database lock & 1 Jan 2015 \\
\hline Statistical analysis & Jan 2015 \\
\hline Results meeting & Feb 2015 \\
\hline Submission for publication & July 2015 \\
\hline Study Archiving & 2015 \\
\hline
\end{tabular}

\subsection{Patient recruitment and termination}

As all patients (except those who are excluded or opt out) at sites will be recruited into the study, the final number of total patients and patients per site is currently unknown. As per the CTRA, sites will be paid as a percentage of the number of patients they enrolled out of the overall number of patients enrolled in the study.

Sites will be required to regularly complete the screening log in the electronic CRF to capture details of ICU patients who met the inclusion criteria for the study but who were excluded (i.e. met one or more of the exclusion criteria). Ideally the log should be updated in real time with these ineligible patients to ensure that patients do not feature more than once in the database. Additionally, at the end of each block, sites need to enter the number of patients aged 16 years or older who were admitted to the ICU in the previous month. 
CRAs are to contact sites not maintaining the logs regularly to remind/encourage them to do so. Telephone calls should be recorded and significant discussions with site personnel documented.

Any site underperforming - i.e. taking too long to enter data, resolve data queries, making multiple protocol violations, recruiting ineligibile patients etc - the study monitor / project manager should discuss causes and assist site to address poor performance. If poor performance continues to cause concern, a final warning may be given that the site will be discontinued.

\subsection{Monitoring Activities: Set up, ongoing and closure}

\subsection{Site Selection}

Site selection has been completed as listed in 1.3 Participating Sites. The study design does not allow for additional sites.

\subsection{Site Initiation}

A start-up meeting in Wellington, is planned for March 2014, at which, training will be provided about the protocol, data entry, fluid management and ICH-GCP.

There will not be an on-site 'site initiation'. Sites will be responsible for ensuring they are ready to start the study by 1 April 2014 and MRINZ will check (by email) that all necessary pre-study essential documents, and approvals and supplies are in place including (but not limited to) HDEC approval, CTA / Indemnity sign off, eCRF access set-up and training and receipt of the study investigational product (IP). There will be an early first monitoring visit to ensure understanding of the protocol.

Prior to shipment of the IP to a particular site, it should be confirmed with the site that they are ready and able to take receipt of it and that the storage logistics are appropriate.

The Site visit log will be completed by each study team member visiting the site and countersigned by a site representative. 


\subsection{Monitoring Visit}

The monitor (and any accompanying study team members) must sign the Study Site Visit Log at every visit and ensure that the dates recorded on this log are consistent with those entered on the Monitoring Visit Report. The monitor should bring the protocol, the data completion manual (data dictionary), paper CRFs, laptop and datastick for access to the SPLIT website during the visit.

\subsection{Scheduling of monitoring visits}

The research coordinator at each site will require prior notification of planned visits in keeping with the time taken to obtain medical records and availability of site staff and accommodation at site. This time and process for obtaining medical records should be ascertained in advance by monitors. Some sites may also have a limit on the number of medical records that can be 'checked out' and this may determine the frequency or length of visits (eg if only a small number can be checked out each day).

The first monitoring visit should be scheduled as soon as mutually convenient for the monitor and site staff, but within 4 weeks of commencement of the study, in order to address any systematic issues or questions that may arise at randomisation. Subsequent monitoring visits will be performed according to individual recruitment rates, quality issues, clinical trial site compliance or other clinical trial site issues. The need for additional visits because of concerns with a site's conduct will be explained in the Monitoring Visit Report.

In addition to on-site monitoring visits, sites will be contacted regularly by email and/or phone. These contacts should be kept in the relevant Trial Master File (TMF).

Remote data monitoring should also be performed by the monitoring team and PMs to assess recruitment rate, timing of data capture compared with randomisation dates, outstanding data queries, and data completion. Sites will be provided with reporting to enable the site staff to complete appropriate logistic checks of the data entered in order to ensure data validity These reports will be overseen by the PM during and at the end of the study to ensure the site has complied with this.

The objectives of routine monitoring visits are to: 


\begin{tabular}{|c|c|}
\hline \multicolumn{2}{|c|}{ Monitoring Checklist - KEY POINTS } \\
\hline 1. & $\begin{array}{l}\text { Ensure consent is appropriately obtained in accordance with ethics committee (EC) approval } \\
\text { requirements: } \\
\text { - Check with the site that the pre-defined procedure for opt-out consent that documents the } \\
\text { process for ensuring every participant or their family receive an information sheet, and the } \\
\text { opportunity to opt out of data collection, is present and being adhered to. }\end{array}$ \\
\hline 2. & Any opt-out forms are kept in the Investigator Site file \\
\hline 3. & Verify e-CRF entry against source documents in accordance to the SDV plan. \\
\hline 4. & $\begin{array}{l}\text { Verify the patient has received the correct study fluid and other study procedures are being performed } \\
\text { according to protocol requirements for the proportion of patients specified in the SDV plan. }\end{array}$ \\
\hline 5. & $\begin{array}{l}\text { Verify the patient fulfilled the eligibility criteria at the time of randomisation for the proportion of } \\
\text { patients specified in the SDV plan. }\end{array}$ \\
\hline 6. & $\begin{array}{l}\text { Check and verify whether any reportable adverse events (as defined in the DMC guidelines) or adverse } \\
\text { drug reactions (ADRs) have occurred since the last visit (can only do this in the proportion of patients to } \\
\text { have SDV). } \\
\text { As per the DMC guidelines, Serious Adverse Events will only be reported if they are thought to be } \\
\text { related to administration of the study treatment. } \\
\text { Check that all reportable events were reported in the e-CRF to the Coordinating Centre and Cl within } \\
\text { the appropriate timeframe: } \\
\text { - Either } 24 \text { hours of knowledge of the event if it is a serious ADR/SUSAR } \\
\text { - Verify event report details including documentation of causality assessment by the Principal } \\
\text { Investigator } \\
\text { - Confirm that reports of such events to the EC or Regulatory Authorities have been made in } \\
\text { accordance with local requirements and associated documentation filed appropriately. } \\
\text { Re-train/educate site as necessary in reporting requirements }\end{array}$ \\
\hline 7. & $\begin{array}{l}\text { Check that relevant protocol deviations / ineligible patients are being reported in the eCRF and use } \\
\text { visit to re-educate / emphasise strategy for avoiding these. }\end{array}$ \\
\hline 8. & $\begin{array}{l}\text { Discuss project-related activities with the investigator and site staff. Use visit to encourage and support } \\
\text { sites. Raise any areas of concern in person and document in monitoring visit report. }\end{array}$ \\
\hline 9. & Check eCRF access is adequate for site staff \\
\hline 10. & Check Investigator's Site File maintenance. \\
\hline 11. & esolved issues. \\
\hline
\end{tabular}

\subsection{Study non-compliance or misconduct}


Any critical issues identified by the monitor at the site (including non-compliance, errors and discrepancies, suspicion of scientific misconduct or fraud) must be immediately notified to the $\mathrm{PM}$ and $\mathrm{Cl}$, documented appropriately and followed up to resolution. The critical issue should then be escalated as soon as possible to the Management Committee depending upon the nature and severity of the issue. The discussions are to be documented in writing and tracked until resolved.

\subsection{Source Data Verification (SDV)}

100\% SDV will be performed for 2-3 early-recruited patients at every site. After this, a reduced SDV plan as below (partial SDV) will be utilised if monitor / PM is confident of the site's competence. Additional SDV may be required if error rate is of concern. Any errors will be discussed at the time of the visit and listed on a spreadsheet sent to the site, with the monitoring report.

In cases where a new RC replaces the original RC at a site, evidence of their training should be checked, including review of the Training Statement (Section 11.3 of ISF). If appropriate, $100 \%$ SDV will be performed on the first few patients on whom a new RC enters data.

$100 \%$ SDV must be performed on ALL patients for the CRF sections below:

1. Primary outcome measure - All creatinines will be verified against Source data, including baseline, pre-study, daily days $0-7$ and highest.

\subsection{First monitoring visit}

The first visit will take place within $1-4$ weeks of the start of the study. The purpose of this monitoring visit is to ensure sites have adequate resources and to check the first patients' data against source data. Patients to be monitored will be selected on a convenience sampling basis for whom medical notes are readily available in the ICU on the date of the visit. This is because it will be difficult to obtain medical notes on patients who have recently been discharged from the ICU, and the large number of patients likely to have been enrolled by the first visit. 


\subsection{Partial SDV}

Because of the large numbers of patients anticipated, after the first visit, $\mathbf{1}-\mathbf{2} \%$ of randomly selected patients will be $100 \%$ monitored throughout the study. Monitoring visits are anticipated 3 - 4 times per site throughout the trial.

If sites are having difficulty with the study, the percentage of patients monitored or the frequency will be increased.

Misunderstandings of type and timing of data to be collected must be scrutinised. This should especially be done at the first monitoring visit to assist site staff with comprehending ongoing data entry.

\subsection{Selection of patients for partial SDV}

The random selection of patients will be identified using the 'RAND' number generation function in Excel and a list of the patients randomised at the site to be visited. The list will include all patients, not already monitored. Against this list of patients, line up an equal length list of random numbers, generated by Excel. Then sort the random numbers in order and select the top $1-2 \%$ of patient numbers at the top of the list. If a wide selection of patients (across the study period) is not selected using the random method, groups of patient (based on numerical patient ID) may be selected (eg. $400-600$ ) and then the random method used.

\subsection{Study treatment}

- Check study treatment storage (immediate and secondary) for adequate security and temperature control in accordance with local site practice.

- As this is a 'whole of unit' study and the study fluid will also be used for patients who are not enrolled, drug accountability is not being requested at a patient level. At the end of the study the following procedure for overall accountability will be applied:

- $\quad$ Sites are responsible for documenting SPLIT fluid use on the eCRF from the source document (individual patient's 24 hour ICU flowcharts are source data)

- Amount of each type of fluid used for patients will be obtained from the eCRF

- Amount of each type of fluid destroyed by site will be documented

- Amount of each type of fluid shipped to site will be obtained

- Accountability will be based on the calculation of:

- Amount Used plus Amount Destroyed equals Amount Shipped. 
It is acknowledged that this will not be an exact balance, as some patients will receive fluid but will:

- not be eligible for data collection

- will not consent to data collection

There may also be some wastage at the bedside.

\subsection{Monitoring visit reporting}

Monitoring visit reports (see APPENDIX ONE) will be completed as soon as possible after the completion of site visit. The monitoring visit report will be reviewed by another PM at MRINZ, before distribution to PI and RC, unless otherwise agreed. The report should be filed in the site's Investigator file and the Trial Master File. Key issues that impact study conduct and data integrity should be documented in the monitoring visit report and tracked to completion. These include:

- GCP non-compliance

- Protocol adherence (protocol violations/noncompliance)

- Investigational product accountability

- Status of Site Investigator's File

- Other monitoring activities completed

- Discussions with RC / PI and outcomes / plans made

- Deviations from the monitoring frequency

The report should also contain details (e.g. a listing of):

- Number of patients enrolled

- eCRF completion and review status for patients reviewed including resolution of queries.

- Source data verification: indicate which patients have been verified against source data, which fields contained possible errors and guidance for possible corrections.

This listing may be in the format of an excel spreadsheet/s which is/are attached to the report narrative.

At each monitoring visit or following receipt of the monitoring visit follow-up correspondence, any errors or omissions in data recorded on the eCRFs will be brought to the attention of the site personnel. The sites should make corrections to the data accordingly, via the eCRF - this is preferably performed during the monitoring visit so that query specific explanations can be discussed. All data corrections will be saved in an audit 
trail, which will include the reason for the change and the date and electronic signature of the person making the change.

\subsection{Source Documents}

Source documents are defined as the original documents and records where the data was first captured (or copies or transcriptions certified after verification as being accurate copies) and include but is not limited to: Hospital records, clinical charts, dispensing/prescription forms and electronic laboratory reports.

\section{$14.20 \quad$ Remote monitoring}

The monitor will be able to review the status of eCRF pages on an ongoing basis via webaccess, to ensure that forms are being completed per instructions and queries are being resolved correctly. Please note that sometimes manually raised queries may be resolved incorrectly and should be checked before the monitor 'closes' a query.

\subsection{Close-out Visit}

Closure visits should be performed once the final forms have been entered for each site. These visits will be a combination of final monitoring as well as close-out work.

The following should be undertaken to ensure:

- All outstanding SDV has been completed and all queries resolved during the visit

- The site Investigator files are complete and matching documents required in the Sponsor files are filed at MRINZ

- All study treatment has been reconciled and destroyed or destruction has been planned

- That site agrees to remain committed to any trial-related tasks (such as last-minute queries, document sign-off processes, etc.) until the site is closed

- That final payment status is discussed with the investigator if required

- Procedures in place for archiving research records for 15 years and confirmation of where records will be stored (address of archiving facility/details of offsite archiving provider to be obtained)

- Documentation of the close-out visit is reported in a close-out visit report and will include a list of the final tasks to be performed, responsibility for them and their due date.

\subsection{Interim analyses and Data Monitoring Committee}


An independent Data Monitoring Committee (DMC) will review the overall trial progress as well as safety data of the administered treatments, as the study proceeds. No interim analyses are scheduled for this study, as outlined in the DMC Charter.

\subsection{COMMUNICATION}

\section{Participating Site Communication during study}

\begin{tabular}{|c|c|c|}
\hline Location & Format & Information Provided \\
\hline In person & Meetings & $\begin{array}{l}\text { - Investigator's meeting } \\
\text { - Initiation, monitoring and close out visits } \\
\text { - Ad hoc visits }\end{array}$ \\
\hline $\begin{array}{l}\text { Online data } \\
\text { system }\end{array}$ & $\begin{array}{l}\text { Real time } \\
\text { reports }\end{array}$ & $\begin{array}{l}\text { - Excel tracker of Data query status (opened, answered, } \\
\text { closed) } \\
\text { - Data completion status (red crosses, green ticks and orange } \\
\text { question marks) } \\
\text { - Reporting capability will be available to sites in the trial } \\
\text { database; however this will not be available by the time the } \\
\text { study commences } \\
\text { - Ad hoc reports and listings can be performed as required; } \\
\text { however, there may be budget limitations around the } \\
\text { request of these so will have to be authorised by } \mathrm{NZ} \mathrm{Cl}\end{array}$ \\
\hline $\begin{array}{l}\text { Study } \\
\text { Documents } \\
\text { on website }\end{array}$ & PDF documents & $\begin{array}{l}\text { - Protocol } \\
\text { - Paper CRFs and data completion manual }\end{array}$ \\
\hline $\begin{array}{l}\text { Email / Post } \\
\text { / Telephone }\end{array}$ & $\begin{array}{l}\text { Pdf / paper } \\
\text { documents / } \\
\text { one on one calls }\end{array}$ & $\begin{array}{l}\text { - Lever arch file for 'Essential Documents' } \\
\text { - Initiation, Monitoring \& Close out visit reports } \\
\text { - Safety Reports } \\
\text { - Ad hoc updates and requests }\end{array}$ \\
\hline
\end{tabular}




\subsection{Study Team Communication}

\begin{tabular}{|c|c|c|}
\hline Meetings & Frequency & Purpose \\
\hline $\begin{array}{l}\text { Study Team } \\
\text { In Person / } \\
\text { Email / } \\
\text { Telephone }\end{array}$ & PRN & $\begin{array}{l}\text { - Dissemination of updates, new information, impending } \\
\text { work to be done } \\
\text { - Discussion of problems, concerns, troubleshooting, sharing } \\
\text { tips, other feedback } \\
\text { - Requesting support, trouble shooting, answers to } \\
\text { - } \text { - Updastions }\end{array}$ \\
\hline $\begin{array}{l}\text { Management } \\
\text { Committee } \\
\text { Email / } \\
\text { Telephone }\end{array}$ & PRN & $\begin{array}{l}\text { - Provide high level update on project status } \\
\text { - Discussion and resolution of critical issues that affect the } \\
\text { study outcomes. } \\
\text { - Discuss feedback from sites and other stakeholders } \\
\text { - Develop / approve sub studies }\end{array}$ \\
\hline
\end{tabular}




\subsection{5 monitoring visit report template / EXAMPLE}

ROUTINE MONITORING REPORT

\begin{tabular}{|l|l|}
\hline Protocol summary title: The SPLIT Study & $\begin{array}{l}\text { Site } \\
\text { Abbreviation: }\end{array}$ \\
\cline { 2 - 2 } & Site name: \\
\cline { 2 - 2 } & Date of visit: \\
\hline Principal Investigator: & \\
\hline Site staff present: & \\
\hline MRINZ staff present: & \\
\hline
\end{tabular}

\begin{tabular}{|c|c|}
\hline \multicolumn{2}{|l|}{ Study Status } \\
\hline Current Allocation: & Fluid $A$ or $B$ \\
\hline Current enrolment rate: & $\begin{array}{l}a \text { per week } \\
\text { ( } b \text { in } c \text { weeks) }\end{array}$ \\
\hline $\begin{array}{l}\text { Current enrolments: Fluid A } \\
\text { Current enrolments: Fluid B }\end{array}$ & $\begin{array}{l}d \\
e\end{array}$ \\
\hline $\begin{array}{l}\text { Reported protocol } \\
\text { violations: }\end{array}$ & $x(y / b$ patients $=0 \%)$ \\
\hline
\end{tabular}




\begin{tabular}{|c|c|}
\hline Item & Comment or Follow up \\
\hline \multicolumn{2}{|c|}{ 1. ENROLMENT \& CONSENT PROCEDURE } \\
\hline \multicolumn{2}{|l|}{ 1.1 Enrolment rate } \\
\hline \multicolumn{2}{|l|}{1.2 Eligibility } \\
\hline \multicolumn{2}{|l|}{$\begin{array}{l}\text { Post-randomization } \\
\text { deviations from } \\
\text { protocol }\end{array}$} \\
\hline \multicolumn{2}{|l|}{ 1.4 Consenting issues } \\
\hline 1.5 Other & - \\
\hline \multicolumn{2}{|l|}{ 2. STUDY TREATMENT } \\
\hline \multicolumn{2}{|l|}{$\begin{array}{l}2.1 \text { Adequacy of storage } \\
\operatorname{area}(\mathrm{s})\end{array}$} \\
\hline \multicolumn{2}{|l|}{$\begin{array}{l}2.2 \text { Reconciliation \& } \\
\text { accountability }\end{array}$} \\
\hline \multicolumn{2}{|l|}{2.3 Other } \\
\hline \multicolumn{2}{|c|}{ 3. DATA COLLECTION / DOCUMENTATION } \\
\hline \multicolumn{2}{|l|}{3.1 Timeliness } \\
\hline \multicolumn{2}{|l|}{$\begin{array}{l}\text { 3.2 Accuracy and } \\
\text { understanding }\end{array}$} \\
\hline \multicolumn{2}{|l|}{$\begin{array}{l}3.3 \text { Access to source } \\
\text { documents }\end{array}$} \\
\hline \multicolumn{2}{|l|}{ 3.4 Essential documents } \\
\hline \multicolumn{2}{|l|}{ 3.5 Website issues } \\
\hline \multicolumn{2}{|l|}{3.5 Other } \\
\hline \multicolumn{2}{|l|}{ 4. SAFETY REPORTING } \\
\hline \multicolumn{2}{|l|}{4.1 Site specific reports } \\
\hline $\begin{array}{l}\text { 4.2 Processing other site } \\
\text { reports }\end{array}$ & - \\
\hline
\end{tabular}




\begin{tabular}{|l|l|}
\hline Item & \multicolumn{1}{|c|}{ Comment or Follow up } \\
\hline 4.3 Other & - \\
\hline 5. OTHER & \\
\hline 5.1 & \\
\hline
\end{tabular}

Documents collected during this visit: none $\square$

\begin{tabular}{|l|l|}
\hline$\#$ & Description \\
\hline DC1 & \\
\hline DC2 & \\
\hline
\end{tabular}

Document filed into ISF during this visit: none $\square$

\begin{tabular}{|l|l|}
\hline$\#$ & Description \\
\hline DF1 & \\
\hline DF2 & \\
\hline
\end{tabular}

Attachments to this report: none $\square$

\begin{tabular}{|l|l|l|l|}
\hline$\#$ & Description & Action Required & Due by / \\
responsible
\end{tabular}

Follow up Items:

\begin{tabular}{|l|l|l|l|}
\hline$\#$ & Description & $\begin{array}{l}\text { Due by / } \\
\text { responsible }\end{array}$ & \\
\hline F1 & & & \\
\hline F2 & & & \\
\hline
\end{tabular}

Overall Comments 


\section{\# $\quad$ Description}

C1

C2

Report prepared by:

Name

Role

Date: 


\section{Appendix 3: Serious adverse event}

\section{The SPLIT Study: Safety Report}

Protocol title: $\quad 0.9 \%$ Saline vs. Plasma-Lyte ${ }^{\circledR} 148$ for Intensive Care Fluid Therapy

\section{Serious Adverse Report}

There has been a Serious Adverse Report lodged for a patient in the SPLIT Trial. The relationship with SPLIT Study Fluid has been determined as 'possibly related'.

The details of this case are as follows:

Past history of end stage renal failure secondary to insulin treated Type 2 diabetes (not metformin), peripheral neuropathy, asthma, dyslipidaemia, and significant hepatic steatosis. The steatosis was associated with an elevated GGT but otherwise normal liver function tests. Maintenance peritoneal dialysis was uncomplicated, although perhaps unusually for such a patient, blood pressure tended to be low (108/66) and was on no anti-hypertensives. Pre-operative dobutamine stress echocardiogram demonstrated good LV function and no inducible ischaemia.

Live donor renal transplantation was surgically straight forward and a time-zero biopsy showed mild ATN. The first arterial blood gas sample was taken 1 hour after induction of anaesthesia, around the time of surgical incision, which showed pH 7.39 and lactate 2.1 $\mathrm{mmol} / \mathrm{L}$ (normal range 0.5 - 1.6). Anaesthesia was otherwise generally unremarkable, but there was a requirement to commence a low-dose metaraminol infusion after 2 hours (which is not uncommon) and heart rate slowly rose from $80 / \mathrm{min}$ to $100 / \mathrm{min}$ by the end of surgery. Plasmalyte 148 infusion had been initiated at commencement of anaesthesia and a total of $2 \mathrm{~L}$ was given over the course of the $4 \mathrm{~h}$ procedure. In the post-anaesthesia care unit the next arterial sample had a lactate of 4.9 and pH 7.31. After a short period of postanaesthesia recovery, the patient was then transferred to a HDU bed in our intensive care department, which is our standard practice for renal transplants.

It was initially presumed that the elevated lactate represented poor tissue perfusion and further volume loading (with SPLIT study fluid) was indicated to increase preload and cardiac output along with switching the metaraminol to a noradrenaline infusion. However, the lactate continued to rise going from 5.1 immediately after HDU admission to 14.2 $\mathrm{mmol} / \mathrm{L}$ with $\mathrm{pH} 7.09$ in the first 4 hours during which time $4 \mathrm{~L}$ of study fluid was given. Noradrenaline requirements also rose significantly, but the patient required little or no supplemental oxygen, had good peripheral perfusion and reasonable urine output (100 $200 \mathrm{ml} / \mathrm{hr}$ ) with a falling creatinine. A Doppler ultrasound of the transplant kidney showed good blood flow and an ECG was normal. Although there were no focal clinical signs to specifically suggest intestinal ischaemia, it was agreed that a CT to rule this complication out would be necessary. 
Unfortunately, immediately after injection of IV contrast for the CT scan, the patient had a cardio-respiratory arrest from which resuscitation was successful after $10 \mathrm{~min}$. It was thought that this was a contrast reaction occurring when there was limited cardiovascular reserve. The scan was completed without further contrast and did not suggest bowel ischaemia.

After return to ICU, the patient was continued on mechanical ventilation initiated during the cardiac arrest and was commenced on CVVHDF to try and improve the metabolic state. Despite using bicarbonate-based dialysate, lactate levels remained persistently elevated between 13 and $17 \mathrm{mmol} / \mathrm{L}$. An echocardiogram showed no abnormalities with good left ventricular function, and a repeat laparotomy definitively excluded bowel ischaemia. There was continued deterioration over the 20 hours after the cardiac arrest, the patient eventually became unsupportable on maximal therapy, and died. This was $32 \mathrm{~h}$ after the start of surgery and $26 \mathrm{~h}$ after ICU admission.

A post-mortem was performed and (on verbal report) did not find any evidence of ischaemic tissues or organs which could have been a source of lactate production. A muscle biopsy did not show any evidence of mitochondrial disease. We are still awaiting the final post-mortem report with the full tissue histology.

In summary:

- The patient had significant hepatic steatosis and probably had limited ability to metabolise lactate.

- The underlying problem started intra-operatively, with the lactate rising very early during the procedure, and certainly before any significant surgery had occurred (including re-perfusion of the transplant

- kidney)

- Lactate particularly rose during the early post-operative period during which time $4 \mathrm{~L}$ of study fluid was administered, and $2 \mathrm{~L}$ of Plasmalyte was given intra-operatively from the start of anaesthesia

- No clinical or post-mortem evidence (pending final report) of a specific source of tissue hypoxia and potential lactate production

- The rising lactate was associated with increasing circulatory disturbance. However, the clinical staff involved considered that the shock followed rather than preceded the elevation in lactate, and that the lactate levels seemed to be well out of proportion and not explained by the degree of circulatory shock (such as we would see in sepsis)

- The later events such as failure of CVVHDF to clear the lactate and the cause of death is confounded by the cardiac arrest and possible contrast reaction. 
In terms of possible explanations, we seem to have the following options (including combinations of these):

- Reduced ability to clear lactate (likely contributor, but increased production is also required)

- An undiagnosed source of lactate production from specific tissue or organ ischaemia (possible)

- Generalised impairment of tissue perfusion of unknown origin as the primary initiating cause (unlikely given the clinical course)

- Increased lactate production due to a pre-existing biochemical abnormality such as an inborn error of metabolism (unlikely) or thiamine deficiency (possible)

- Increased lactate production due to peri-operative treatment (possible)

Looking at the last of these options, none of the drugs known to be associated with elevated lactate were used (propofol was only used for induction of anaesthesia) and so the study treatment (SPLIT fluid) needs to be considered. This is particularly relevant if the study treatment was Plasmalyte, as the patient would have received a total of $6 \mathrm{~L}$ of Plasmalyte over the 12 hours from the start of anaesthesia during which time the lactate increased from 2.1 to $14.2 \mathrm{mmol} / \mathrm{L}$. As you know, Plasmalyte contains $27 \mathrm{mmol} / \mathrm{L}$ acetate and and $23 \mathrm{mmol} / \mathrm{L}$ gluconate. There is a syndrome of impaired acetate handling in some patients with chronic renal failure associated with hypotension during dialysis, and also case reports of high lactate levels occurring during acetate exposure in resuscitation of patients without renal failure (see attached example).

The biochemical explanation for this is that acetate infusion increases acetyl CoA, which in turn inhibits pyruvate dehydrogenase and shunts glycolysis intermediates toward lactate.

We are therefore left with some uncertainty as to the cause of the high lactate levels in this case. The leading options are an undiagnosed source from generalised or regional tissue hypoxia/ischaemia or a metabolic pathway abnormality promoting the production of lactate, which could be due to significant acetate exposure if Plasmalyte was the blinded study treatment.

Thiamine deficiency (thiamine being a co-factor for the pyruvate dehydrogenase enzyme) was not considered at the time, and is another possible contributor to a change in the flux of biochemical pathways towards lactate.

We have therefore concluded that SPLIT study treatment was one of several possible contributing causes to this death. However, the clinical problem started several hours before randomisation, and at most the study treatment received after enrolment exacerbated rather than caused the sequence leading to death. It is less likely to have been a contributor if the $4.7 \mathrm{~L}$ of study fluid given was $0.9 \%$ saline, as the issue was a lactic, not hyperchloraemic, acidosis. ICU clinical staff involved stated that if the SPLIT study was not 
running at the time that they would have chosen Plasmalyte for crystalloid volume expansion, given the presence of a metabolic acidosis.

\section{Principal Investigator Comments}

The relationship between administration of SPLIT study fluid and this death remains uncertain.

\section{Recommendations for Investigators and Research Co-ordinators}

This event was reviewed by the DMC and the study management committee. The DMC recommended that the study continue without modification of the study protocol and this recommendation is endorsed by the study management committee. 